\title{
The nutrition transition, supermarkets, and nutritional outcomes in developing countries
}

\author{
Dissertation \\ to obtain the $\mathrm{Ph}$. D. degree \\ in the Faculty of Agricultural Sciences, \\ Georg-August-University Göttingen, Germany
}

presented by

Simon Chege Kimenju

born in Nyandarua, Kenya

Göttingen, July 2014 
D7

1. Name of referee: Prof. Dr. Matin Qaim

2. Name of co-referee: Prof. Stephan Klasen, PhD

Date of dissertation: 24.07.2014 


\section{Summary}

Many developing countries are currently undergoing a rapid nutrition transition. This transition is characterized by changes in dietary habits towards more energy-dense, often processed foods with high fat and sugar contents, and more sedentary lifestyles. As a result, overweight and obesity rates have increased. Worldwide obesity has more than doubled since 1980. In 2008, $34 \%$ of all adults were overweight or obese. For children under five, an estimated $6.6 \%$ were either overweight or obese in 2011, an increase from $4.5 \%$ in 1990. At the same time, undernutrition rates are still high. Globally, about $26 \%$ of all children under five were stunted, while 16\% were underweight in 2011. This coexistence of undernutrition and overweight/obesity, referred to as the dual burden of malnutrition, has been observed in many developing countries, sometimes even within the same households. The nutrition transition is driven by demand-side factors, such as rising incomes and urbanization, as well as supply-side factors, such as globalizing food systems. The food retail sector is becoming more and more modernized, and supermarkets are playing an increasing role. In fact, some developing countries have witnessed a 'supermarket revolution', depicting a rapid spread of supermarkets within a short period of time. The retail format has an influence on the types of foods offered, as well as on sales prices and shopping atmosphere, which may affect consumer food choices.

This dissertation comprises three essays. In the first two essays, we analyze whether the spread of supermarkets in developing countries has an effect on food consumption patterns, and whether it contributes directly to rising overweight and obesity. We address this question using cross-section household and individual level data collected in Kenya in a quasi-experimental setting. Kenya has recently witnessed a rapid spread of supermarkets that now account for about $10 \%$ of national grocery sales. In addition, over $25 \%$ of the women in Kenya are overweight or obese. In the third essay, we analyze the effect of the nutrition transition on child malnutrition indicators using a cross-country regression approach with secondary panel data.

In the first essay, we analyze the effect of supermarkets on dietary behavior. The available literature suggests that supermarkets affect dietary patterns, although hard evidence is scarce. A study in Guatemala found that supermarket shoppers consume more processed foods with adverse nutritional outcomes. This is in contrast to a study in Tunisia showing that supermarket shoppers had higher dietary quality. We contribute to this limited literature by collecting and 
using detailed household level data on food purchases from different retail formats. We account for potential endogeneity of supermarket purchases in the regression models using instrumental variable techniques. We find that supermarket purchases increase the consumption of processed foods, both in terms of expenditure shares as well as calorie shares. An increase in the share of supermarket expenditure by one percentage point increases the share of expenditure on processed foods by 0.38 percentage points. In addition, a one percentage point increase in the share of supermarket purchases increases calorie consumption by $0.85 \%$. For average consumers that currently do not purchase any food in supermarkets, a switch to supermarkets would translate into an additional daily consumption of 200 kilocalories, everything else held constant. This effect is partly driven by lower prices per calorie. We conclude that supermarkets affect dietary behavior, thus contributing directly to the nutrition transition.

In the second essay, we extend this analysis to examine whether supermarkets are a causal factor of overweight or obesity. Research on the impact of supermarkets on consumer nutritional status in developing countries is rare; we are only aware of one study in Guatemala. In that study, it was found that food purchase in supermarkets increases the body mass index (BMI) of consumers. However, the research for Guatemala builds on a household living standard survey that was not specifically designed for analyzing the nutritional impact of supermarkets. Hence, a few variables of interest, such as food quantities purchased in different retail outlets, were not properly captured. Moreover, the impact on BMI was analyzed for all individuals in the sample above 10 years of age, an approach that masks possible differences between adults and children. BMI is only a suitable indicator of nutritional status for adults. We use the household level data from Kenya, which we supplement with individual level anthropometric measures. To deal with the likely endogeneity of supermarket purchase variable, we employ instrumental variable regressions. We analyze the impact of supermarket purchase on nutritional status, separately for adults and for children and adolescents. We also examine impact pathways through which supermarkets affect nutritional status by estimating a system of structural equations. Controlling for other factors, buying in a supermarket increases the BMI of adults by $1.7 \mathrm{~kg} / \mathrm{m}^{2}$ and raises the probability of adult overweight or obesity by 13 percentage points. For children and adolescents we do not find a significant impact on overweight. Instead, buying in a supermarket tends to decrease child undernutrition through a positive impact on height-for-age $z$-scores and a negative 
effect on severe stunting. For both adults and children, the nutrition impacts of supermarkets occur through higher calorie consumption and changes in dietary composition.

In the third essay, we study the effect of the nutrition transition on childhood nutritional status. One point of criticism against the use of underweight as an indicator of child undernutrition is that it is likely affected by the nutrition transition, indicating a reduction in undernutrition although nutritional quality may not really have improved. As an alternative, stunting is viewed as a more reliable indicator. It has been argued that stunting is less affected by the nutrition transition, although this has hardly been studied. We analyze the effect of the nutrition transition on childhood underweight, overweight, and stunting, employing a crosscountry regression approach. We use fat consumption, share of modern retail in grocery sales, and the prevalence of overweight women as indicators of the nutrition transition. Pooling data from Demographic and Health Surveys, Planet Retail, FAOSTAT, and World Development Indicators, we estimate fixed effects and random effects panel models. Our results show that the nutrition transition has an effect on child weight, as hypothesized previously. It significantly and consistently reduces underweight rates, while the effects on child overweight are less clear. In contrast to widely held beliefs, we also find clear and consistent evidence that the nutrition transition reduces child stunting.

We derive several general conclusions. Among other factors, supermarkets are drivers of the nutrition transition in developing countries, contributing to dietary changes among consumers. Supermarkets are causing consumers not only to eat more calories, but also to get a bigger share of their calories from processed foods. The direct impact of supermarket purchase on nutrition outcomes varies by age cohort and initial nutritional status. The results for Kenya show that supermarkets increase adult BMI and overweight, whereas for children the effect is a reduction in undernutrition. Based on the cross-country analysis, we find that the nutrition transition reduces both child underweight and stunting, while the expected impact on child overweight is not so clear. Hence, the primary and secondary data analyses suggest that the nutrition transition has positive effects in terms of reducing child stunting. These results challenge the general view that the nutrition transition would only have undesirable health effects in developing countries. Of course, more research is needed to confirm these results, but our findings indicate that simplistic conclusions may not be justified. 


\section{Acknowledgements}

I am grateful to a lot of people whose support in various ways made this work possible. First, I am grateful to my supervisor, Prof. Dr. Matin Qaim for his support, guidance, and encouragement. He was always available for discussion and gave quick feedback, ensuring that this work moved smoothly without delay. I would also like to thank Prof. Stephan Klasen, PhD, for co-supervising this dissertation. His comments to my work were very valuable in improving it. I am also grateful to Prof. Xiaohua $\mathrm{Yu}, \mathrm{PhD}$, for serving on my examination committee.

The friendship and togetherness provided by my colleagues and fellow doctoral students at the GlobalFood Research Training Group (RTG) provided a good and stimulating working environment. I appreciate the collaboration I had with Ramona Rischke in this work. Working together with her as a team led me to discover other possible perspectives and approaches. To Brian Chiputwa and Hanna Ihli, I am thankful for your friendship and close discussions we always had. You always triggered my thinking to new ideas. I am also grateful to fellow doctoral students at the Chair of International Food Economics and Rural Development for their support and the interactions we had.

This research was financially supported by the German Research Foundation (Deutsche Forschungsgemeinschaft, DFG) as part of the GlobalFood RTG. This financial support is gratefully acknowledged. The support of the University of Nairobi in fieldwork coordination, particularly through Dr. Jonathan Nzuma and our dedicated team of enumerators, is also much appreciated. Furthermore, I wish to thank all persons, particularly management staff of various supermarkets and nutritionists, who gave us their time and helped us to understand the retail and nutritional contexts when we were designing the study. I am particularly grateful to my nutritionist friends, Shadrack Oiye and Triza Kinuthia, who were very instrumental in helping me understand nutritional aspects.

This study would not have been possible without the help of various people at the study sites in Kenya. These include management staff of various supermarkets, the provincial administration, the county councils, ministry of health officials, and many community health workers. In particular, Earnest Macharia in Olkalou, Titus Kiarie in Njabini and elder Mutugi in Mwea. They were very helpful in ensuring that we got a good reception in their towns. In 
addition, I am indeed grateful to all survey respondents who agreed to participate in the interviews.

The support I got from my family was very instrumental. I am greatly indebted to my wife Christine for her love, unceasing support, encouragement and the stimulating academic exchanges that we usually have. In her, I have the perfect partner indeed. My daughter Natalia brought greater happiness into our home, which contributed towards my motivation. She also helped instill in me a new sense of time management, which was very instrumental in moving this work forward. Finally, I am grateful to my parents, Mr. Joseph Kimenju and Mrs. Elizabeth Kimenju for all their support towards my academic ambitions, encouragement and prayers, and to all my other family members for their moral support and prayers.

This dissertation is dedicated to all those people who are living with nutritionally-related diseases or conditions in developing countries. 


\section{Table of Contents}

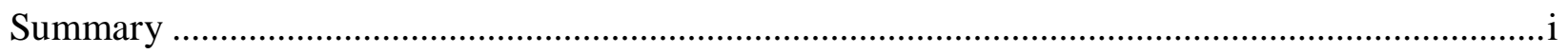

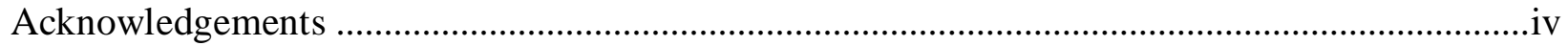

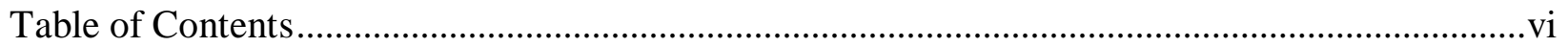

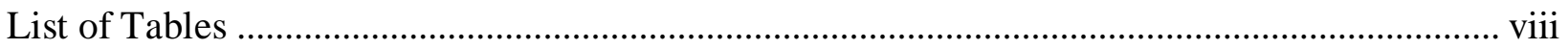

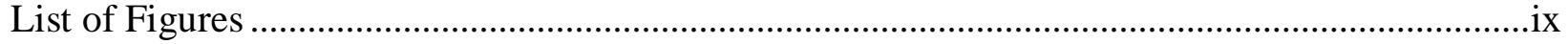

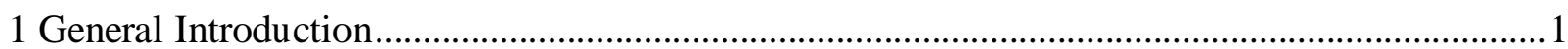

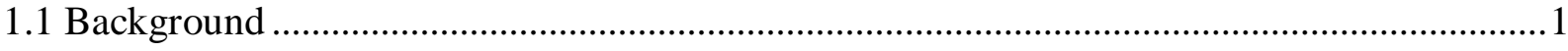

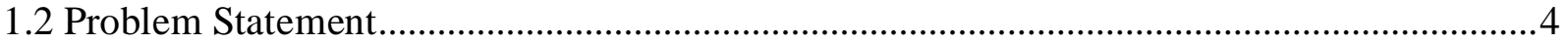

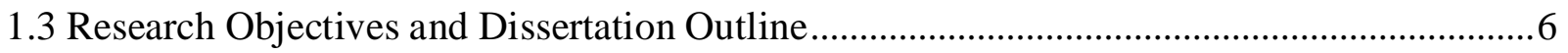

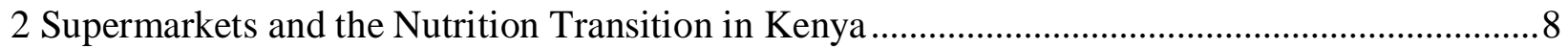

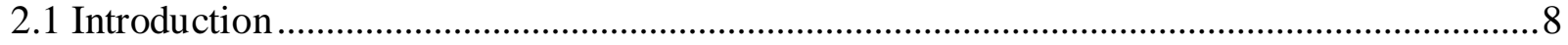

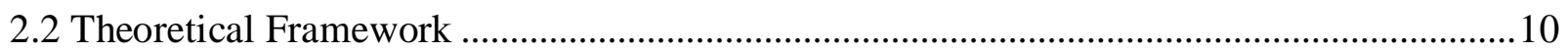

2.2.1 Food Environment in Kenya ….............................................................................. 10

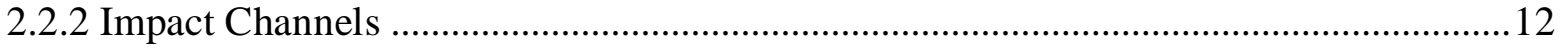

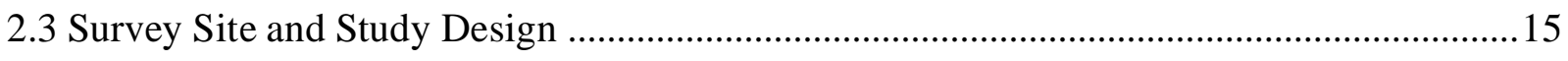

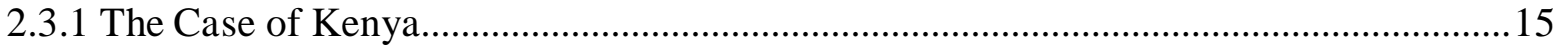

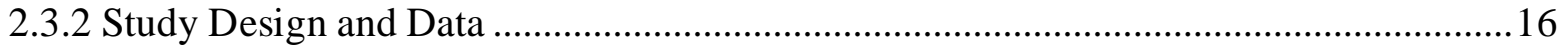

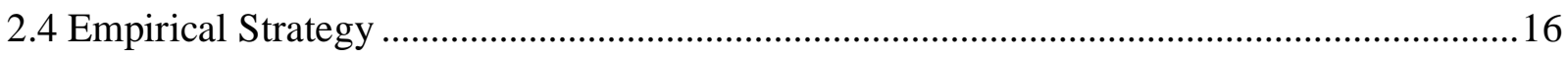

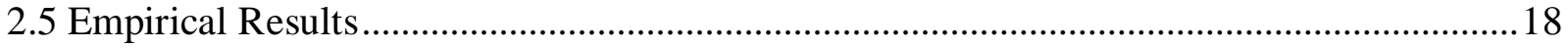

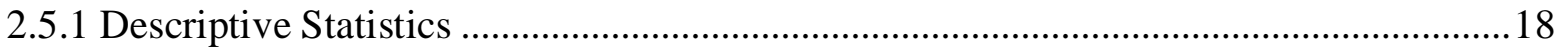

2.4.2 Food Expenditure Shares by Levels of Processing …................................................22

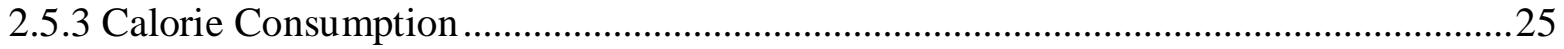

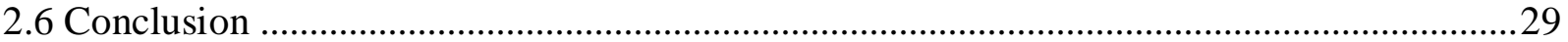

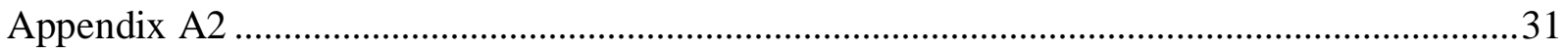

3 Do Supermarkets Contribute to the Obesity Pandemic in Developing Countries? .....................35

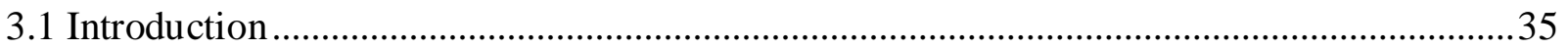

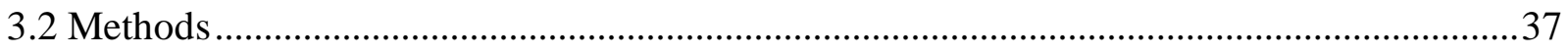

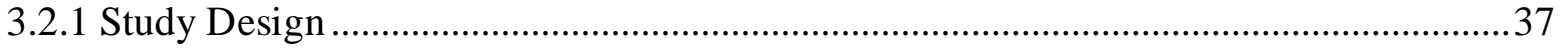

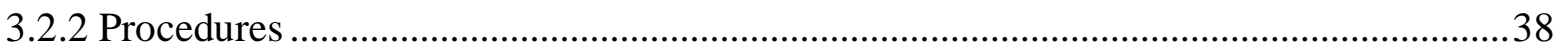




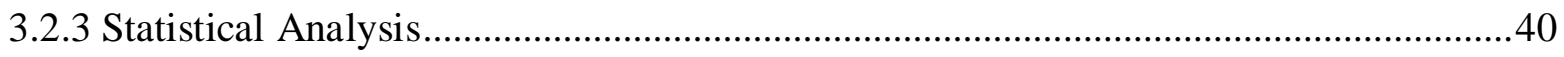

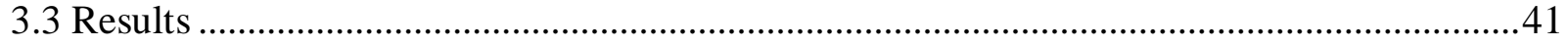

3.3.1 Impact of Supermarket Purchase on Nutritional Status .................................................42

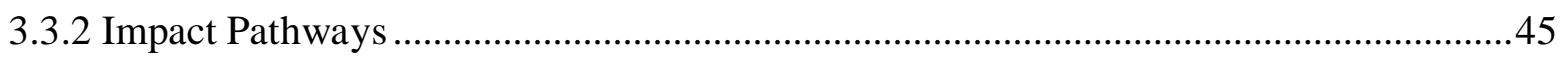

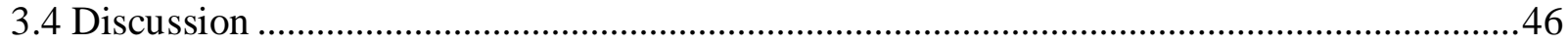

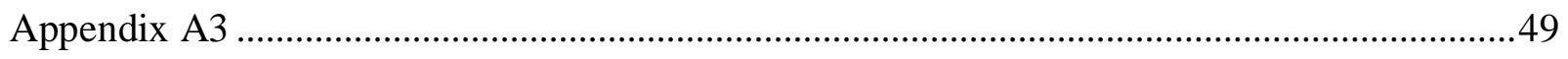

4 The Nutrition Transition and Indicators of Child Malnutrition ....................................................57

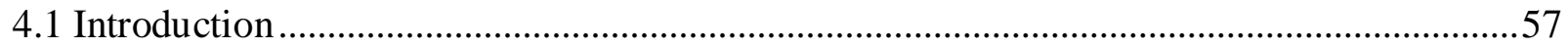

4.2 Dietary Trends and Child Nutrition: Expected Relationships …………………………........58

4.3 Materials and Methods …………………………………...................................................

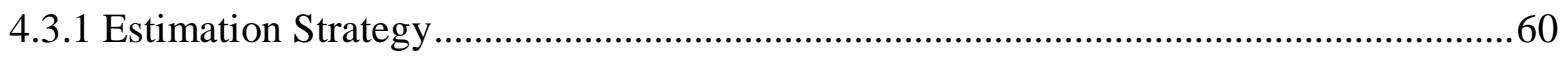

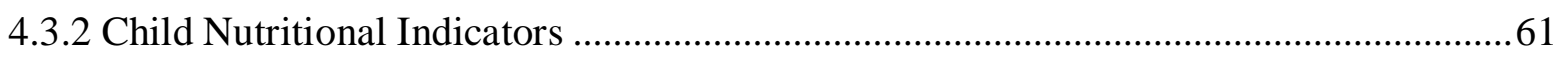

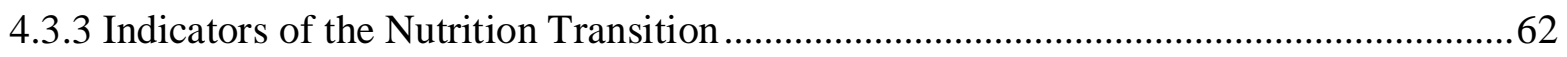

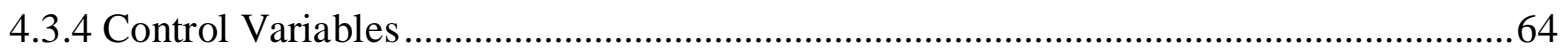

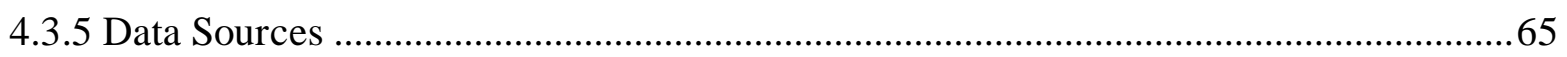

4.3.6 Sample Size and Handling of Missing Data ..................................................................67

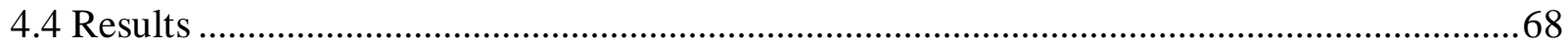

4.4.1 Effect of the Nutrition Transition on Child Weight ......................................................68

4.4.2 Effect of the Nutrition Transition on Stunting ...........................................................73

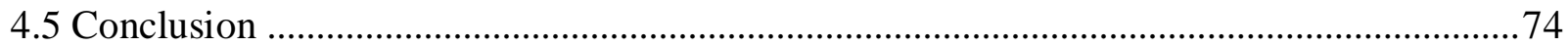

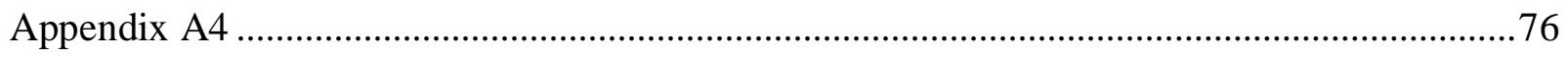

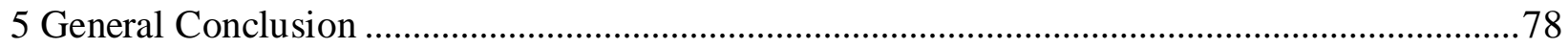

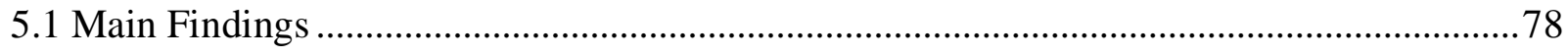

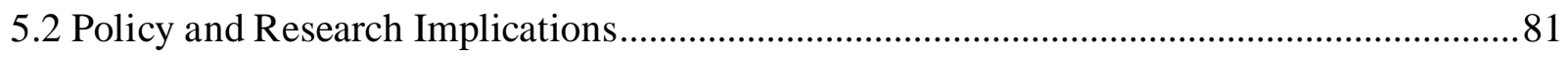

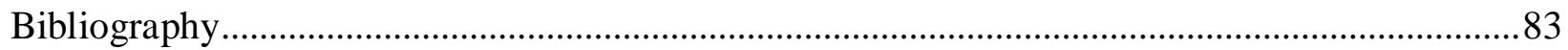

General Appendix ............................................................................................................ 94

Household Questionnaire (Kenya) .................................................................................. 


\section{List of Tables}

Table 2.1. Defining features of different retail outlets - the case of Kenya ...............................11

Table 2.2. Household characteristics of sample ......................................................................... 19

Table 2.3. Access to retail outlets and shopping behavior ........................................................20

Table 2.4a. OLS and IV regression results - Food expenditure shares by levels of industrial

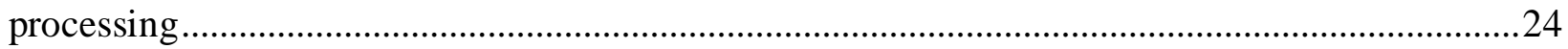

Table 2.4b. OLS and IV regression results - Food expenditure shares by levels of industrial

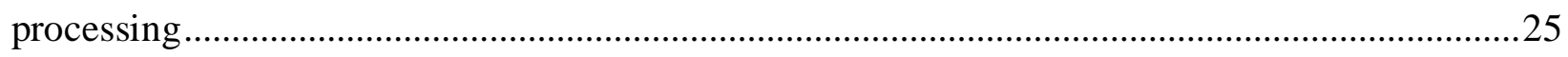

Table 2.5. OLS and IV regression results - Calorie availability at home..................................22

Table A2.1. Summary statistics of main dependent and explanatory variables ...........................31

Table A2.2. Expenditure shares $1^{\text {st }}$ stage results of main models ...............................................32

Table A2.3. Share of calories from different food categories - OLS and IV estimates.................33

Table A2.4. Food budget shares and prices per calories, OLS and IV estimation .......................33

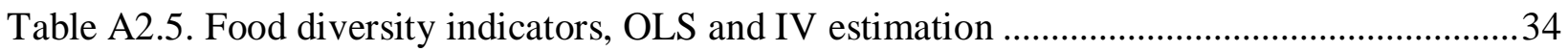

Table 3.1. Comparison of nutrition variables by supermarket purchase ......................................42

Table 3.2. Impact of supermarket purchase on adult nutrition ..................................................43

Table 3.3. Impact of supermarket purchase on child/adolescent nutrition ..................................44

Table 3.4. Impact pathways of supermarket purchase on adult BMI …......................................45

Table 3.5. Impact pathways of supermarket purchase on child/adolescent HAZ ........................46

Table A3.1. Descriptive statistics for variables used in adult nutrition models ...........................49

Table A3.2. Descriptive statistics for variables used in child/adolescent nutrition models...........50

Table A3.3. First-stage results of instrumental variable models for impact of supermarket

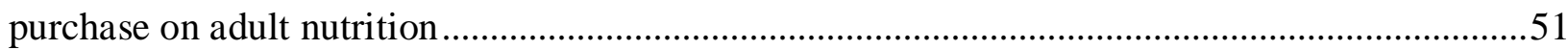

Table A3.4. First-stage results of instrumental variable models for impact of supermarket

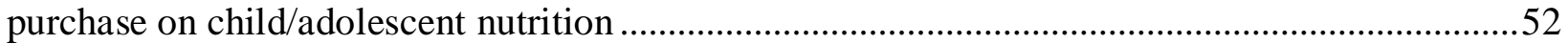

Table A3.5. Impact of supermarket purchase on child/adolescent mild and severe stunting ........53

Table A3.6. Causal chain model to explain the impact of supermarket purchase on adult BMI ..54

Table A3.7. Causal chain model to explain the impact of supermarket purchase on

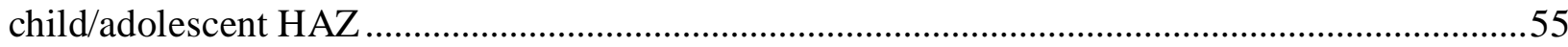

Table 4.1. Association between the nutrition transition, child overweight and underweight ........69

Table 4.2. Effect of the nutrition transition on child overweight .............................................. 71 
Table 4.3. Effect of the nutrition transition on underweight ..................................................... 72

Table 4.4. Association between the nutrition transition and stunting ........................................ 73

Table 4.5. Effect of the nutrition transition on stunting ........................................................... 74

\section{List of Figures}

Figure 2.1. Conceptual framework - food environment, consumption and influencing factors ....14

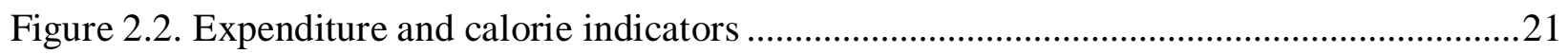

Figure A3.1. Most important reason for shopping in supermarket. ..............................................56

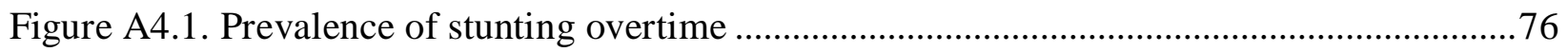

Figure A4.2. Prevalence of underweight over time ................................................................ 76

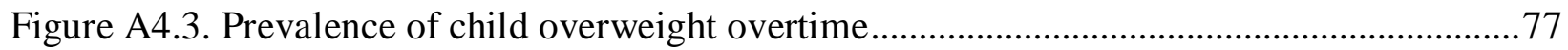




\section{General Introduction}

\subsection{Background}

Many developing countries are currently undergoing a rapid nutrition transition. This transition is characterized by changes in dietary habits towards more energy-dense, often processed foods with high fat and sugar contents, and more sedentary lifestyles (Popkin \& Ng, 2007). While the nutrition transition in developed countries occurred gradually, in many developing countries it is taking place within a much shorter period of time (Popkin, 2004). The nutrition transition in developing countries follows several phases. It begins with increased importation and domestic production, and hence consumption, of edible oils (Popkin \& $\mathrm{Ng}, 2007$ ). This phase is then followed by the increased consumption of foods with higher fat content such as animal source foods (meats and dairy). As observed, a striking feature of dietary transformation in Asian countries was the increasing consumption of meat, milk, and other animal products, as consumption of traditional cereals declined (Pingali, 2007). The next phase is characterized by an increased demand and consumption of convenience foods and beverages, as rates of urbanization increase and as more women enter into the labor force (Pingali, 2007). Another characteristic of this phase is increased consumption of food away from home (Hawkes et al., 2009).

In addition to the changes in dietary patterns, declining physical activity and increasing sedentary time have been observed in the globe ( $\mathrm{Ng} \&$ Popkin, 2012), with $31 \%$ of all adults in the world being insufficiently active (WHO, 2011). These trends are not limited to developed countries, but are being observed in the developing world as well. In fact, China and Brazil are identified as the countries with the "highest absolute and relative rates of decline in total physical activity and some of the higher increases in sedentary time" ( $\mathrm{Ng} \&$ Popkin, 2012). One of the reasons for reductions in physical activity in the world is a declining importance of the agriculture and other traditional sectors, as sectors that require less physical activity such as manufacturing and services become more important (Ng \& Popkin, 2012). Even in previously labor-intensive sectors such as farming and mining, there has been increased use of technology, contributing to low physical activity at work (Popkin et al., 2012). Better access to home technologies, vehicles for transportation, and increased abandonment of active-leisure activities are important factors that reduce leisure-related physical activity. As physical activity reductions 
take place, time allocated to sedentary activities has increased, a situation that is mostly associated with access to and growth of different media technologies (Ng \& Popkin, 2012).

A consequence of the nutrition transition are rising rates of overweight and obesity (Popkin, 2004, Popkin \& Ng 2007). In 2008, 34\% of all adults, or about 1.46 billion people, were overweight or obese (Finucane et al., 2011). Almost 500 million people, or $11 \%$ of all adults, were obese. Worldwide, adult obesity has more than doubled since 1980. For children under five years of age, an estimated $6.6 \%$, or about 40 million, were either overweight or obese in 2011, an increase from $4.5 \%$ in 1990 (UNICEF et al., 2012). Increasing overweight rates may give the perception that undernourishment is no longer a big problem. However, this is not the case. Globally, about $26 \%$ of all children under five, or about 165 million, were stunted in 2011. About 16\%, or 101 million, were underweight. Regionally, Africa has the largest child undernutrition rates, with $35 \%$ of children under five being stunted in 2011. This coexistence of undernutrition and overweight/obesity, referred to as the dual burden of malnutrition, has been observed in many developing countries, sometimes even within the same households (Doak et al., 2005; Lee et al., 2012; Roemling \& Qaim, 2013).

Overweight and obesity are important risk factors for non-communicable diseases (NCDs). Increased body mass increases the risk of coronary heart disease, stroke, and type 2 diabetes and some cancers. Globally, overweight and obesity contribute to $44 \%$ of the diabetes burden and $23 \%$ of the ischemic heart disease burden (WHO, 2009). These NCDs are major causes of death in the world. Out of the 57 million deaths that occurred in the world in 2008, 36 million, or $63 \%$, were due to NCDs, principally cardiovascular diseases, diabetes, cancer, and chronic respiratory diseases. Nearly $80 \%$ of these NCD deaths, or 29 million, occurred in lowand middle-income countries (WHO, 2011). In some regions of the world such as the African continent, there are still more deaths from infectious diseases than NCDs. Even there, however, NCDs are growing rapidly in importance and are projected to be the most common cause of death by 2030 (WHO, 2011). Even before causing death, NCDs come with other costs, mainly increased medical expenditures for individuals, households, and countries. It is estimated that obese individuals have medical costs that are about $30 \%$ higher than their normal weight counterparts, and that obesity may account for up to $3 \%$ of a country's total healthcare expenditures (Withrow \& Alter, 2011). Since in poorer countries most health-care costs must be 
paid by patients out-of-pocket, such costs of health care for NCDs create significant strains on household resources.

The nutrition transition being witnessed in developing countries can be attributed to several factors. Demand-side factors, such as increasing incomes, urbanization, and formal employment play an important role. Income growth leads to major shifts in demand across different types of food, while urbanization brings about lifestyle changes, including those related to levels of physical activity and dietary needs. As a result of these factors, consumers are shifting from less expensive staple foods to higher-value products, and they are spending an increasing share of their income on processed convenience foods (Pingali, 2007). Demand-side factors are only part of the explanation though. Globalization aspects, such as freer trade, a push towards the reduction of trade barriers in the developing world, and the increasing penetration of international corporations perpetuate these factors (Hawkes et al., 2009). Globalization of food systems is an important aspect that is driving the nutrition transition from the supply side. Changes in the food systems have been influenced by global food advertising and promotion, liberalization of international food trade and foreign direct investment (FDI), and growth of transnational food companies (Hawkes et al., 2009). The growth of transnational food companies, including global supermarket chains, is particularly important, especially considering the speed at which it has occurred. In some of the developing countries without global supermarket chains, there are domestic chains that have usually adopted the look and functioning like those of global chains (Popkin et al., 2012). While it took several decades in developed countries, the spread of supermarkets is now occurring within a much shorter time period in developing countries. In fact, supermarkets have spread so rapidly in some developing countries that the term "supermarket revolution" has been coined (Reardon et al., 2003). The share of modern retail in food markets increased from 5-10\% in 1990 to $50-60 \%$ in 2000 in South America, South Africa, and East Asia, the so called first-wave countries of the supermarket revolution (Reardon \& Timmer, 2007). In the second wave countries, which include parts of Southeast Asia, Central America and Mexico, and Southern-Central Europe, the share of modern retail increased to $30-50 \%$ in the early 2000 s, and $10-20 \%$ in the third-wave countries. Third wave countries include some in Africa such as Kenya and Zambia, some countries in Central and South America such as Nicaragua and Peru, and Southeast Asia such as Vietnam. 
This wave also includes China, India, and Russia (Reardon \& Timmer, 2007). Thus the retail market is increasingly becoming modernized in most of the developing world.

The retail format can have an influence on the types of products offered, prices and shopping atmosphere, which may affect consumer food choices (Hawkes, 2008; Timmer, 2008) It is known that emerging supermarkets have readily available stocks of highly processed foods and drinks (Hawkes, 2008; Pingali, 2007; Reardon et al., 2003), which are likely to increase consumption of such foods among supermarket shoppers. Additionally, supermarkets engage in marketing strategies. Pricing and promotion are some of the strategies that food marketers use to influence the volume of consumption (Chandon \& Wansink, 2012). Since supermarkets are dealing with large quantities of branded and packaged (often processed) goods, they have a greater flexibility in determining prices for such goods.

\subsection{Problem Statement}

As a result of the spread of supermarkets in developing countries, recent research has analyzed their effects. Several studies looked at farms and other rural households that may be impacted through participating in supermarket procurement channels (Dube et al., 2012; Rao et al., 2012; Rao \& Qaim, 2011; Reardon et al., 2012; Stokke, 2009). The dietary implications of the supermarket revolution have received less attention, however. The few studies that look at the relationship between supermarkets and nutrition have been carried out in high-income countries (Laraia et al., 2004; Moore et al., 2008; Pearce et al., 2008). Most of this work shows that supermarkets increase the consumption of healthy foods such as fresh fruits and vegetables. For developing countries, the reigning hypothesis is that supermarkets would increase the consumption of energy-dense, processed foods (Hawkes, 2008), but empirical studies are hardly available. We are aware of only two studies that have looked at the dietary implications of supermarkets for consumers in developing countries (Asfaw, 2008; Tessier et al., 2008). While Asfaw (2008) showed that supermarket purchases in Guatemala increased the share of processed foods at the expense of traditional staple foods, Tessier et al. (2008) found that regular users of supermarkets in Tunis had a slightly improved dietary quality. Methodologically, only Asfaw (2008) addressed the potential endogeneity of supermarket purchases in the statistical analysis. However, his research for Guatemala builds on a general household living standard survey that was not specifically designed for analyzing dietary implications of supermarkets. Hence, key 
variables of interest, such as food quantities purchased in different retail outlets, were not properly captured. In this dissertation, this small body of literature is extended, addressing some of the data and methodological limitations of previous work.

Research on the impact of supermarkets on consumer nutritional status in developing countries is rare. In the USA, access to supermarkets is often associated with lower obesity rates (Drewnowski et al., 2012; Lear et al., 2013; Michimi \& Wimberly, 2010 ; Morland et al., 2006). This may not be the case in developing countries. Our literature search revealed only one study that has analyzed the impacts of supermarkets on nutritional status in a developing country (Asfaw, 2008). In that study that was carried out in Guatemala, food purchase in supermarkets was found to have an increasing effect on the body mass index (BMI) of consumers. As similarly argued above, this research for Guatemala is based on a household living standard survey that was not specifically designed for analyzing the nutritional impact of supermarkets. Important variables in such an analysis, such as food quantities purchased in different retail outlets, were not properly captured. The study analyzed the impact of supermarket purchase on BMI for all individuals above 10 years of age. This approach may mask possible differences between adults and children since BMI is only a suitable indicator of nutritional status for adults. For children and adolescents, literature recommends other indicators that compare individual measures to a reference population of the same age (de Onis et al., 2007).

This dissertation comprises three essays. The first essay focuses on the impact of supermarkets on dietary behavior. In the second essay, we analyze whether supermarkets are a direct causal factor of overweight or obesity. These two essays are based on a household and individual level survey that was specifically designed to answer these questions in a quasiexperimental setting in Kenya.

The focus of the third essay is on the effect of the nutrition transition on child malnutrition. The generally accepted hypothesis is that the nutrition transition will affect adult weight (Hawkes, 2008; Hawkes et al., 2009; Popkin et al., 2012). Empirical research, though scarce, shows that buying in supermarkets, which is one aspect of the nutrition transition, increases adult BMI and the probability of being overweight (Asfaw, 2008). Related research for children does not exist. However, it is naturally expected that the nutrition transition will increase child weight, especially with numbers showing that child overweight rates in developing countries are also increasing. As the number of children who are overweight increases, the number of those who 
are underweight has reduced. Since underweight is a weight-based indicator, a growing observation is that this reduction may actually be due to the nutrition transition (de Haen et al., 2011; de Onis et al., 2004; Haddad, 2013; Lutter et al., 2011; Misselhorn, 2010; UNICEF, 2013). In contrast, stunting has decreased much slower, and it remains a problem of higher magnitude. This has given rise to the notion that the nutrition transition would only have an effect on child weight and not growth. If this were the case, reduced child undernutrition as suggested by the underweight indicator would be misleading. However, the notion that the nutrition transition would reduce child underweight but not stunting is not based on strong empirical evidence. In fact, this relation has never been analyzed explicitly. We address this research using a crosscountry regression approach.

\subsection{Research Objectives and Dissertation Outline}

As discussed above, this dissertation has three essays with the following focus: the impact of supermarkets on dietary behavior, the impact of supermarkets on nutrition status, and the impact of the nutrition transition on child malnutrition indicators. Specifically, this dissertation addresses the following research questions:

1. Does the spread of supermarkets in developing countries affect food dietary behavior?

2. Does the spread of supermarkets in developing contribute directly to rising overweight and obesity?

3. What is the effect of the nutrition transition on child malnutrition indicators in developing countries?

To address the first two research questions, we rely on cross-section household and individual level data collected in Kenya in 2012 in a quasi-experimental setting. The data collection was specifically tailored to answer these questions. Kenya has recently witnessed a rapid spread of supermarkets that now account for about $10 \%$ of national grocery sales (PlanetRetail, 2013a). In addition, over $25 \%$ of the women in Kenya are overweight or obese (KNBS \& ICFMacro, 2010). In the analysis, we account for potential endogeneity of supermarket purchases in the regression models using instrumental variable techniques. Analysis for the second research question is done separately for adults and for children and adolescents. In addition, we examine impact pathways 
through which supermarkets affect nutritional status by estimating a system of structural equations. Specific details on data collection (see the household questionnaire used in the General Appendix) and variables, and the detailed information on the estimation methods are given in the respective chapters 2 and 3 of this dissertation.

The analysis for the third question relies on a cross-country approach, where we regress measures of child malnutrition on indicators of the nutrition transition and a set of control variables. We use fat consumption, share of modern retail in grocery sales, and the prevalence of overweight women as indicators of the nutrition transition. We pool data from Demographic and Health Surveys, Planet Retail, FAOSTAT, and World Development Indicators and estimate fixed effects and random effects panel data models. Chapter 4 of this dissertation gives detailed information on variables used and the sources of data, as well as the specific estimation strategies used. In chapter 5, the main findings are summarized and a general conclusion is given. 


\section{Supermarkets and the Nutrition Transition in Kenya ${ }^{1}$}

Abstract. Many low income countries experience a "nutrition transition" towards the consumption of more energy-dense, highly processed foods and more sedentary lifestyles. Among the consequences, overweight and obesity and related non-communicable diseases are rising. It remains unclear to what extent the concurrent spread of supermarkets is spurring the nutrition transition. This paper investigates the effect of supermarkets on consumption patterns using cross-sectional household survey data collected in Kenya in 2012. To establish causality, we use quasi-experimental data, with study sites differing in supermarket access, and employ instrumental variable techniques to allow for endogeneity of supermarket purchases. We find that supermarket purchases increase the consumption of processed foods at the expense of unprocessed foods. Supermarket purchases increase per capita calorie availability, which is supported by lower prices per calorie, particularly for processed foods. Our results imply that supermarkets contribute to the nutrition transition, while effects on nutrient adequacy are less clear.

\subsection{Introduction}

Many low and middle income countries are experiencing a nutrition transition, which is understood as a rapid change of diets towards more energy-dense, often (highly) processed and convenience foods and beverages that tend to be rich in fat, caloric sweeteners and salt. In some countries, the onset of these trends was in the mid-1990s already (1997). This "westernization" of diets (Pingali, 2007, p. 4) and a concurrent trend towards more sedentary lifestyles were soon being observed with concern, because they were found to contribute to surging rates of overweight and obesity, which are risk factors for nutrition related non-communicable diseases such as diabetes, cardiovascular diseases and certain types of cancer (e.g. Rosin, 2008; Sturm, 2002). Given still prevailing rates of undernutrition and related nutritional deficiencies, many low income countries are now facing a double burden of malnutrition where undernutrition and

\footnotetext{
11 This chapter is co-authored by Ramona Rischke, Stephan Klasen, and Matin Qaim. The following roles were performed by me: conceptualization and designing of the study in cooperation with all co-authors; implementation of the survey in cooperation with Ramona Rischke; interpretation of the research results in cooperation with all coauthors; and revision of the paper in cooperation with all co-authors.
} 
obesity coexist, sometimes even in the same households (Popkin et al., 2012; Roemling and Qaim, 2013).

These nutritional transformations have been associated with changes on both the demand as well as the supply side: changing demand patterns, commonly linked to rising incomes, and urbanization processes, coincided with a 'retail revolution', a rapid spread of supermarkets (SMs) and fast food outlets. While Mergenthaler et al. (2009) provide case study evidence to suggest demand side factors to predominate, both trends are often believed to be mutually reinforcing (Hawkes, 2008; Popkin et al., 2012; Reardon et al., 2004).

The consumption of processed and highly processed foods and beverages is often singled out as an important factor contributing to unhealthy diets, as this category includes high calorie foods with only poor micronutrient content, such as sugary beverages, sweets, and all kinds of salted snacks (Monteiro et al., 2010). Spreading supermarkets and fast food outlets, in turn, are suspected to improve the availability of these products and to increase their desirability even among poor households in remote areas (Asfaw, 2008; Hawkes et al., 2009). On the other hand, supermarkets could provide more stable and affordable access to a greater variety of foods and drinks, which might improve the dietary diversity and overall dietary quality of consumers (Asfaw, 2008; Hawkes, 2008).

In any case, supermarkets have the potential to affect dietary choices to the better or worse, and it is important to better understand the dynamics at play. For this reason, our research questions are: How do supermarkets affect consumption patterns of households? Secondly, what factors determine where consumers source their food from? For our empirical analysis, we rely on survey data collected from in Kenya in 2012. Very rich and highly disaggregated food consumption data allow us to analyze consumption patterns with a particular focus on goods associated with the nutrition transition, and at different levels of processing.

Our contribution to the literature is threefold: first, we use detailed data on actual food purchases from different retail formats in addition to measures of physical access which the food environment literature is often restricted to (notable exceptions are Asfaw, 2008; Tessier et al., 2008). Secondly, in contrast to most other studies, we account for potential endogeneity of supermarket purchases (selection effects) using instrumental variable techniques and further improve identification by a quasi-experimental survey design. Lastly, given the very few studies 
on this issue in developing countries, we add the first case study of this issue in Sub-Saharan Africa.

For our quasi-experimental design, we chose survey locations among small towns such that they differ in terms of when, if at all, a local supermarket was established, whereas being comparable in other aspects. While most households in large Kenyan towns have fairly good access to supermarkets, this is not yet true for small towns. Small towns in Kenya (less than 50,000 inhabitants) are of particular relevance also because they accommodate $70 \%$ of the urban population, and manifestations of lifestyle changes are less obvious and less well studied (KNBS, 2010a; KNBS, 2010b). Adding to the relevance of our case study, Kenya can be classified a double burden country with 2008/09 Demographic and Health Survey data showing $25 \%$ of women of ages 15-49 being overweight or obese and $35 \%$ of children below age 5 being stunted (KNBS and ICFMacro, 2010).

In a contribution to the non-empirical literature, we provide a detailed account of the current food environment and different retail formats in Kenya and shed some light on the rationale behind consumer decisions. This is relevant as it creates a reference point in a highly dynamic market (Neven et al., 2006; PlanetRetail, 2013a). In order to understand potential interactions between the food environment and consumption patterns, we refine a theoretical framework from the literature for the setting at hand.

\subsection{Theoretical Framework}

The term food environment refers to the "[food related] physical and infrastructural features of the area" (Giskes et al., 2011, p. e96) such as access to and the density of different types of retail outlets, including supermarkets. There are several pathways through which supermarkets can influence consumption patterns that go beyond making goods available. To inform our hypotheses, we will characterize the Kenyan food environment before elaborating on the impact channels.

\subsubsection{Food Environment in Kenya}

In Kenya, typical for a low-income country, common alternatives to supermarkets are smaller self-service stores and, more traditionally, kiosks. Comparing supermarkets and relevant competitors (see Table 2.1 for details), several features stand out: supermarkets are self-service 
stores, while kiosks are strictly over-the-counter shops. As opposed to kiosks, supermarkets stock large varieties of different kinds of food and non-food products. This is in terms of product ranges and in terms of brands and features of the same product, i.e. different flavors, functionalities (e.g. nutrients added to food) and levels of processing. High value non-food items (e.g. electronics, furniture) are uniquely offered by supermarkets. The characteristics of small self-service stores are in between those of supermarkets and kiosk.

Table 2.1. Defining features of different retail outlets - the case of Kenya

\begin{tabular}{|c|c|c|c|}
\hline & Supermarket & $\begin{array}{l}\text { Small self-service } \\
\text { store }\end{array}$ & $\begin{array}{l}\text { Kiosk (traditional } \\
\text { retail) }\end{array}$ \\
\hline Size indicators & $\begin{array}{l}>150 \mathrm{~m}^{2}(\text { Neven and } \\
\text { Reardon, 2004) } \\
\text { - Typically }>1 \text { floor } \\
\text { - Typically >2 } \\
\text { modern cash } \\
\text { counters }\end{array}$ & $\begin{array}{l}<150 \mathrm{~m}^{2} \text {, though size } \\
\text { in small towns } \\
\text { typically } \\
10-30 \mathrm{~m}^{2} \\
\text { - Typically } 1 \text { floor } \\
\text { - Typically 0-2 } \\
\text { modern cash } \\
\text { counters }\end{array}$ & $\begin{array}{l}\text { - } 1-10 \mathrm{~m}^{2} \\
\text { - No modern cash } \\
\text { counter }\end{array}$ \\
\hline Service features & $\begin{array}{l}\text { - Self-service } \\
\text { - One-stop shopping } \\
\text { - More sophisticated } \\
\text { shopping } \\
\text { atmosphere: } \\
\text { - Spacious isles } \\
\text { - Full shelves } \\
\text { - Clean \& bright } \\
\text { - No credit }\end{array}$ & $\begin{array}{l}\text { - Self-service } \\
\text { - Narrow aisles, often } \\
\text { little light }\end{array}$ & $\begin{array}{l}\text { - Over-the-counter } \\
\text { service } \\
\text { - Direct contact to } \\
\text { shop owner }\end{array}$ \\
\hline Product features & $\begin{array}{l}\text { - Large variety of } \\
\text { different food and } \\
\text { non-food products } \\
\text { - Large variety of } \\
\text { brands and features } \\
\text { within product } \\
\text { categories } \\
\text { - Frozen and } \\
\text { refrigerated foods } \\
\text { - Small to very large } \\
\text { packaging sizes } \\
\text { - High value non-food } \\
\text { items, e.g. } \\
\text { electronics, } \\
\text { furniture, clothes }\end{array}$ & $\begin{array}{l}\text { - Large variety of } \\
\text { different food } \\
\text { products } \\
\text { - Limited variety of } \\
\text { non-food products, } \\
\text { brands and product } \\
\text { features } \\
\text { - Neither frozen, nor } \\
\text { cooled foods } \\
\text { - Small to fairly large } \\
\text { packaging sizes } \\
\text { - No high value non- } \\
\text { food items }\end{array}$ & $\begin{array}{l}\text { - Limited but often } \\
\text { fair variety of } \\
\text { different food } \\
\text { products } \\
\text { - Only fast-moving } \\
\text { non-food products, } \\
\text { limited brands and } \\
\text { product features } \\
\text { - Neither frozen, nor } \\
\text { cooled foods } \\
\text { - Very small to small } \\
\text { packaging sizes } \\
\text { - No high value non- } \\
\text { food items }\end{array}$ \\
\hline
\end{tabular}




\subsubsection{Impact Channels}

The basic argument for an effect of supermarkets on diets is that the food environment affects where people do their shopping, which in turn influences their dietary practice (Asfaw, 2008), and that introducing supermarkets significantly alters the food environment. Figure 2.1 illustrates potential relationships between food environments, consumption choices and dietary practice (see Figure 2.1, column 3) as developed and refined from the literature. Supermarkets improve physical access to and increase the availability of goods. By offering more types of goods, brands, flavors, functional foods and levels of processing supermarkets offer a larger variety of all types: healthy, 'health neutral' and unhealthy products, regardless of the consumer's dietary needs. This is expected to increase the dietary diversity of consumers. At the same time, changing quantities and substitution within and across food categories could be enhancing as well as deteriorating dietary quality (Asfaw, 2008; Hawkes, 2008). Thus, the expected magnitude of these effects has to be further elaborated on and will closely be linked to likely effects on relative prices.

Reardon et al. (2004) argue that supermarkets in low income countries have a price advantage with industrially processed goods with long shelf-lives. In this context, the term 'processed foods' refers mainly to highly processed foods. These are predominantly ready-to-eat products, produced for instance by adding spices, preservatives, synthetic vitamins, by frying, cooking or baking (Monteiro et al., 2004). It is highly processed foods for which supermarkets are expected to have the strongest advantage over other retail formats. Even though this classification puts flour enriched with vitamins and potato chips in the same processing category, highly processed foods tend to be high in salt, sugar and saturated fats, are often considered unhealthy and found to contribute to developing non-communicable diseases. See Monteiro et al (2010) and Asfaw (2011) for a discussion of underlying evidence from the medical literature. The effect of supermarkets on prices is, however, controversial in the empirical literature. Price premiums were detected in some cases (Schipmann and Qaim, 2011) and examples of consistently smaller prices in others (Hawkes, 2008).

Following another line of argument, Chandon and Wansink (2012, p. 572) point out that highly processed foods are highly differentiated and not bound to commodity prices because: "With these branded products, marketers can establish their own price depending on which 
consumer segment they wish to target." As an example to the contrary, Popkin et al. (2012) mention production related price reductions in edible oils that had already by the mid 1990's enabled poor households to increase their energy intake. Reviewing evidence on pricing strategies of supermarkets in low income countries, Hawkes (2008) finds that supermarkets tend to be more expensive upon market entry but become more price-competitive later, and first among processed foods as discussed above. On a related note, supermarkets facilitate bulk shopping by offering large packaging sizes, which is likely accompanied by quantity discounts. However, poor consumers have a limited capacity to utilize these discounts. In fact, one advantage of kiosks is that they often offer credit and smallest amounts of products.

Apart from influencing relative prices, supermarkets use a variety of marketing strategies to influence what and how much customers are buying, many of them affecting consumers subconsciously (Monteiro et al., 2010). In this context, Hawkes (2008, p. 682) talks about the food industry making food desirable. See Chandon and Wansink (2012) for a comprehensive review of marketing strategies and related outcomes. Interestingly, the authors refer to studies showing that temporary price discounts and offering large packaging sizes, relevant strategies for supermarkets in our survey locations, can increase the consumption of respective goods rather than merely shifting it across brands or time. Following this line of argument, supermarkets are hypothesized to increase overall consumption of all food groups (Hawkes, 2008).

At the same time, a number of demand side factors can directly influence both dietary practices and the place of shopping. These include economic factors (e.g. disposable income), individual and household preferences (e.g. for taste or habits), social and individual norms and beliefs (e.g. attitudes towards modern or traditional foods and outlets, the maintained and aspired lifestyle and beauty ideals) and personal health concerns. We will incorporate proxies for them as control variables in the empirical analysis.

Existing studies confirm that the impact of supermarkets on diets is context specific in nature and that important research gaps remain with respect to mediating factors: most studies have been carried out in high income countries (e.g. Cummins et al., 2005; Laraia et al., 2004; Moore et al., 2008; Morland et al., 2006; Pearce et al., 2008; Powell et al., 2007; Wrigley et al., 2003). Two studies were conducted in a developing country context, which further contribute to the literature by considering supermarket purchases rather than supermarket access. Asfaw (2008) finds that supermarket purchases in Guatemala increase the share of partially and highly 
processed foods at the expense of staple foods and that supermarket purchases are positively associated with BMI. Tessier et al. (2008) in a similarly titled paper conclude that regular users of supermarkets in Tunis have a slightly improved dietary quality.

Figure 2.1. Conceptual framework - food environment, consumption and influencing factors

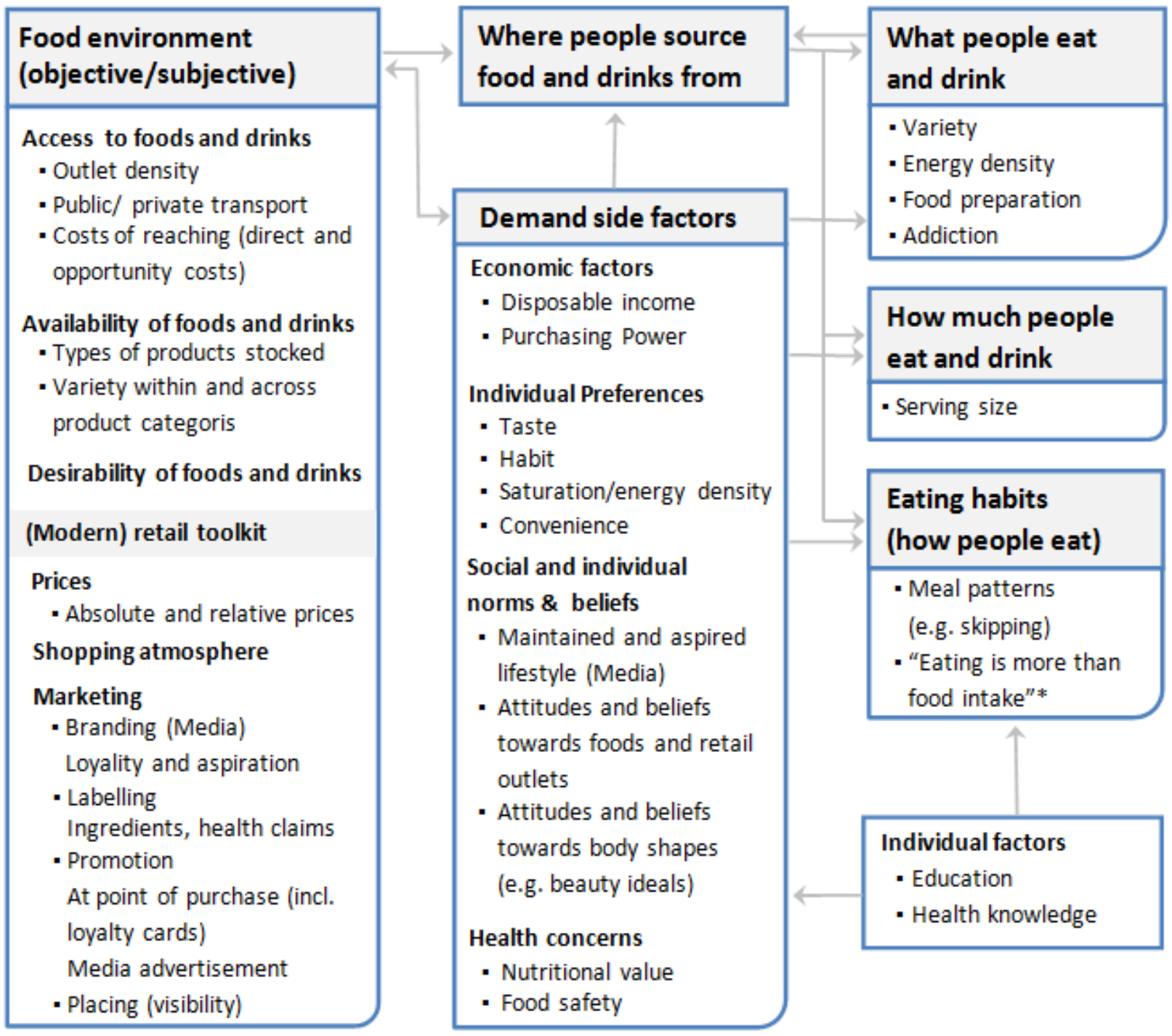

Because supermarkets in small towns have a limited catchment area and thus need to target a broad customer base, we assume them to offer a wide range of product qualities and prices. Yet, following the discussion of this section, we hypothesize that their pricing strategy leads to lower 
prices per calorie. In terms of consumption, as a result of food environment changes due to supermarkets and their pricing strategy we hypothesize that:

$\mathrm{H} 1_{1}$ : Supermarket customers eat differently: supermarket purchases increase per capita consumption shares of processed and highly-processed foods.

$\mathrm{H}_{2}$ : Supermarket customers eat more: supermarket purchases increase total per capita consumption.

$\mathrm{H}_{3}$ : Supermarket customers eat more types of food: supermarket purchases increase the dietary diversity of consumers.

\subsection{Survey Site and Study Design}

\subsubsection{The Case of Kenya}

Supermarkets have been spreading rapidly throughout Kenya and the pattern has been similar to the retail revolution described in other low income countries (Neven et al., 2006; Reardon et al., 2004). In the early 2000s, Kenya's retail sector was already classified as one of the most dynamic in Sub-Sahara Africa (Neven et al., 2006). Today, despite being highly fragmented, it is among the most developed retail sectors in Sub-Sahara Africa (PlanetRetail, 2013a). This fragmentation explains why the top three retailers in 2013 only had a market share of around 5\% while in 2003 already, supermarkets more generally had a 20\% market share of the urban food retail market (Neven and Reardon, 2004; PlanetRetail, 2013a). Interestingly from a domestic policy perspective and in contrast to the experience of countries with an early supermarket revolution (Reardon et al., 2004), none of today's top five supermarket chains in Kenya are owned by international corporations or foreign firms, but by Kenyan enterprises. It should also be noted that while quite a number of supermarkets do not belong to chains at all or have only a few outlets, they do not qualitatively differ from chain supermarkets.

For a full picture of the urban food environment in Kenya, please note that international and other fast food chains are still restricted to large towns. Only in large towns are supermarkets offering fresh fruits and vegetables, have built-in butcheries, restaurants and large bakeries. Western style convenience processing (pre-cut vegetables, prepared salads, frozen or tinned ready-to-heat food) is only available there. Visiting large town supermarkets or hypermarkets ten times larger in size (Neven et al., 2006), it becomes evident that lifestyle and status play a 
significant role and that 'shopping atmosphere' is not an abstract concept but a strong force. However, Neven et al. (2006), who analyze patterns of the retail revolution in Kenya and consumer attitudes in Nairobi, already put forward that the introduction of supermarkets in small towns, from a consumer perspective, is likely to be as impressive and as powerful in influencing consumer choices, as the introduction of hypermarkets in large towns or mini-supermarkets in rural areas. Note that product ranges of supermarkets, small self-service stores and kiosks in small towns are surprisingly similar. The main differences are qualitative in nature and as outlined in the section 2.2.1.

\subsubsection{Study Design and Data}

This study uses data from a household consumption survey conducted in three small towns in Central Province, Kenya. A total of 453 households were interviewed between July and August 2012. Our identification strategy to test for a causal relationship between supermarkets and consumption patterns relies on a quasi-experimental survey design: we selected three towns that differ in terms of their access to supermarkets while being comparable in other aspects: One with a well-established supermarket (Ol Kalou: one supermarket since 2002), One with a supermarket opened fairly recently but with a sufficient time lag to allow inhabitants to get used to it (Mwea: one supermarket since August 2011) and One town with no supermarket up to that point in time. We applied systematic random sampling. Our sampling frame, produced for this survey, covered the town centers and close peripheries (about $2.5 \mathrm{~km}$ radius), which corresponded to the most densely populated parts of the town and town outskirts.

\subsection{Empirical Strategy}

In general terms, our model can be specified as proposed by Asfaw (2008):

$$
\begin{gathered}
\boldsymbol{D}_{i}=\propto \boldsymbol{X}_{i}+\beta S_{i}+\varepsilon_{i} \\
S_{i}=\gamma \boldsymbol{X}_{i}+\delta \boldsymbol{Z}_{i}+\omega_{i}
\end{gathered}
$$

where $\boldsymbol{D}_{i}$ refers to dietary indicators of household $i, \boldsymbol{X}_{i}$ to explanatory variables and $S_{i}$ to the measure of supermarket purchases, our main variable of interest. Because supermarket purchases are likely to be endogenous, we use a two stage least squares instrumental variable approach and 
thus add equation (2.2) to the model, where $\boldsymbol{Z}_{i}$ refers to the excluded instruments. $\varepsilon_{i}$ and $\omega_{i}$ are error terms.

Supermarket purchases, i.e. the intensity of supermarket purchases, are conceptualized using the share of supermarket purchases from the overall food basket. Note that this share can be positive for non-supermarket locations due to out-of-town shopping. Endogeneity of supermarket purchases might result from self-selection on non-observables, i.e. systematic differences between frequent supermarket customers and others. We use distance to the nearest supermarket as an instrument. This reflects our initial hypothesis that supermarket access will induce people to shop there. At the same time, we claim this variable to be exogenous: while market potential drives the decision to establish a supermarket in a particular town, we argue that this potential boils down to demand side factors, which we control for, and to road infrastructure so as to facilitate logistics. While supermarket managers in our survey towns explained that the location within town was substantially driven by the availability of large plots, we believe between town road infrastructure to be exogenous to our analysis. Distance is measured as physical linear distance between household and nearest supermarket based on GPS readings. Note that there is only one supermarket per supermarket location, consumers mostly go there by foot and linear distances approximate walking distances well. For the town without a supermarket, the closest supermarkets can only be reached using public or private transport.

Our explanatory variables mirror the demand side and individual factors from our conceptual framework presented earlier (see Figure 2.1). Individual level factors, such as education or age, refer to either the household head or to the person responsible for food purchases and preparation. Food consumption was captured with a 30 day recall period because we expect decisions regarding where to shop to vary during a wage cycle (e.g. households shopping in bulk in supermarkets after getting paid while increasingly shopping for small portion sizes at kiosks towards the end of the month). In very disaggregated form (e.g. differentiating between fortified and unfortified flour and different types of cooking oil), we asked how much quantity was consumed by the household during the last month. This was for consumption inside the house, since food eaten outside the home is more specific to the individual and usually not sourced from supermarkets, but from street hawkers, restaurants and sometimes kiosks. We asked the households to break down the total quantity consumed into quantities consumed from purchases, own production, or other sources (e.g. gifts). For purchases, the respondents were also 
reporting how much they spent and what quantity they bought where (supermarkets, smaller selfservice stores or traditional, i.e. all other outlets). Because outlets in the latter category only have few overlapping products, we can still and most notably identify the quantity bought in kiosks. Monetary values for own production and other sources are imputed so as to include it in the food expenditure aggregate. For this, we use median unit values reported for the same good by neighboring households. The expenditure share of a particular retail outlet is from the total food expenditure of that household.

Based on the classifications used by Asfaw (2011) and Monteiro et al. (2010), we differentiate products by levels of industrial processing into unprocessed foods (e.g. fresh fruits and vegetables), primary processed foods (e.g. rice, sugar and cooking oils), and highly processes foods (e.g. breakfast cereals, bread and sweets). These categories are mutually exclusive and jointly exhaustive with the exception of alcoholic beverages, which are excluded. We then conceptualize consumption patterns by expenditure shares and calorie shares on different processing categories. Overall consumption is considered in terms of per capita calorie availability per day and we briefly analyze households' food budget shares also.

\subsection{Empirical Results}

\subsubsection{Descriptive Statistics}

The survey locations differ quite substantially in terms of size: Njabini is the smallest and least urbanized town with an estimate of 1870 households (estimate based on our sampling frame). Mwea is the largest town with an estimate of 7650 households. Still, in terms is physical and social infrastructure (e.g. main roads being tarmac roads, having access to banks, a hospital, several health centers and other services, having similar administrative structures), all survey locations are comparable. In terms of ethnicity and religion, Kikuyu and Christian are by far the most prevalent in all survey towns, with rates exceeding $80 \%$ and $90 \%$, respectively.

Table 2.2 summarizes household characteristics by survey locations. The sample size across survey locations ranges from 134 to 161 households. The average household size in Njabini exceeds the other locations by one additional household member. Three quarters of all households in the sample are male headed. Household heads, on average, are 38 years old, with 
significant differences for $\mathrm{Ol}$ Kalou (younger heads) and Njabini (older ones). Despite having older heads, Njabini seems to be lagging behind regarding their highest level of education.

Table 2.2. Household characteristics of sample

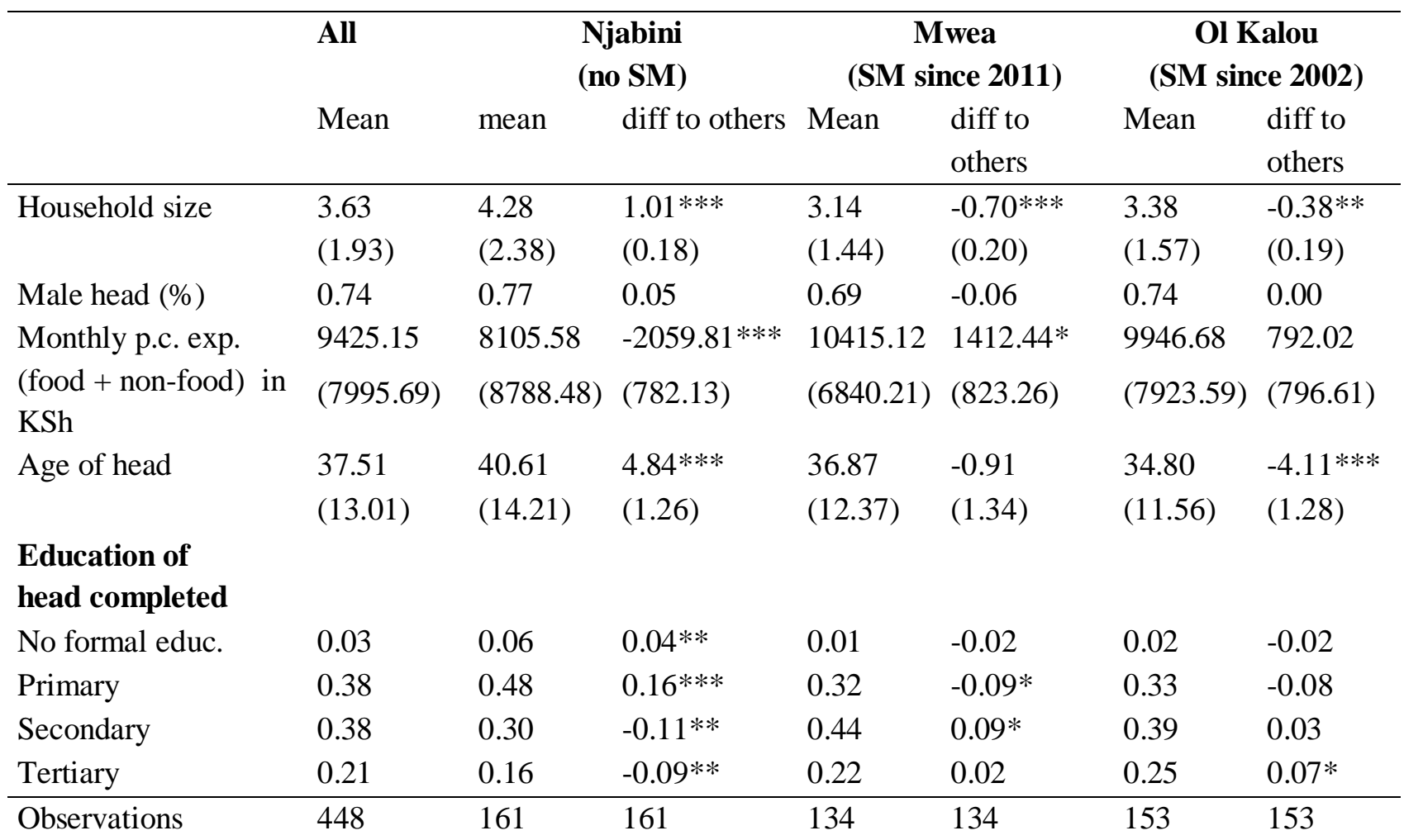

$*, * *, * * *$, statistically significant at the $10 \%, 5 \%$, and $1 \%$, level respectively. Means are shown with standard deviation in parenthesis. KSh, Kenya shillings

Average monthly per capita expenditure amount to $9,425 \mathrm{KSh}$, while being significantly and quite substantially smaller in Njabini. We are not aware of an up to data poverty estimate, but based on the latest poverty line (year 2005) and subsequent consumer price statistics publicly available, we extrapolate today's poverty line to be around 7,500 KSh per capita per month. This would yield a poverty headcount of $47 \%$ in our sample. The latest poverty estimate according to World Bank statistics was 46\% in 2005.

Table 2.3 provides an overview of access to different retail outlets and shopping behavior: in our supermarket locations, the average distance to the local supermarket is below $1 \mathrm{~km}$, while the nearest supermarket is $40 \mathrm{~km}$ away from Njabini. Kiosks are very close to most households and can be reached within 5 minutes on average. Food expenditure shares devoted to different retail outlets are as expected: Ol Kalou has the highest food expenditure share from supermarkets, followed by Mwea and Njabini. In Ol Kalou, the average supermarket share is 
$17 \%$, in Mwea already $11 \%$ of the food expenditure goes to supermarkets. Even in Njabini, the mean supermarket share is positive and $14 \%$ of households bought some food in supermarkets. In Ol Kalou, $84 \%$ of households frequented the supermarket, $80 \%$ in Mwea. Interestingly, in all towns, the frequency of shopping in kiosks is very high, it does not vary much from the overall mean of 25 times last month and traditional retail is by far the most important source for food with expenditure shares ranging from $66 \%$ to $75 \%$ across towns.

Table 2.3. Access to retail outlets and shopping behavior

\begin{tabular}{|c|c|c|c|c|}
\hline & mean/sd & $\begin{array}{l}\text { Njabini } \\
\text { (no SM) } \\
\text { mean/sd }\end{array}$ & $\begin{array}{l}\text { Mwea } \\
\text { (SM since } \\
\text { 2011) } \\
\text { mean/sd } \\
\end{array}$ & $\begin{array}{c}\text { Ol Kalou } \\
\text { (SM since } \\
\text { 2002) } \\
\text { mean/sd }\end{array}$ \\
\hline \multicolumn{5}{|l|}{$\begin{array}{l}\text { Number of times shopping } \\
\text { in [...] last month }\end{array}$} \\
\hline Supermarket & $\begin{array}{l}3.05 \\
(5.36)\end{array}$ & $\begin{array}{c}0.36 \\
(0.98)\end{array}$ & $\begin{array}{l}2.70 \\
(3.27)\end{array}$ & $\begin{array}{c}5.77 \\
(7.46)\end{array}$ \\
\hline Small self-service store & $\begin{array}{c}2.50 \\
(5.73)\end{array}$ & $\begin{array}{c}4.08 \\
(8.44)\end{array}$ & $\begin{array}{c}0.53 \\
(1.91)\end{array}$ & $\begin{array}{c}2.71 \\
(3.66)\end{array}$ \\
\hline Kiosk & $\begin{array}{c}25.62 \\
(16.82)\end{array}$ & $\begin{array}{c}23.84 \\
(17.69)\end{array}$ & $\begin{array}{c}29.33 \\
(15.78)\end{array}$ & $\begin{array}{c}24.18 \\
(16.38)\end{array}$ \\
\hline Distance to $\mathrm{SM}$ in $\mathbf{k m}$ & $\begin{array}{c}14.55 \\
(20.44)\end{array}$ & $\begin{array}{c}39.29 \\
(14.35)\end{array}$ & $\begin{array}{c}0.67 \\
(0.49)\end{array}$ & $\begin{array}{c}0.68 \\
(0.41)\end{array}$ \\
\hline \multicolumn{5}{|l|}{$\begin{array}{l}\text { Travelling time to }[. . .] \\
\text { (min. one way) }\end{array}$} \\
\hline Supermarket & $\begin{array}{c}47.64 \\
(47.29)\end{array}$ & $\begin{array}{l}103.68 \\
(33.73)\end{array}$ & $\begin{array}{l}16.54 \\
(9.08)\end{array}$ & $\begin{array}{c}15.90 \\
(10.59)\end{array}$ \\
\hline Kiosk & $\begin{array}{c}5.33 \\
(5.82)\end{array}$ & $\begin{array}{l}8.30 \\
(7.58)\end{array}$ & $\begin{array}{l}2.95 \\
(2.73)\end{array}$ & $\begin{array}{c}4.31 \\
(4.15)\end{array}$ \\
\hline $\begin{array}{l}\text { Share of HHs buying in } \\
\text { supermarket } \\
\text { Expenditure shares in [...] }\end{array}$ & 0.58 & 0.14 & 0.80 & 0.84 \\
\hline Supermarket & $\begin{array}{l}0.10 \\
(0.12)\end{array}$ & $\begin{array}{c}0.02 \\
(0.06)\end{array}$ & $\begin{array}{c}0.11 \\
(0.10)\end{array}$ & $\begin{array}{c}0.17 \\
(0.13)\end{array}$ \\
\hline Small self-service store & $\begin{array}{l}0.05 \\
(0.11)\end{array}$ & $\begin{array}{c}0.08 \\
(0.13)\end{array}$ & $\begin{array}{c}0.02 \\
(0.10)\end{array}$ & $\begin{array}{c}0.05 \\
(0.08)\end{array}$ \\
\hline Traditional retail & $\begin{array}{c}0.70 \\
(0.19)\end{array}$ & $\begin{array}{c}0.71 \\
(0.20)\end{array}$ & $\begin{array}{c}0.75 \\
(0.17)\end{array}$ & $\begin{array}{c}0.66 \\
(0.17)\end{array}$ \\
\hline Own production & $\begin{array}{c}0.11 \\
(0.15)\end{array}$ & $\begin{array}{c}0.16 \\
(0.17)\end{array}$ & $\begin{array}{c}0.08 \\
(0.13)\end{array}$ & $\begin{array}{c}0.09 \\
(0.13)\end{array}$ \\
\hline Observations & 448 & 161 & 134 & 153 \\
\hline
\end{tabular}


Asked for the most important reasons to shop in different retail outlets, more than half of the respondents in supermarket locations reported (perceived) lower prices (see Table 2.4). Improved availability, e.g. more variety of food and non-food products, was reported by $16 \%$ of respondents in $\mathrm{Ol} \mathrm{Kalou}$ and $8 \%$ in Mwea. The possibility for one-stop-shopping and other factors we attribute to convenience were most important to $11 \%$ of respondents in SM locations. For shopping in kiosks on the other hand, physical access is by far the most important reason in all towns, ranging from $52 \%$ in Njabini to $69 \%$ in Mwea. Note that the importance of perceived lower prices in supermarkets and physical access in the case of kiosks is consistent to what Neven et al. (2006) found in the case of consumers in Nairobi.

Comparing price ranges across outlets (not shown) cannot easily support the perception of lower prices (per $\mathrm{kg}$ ) offered by supermarkets. Irrespective of quality differences, most price ranges do not seem to differ much across stores. We will return to this issue below, but at this point the question remains if food expenditure serves as an accurate indicator of food consumption across retail outlets given that they might reflect price differences. Figure 2.2 plots several expenditure indicators against calorie indicators, with per capita variables using adult equivalent scales.

Figure 2.2. Expenditure and calorie indicators
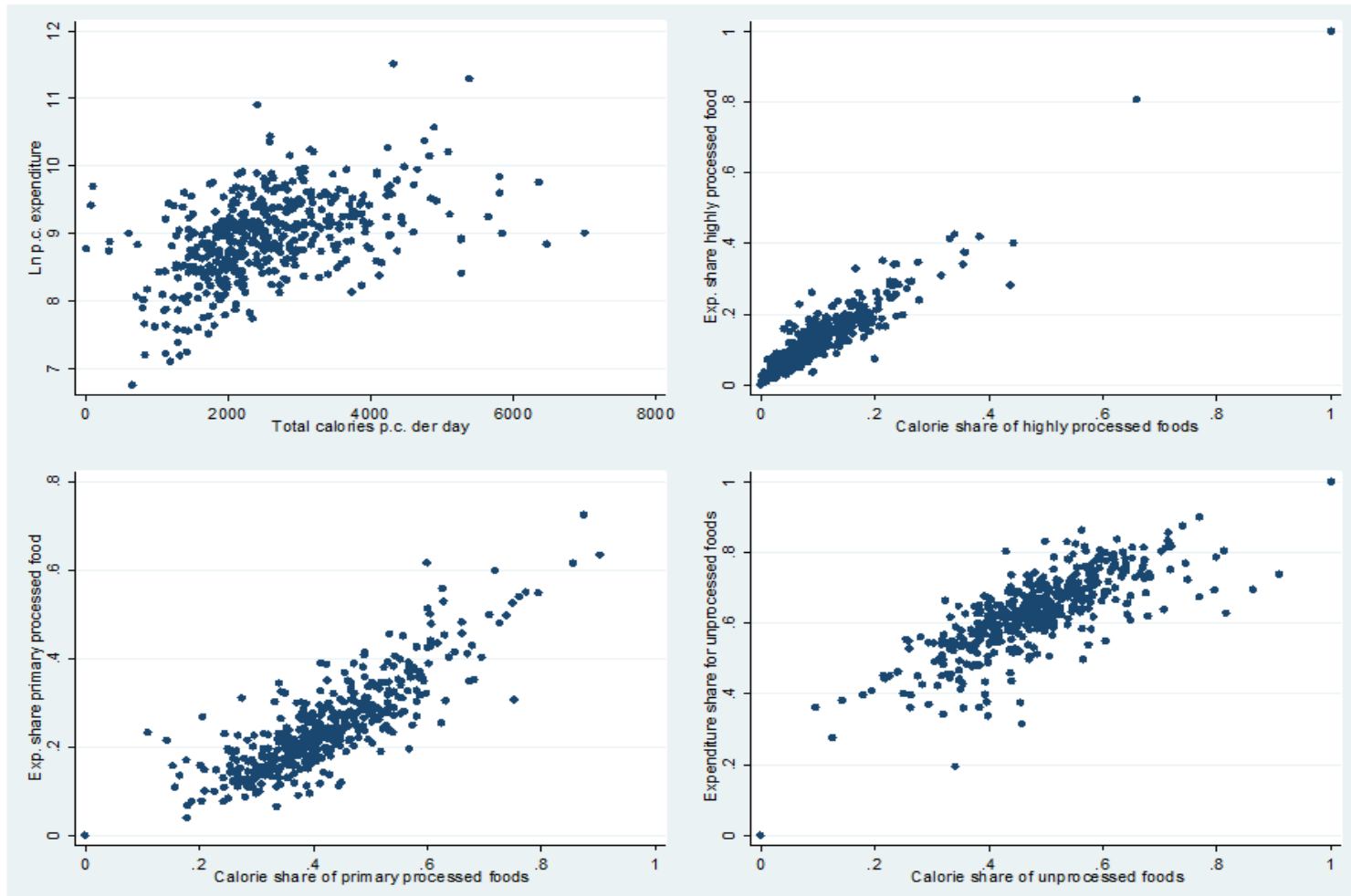
The upper left plot could suggest a non-linear relationship between log p.c. expenditure and p.c. calorie availability, which is particularly pronounced once calorie availability becomes very large and likely to exceed actual p.c. calorie intake (e.g. due to food wastage or hosting guests). Plotting food expenditure shares against calorie shares for different levels of processing (remaining plots) reveal strong positive and rather linear relationships so that both indicators seem to capture the same aspects of food consumption and are thus interesting for further analysis. Only in the case of highly processed foods, however, are expenditure and calorie shares so close to each other in absolute terms. Note that $5 \%$ of households do not report any consumption of highly processed foods. For primary processed foods, median expenditure shares are $23 \%$, calorie shares $40 \%$, suggesting that prices per calorie are lowest in this food category. Unprocessed foods contribute around $47 \%$ of calories for the median consumer, while $63 \%$ of food expenditure is spent on these items.

\subsubsection{Food Expenditure Shares by Levels of Processing}

Our main empirical results regarding expenditure shares by levels of processing using OLS and IV specifications are shown in Table 2.4 (2.4a and 2.4b). Summary statistics of all variables

used, first stage results and some robustness checks are found in the Appendix A2. Robust standard errors are used in all specifications. We tested each model for cluster effects at the neighborhood level, our primary sampling unit, and use cluster robust standard errors whenever required. Note that all IV specifications reported in this paper have first stage test statistics, i.e. exclusion and weak instrument criteria meeting or well exceeding conventional thresholds.

The OLS results confirm our initial expectations: supermarket purchases are positively associated with expenditure shares of highly and primary processed foods, while the share of unprocessed foods is declining. In the IV specifications, supermarket purchases lose their significance in case of highly processed foods, and remain significant in all other cases. At the same time, the effect size of supermarket purchases changes in some cases, with the point estimate for all processed foods, for example, increasing from 0.21 to 0.38 . In sum we take this as an indication that endogeneity is a relevant issue here that we rightfully account for.

How are these coefficients to be interpreted? If the supermarket expenditure share increased by 1 percentage point (the average share is $9 \%$ ), the expenditure share on processed foods would increase by 0.38 percentage points. However, considering that the average share in 
our supermarket locations is $14 \%$ against $1 \%$ where no SM is present, looking at a 10 percentage point increase in purchases seems like a plausible treatment scenario, and would be associated with a 3.8 percentage point increase in expenditure shares on processed food (an increase from 34 to around $38 \%$ for the average consumer in the non-SM location). We find positive income effects regarding highly and unprocessed foods, and negative income effects with respect to primary processed food. Note that these effects include quality effects of unknown magnitude. Other variables have the expected signs.

Robustness checks (not shown) include testing different sets of control variables, and restricting the sample to the supermarket locations only. Generally we find the direction of main effects and their statistical significance to be robust, but effect sizes are sensitive to model specifications. Interestingly, for all expenditure shares, the effects remain stable when excluding our non-supermarket location from the sample. Another interesting finding regards interaction effects that we find between supermarket shares and an indicator variable for households whose kiosk consumption exceeds the town median. The idea was that depending on their shopping intensity in traditional outlets, households might frequent supermarkets for different reasons and with different outcomes. Indeed, in the case of primary and all processed foods, controlling for frequent kiosk consumption increases the effect of supermarket purchases, but less among frequent kiosk consumer. It is the other way around for unprocessed foods. Note, however that the interaction effects should be interpreted with care because first, frequent consumers tend to have lower supermarket expenditure shares and second, kiosk purchases might be subject to selection effects also. Other interaction effects with total expenditure or education, for example, were not significant. 
Table 2.4a. OLS and IV regression results - Food expenditure shares by levels of industrial processing

\begin{tabular}{|c|c|c|c|c|}
\hline & $\begin{array}{c}\text { (1) OLS } \\
\text { Expenditure } \\
\text { share highly } \\
\text { processed food }\end{array}$ & $\begin{array}{c}\text { (2) IV } \\
\text { Expenditure } \\
\text { share highly } \\
\text { processed food }\end{array}$ & $\begin{array}{c}\text { (3) OLS } \\
\text { Exp. share } \\
\text { primary } \\
\text { processed food }\end{array}$ & $\begin{array}{c}\text { (4) IV } \\
\text { Expenditure share } \\
\text { primary processed } \\
\text { food }\end{array}$ \\
\hline SM expenditure share & $\begin{array}{l}0.0766^{*} \\
(0.041)\end{array}$ & $\begin{array}{l}0.0712 \\
(0.091)\end{array}$ & $\begin{array}{c}0.1336^{* * * *} \\
(0.039)\end{array}$ & $\begin{array}{c}0.2109^{* *} \\
(0.086)\end{array}$ \\
\hline Ln p.c. expenditure & $\begin{array}{c}0.0225^{* * *} \\
(0.008)\end{array}$ & $\begin{array}{c}0.0227^{* *} \\
(0.010)\end{array}$ & $\begin{array}{c}-0.0829^{* * * *} \\
(0.009)\end{array}$ & $\begin{array}{c}-0.0863^{\text {**** }} \\
(0.010)\end{array}$ \\
\hline Household size & $\begin{array}{c}-0.0009 \\
(0.003)\end{array}$ & $\begin{array}{c}-0.0009 \\
(0.003)\end{array}$ & $\begin{array}{l}0.0062 \\
(0.005)\end{array}$ & $\begin{array}{l}0.0062 \\
(0.004)\end{array}$ \\
\hline$=1$ if head is married & $\begin{array}{c}-0.0228^{* * *} \\
(0.009)\end{array}$ & $\begin{array}{c}-0.0228^{* *} \\
(0.009)\end{array}$ & $\begin{array}{r}-0.0089 \\
(0.012)\end{array}$ & $\begin{array}{r}-0.0089 \\
(0.011)\end{array}$ \\
\hline $\begin{array}{l}\text { Education of head in } \\
\text { years } \\
\text { Age of cook }\end{array}$ & $\begin{array}{c}0.0041^{* * *} \\
(0.001)^{* * *} \\
-0.0061^{* * *} \\
(0.002)\end{array}$ & $\begin{array}{c}0.0041^{* * *} \\
(0.001)^{* * *} \\
-0.0061^{* * *} \\
(0.002)\end{array}$ & $\begin{array}{c}-0.0009 \\
(0.001) \\
0.0002 \\
(0.002)\end{array}$ & $\begin{array}{l}-0.0014 \\
(0.001) \\
0.0003 \\
(0.002)\end{array}$ \\
\hline $\begin{array}{l}\text { Age of cook squared } \\
=1 \text { if } \mathrm{HH} \text { does } \\
\text { farming }\end{array}$ & $\begin{array}{c}0.0001^{* * * *} \\
(0.000) \\
-0.0346^{* * * *} \\
(0.008)\end{array}$ & $\begin{array}{c}0.0001^{* * * *} \\
(0.000) \\
-0.0347^{* * *} \\
(0.008)\end{array}$ & $\begin{array}{c}0.0000 \\
(0.000) \\
-0.0243^{* *} \\
(0.009)\end{array}$ & $\begin{array}{c}0.0000 \\
(0.000) \\
-0.0224^{* *} \\
(0.009)\end{array}$ \\
\hline Mwea (SM 2011) & & & $\begin{array}{c}0.0247 * * \\
(0.010)\end{array}$ & $\begin{array}{c}0.0241 * * \\
(0.009)\end{array}$ \\
\hline Constant & $\begin{array}{l}0.0462 \\
(0.079)\end{array}$ & $\begin{array}{l}0.0445 \\
(0.090)\end{array}$ & $\begin{array}{c}0.9562^{* * * *} \\
(0.077)\end{array}$ & $\begin{array}{c}0.9810^{* * * *} \\
(0.084)\end{array}$ \\
\hline $\begin{array}{l}\text { Observations } \\
R^{2}\end{array}$ & $\begin{array}{c}448 \\
0.256\end{array}$ & $\begin{array}{c}448 \\
0.256\end{array}$ & $\begin{array}{c}448 \\
0.316\end{array}$ & $\begin{array}{c}448 \\
0.310\end{array}$ \\
\hline
\end{tabular}


Table 2.4b. OLS and IV regression results - Food expenditure shares by levels of industrial processing

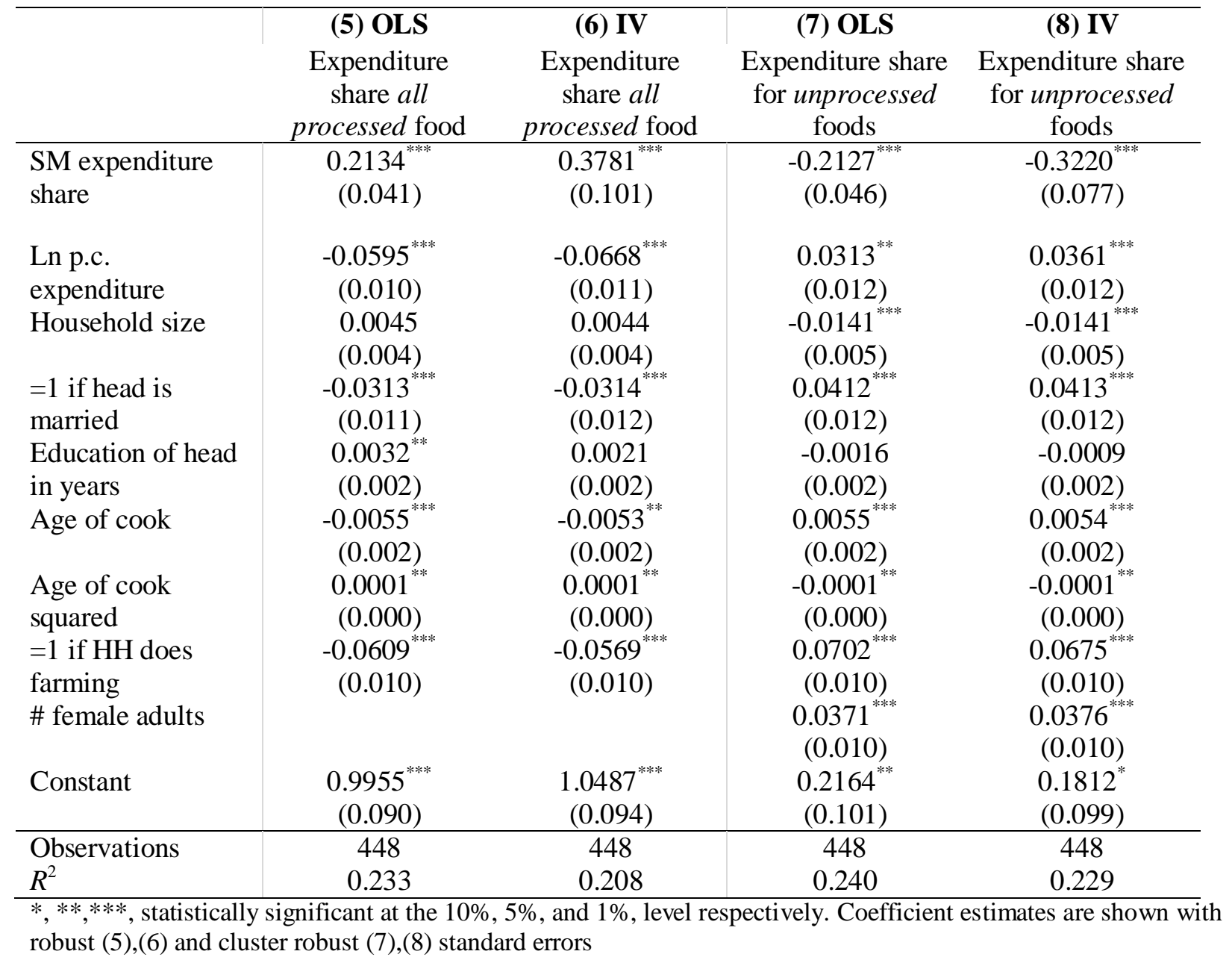

\subsubsection{Calorie Consumption}

Turning to the models on calorie shares from different kinds of food, supermarkets have less pronounced effects than before (see Table A2.3 in Appendix A2). A positive relationship between supermarket purchases and calorie shares remains significant over both OLS and IV specifications in the case of all processed foods only. The direction of all other effects is as expected but mostly insignificant. In accordance with our previous findings, negative income effects are found for primary foods and positive for both highly and unprocessed foods. In other robustness checks (not shown), the effect size of supermarket purchases on calorie shares from all processed foods ranges from 1.1 percentage point in OLS to 2.2 percentage points in IV 
specifications given a 10 percentage point increase in supermarket purchases. The average household in our non-supermarket location consumed $49 \%$ of their calories from primary processed food. Again, the effect size rises when we include a dummy for frequent kiosk consumers and an interaction with supermarket purchases but in this case, for high frequency consumers, the effect of supermarket purchases almost cancels out.

What do we take away up to this point? Supermarkets indeed influence consumption patterns in that they are associated with higher consumption shares of processed foods (incl. beverages). This is in terms of expenditure as well as calorie shares of these goods and at the expense of unprocessed foods. These results partly confirm our hypothesis 1 (see section 2.2). The contradicting part concerns highly processed foods, where we expected stronger and significant effects of supermarkets purchases. Given positive income effects we find for highly processed foods, however, we expect a stronger shift towards these goods as income levels are increasing.

In order to address our second hypothesis that supermarket purchases increase overall consumption, we analyze per capita calorie availability per day. Because of a high standard deviation (see Table A2.1 in Appendix A2), we use the log of p.c. calories in our regressions. This produces more robust results as compared to using absolute values. Table 2.5 presents our main results. We find supermarkets to be positively and significantly associated with higher p.c. calories so that we cautiously confirm our hypothesis. In the IV specification, the semielasticities indicate that p.c. calories increase by $0.85 \%$ in response to a 1 percentage point increase of supermarket purchases. In case of our example used before, a 10 percentage point increase in supermarket purchases would increase p.c. calories by $8.5 \%$ or around 200 calories per capita per day in the case of an average consumer in the non-supermarket location. Models (4) and (6) again show a significant interaction between frequent kiosk consumers and supermarket purchases. Above median kiosk purchases are associated with higher p.c. calories while supermarket purchases among frequent kiosk consumers have a negative effect on p.c. calories. Effect sizes of supermarket purchases are higher in the IV as compared to the OLS specifications. This might reflect measurement errors in calories consumed which would bias OLS results towards zero if they are random. IV techniques account for random measurement errors. 
Table 2.5. OLS and IV regression results - Calorie availability at home

\begin{tabular}{|c|c|c|c|c|c|}
\hline & $\begin{array}{c}\text { (1) OLS } \\
\log \text { of per } \\
\text { capita } \\
\text { calories per } \\
\text { day } \\
\end{array}$ & $\begin{array}{c}\text { (2) IV } \\
\log \text { of per } \\
\text { capita } \\
\text { calories per } \\
\text { day } \\
\end{array}$ & $\begin{array}{l}\text { (3) } 1^{\text {st }} \text { stage } \\
\text { SM } \\
\text { expenditure } \\
\text { share }\end{array}$ & $\begin{array}{c}\text { (4) OLS } \\
\text { log of per } \\
\text { capita } \\
\text { calories per } \\
\text { day }\end{array}$ & $\begin{array}{c}\text { (5) IV } \\
\text { log of per } \\
\text { capita } \\
\text { calories per } \\
\text { day } \\
\end{array}$ \\
\hline SM expenditure share & $\begin{array}{c}0.3706^{* *} \\
(0.186)\end{array}$ & $\begin{array}{l}0.8485^{*} \\
(0.504)\end{array}$ & & $\begin{array}{c}0.9140^{* * *} \\
(0.291)\end{array}$ & $\begin{array}{l}1.2479^{*} \\
(0.672)\end{array}$ \\
\hline Ln p.c. expenditure & $\begin{array}{l}0.3599^{* * *} \\
(0.056)\end{array}$ & $\begin{array}{l}0.3397^{* * *} \\
(0.068)\end{array}$ & $\begin{array}{c}0.0348^{* * *} \\
(0.009)\end{array}$ & $\begin{array}{l}0.3943^{* * *} \\
(0.057)\end{array}$ & $\begin{array}{c}0.3854^{* * *} \\
(0.067)\end{array}$ \\
\hline $\begin{array}{l}\text { HH size using adult } \\
\text { equivalent scales }\end{array}$ & $\begin{array}{l}-0.0055 \\
(0.024)\end{array}$ & $\begin{array}{l}-0.0067 \\
(0.024)\end{array}$ & $\begin{array}{c}0.0067^{* *} \\
(0.003)\end{array}$ & $\begin{array}{l}-0.0091 \\
(0.022)\end{array}$ & $\begin{array}{c}-0.0104 \\
(0.023)\end{array}$ \\
\hline$=1$ for male head & $\begin{array}{c}-0.2220^{* * * *} \\
(0.060)\end{array}$ & $\begin{array}{c}-0.2155^{* * *} \\
(0.060)\end{array}$ & $\begin{array}{r}-0.0071 \\
(0.011)\end{array}$ & $\begin{array}{c}-0.2151^{* * *} \\
(0.058)\end{array}$ & $\begin{array}{c}-0.2105^{* * *} \\
(0.059)\end{array}$ \\
\hline $\begin{array}{l}\text { Education of head in } \\
\text { years }\end{array}$ & $\begin{array}{l}0.0025 \\
(0.008)\end{array}$ & $\begin{array}{l}0.0001 \\
(0.008)\end{array}$ & $\begin{array}{c}0.0033^{* *} \\
(0.001)\end{array}$ & $\begin{array}{l}0.0031 \\
(0.008)\end{array}$ & $\begin{array}{l}0.0018 \\
(0.008)\end{array}$ \\
\hline Age of cook & $\begin{array}{r}-0.0060 \\
(0.008)\end{array}$ & $\begin{array}{l}-0.0051 \\
(0.008)\end{array}$ & $\begin{array}{r}-0.0029 \\
(0.002)\end{array}$ & $\begin{array}{l}-0.0062 \\
(0.008)\end{array}$ & $\begin{array}{l}-0.0058 \\
(0.008)\end{array}$ \\
\hline Age of cook squared & $\begin{array}{l}0.0001 \\
(0.000)\end{array}$ & $\begin{array}{l}0.0001 \\
(0.000)\end{array}$ & $\begin{array}{l}0.0000 \\
(0.000)\end{array}$ & $\begin{array}{l}0.0001 \\
(0.000)\end{array}$ & $\begin{array}{l}0.0001 \\
(0.000)\end{array}$ \\
\hline$=1$ if $\mathrm{HH}$ does farming & $\begin{array}{l}0.1996^{* * * *} \\
(0.053)\end{array}$ & $\begin{array}{c}0.2066^{* * *} \\
(0.053)\end{array}$ & $\begin{array}{c}-0.0090 \\
(0.011)\end{array}$ & $\begin{array}{l}0.2220^{* * * *} \\
(0.055)\end{array}$ & $\begin{array}{c}0.2279^{* * * *} \\
(0.054)\end{array}$ \\
\hline $\begin{array}{l}\text { Livelihood: public } \\
\text { sector employment }\end{array}$ & $\begin{array}{c}-0.1599^{* * *} \\
(0.070)\end{array}$ & $\begin{array}{c}-0.1963^{* * * *} \\
(0.075)\end{array}$ & $\begin{array}{l}0.0616^{* * * *} \\
(0.019)\end{array}$ & $\begin{array}{c}-0.2059^{* * * *} \\
(0.074)\end{array}$ & $\begin{array}{c}-0.2317^{* * * *} \\
(0.084)\end{array}$ \\
\hline $\begin{array}{l}\text { Livelihood: private } \\
\text { sector employment }\end{array}$ & $\begin{array}{l}0.0202 \\
(0.066)\end{array}$ & $\begin{array}{l}-0.0063 \\
(0.074)\end{array}$ & $\begin{array}{c}0.0324^{* *} \\
(0.013)\end{array}$ & $\begin{array}{l}-0.0482 \\
(0.065)\end{array}$ & $\begin{array}{c}-0.0680 \\
(0.078)\end{array}$ \\
\hline $\begin{array}{l}\text { Livelihood: self- } \\
\text { employment }\end{array}$ & $\begin{array}{l}-0.0862 \\
(0.063)\end{array}$ & $\begin{array}{l}-0.0972 \\
(0.060)\end{array}$ & $\begin{array}{l}0.0008 \\
(0.011)\end{array}$ & $\begin{array}{c}-0.1443^{* *} \\
(0.066)\end{array}$ & $\begin{array}{c}-0.1550^{* *} \\
(0.061)\end{array}$ \\
\hline $\begin{array}{l}\text { Livelihood: casual } \\
\text { labor } \\
\text { Ln distance to SM }\end{array}$ & $\begin{array}{l}0.0864 \\
(0.084)\end{array}$ & $\begin{array}{c}0.0760 \\
(0.088)\end{array}$ & $\begin{array}{c}0.0067 \\
(0.014) \\
-0.0250^{* * * *} \\
(0.002)\end{array}$ & $\begin{array}{c}0.0056 \\
(0.085)\end{array}$ & $\begin{array}{c}-0.0114 \\
(0.101)\end{array}$ \\
\hline $\begin{array}{l}=1 \text { for }>\text { median } \\
\text { KIOSK consumpt. } \\
\text { Interaction } \\
\text { i.KIOSK*SMshare }\end{array}$ & & & & $\begin{array}{c}0.2941^{* * * *} \\
(0.082)^{*} \\
-1.2260^{* * *} \\
(0.387)\end{array}$ & $\begin{array}{c}0.3317^{\text {**** }} \\
(0.100) \\
-1.5326^{* *} \\
(0.684)\end{array}$ \\
\hline Constant & $\begin{array}{l}4.6185^{* * *} \\
(0.493)\end{array}$ & $\begin{array}{l}4.7705^{* * *} \\
(0.579)\end{array}$ & $\begin{array}{c}-0.1928^{* *} \\
(0.096)\end{array}$ & $\begin{array}{l}4.1970^{* * * *} \\
(0.535)\end{array}$ & $\begin{array}{l}4.2512^{* * * *} \\
(0.588)\end{array}$ \\
\hline $\begin{array}{l}\text { Observations } \\
R^{2}\end{array}$ & $\begin{array}{c}448 \\
0.238\end{array}$ & $\begin{array}{c}448 \\
0.229\end{array}$ & $\begin{array}{c}448 \\
0.379\end{array}$ & $\begin{array}{c}448 \\
0.277\end{array}$ & $\begin{array}{c}448 \\
0.274\end{array}$ \\
\hline
\end{tabular}

The finding that supermarket purchases are associated with higher calorie availability is interesting in itself. However, it is worthwhile to investigate further demand effects: since calorie availability is significantly higher holding total expenditure fixed, we expect households either to 
spend a higher proportion of their expenditure on food, or to source calories at lower prices. Note that this concerns prices per calories and not prices per physical unit $(\mathrm{kg})$ as discussed in chapter 0 . In fact, we cannot find significant effects of supermarket purchases on the food budget share (controlling for total expenditure, see Table A2.4 in Appendix A2). Prices per calories however, are indeed significantly negatively affected by supermarket purchases in the IV specifications, which are much more reliable in this case because of reversed causality between prices and expenditure shares by construction (Table A2.4 in Appendix A2). Thus an important reason for the higher calorie consumption resulting from supermarket purchases is their lower price.

It is not straightforward to assess implications of these findings on nutrient adequacy. One crude proxy of dietary quality is dietary diversity, usually measured by the number of distinct food products or major food categories (e.g. cereals, roots and tubers, dairy) consumed (Ruel, 2002). We do find supermarket purchases to increase the dietary diversity of households (see Table A2.5 in Appendix A2), which is notable since we established that supermarkets add very few products to what is available in other outlets. Yet, a 10 percentage point increase in supermarket purchases, adds 3.2 products to the diet. However, this measure has several weaknesses. First, measures of dietary diversity typically use shorter recall periods. Also, even if we took a positive relationship between dietary diversity and nutrient adequacy as a given, determining the threshold between a high and a low quality diet is a sensitive and context specific issue and requires further research (Ibid). This is especially true in a nutrition transition context where the nature of products are added to the diet consumed is crucial.

One weakness of our empirical setup regards the lack of town dummies in our main specifications. Inclusion would be appealing in order to capture systematic town differences, such as general price or consumption differences. However, including town dummies in the IV specification renders our instrument to work poorly: because we only sampled three towns, town dummies are highly correlated with distance to supermarkets and distance becomes insignificant in our first stage. However, once livelihood sources are controlled for, towns remain significant only in few cases and furthermore, the coefficients of supermarket purchases remain fairly robust. Furthermore, using expenditure shares rather than absolute expenditures as a measure of consumption should reduce the impact of general price differences across towns.

Note again that the food consumption we are analyzing here is limited to the food that is consumed or better available for consumption at home, which is most relevant for supermarkets 
and competing outlets. Substitution effects with consumption outside home are possible but not explicitly addressed. For robustness checks, we control for food expenditure away from home, which does not alter our main results. The median expenditure shares on food away from home ranges from 5-9\% per town (the mean budget share on food inside home is $46 \%$ ).

\subsection{Conclusion}

This paper was motivated by the literature of the nutrition transition and negative health consequences in low income countries. Alongside other lifestyle changes, dietary changes have been linked in the literature to rising rates of nutrition-related non-communicable diseases and argued to be demand as well as supply side driven. The rapid spread of supermarkets in low income countries is suspected to advance the nutrition transition by increasing the availability, affordability and by purposeful marketing associated foods and beverages to consumers. We analyze the effect of supermarkets on consumption patterns using very detailed household survey data collected for this purpose in a quasi-experimental setting in Kenya in 2012.

With respect to the affordability of food products, we established that lower (perceived) prices are by far the most important reason for consumer to shop at supermarkets. The strongest incentive to shop at kiosks, the main traditional competitor to supermarkets, is physical access. In sum, drivers of retail outlet choices in small urban towns are similar to the ones that have been reported for large towns (Neven et al., 2006), which suggests that our findings are relevant beyond the important group of small towns that we are looking at.

In terms of consumption patterns, we find that supermarket purchases increase the consumption of processed at the expense of unprocessed foods. This holds in terms of expenditure shares as well as calorie shares and is mainly driven by an increased consumption of primary processed goods. While we had expected a stronger effect on highly processed foods (hypothesis $\mathrm{H}_{1}$ ), this does nevertheless suggest that the nutrition transition is advancing with spreading supermarkets, which is further expected to accelerate as income levels are rising.

As consumption patterns change towards more processed food, we find a positive effect of supermarket purchases on p.c. calorie availability, which confirms our hypothesis that frequent supermarket consumers consume more (hypothesis $\mathrm{H}_{2}$ ). We do not find that households increase their food budget share but we confirm that the increase in total calories is 
supported by a negative effect of supermarket purchases on prices paid per calorie. Particularly with primary processed foods, money can buy more calories.

Supermarket purchases also increase the dietary diversity of consumers, confirming our hypothesis $\left(\mathrm{H}_{3}\right)$. However, it is out of the scope of this paper to investigate implications for nutrient adequacy that we are ultimately concerned with and which are not straightforward. For the reason that supermarket purchases are not found to significantly increase the consumption of highly processed foods, negative health effects might be less pronounced than initially expected. To the extent that supermarket purchases contribute to a well-balanced diet, beneficial effects might be detected for some parts of the population. It also remains unclear how rising income levels will change the picture since we found positive income effects for both, highly processed as well as unprocessed foods, i.e. fresh produce. More research is needed to assess nutritional outcomes and dynamics of the nutrition transition in the long run.

Methodologically, our results confirm the adequacy of addressing endogeneity in supermarket purchases, which former studies have often neglected.

While our results contribute to causally linking the retail revolution with the nutrition transition in developing countries, they lead to further research questions. In particular, future research should investigate what type of supermarket and associated food environment leads to stronger or weaker effects; also, the net effect of lower prices per calorie, more diversity, and a higher share of processed foods might have different nutritional implications in different contexts. Lastly, considering the impact of very large supermarkets with a drastically expanded offering (including fresh fruit and vegetables as well as meat) on consumption pattern would be an important question for future research. 


\section{Appendix A2}

Table A2.1. Summary statistics of main dependent and explanatory variables

\begin{tabular}{|c|c|c|c|c|c|c|c|}
\hline \multirow[b]{2}{*}{$\begin{array}{l}\text { Explanatory } \\
\text { variables }\end{array}$} & \multirow{2}{*}{$\begin{array}{c}\text { All } \\
\text { Mean }\end{array}$} & \multicolumn{2}{|c|}{$\begin{array}{l}\text { Njabini } \\
\text { (no SM) }\end{array}$} & \multicolumn{2}{|c|}{$\begin{array}{c}\text { Mwea } \\
(\text { SM since 2011) }\end{array}$} & \multicolumn{2}{|c|}{$\begin{array}{c}\text { Ol Kalou } \\
\text { (SM since 2002) }\end{array}$} \\
\hline & & Mean & $\begin{array}{l}\text { Diff to } \\
\text { others }\end{array}$ & Mean & $\begin{array}{l}\text { Diff to } \\
\text { others }\end{array}$ & Mean & $\begin{array}{l}\text { Diff to } \\
\text { others }\end{array}$ \\
\hline \multicolumn{8}{|l|}{$\begin{array}{l}\text { Food expenditure } \\
\text { shares: }\end{array}$} \\
\hline Unprocessed & $\begin{array}{c}0.63 \\
(0.11)\end{array}$ & $\begin{array}{c}0.65 \\
(0.12)\end{array}$ & $\begin{array}{c}0.03 * * * \\
(0.01)\end{array}$ & $\begin{array}{c}0.62 \\
(0.12)\end{array}$ & $\begin{array}{l}-0.02 \\
(0.01)\end{array}$ & $\begin{array}{c}0.62 \\
(0.10)\end{array}$ & $\begin{array}{l}-0.02 \\
(0.01)\end{array}$ \\
\hline Primary processed & $\begin{array}{c}0.25 \\
(0.11)\end{array}$ & $\begin{array}{c}0.24 \\
(0.12)\end{array}$ & $\begin{array}{l}-0.00 \\
(0.01)\end{array}$ & $\begin{array}{c}0.25 \\
(0.10)\end{array}$ & $\begin{array}{c}0.01 \\
(0.01)\end{array}$ & $\begin{array}{c}0.24 \\
(0.09)\end{array}$ & $\begin{array}{l}-0.00 \\
(0.01)\end{array}$ \\
\hline Highly processed & $\begin{array}{c}0.12 \\
(0.10)\end{array}$ & $\begin{array}{c}0.10 \\
(0.10)\end{array}$ & $\begin{array}{c}-0.03 * * * \\
(0.01)\end{array}$ & $\begin{array}{c}0.13 \\
(0.11)\end{array}$ & $\begin{array}{c}0.01 \\
(0.01)\end{array}$ & $\begin{array}{c}0.13 \\
(0.08)\end{array}$ & $\begin{array}{l}0.02 * * \\
(0.01)\end{array}$ \\
\hline All processed & $\begin{array}{c}0.36 \\
(0.11)\end{array}$ & $\begin{array}{c}0.34 \\
(0.12)\end{array}$ & $\begin{array}{c}-0.04 * * * \\
(0.01)\end{array}$ & $\begin{array}{c}0.38 \\
(0.12)\end{array}$ & $\begin{array}{l}0.02 * \\
(0.01)\end{array}$ & $\begin{array}{c}0.38 \\
(0.10)\end{array}$ & $\begin{array}{l}0.02 * \\
(0.01)\end{array}$ \\
\hline \multicolumn{8}{|l|}{ Calorie shares: } \\
\hline Unprocessed & $\begin{array}{c}0.48 \\
(0.12)\end{array}$ & $\begin{array}{c}0.50 \\
(0.13)\end{array}$ & $\begin{array}{l}0.03 * * \\
(0.01)\end{array}$ & $\begin{array}{c}0.47 \\
(0.12)\end{array}$ & $\begin{array}{l}-0.02 \\
(0.01)\end{array}$ & $\begin{array}{c}0.47 \\
(0.11)\end{array}$ & $\begin{array}{l}-0.01 \\
(0.01)\end{array}$ \\
\hline Primary processed & $\begin{array}{c}0.42 \\
(0.13)\end{array}$ & $\begin{array}{c}0.42 \\
(0.14)\end{array}$ & $\begin{array}{c}0.00 \\
(0.01)\end{array}$ & $\begin{array}{c}0.43 \\
(0.12)\end{array}$ & $\begin{array}{c}0.01 \\
(0.01)\end{array}$ & $\begin{array}{c}0.42 \\
(0.12)\end{array}$ & $\begin{array}{l}-0.01 \\
(0.01)\end{array}$ \\
\hline Highly processed & $\begin{array}{c}0.10 \\
(0.09)\end{array}$ & $\begin{array}{c}0.08 \\
(0.09)\end{array}$ & $\begin{array}{c}-0.03 * * * \\
(0.01)\end{array}$ & $\begin{array}{c}0.11 \\
(0.10)\end{array}$ & $\begin{array}{c}0.01 \\
(0.01)\end{array}$ & $\begin{array}{c}0.11 \\
(0.08)\end{array}$ & $\begin{array}{l}0.02 * \\
(0.01)\end{array}$ \\
\hline All processed & $\begin{array}{c}0.52 \\
(0.12)\end{array}$ & $\begin{array}{c}0.50 \\
(0.13)\end{array}$ & $\begin{array}{c}-0.03 * * \\
(0.01)\end{array}$ & $\begin{array}{c}0.53 \\
(0.12)\end{array}$ & $\begin{array}{c}0.02 \\
(0.01)\end{array}$ & $\begin{array}{c}0.52 \\
(0.11)\end{array}$ & $\begin{array}{c}0.01 \\
(0.01)\end{array}$ \\
\hline $\begin{array}{l}\text { Calories p.c. per day } \\
\text { (adult equivalent) }\end{array}$ & $\begin{array}{c}2561.01 \\
(1049.87)\end{array}$ & $\begin{array}{l}2311.84 \\
(958.24)\end{array}$ & $\begin{array}{c}-388.94 * * * \\
(101.84)\end{array}$ & $\begin{array}{c}2608.23 \\
(1095.87)\end{array}$ & $\begin{array}{c}67.38 \\
(108.41)\end{array}$ & $\begin{array}{r}2781.84 \\
(1052.26)\end{array}$ & $\begin{array}{c}335.36 * * * \\
(103.50)\end{array}$ \\
\hline Price per calorie & $\begin{array}{c}0.04 \\
(0.02)\end{array}$ & $\begin{array}{c}0.04 \\
(0.02)\end{array}$ & $\begin{array}{l}-0.00 \\
(0.00)\end{array}$ & $\begin{array}{c}0.05 \\
(0.01)\end{array}$ & $\begin{array}{c}0.00 \\
(0.00)\end{array}$ & $\begin{array}{c}0.04 \\
(0.01)\end{array}$ & $\begin{array}{l}-0.00 \\
(0.00)\end{array}$ \\
\hline $\begin{array}{l}\text { Food budget share } \\
\text { (inside home) }\end{array}$ & $\begin{array}{c}0.46 \\
(0.15)\end{array}$ & $\begin{array}{c}0.49 \\
(0.15)\end{array}$ & $\begin{array}{c}0.06 * * * \\
(0.01)\end{array}$ & $\begin{array}{l}0.42 \\
(0.15)\end{array}$ & $\begin{array}{c}-0.05 * * * \\
(0.02)\end{array}$ & $\begin{array}{c}0.45 \\
(0.13)\end{array}$ & $\begin{array}{l}-0.01 \\
(0.01)\end{array}$ \\
\hline Food diversity: & & & & & & & \\
\hline $\begin{array}{l}\text { \# products con-sumed } \\
\text { (less alcohol) }\end{array}$ & $\begin{array}{r}39.72 \\
(12.69)\end{array}$ & $\begin{array}{c}35.29 \\
(12.55)\end{array}$ & $\begin{array}{c}-6.92 * * * \\
(1.21)\end{array}$ & $\begin{array}{c}44.12 \\
(12.53)\end{array}$ & $\begin{array}{c}6.28 * * * \\
(1.28)\end{array}$ & $\begin{array}{c}40.53 \\
(11.48)\end{array}$ & $\begin{array}{c}1.23 \\
(1.26)\end{array}$ \\
\hline $\begin{array}{l}\text { \# food groups } \\
\text { consumed }\end{array}$ & $\begin{array}{l}10.86 \\
(1.35)\end{array}$ & $\begin{array}{l}10.53 \\
(1.36)\end{array}$ & $\begin{array}{c}-0.52 * * * \\
(0.13)\end{array}$ & $\begin{array}{l}11.04 \\
(1.61)\end{array}$ & $\begin{array}{l}0.25 * \\
(0.14)\end{array}$ & $\begin{array}{l}11.05 \\
(0.97)\end{array}$ & $\begin{array}{l}0.29 * * \\
(0.13)\end{array}$ \\
\hline Observations & 448 & 161 & 161 & 134 & 134 & 153 & 153 \\
\hline
\end{tabular}


Table A2.2. Expenditure shares $1^{\text {st }}$ stage results of main models

\begin{tabular}{|c|c|c|c|}
\hline & $\begin{array}{c}\text { (1) } \mathbf{1}^{\text {st }} \text { stage } \\
\text { Highly processed/ } \\
\text { all processed food }\end{array}$ & $\begin{array}{c}\text { (2) } \mathbf{1}^{\text {st }} \text { stage } \\
\text { Primary processed } \\
\text { food }\end{array}$ & $\begin{array}{c}\text { (3) } \mathbf{1}^{\text {st }} \text { stage } \\
\text { Unprocessed food }\end{array}$ \\
\hline & $\begin{array}{l}\text { SM expenditure } \\
\text { share }\end{array}$ & $\begin{array}{l}\text { SM expenditure } \\
\text { share }\end{array}$ & $\begin{array}{l}\text { SM expenditure } \\
\text { share }\end{array}$ \\
\hline Ln p.c. expenditure & $\begin{array}{c}0.0353^{* * *} \\
(0.009)\end{array}$ & $\begin{array}{c}0.0358^{\text {***** }} \\
(0.010)\end{array}$ & $\begin{array}{c}0.0354^{\text {***** }} \\
(0.012)\end{array}$ \\
\hline HH size & $\begin{array}{l}0.0043 \\
(0.003)\end{array}$ & $\begin{array}{l}0.0034 \\
(0.003)\end{array}$ & $\begin{array}{l}0.0046 \\
(0.003)\end{array}$ \\
\hline$=1$ if head is married & $\begin{array}{l}0.0010 \\
(0.011)\end{array}$ & $\begin{array}{l}0.0019 \\
(0.009)\end{array}$ & $\begin{array}{l}0.0010 \\
(0.008)\end{array}$ \\
\hline Education of head in years & $\begin{array}{c}0.0051^{\text {**** }} \\
(0.001)\end{array}$ & $\begin{array}{c}0.0050^{* * * *} \\
(0.002)\end{array}$ & $\begin{array}{c}0.0051^{* * *} \\
(0.001)\end{array}$ \\
\hline Age of cook & $\begin{array}{r}-0.0025 \\
(0.002)\end{array}$ & $\begin{array}{r}-0.0018 \\
(0.002)\end{array}$ & $\begin{array}{r}-0.0025 \\
(0.002)\end{array}$ \\
\hline Age of cook squared & $\begin{array}{l}0.0000 \\
(0.000)\end{array}$ & $\begin{array}{l}0.0000 \\
(0.000)\end{array}$ & $\begin{array}{l}0.0000 \\
(0.000)\end{array}$ \\
\hline Mwea (SM 2011) & & $\begin{array}{r}-0.0157^{*} \\
(0.008)\end{array}$ & \\
\hline \# female adults & & & $\begin{array}{l}-0.0011 \\
(0.005)\end{array}$ \\
\hline$=1$ if $\mathrm{HH}$ does farming & $\begin{array}{c}-0.0135 \\
(0.010)\end{array}$ & $\begin{array}{c}-0.0532^{* * *} \\
(0.018)\end{array}$ & $\begin{array}{r}-0.0135 \\
(0.009)\end{array}$ \\
\hline Ln distance to SM & $\begin{array}{c}-0.0252^{* * * *} \\
(0.002)\end{array}$ & $\begin{array}{c}-0.0305^{* * *} \\
(0.003)\end{array}$ & $\begin{array}{c}-0.0252^{* * *} \\
(0.002)\end{array}$ \\
\hline Constant & $\begin{array}{c}-0.2056^{* *} \\
(0.093)\end{array}$ & $\begin{array}{r}-0.1976^{*} \\
(0.100)\end{array}$ & $\begin{array}{c}-0.2058^{*} \\
(0.116)\end{array}$ \\
\hline Observations & 448 & 448 & 448 \\
\hline$R^{2}$ & 0.351 & 0.384 & 0.351 \\
\hline
\end{tabular}


Table A2.3. Share of calories from different food categories - OLS and IV estimates

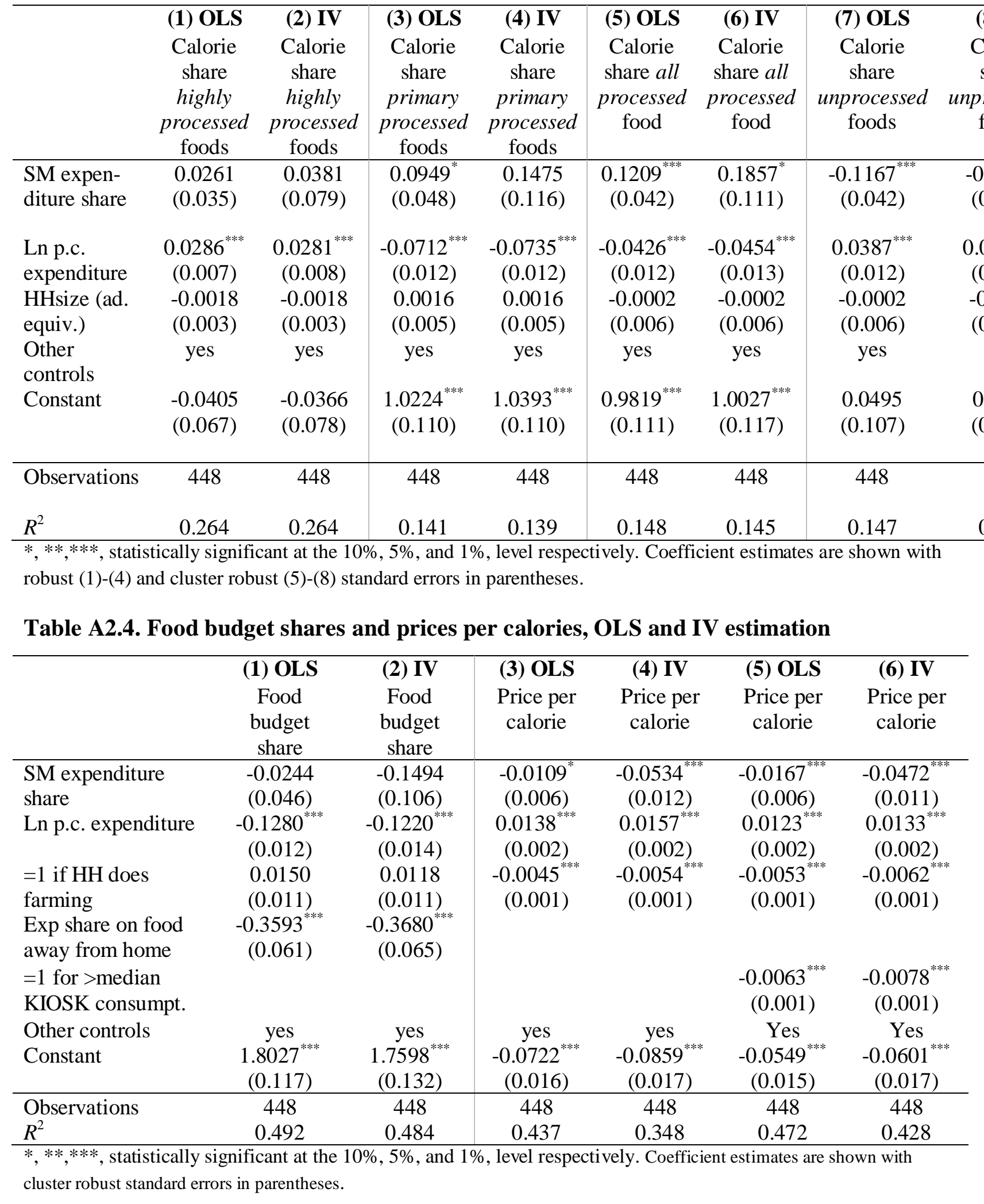


Table A2.5. Food diversity indicators, OLS and IV estimation

\begin{tabular}{lcccc}
\hline & $\mathbf{( 1 )}$ OLS & $\mathbf{( 2 )} \mathbf{~ I V}$ & $\mathbf{( 3 )}$ OLS & (4) IV \\
& \# food groups & \# food groups & \# products & \# products \\
& consumed by & consumed by & consumed by & consumed by \\
& HH (excl. & HH (excl. & HH (excl. & HH (excl. \\
& alcohol) & alcohol) & alcohol) & alcohol) \\
\hline SM expenditure share & $1.6550^{* * * *}$ & $2.8555^{* * *}$ & $11.1922^{* * *}$ & $31.7750^{* * *}$ \\
& $(0.534)$ & $(1.076)$ & $(3.866)$ & $(6.308)$ \\
Ln p.c. expenditure & $0.2472^{*}$ & 0.1940 & $8.0892^{* * * *}$ & $7.1769^{* * * *}$ \\
& $(0.125)$ & $(0.146)$ & $(1.277)$ & $(1.148)$ \\
1 if HH does farming & $0.3997^{* * *}$ & $0.4264^{* * *}$ & $4.5453^{* * *}$ & $5.0019^{* * *}$ \\
& $(0.136)$ & $(0.136)$ & $(1.244)$ & $(1.142)$ \\
Other controls & yes & yes & yes & Yes \\
Constant & $8.8784^{* * *}$ & $9.2635^{* * *}$ & $-38.5969^{* * *}$ & $-31.9951^{* * *}$ \\
& $(1.088)$ & $(1.179)$ & $(10.774)$ & $(9.666)$ \\
\hline Observations & 448 & 448 & 448 & 448 \\
$R^{2}$ & 0.172 & 0.163 & 0.327 & 0.297 \\
\hline$*, * * * * *$, statistically significant at the $10 \%, 5 \%$, and $1 \%$, level respectively. Coefficient estimates are shown with \\
standard errors in parentheses.
\end{tabular}




\section{Do Supermarkets Contribute to the Obesity Pandemic in Developing Countries? ${ }^{2}$}

Abstract. Many developing countries are currently undergoing a nutrition transition with rising rates of obesity, and a resulting surge in chronic diseases. This nutrition transition coincides with a rapid expansion of supermarkets, partly replacing more traditional food retail outlets. One important question is whether this expansion of supermarkets in developing countries is just a business response to changing consumer demands and lifestyles, or whether supermarkets are a causal factor of overweight and obesity. We address this question, building on cross-section observational data collected in Kenya using a quasi-experimental survey design. We employ instrumental variable regressions to analyze the impact of supermarket purchase on nutritional status of adults and of children and adolescents. We also estimate causal chain models to examine the pathways through which supermarkets affect nutritional status. Controlling for other factors, buying in a supermarket increases the body mass index of adults and raises the probability of adult overweight or obesity by 13 percentage points. For children and adolescents we do not find a significant impact on overweight. Instead, buying in a supermarket tends to decrease child undernutrition measured by height-for-age z-scores. Impacts of supermarkets depend on many factors, including people's initial nutritional status. Kenya and many other developing countries face a dual burden of malnutrition, where adult overweight coexists with childhood stunting. For both, adults and children, the nutrition impacts of supermarkets occur through higher calorie consumption and changes in dietary composition.

\subsection{Introduction}

Many developing countries are currently undergoing a rapid nutrition transition characterized by changes in dietary habits towards more energy-dense, processed foods and more sedentary lifestyles (Pingali, 2007). A conspicuous result are rising rates of overweight and obesity with serious negative implications for people's health (Hawkes et al., 2009; Popkin et al., 2012; Wang

\footnotetext{
2 This chapter is co-authored by Ramona Rischke, Stephan Klasen, and Matin Qaim. The following roles were performed by me: conceptualization and designing of the study in cooperation with all co-authors; implementation of the survey in cooperation with Ramona Rischke; data analysis; interpretation of the research results in cooperation all co-authors; writing of the paper in cooperation with Matin Qaim; and revision of the paper with all co-authors.
} 
et al., 2011). In 2008, 34\% of all adults in the world were overweight or obese (Finucane et al., 2011). While average overweight rates are still higher in most industrialized countries, many developing countries are rapidly catching up. The nutrition transition is driven by rising incomes, urbanization, and globalizing food systems (Hawkes et al., 2009; Mergenthaler et al., 2009; Popkin et al., 2012). It is associated with a modernization of the food retail sector, including a growing role of supermarkets (Timmer, 2009). In some developing countries, supermarkets have spread so rapidly that the term 'supermarket revolution' has been coined (Reardon et al., 2003). The retail format has an influence on the types of products offered, as well as on sales prices and shopping atmosphere, which may affect consumer food choices (Hawkes, 2008; Swinburn et al., 2011; Timmer, 2009). Hence, one important question is whether the expansion of supermarkets contributes directly to rising overweight and obesity in developing countries. Here, we address this question using observational data collected in Kenya.

Recent research has analyzed effects of supermarkets in developing countries. Several studies suggest that the spread of supermarkets leads to dietary changes for urban consumers in developing countries (Asfaw, 2008; Asfaw, 2011; Hawkes, 2008; Tessier et al., 2008). Most of this work shows that supermarket purchase is associated with increased consumption of energydense, processed foods (Asfaw, 2008; Asfaw, 2011; Hawkes, 2008), although in one case supermarkets were found to increase dietary quality (Tessier et al., 2008). Research on the impact of supermarkets on consumer nutritional status in developing countries is rare. Studies in the USA show that access to supermarkets is nowadays often associated with lower obesity rates (Drewnowski et al., 2012; Lear et al., 2013; Michimi \& Wimberly, 2010 ; Morland et al., 2006), but the situation in developing countries is different. We are aware of only one study that has looked at impacts of supermarkets on nutritional status in a developing country, namely Guatemala (Asfaw, 2008). In that study it was found that food purchase in supermarkets increases the BMI of consumers. However, the research for Guatemala builds on a household living standard survey that was not specifically designed for analyzing the nutritional impact of supermarkets. Hence, a few variables of interest, such as food quantities purchased in different retail outlets, were not properly captured. Moreover, the impact on BMI was analyzed for all individuals in the sample above 10 years of age, an approach that masks possible differences between adults and children. BMI is a suitable indicator of nutritional status only for people who have reached their final body height. For children and adolescents, it is recommended to use 
indicators such as BMI-for-age or height-for-age Z-scores, which set individual measures in relation to a reference population of the same age (de Onis et al., 2007).

We address these shortcomings in the previous literature by using data from a survey of Kenyan consumers that was specifically designed for this purpose. Kenya has recently witnessed a rapid spread of supermarkets that now account for about $10 \%$ of national grocery sales (PlanetRetail, 2013a). This retail share of supermarkets in Kenya is lower than in many middleincome countries, but it is already higher than in most other low-income countries in SubSaharan Africa and Asia. Hence, trends observed in Kenya may be helpful to predict future developments in other poor regions. We use data from a survey of households and individuals to analyze the impact of supermarket purchase on nutritional status. We also examine impact pathways. The analysis is carried out separately for adults and for children and adolescents, because impacts may differ by age cohort.

\subsection{Methods}

\subsubsection{Study Design}

We conducted a cross-section survey of 453 households to collect observational data at household and individual levels. The survey was carried out in July and August 2012 in Central Province of Kenya. Central Province has the second highest prevalence of overweight and

obesity in Kenya after Nairobi. About 35\% of the women aged 15-49 years are overweight or obese in Central Province (KNBS \& ICFMacro, 2010). We decided to sample households from small towns, some of which already have a supermarket, while others do not. This provided a quasi-experimental setting, which we exploit for our analysis. Three towns were purposively selected: Ol Kalou, where a supermarket has been operating since 2002, Mwea, where a supermarket was opened in 2011, and Njabini, where no supermarket had yet been established at the time of the survey. The three towns are similar in general characteristics, such as size of the urban catchment area, infrastructure, as well as financial and social institutions. We deliberately did not choose bigger towns and cities for the survey, because all of them already have one or more supermarkets. Hence, it would have been impossible to identify control locations without a supermarket. 
Systematic random sampling was used to select households for interview within the urban and peri-urban areas of the three towns. A group of eight local enumerators was involved in the survey; we used the same enumerators in all locations. Prior to data collection, the enumerators were trained thoroughly in all aspects of administering the questionnaire, including anthropometric measurements. Data on socioeconomic characteristics, including food consumption and expenditure, were collected at the household level. Details on food consumption at home were collected using a 30-day recall period (de Haen et al., 2011), which allowed us to also capture purchases that are undertaken by households only once per month. During a questionnaire pre-test we learned that shopping behavior and places of purchase may differ according to the wage cycle. Data on food consumption quantities, expenditures, and place of purchase were collected in disaggregated form for 170 food items.

In addition to the household-level data, we collected individual-level data such as food eaten away from home as well as work and leisure related physical activity from household members. In each household, up to three household members were randomly selected for anthropometric measurement: one male adult, one female adult, and one child or adolescent in the 5-19 years age range. Children below 5 years of age were not chosen for measurement. Participation was voluntary. Prior to taking anthropometric measures we obtained written consent from all adults through signatures for themselves and their children. In total, we took individual data from 615 adults and 216 children and adolescents.

\subsubsection{Procedures}

The main nutritional outcome variable for adults is body mass index (BMI), defined as weight in kilograms divided by squared height in meters. Adults with a BMI $\geq 25 \mathrm{~kg} / \mathrm{m}^{2}$ are classified as overweight or obese (WHO, 2000). For children, we use two nutritional outcome variables, namely BMI-for-age Z-scores (BAZ) and height-for age Z-scores (HAZ), which are calculated based on the World Health Organization (WHO) growth reference for school-aged children and adolescents (de Onis et al., 2007). Childhood overweight/obesity is defined as a BAZ > 1 standard deviation (SD) from the median of the reference population (WHO, 2006). Stunting is defined as $\mathrm{HAZ}<-2 \mathrm{SD}$, mild stunting as $\mathrm{HAZ}<-1$, and severe stunting as $\mathrm{HAZ}<-3$.

The exposure variable for the impact assessment is food purchase in supermarkets. Supermarkets in this context are defined as large modern retail formats with at least two cash 
counters and offering a relatively large variety of food items, including cooled and frozen foods. Supermarkets also have a variety of non-food items, such as clothing, electronic devices, and furniture. Supermarkets are distinguished from more traditional retail outlets, including wet markets, kiosks, and small corner stores. Supermarket purchase is measured in two different ways, first as a dummy variable that takes a value of one for households that purchased at least some of their food in supermarkets, and second as a continuous variable measuring the share of supermarket purchases in total household food expenditure. Households that do not buy in supermarkets (i.e., the dummy and the supermarket share are equal to zero) obtained all of their food from traditional sources.

Other factors that may influence nutritional status and for which we collected data include age, gender, education, physical activity during work and leisure, and household living standard. We measure living standard in terms of consumption expenditure. Furthermore, nutritional knowledge and awareness may play a role. In Kenya, district hospitals are responsible for coordinating nutrition awareness programs. We used household distance to the nearest district hospital as a proxy for nutritional awareness.

We also analyze the impact of supermarkets on calorie consumption and on calories from processed foods. Quantities of food consumed in the household were converted into calories using food composition tables developed for Kenyan foods (FAO, 2010; Sehmi, 1993). A few foods that could not be found in these local food composition tables were converted into calories using international values (FAO, 2012). For food away from home, survey respondents reported dishes consumed, not ingredients. To determine calories from these dishes, actual cooking was done with the help of restaurant operators who advised on types and quantities of ingredients that went into a particular dish, and serving portions. The dishes were then converted into calories after adjusting for edible portions and weight changes due to cooking (EuroFIR, 2008). Calories consumed at home at the household level were allocated to individuals based on adult equivalence scales for energy requirements, assuming light physical activity (FAO et al., 2004). We also took into account the number of meals consumed away from home by individual household members. For adults, individual calories consumed away from home were added. For children and adolescents, the data on food away from home are less accurate and contain several missing values, so that only calories from foods consumed at home were considered. Since all supermarket purchases fall into this "consumed at home" category, this limitation should not 
affect our analysis much. To differentiate between calories from processed and unprocessed foods, we follow common classifications in the literature (Asfaw, 2011; Monteiro et al., 2011). Foods are considered processed if any industrial method was used to develop food products from fresh whole foods.

\subsubsection{Statistical Analysis}

Our main objective is to analyze the impact of supermarket purchase on nutritional status of adults and of children and adolescents. For this purpose, we estimate models of the following type:

$$
N_{i}=\beta_{0}+\beta_{1} S_{i}+\beta_{2} Z_{i}+\varepsilon_{i}
$$

where $N_{i}$ is the outcome variable characterizing nutritional status of individual $i, S_{i}$ is supermarket purchase, $\boldsymbol{Z}_{i}$ is a vector of control variables, including individual and household characteristics, and $\varepsilon_{i}$ is a random error term.

In this model, the supermarket purchase variable may potentially be endogenous, since there could be unobserved factors that determine supermarket purchase and nutritional status simultaneously. This could lead to biased impact estimates. To avoid this problem, we use an instrumental variable (IV) approach. Supermarket purchase is instrumented with the household distance to the nearest supermarket (measured through GPS coordinates), which can be located in the same town or, in the case of Njabini, also in a different town. Distance to supermarket is a valid instrument, since it is exogenous, significantly correlated with supermarket purchase, and not directly correlated with nutritional status. For continuous outcome variables (such as BMI or HAZ), we use an IV two-stage least squares estimator. For binary outcome variables (such as overweight/obese or stunted) we use an IV probit estimator. Marginal effects from the IV probit are evaluated at sample mean values.

In addition to the reduced-form models in equation (3.1), we also analyze possible pathways through which supermarkets affect nutritional outcomes of adults and children/adolescents by estimating structural equation models. On the one hand, supermarket purchase may influence the amount of calories consumed. On the other hand, dietary composition and the types of calories consumed may also be affected. The available literature suggests that the share of calories from processed foods may increase BMI even after controlling for the total amount of calories consumed. ${ }^{11}$ We model a causal chain, hypothesizing that supermarket purchase affects total calorie consumption and the share of calories from processed 
foods, and that these two variables both affect nutritional status. The causal chain is modeled as follows:

$$
\begin{aligned}
& N_{i}=\beta_{0}+\beta_{1} C_{i}+\beta_{2} P_{i}+\beta_{3} \boldsymbol{T}_{i}+\varepsilon_{i 1} \\
& C_{i}=\alpha_{0}+\alpha_{1} S_{i}+\alpha_{2} \boldsymbol{U}_{i}+\varepsilon_{i 2} \\
& P_{i}=\delta_{0}+\delta_{1} S_{i}+\delta_{2} \boldsymbol{V}_{i}+\varepsilon_{i 3} \\
& S_{i}=\gamma_{0}+\gamma_{1} D_{i}+\gamma_{2} \boldsymbol{W}_{i}+\varepsilon_{i 4}
\end{aligned}
$$

where $N_{i}$ is the nutritional status of individual $i, C_{i}$ is calorie consumption of the same individual, $P_{i}$ is the share of calories from processed foods, $S_{i}$ is supermarket purchase, and $D_{i}$ is distance to the nearest supermarket. $\boldsymbol{T}_{i}, \boldsymbol{U}_{i}, \boldsymbol{V}_{i}$, and $\boldsymbol{W}_{i}$ are vectors of individual and household characteristics, while $\varepsilon_{i 1}$ to $\varepsilon_{i 4}$ are random error terms. This system of simultaneous equations is estimated using a three-stage least squares estimator. We estimate separate models for adults and for children and adolescents.

\subsection{Results}

While $41 \%$ of the adults in our sample are classified as either overweight or obese, only $10 \%$ of the children and adolescents fall into this category. On the other hand, $21 \%$ of the children in our sample are affected by stunting, a common indicator of child undernutrition (see Tables A3.1 and A3.2 in Appendix A3). Table 3.1 compares nutrition related variables between individuals from households that buy and do not buy in supermarkets. Adults in supermarket-buying households have a significantly higher BMI and are more likely to be overweight or obese. They also consume significantly more calories, and a greater share of their calories comes from processed foods. For children and adolescents, the patterns are different. While there is a slight difference in mean BAZ between supermarket buyers and non-buyers, this difference is not statistically significant. Yet we observe significantly higher HAZ among children from households that buy in a supermarket, and a lower prevalence of stunting. This points at possible differences between adults and children. 
Table 3.1. Comparison of nutrition variables by supermarket purchase

\begin{tabular}{|c|c|c|c|}
\hline Category & Variable & $\begin{array}{c}\text { Household buys in } \\
\text { supermarket }\end{array}$ & $\begin{array}{l}\text { Household does } \\
\text { not buy in } \\
\text { supermarket }\end{array}$ \\
\hline \multirow{7}{*}{ Adults } & BMI & $25.22 *(4.73)$ & $24.43(4.98)$ \\
\hline & Overweight or obese (dummy) & $0.45^{*}(0.50)$ & $0.36(0.48)$ \\
\hline & Underweight (dummy) & $0.04(0.19)$ & $0.04(0.20)$ \\
\hline & Calorie consumption per day (kcal) & $\begin{array}{l}3500.70 * * \\
(1230.79)\end{array}$ & $\begin{array}{c}3143.32 \\
(1426.80)\end{array}$ \\
\hline & $\begin{array}{l}\text { Share of calories from processed } \\
\text { foods }(\%)\end{array}$ & $51.52 * * *(11.25)$ & $44.36(20.55)$ \\
\hline & $\begin{array}{l}\text { Food expenditure (Ksh per AE and } \\
\text { month) }\end{array}$ & $\begin{array}{l}6954.96 * * * \\
(5351.4)\end{array}$ & $4916.79(3016.0)$ \\
\hline & Number of observations & 357 & 258 \\
\hline \multirow{7}{*}{$\begin{array}{l}\text { Children/ } \\
\text { adolescents }\end{array}$} & BMI-for-age Z-score & $-0.26(1.09)$ & $-0.36(0.90)$ \\
\hline & Overweight or obese (dummy) & $0.10(0.30)$ & $0.09(0.30)$ \\
\hline & Height-for-age Z-score & $-0.76 * * *(1.09)$ & $-1.35(1.43)$ \\
\hline & Stunted (dummy) & $0.14(0.34)$ & $0.28 * *(0.45)$ \\
\hline & Calorie consumption per day (kcal) & $2531.67(959.88)$ & $\begin{array}{c}2310.54 \\
(1428.13)\end{array}$ \\
\hline & $\begin{array}{l}\text { Share of calories from processed } \\
\text { foods }(\%)\end{array}$ & $52.15 * * *(10.27)$ & $44.14(21.66)$ \\
\hline & Number of observations & 110 & 106 \\
\hline
\end{tabular}

\subsubsection{Impact of Supermarket Purchase on Nutritional Status}

The mean differences in Table 3.1 are a first indication that buying food in a supermarket may contribute to increasing BMI and a higher prevalence of overnutrition among adults. To test this hypothesis, we regress BMI and the probability of being overweight or obese on supermarket purchase. Estimation results are shown in Table 3.2. Independent of the exact specification, supermarket purchase has significant effects on nutritional outcomes. Buying in a supermarket increases BMI by $1.7 \mathrm{~kg} / \mathrm{m}^{2}$ and the probability of being overweight or obese by 13 percentage points. Similarly, an increase in the share of supermarket purchases by one percentage point increases BMI by $0.08 \mathrm{~kg} / \mathrm{m}^{2}$ and the probability of being overweight or obese by one percentage point. Most of the control variables have the expected signs, with age and living standard contributing to higher BMI, and physical activity to lower BMI. 
Table 3.2. Impact of supermarket purchase on adult nutrition

\begin{tabular}{|c|c|c|c|c|}
\hline Explanatory variables & BMI & BMI & $\begin{array}{c}\text { Overweight/ } \\
\text { obese (dummy) }\end{array}$ & $\begin{array}{l}\text { Overweight/ } \\
\text { obese (dummy) }\end{array}$ \\
\hline Buys in supermarket (dummy) & $1.688^{* *}(0.72)$ & -- & $0.132^{*}(0.07)$ & -- \\
\hline Supermarket purchase share $(\%)$ & -- & $0.080^{*}(0.04)$ & & $0.008^{* *}(0.00)$ \\
\hline Age (years) & $0.110^{* * *}(0.02)$ & $0.112^{* * *}(0.02)$ & $0.011^{* * * *}(0.00)$ & $0.011^{* * *}(0.00)$ \\
\hline Female (dummy) & $0.501(1.08)$ & $0.590(1.09)$ & $0.150(0.12)$ & $0.151(0.12)$ \\
\hline Female-age interaction & $0.066^{* *}(0.03)$ & $0.066^{* *}(0.03)$ & $0.003(0.00)$ & $0.002(0.00)$ \\
\hline Heavy work (dummy) & $-0.892^{* *}(0.35)$ & $-0.946^{* * *}(0.36)$ & $-0.093^{* *}(0.04)$ & $-0.097^{* * * *}(0.04)$ \\
\hline $\begin{array}{l}\text { Leisure-time physical activity (hours } \\
\text { per week) }\end{array}$ & $-0.047^{* *}(0.02)$ & $-0.040^{*}(0.02)$ & $-0.003(0.00)$ & $-0.002(0.00)$ \\
\hline $\begin{array}{l}\text { Household expenditure (1000 Ksh per } \\
\text { AE and month) }\end{array}$ & $0.077^{* * *}(0.03)$ & $0.077^{* *}(0.03)$ & $0.005(0.00)$ & $0.005(0.00)$ \\
\hline $\begin{array}{l}\text { Education of person responsible for } \\
\text { food (years) }\end{array}$ & $0.168^{* * *}(0.05)$ & $0.166^{* * *}(0.06)$ & $0.020^{* * *}(0.01)$ & $0.018^{* * * *}(0.01)$ \\
\hline Married household head (dummy) & $0.915^{* *}(0.39)$ & $1.066^{* * *}(0.40)$ & $0.100^{* *}(0.04)$ & $0.111^{* * *}(0.04)$ \\
\hline $\begin{array}{l}\text { Distance to nearest district hospital } \\
(\log \text { of } \mathrm{km})\end{array}$ & $0.316^{* *}(0.13)$ & $0.386^{* *}(0.17)$ & $0.017(0.01)$ & $0.028^{*}(0.02)$ \\
\hline Constant & $15.401^{* * * *}(0.98)$ & $15.280^{* * * *}(1.01)$ & -- & -- \\
\hline Number of observations & 615 & 615 & 615 & 615 \\
\hline Chi-squared test statistic & $504.98^{* * *}$ & -- & $560.46^{* * *}$ & $339.24^{* * *}$ \\
\hline
\end{tabular}

$*, * *, * * *$, statistically significant at the $10 \%, 5 \%$, and $1 \%$ level, respectively. Marginal effects are shown with robust standard errors in parentheses. Estimates are based on instrumental variable models with the supermarket purchase variables instrumented. For the last two table columns (overweight/obese), instrumental variable probit models were used. First-stage regression results are shown in Appendix A3 (Table A3.3). BMI, body mass index; Ksh, Kenyan shillings; AE, adult equivalent.

Table 3.1 did not reveal significant differences in overweight and obesity between children/adolescents from households that buy and do not buy in supermarkets. The regression results in Table 3.3 confirm that supermarket purchase does not affect BAZ in a significant way. However, supermarket purchase has a positive and significant effect on HAZ. Buying in a supermarket increases HAZ by 0.63 . Similarly, an increase in the share of supermarket purchases by one percentage point increases HAZ by 0.03 . This is evidence that supermarkets contribute to reducing problems of undernutrition among children and adolescents. The supermarket coefficients in the stunting models are negative, but not statistically significant. This may be related to the relatively small sample size. Moreover, how many individuals can be lifted above a threshold depends on the variable distribution and the magnitude of the threshold. The standard threshold for stunting is $\mathrm{HAZ}<-2$, which is what we used for the estimates in Table 3.2. Using common thresholds for mild stunting (HAZ $<-1$ ) and severe stunting (HAZ $<-3$ ), we do find significant effects (Table A3.5 in Appendix A3). Buying in a supermarket decreases the probability of severe stunting by 23 percentage points. 
Table 3.3. Impact of supermarket purchase on child/adolescent nutrition

\begin{tabular}{|c|c|c|c|c|c|}
\hline Explanatory variables & BAZ & HAZ & HAZ & $\begin{array}{l}\text { Stunted } \\
\text { (dummy) }\end{array}$ & $\begin{array}{c}\text { Stunted } \\
\text { (dummy) }\end{array}$ \\
\hline $\begin{array}{l}\text { Buys in supermarket } \\
\text { (dummy) }\end{array}$ & $0.183(0.34)$ & $0.634^{* *}(0.27)$ & -- & $-0.056(0.10)$ & -- \\
\hline $\begin{array}{l}\text { Supermarket purchase share } \\
(\%)\end{array}$ & -- & -- & $0.033^{\text {**** }}(0.01)$ & -- & $-0.004(0.00)$ \\
\hline Age (months) & $\begin{array}{c}-0.004^{* *} \\
(0.00)\end{array}$ & $\begin{array}{c}-0.007^{* * * *} \\
(0.00)\end{array}$ & $\begin{array}{c}-0.008^{* * *} \\
(0.00)\end{array}$ & $\begin{array}{c}0.002^{* * * *} \\
(0.00)\end{array}$ & $\begin{array}{c}0.002^{* * * *} \\
(0.00)\end{array}$ \\
\hline Female (dummy) & $0.107(0.13)$ & $0.082(0.15)$ & $0.130(0.15)$ & $-0.022(0.05)$ & $-0.028(0.05)$ \\
\hline $\begin{array}{l}\text { Household expenditure (1000 } \\
\text { Ksh per AE and month) }\end{array}$ & $0.001(0.01)$ & $0.029^{*}(0.02)$ & $0.024(0.02)$ & $\begin{array}{c}-0.013^{* *} \\
(0.01)\end{array}$ & $\begin{array}{c}-0.013^{* *} \\
(0.01)\end{array}$ \\
\hline $\begin{array}{l}\text { Education of person } \\
\text { responsible for food (years) }\end{array}$ & $0.027(0.02)$ & $0.002(0.03)$ & $0.003(0.03)$ & $-0.000(0.01)$ & $0.000(0.01)$ \\
\hline $\begin{array}{l}\text { Married household head } \\
\text { (dummy) }\end{array}$ & $-0.115(0.16)$ & $0.138(0.20)$ & $0.181(0.20)$ & $-0.073(0.05)$ & $-0.081(0.05)$ \\
\hline $\begin{array}{l}\text { Malaria or respiratory } \\
\text { infection (dummy) }\end{array}$ & -- & $-0.440^{*}(0.26)$ & $-0.430^{*}(0.24)$ & $0.038(0.09)$ & $0.038(0.08)$ \\
\hline Height of female adult (cm) & -- & $0.057^{* * *}(0.02)$ & $0.057^{\text {**** }}(0.02)$ & $\begin{array}{c}-0.014^{* * *} \\
(0.00)\end{array}$ & $\begin{array}{c}-0.014^{* * *} \\
(0.00)\end{array}$ \\
\hline $\begin{array}{l}\text { Age of female adult when the } \\
\text { child was born (years) }\end{array}$ & -- & $0.025^{* *}(0.01)$ & $0.025^{* *}(0.01)$ & $-0.000(0.00)$ & $-0.000(0.00)$ \\
\hline $\begin{array}{l}\text { Household treats drinking } \\
\text { water (dummy) }\end{array}$ & -- & $0.357^{* *}(0.15)$ & $0.345^{* *}(0.15)$ & $-0.066(0.05)$ & $-0.063(0.05)$ \\
\hline $\begin{array}{l}\text { Distance to nearest health } \\
\text { care center (log of } \mathrm{km})\end{array}$ & -- & $-0.040(0.07)$ & $0.025(0.07)$ & $0.047^{*}(0.03)$ & $0.042(0.03)$ \\
\hline Age of female adult (years) & $0.014^{*}(0.01)$ & -- & -- & -- & -- \\
\hline $\begin{array}{l}\text { Physical education at school } \\
\text { (hours per week) }\end{array}$ & $-0.024(0.03)$ & -- & -- & -- & -- \\
\hline $\begin{array}{l}\text { Leisure-time physical activity } \\
\text { (hours per week) }\end{array}$ & $-0.004(0.01)$ & -- & -- & -- & -- \\
\hline $\begin{array}{l}\text { Distance to nearest district } \\
\text { hospital }(\log \text { of } \mathrm{km})\end{array}$ & $0.011(0.06)$ & -- & -- & -- & -- \\
\hline Constant & $-0.607(0.45)$ & $\begin{array}{c}-10.760^{* * * *} \\
(2.57)\end{array}$ & $\begin{array}{l}-10.715^{* * *} \\
(2.54)\end{array}$ & -- & -- \\
\hline Number of observations & 216 & 216 & 216 & 216 & 216 \\
\hline Chi-squared test statistic & $169.347^{* * *}$ & $211.088^{* * *}$ & -- & $156.787^{* * * *}$ & $336.572^{* * *}$ \\
\hline
\end{tabular}

Control variables for these child/adolescent models were chosen based on the broad nutrition and health literature (Asfaw, 2011; Black et al., 2013; Jones-Smith et al., 2012; Kanter \& Caballero, 2012; Lear et al., 2013; Roemling \& Qaim, 2013; Simon et al., 2014). Factors that contribute to overnutrition may be somewhat different from factors that contribute to undernutrition, which is why model specifications in Table 3.3 are not uniform. Most of the 
control variables show the expected signs. Household living standard, height and age of the mother, and treated drinking water increase HAZ and thus reduce child undernutrition, while recent episodes of infectious diseases have a significantly negative effect on HAZ.

\subsubsection{Impact Pathways}

We have shown that buying in supermarkets increases BMI and the probability of overweight and obesity among adults. Now we explore possible impact pathways. Estimation results from the causal chain model for adults are summarized in Table 3.4. The results confirm the hypothesis that total calorie consumption and the share of calories from processed foods both play a significant role. An increase in the supermarket purchase share by one percentage point entails a calorie consumption increase of $15 \mathrm{kcal}$ per day, and an increase in the processed calorie share of 0.33 percentage points. Furthermore, both variables significantly increase adult BMI.

\section{Table 3.4. Impact pathways of supermarket purchase on adult BMI}

\begin{tabular}{lc}
\hline Pathway & $\begin{array}{c}\text { Marginal effect } \\
\text { (standard error) }\end{array}$ \\
\hline $\begin{array}{l}\text { Effect on BMI from } \\
\quad \text { Calorie consumption per day (kcal) }\end{array}$ & $0.002^{* * *}(0.00)$ \\
$\quad$ Share of calories from processed foods $(\%)$ & $0.118^{* * *}(0.04)$ \\
$\begin{array}{l}\text { Effect of supermarket purchase share }(\%) \text { on calorie } \\
\text { consumption per day (kcal) }\end{array}$ & $15.443^{*}(8.53)$ \\
$\begin{array}{l}\text { Effect of supermarket purchase share }(\%) \text { on share of } \\
\text { calorie from processed food }(\%)\end{array}$ & $0.330^{* * *}(0.11)$ \\
$\begin{array}{l}\text { Number of observations } \\
\text { Chi-squared test statistic }\end{array}$ & 615 \\
\hline$*, * * *$, statistically significant at the 10\% and 1\% level, respectively. Estimates are based on causal chain model, full results of \\
which are shown in Appendix A3 (Table A3.6). BMI, body mass index.
\end{tabular}

For children and adolescents, supermarkets do not seem to increase overweight and obesity, but we found that supermarket purchase contributes to reduced undernutrition in terms of higher HAZ. Like overnutrition, undernutrition is determined by the quantity and types of foods consumed, among other factors. Hence, we estimated a causal chain model similar to the one used for adults, but with child/adolescent HAZ as nutritional outcome variable. The main results are shown in Table 3.5. While the effect of supermarket purchase on calorie consumption is positive, it is not statistically significant. Yet, supermarket purchase has a significantly positive 
effect on calories from processed foods, indicating changes in dietary composition. An increase in the supermarket purchase share by one percentage point increases the share of calories from processed foods by 0.45 percentage points. The amount of calories and the share of calories from processed foods both have positive and significant effects on individual HAZ.

\section{Table 3.5. Impact pathways of supermarket purchase on child/adolescent HAZ}

\begin{tabular}{lc}
\hline Pathway & $\begin{array}{c}\text { Marginal effect } \\
\text { (standard error) }\end{array}$ \\
\hline $\begin{array}{l}\text { Effect on HAZ from } \\
\quad \text { Calorie consumption per day (kcal) }\end{array}$ & $0.001^{*}(0.00)$ \\
$\quad \begin{array}{l}\text { Share of calories from processed foods }(\%) \\
\text { Effect of supermarket purchase share }(\%) \text { on calorie }\end{array}$ & $0.025^{*}(0.01)$ \\
$\begin{array}{l}\text { consumption per day (kcal) } \\
\text { Effect of supermarket purchase share }(\%) \text { on share of } \\
\text { calorie from processed food }(\%)\end{array}$ & $0.447^{* *}(0.18)$ \\
$\begin{array}{l}\text { Number of observations } \\
\text { Chi-squared test statistic }\end{array}$ & 216 \\
\hline *,**, statistically significant at the 10\%, 5\%, and 1\% level, respectively. Estimates are based on causal chain model, full results \\
of which are shown in Appendix A3 (Table A3.7). HAZ, height-for-age Z-score.
\end{tabular}

\subsection{Discussion}

The results show that buying in supermarkets increases BMI and the probability of being overweight or obese among adults in Kenya. These effects even hold when we control for other factors that influence BMI and that may be correlated with supermarket purchases, such as household living standard and physical activity. This finding is consistent with the scant literature on the relationship between supermarkets and consumer nutritional outcomes for adults in developing countries (Asfaw, 2008). For children, this relationship has not been analyzed previously. Our data suggest that buying in supermarkets does not contribute to higher overweight and obesity in children and adolescents. Rather, supermarket purchase reduces child undernutrition through a positive impact on HAZ. Supermarkets also reduce the probability of severe stunting.

Supermarket purchase increases adult BMI through two pathways, namely through more calories consumed and through a higher share of calories from processed foods. The impact pathways for child HAZ seem to be similar, although the effect of supermarkets on total calorie consumption is not statistically significant, possibly due to the smaller sample size. Why do supermarkets cause consumers to eat more and change their dietary composition? A 
comprehensive analysis of this question is beyond the scope of this article, but a brief discussion may be useful. While some of the supermarkets in larger Kenyan cities offer fresh products, such as fruits and vegetables or whole grains, this is not yet the case for supermarkets in smaller towns, as analyzed here. Hence, small town consumers who buy a lot in supermarkets will automatically increase the share of processed food in their diet. Also in other developing countries it was shown that supermarkets start to sell processed products first, dealing with fresh foods only at a later stage (Mergenthaler et al., 2009; Reardon et al., 2003; Timmer, 2009). Packaging sizes, prices, and shopping atmosphere may play an important role for consumer food choices, too(Chandon \& Wansink, 2012; Hawkes, 2008; Schipmann \& Qaim, 2011). When asked why they buy in supermarkets, $65 \%$ of the respondents in our sample reported lower food prices as the most important reason (Figure A3.1 in Appendix A3). Whether prices in supermarkets are really lower may be difficult to judge for consumers, due to differences in product choices and packaging sizes. But the perception of lower prices may suffice to increase consumption.

The fact that the same mechanisms lead to nutritional outcomes that differ by age cohort is interesting and underlines the need for disaggregated analysis. For adults who have already reached their final body height, increasing calorie consumption can only lead to higher BMI when other factors are held constant. Waistlines will increase especially when levels of physical activity are low, as is the case with more sedentary lifestyles. For children and adolescents, the situation is different, because higher calorie consumption can also lead to gains in body height, as observed in our study. Moreover, children and adolescents in our sample are more physically active than adults (Tables A3.1 and A3.2 in Appendix A3). Concerning effects on body height, it should be mentioned that - beyond calories - certain micronutrients also play an important role for child growth (Martorell et al., 1994). While not analyzed here, dietary changes through buying in supermarkets may potentially be associated with higher micronutrient consumption. This could be true especially for children from poor households who otherwise have relatively low dietary diversity.

Clearly, the impact of expanding supermarkets in developing countries will much depend on people's initial nutritional status. In Kenya, we observe relatively high overweight rates among adults, while stunting is a more widespread problem among children and adolescents. This socalled dual burden of malnutrition is common in many developing countries (Doak et al., 2005; Roemling \& Qaim, 2013), implying that some of our results may also be of relevance for other 
settings. Reducing child stunting and controlling the global obesity pandemic are both important public health objectives.

The results suggest that the supermarket revolution in developing countries is not just a business response to the rapid nutrition transition, but that supermarkets also contribute to changing food consumption habits and nutritional outcomes. Yet the types of outcomes can be diverse, depending on many factors. Hence, simple conclusions on whether supermarkets are good or bad for nutrition and health are not justified. It should also be noted that impacts may change over time. Rates of child undernutrition will decrease and childhood obesity may increase when household incomes rise. Furthermore, supermarkets may gradually offer a greater variety of products, including more fresh and healthy foods, which can contribute to nutritional improvements, as shown in the USA (Lear et al., 2013; Michimi \& Wimberly, 2010 ). Our analysis should not be seen as the final judgment about supermarket nutritional impacts in developing countries, but as early evidence that can contribute to a better understanding of this complex and emerging theme. To reduce negative health outcomes, the nutrition transition should be accompanied by broader nutrition education and awareness campaigns. In some cases, specific regulations for supermarkets and other actors in the food industry may be required. 


\section{Appendix A3}

Table A3.1. Descriptive statistics for variables used in adult nutrition models

\begin{tabular}{lcc}
\hline Variable & Mean & $\begin{array}{c}\text { Standard } \\
\text { deviation }\end{array}$ \\
\hline BMI & 24.893 & 4.845 \\
Overweight (dummy) & 0.270 & 0.444 \\
Obese (dummy) & 0.143 & 0.350 \\
Underweight (dummy) & 0.039 & 0.194 \\
Calorie consumption per day (kcal) & 3350.776 & 1327.238 \\
Share of calories from processed foods (\%) & 48.51 & 16.21 \\
Food expenditure (Ksh per AE and month) & 6099.922 & 4628.725 \\
Buys in supermarket (dummy) & 0.580 & 0.494 \\
Supermarket purchase share (\% of total food & 9.671 & 11.596 \\
expenditure) & 15.105 & 20.478 \\
Distance to nearest supermarket (km) & 34.763 & 11.905 \\
Age (years) & 0.641 & 0.480 \\
Female (dummy) & 0.460 & 0.499 \\
Heavy work (dummy) & 8.806 & 7.221 \\
Leisure-time physical activity (hours per week) & 12005.460 & 10041.010 \\
Household expenditure (Ksh per AE and month) & 9.724 & 3.778 \\
Education of person responsible for food (years) & 2.642 & 1.233 \\
Household size (AE) & 0.735 & 0.442 \\
Married household head (dummy) & 0.654 & 0.476 \\
Household does farming (dummy) & 0.598 & 0.491 \\
Household owns television (dummy) & 10.426 & 7.171 \\
Distance to nearest district hospital (km) & 615 & \\
Number of observations & & \\
\hline BM, body & &
\end{tabular}

BMI, body mass index; Ksh, Kenyan shillings; AE, adult equivalent. 
Table A3.2. Descriptive statistics for variables used in child/adolescent nutrition models

\begin{tabular}{lcc}
\hline Variable & Mean & $\begin{array}{c}\text { Standard } \\
\text { deviation }\end{array}$ \\
\hline Height-for-age Z-scores (HAZ) & -1.049 & 1.296 \\
Stunted (dummy) & 0.208 & 0.407 \\
BMI-for-age Z-scores (BAZ) & -0.308 & 1.000 \\
Overweight/obese (dummy) & 0.097 & 0.297 \\
Calorie consumption per day (kcal) & 2423.15 & 1214.68 \\
Share of calories from processed foods (\%) & 48.22 & 17.29 \\
Buys in supermarket (dummy) & 0.509 & 0.501 \\
Supermarket purchase share (\% of total food & 8.480 & 11.204 \\
expenditure) & 15.489 & 19.763 \\
Distance to nearest supermarket (km) & 115.755 & 43.717 \\
Age (months) & 0.481 & 0.501 \\
Female (dummy) & 1.473 & 2.076 \\
Physical education at school (hours per week) & 16.589 & 9.504 \\
Leisure-time physical activity (hours per week) & 0.093 & 0.291 \\
Malaria or respiratory infection during last month & 158.126 & 5.845 \\
(dummy) & 35.213 & 10.513 \\
Height of female adult measured in household (cm) & 25.567 & 9.791 \\
Age of female adult measured in the household (years) & 0.833 & 0.374 \\
Age of female adult when the child was born (years) & 0.477 & 0.501 \\
Female adult is the mother (dummy) & 9223.462 & 6193.470 \\
Household treats drinking water (dummy) & 8.769 & 3.833 \\
Household expenditure (Ksh per AE and month) & 3.228 & 1.196 \\
Education of person responsible for food (years) & 0.75 & 0.434 \\
Household size (AE) & 0.699 & 0.460 \\
Married household head (dummy) & 0.537 & 0.500 \\
Household does farming (dummy) & 9.747 & 7.050 \\
Household owns television (dummy) & 2.087 & 2.159 \\
Distance to nearest district hospital (km) & 216 & \\
Distance to nearest health care center (km) & & \\
Number of observations & & \\
\hline Ku Kenyas & & \\
\hline
\end{tabular}

Ksh, Kenyan shillings; AE, adult equivalent. 
Table A3.3. First-stage results of instrumental variable models for impact of supermarket purchase on adult nutrition

\begin{tabular}{|c|c|c|}
\hline Explanatory variables & $\begin{array}{l}\text { Buys in supermarket } \\
\text { (dummy) }\end{array}$ & $\begin{array}{c}\text { Supermarket purchase } \\
\text { share }(\%)\end{array}$ \\
\hline Distance to nearest supermarket (log of km) & $-0.502^{* * * *}(0.04)$ & $-2.272^{* * * *}(0.19)$ \\
\hline Age (years) & $-0.021^{* *}(0.01)$ & $-0.097^{* *}(0.04)$ \\
\hline Female (dummy) & $-0.115(0.43)$ & $-1.249(2.19)$ \\
\hline Female-age interaction & $0.007(0.01)$ & $0.033(0.05)$ \\
\hline Heavy work (dummy) & $-0.177(0.14)$ & $-0.249(0.72)$ \\
\hline $\begin{array}{l}\text { Leisure-time physical activity (hours per } \\
\text { week) }\end{array}$ & $0.016^{*}(0.01)$ & $-0.008(0.05)$ \\
\hline $\begin{array}{l}\text { Household expenditure (1000 Ksh per AE } \\
\text { and month) }\end{array}$ & $0.072^{* * *}(0.01)$ & $0.183^{* * *}(0.04)$ \\
\hline $\begin{array}{l}\text { Education of person responsible for food } \\
\text { (years) }\end{array}$ & $0.048^{* *}(0.02)$ & $0.411^{* * * *}(0.11)$ \\
\hline Married household head (dummy) & $0.676^{* * * *}(0.17)$ & $0.788(0.96)$ \\
\hline $\begin{array}{l}\text { Distance to nearest district hospital (log of } \\
\mathrm{km} \text { ) }\end{array}$ & $0.004(0.05)$ & $-1.363^{* * *}(0.33)$ \\
\hline Constant & $-0.401(0.44)$ & $11.065^{* * *}(2.34)$ \\
\hline Number of observations & 615 & 615 \\
\hline Chi-squared test statistic & $242.159^{* * *}$ & -- \\
\hline$F$ statistic & -- & $44.73^{* * *}$ \\
\hline
\end{tabular}


Table A3.4. First-stage results of instrumental variable models for impact of supermarket purchase on child/adolescent nutrition

\begin{tabular}{|c|c|c|c|}
\hline \multirow[b]{2}{*}{ Explanatory variables } & \multicolumn{2}{|c|}{ Buys in supermarket (dummy) } & \multirow{2}{*}{$\begin{array}{c}\text { Supermarket } \\
\text { purchase share } \\
(\%)\end{array}$} \\
\hline & BAZ model & $\begin{array}{l}\text { HAZ/stunted } \\
\text { models }\end{array}$ & \\
\hline Distance to nearest supermarket (log of km) & $-0.547^{* * *}(0.07)$ & $-0.567^{* * *}(0.07)$ & $-3.092^{* * *}(0.28)$ \\
\hline Age (months) & $-0.007^{* *}(0.00)$ & $-0.009^{* * *}(0.00)$ & $-0.017(0.01)$ \\
\hline Female (dummy) & $0.073(0.24)$ & $0.044(0.24)$ & $-1.241(1.16)$ \\
\hline $\begin{array}{l}\text { Household expenditure (1000 Ksh per AE and } \\
\text { month) }\end{array}$ & $0.092^{* * *}(0.03)$ & $0.080^{* * *}(0.03)$ & $0.347^{* * *}(0.11)$ \\
\hline $\begin{array}{l}\text { Education of person responsible for food } \\
\text { (years) }\end{array}$ & $0.024(0.04)$ & $0.028(0.04)$ & $0.169(0.21)$ \\
\hline Married household head (dummy) & $0.206(0.28)$ & $0.163(0.28)$ & $-0.362(1.49)$ \\
\hline Malaria or respiratory infection (dummy) & -- & $0.144(0.40)$ & $-0.675(2.15)$ \\
\hline Height of female adult $(\mathrm{cm})$ & -- & $-0.010(0.02)$ & $-0.024(0.08)$ \\
\hline $\begin{array}{l}\text { Age of female adult when child was born } \\
\text { (years) }\end{array}$ & -- & $-0.007(0.01)$ & $0.015(0.06)$ \\
\hline Household treats drinking water (dummy) & -- & $0.281(0.24)$ & $1.464(1.16)$ \\
\hline $\begin{array}{l}\text { Distance to nearest health care center (log of } \\
\mathrm{km})\end{array}$ & -- & $0.052(0.13)$ & $-1.812^{* *}(0.71)$ \\
\hline Physical education at school (hours per week) & $0.036(0.05)$ & -- & -- \\
\hline $\begin{array}{l}\text { Leisure-time physical activity (hours per } \\
\text { week) }\end{array}$ & $0.018(0.01)$ & -- & -- \\
\hline Age of female adult (years) & $-0.006(0.01)$ & -- & -- \\
\hline $\begin{array}{l}\text { Distance to nearest district hospital (log of } \\
\mathrm{km} \text { ) }\end{array}$ & $-0.029(0.10)$ & -- & -- \\
\hline Constant & $0.033(0.79)$ & $2.219(3.02)$ & $13.296(12.68)$ \\
\hline Observations & 216 & 216 & 216 \\
\hline Chi-squared test statistic & $96.365^{* * *}$ & $111.231^{* * *}$ & -- \\
\hline$F$ statistic & -- & -- & $22.2^{* * *}$ \\
\hline
\end{tabular}


Table A3.5. Impact of supermarket purchase on child/adolescent mild and severe stunting

\begin{tabular}{|c|c|c|c|c|}
\hline \multirow[b]{2}{*}{ Buys in supermarket (dummy) } & \multicolumn{2}{|c|}{ Mildly stunted $(\mathrm{HAZ}<-1)$} & \multicolumn{2}{|c|}{$\begin{array}{c}\text { Severely stunted }(\mathrm{HAZ}<- \\
3)\end{array}$} \\
\hline & $\begin{array}{l}-0.131 \\
(0.09)\end{array}$ & -- & $\begin{array}{c}-0.231^{* * * *} \\
(0.05)\end{array}$ & th \\
\hline Supermarket purchase share (\%) & -- & $\begin{array}{c}-0.009^{* *} \\
(0.00)\end{array}$ & -- & $\begin{array}{c}-0.016^{* * *} \\
(0.00)\end{array}$ \\
\hline Age (months) & $\begin{array}{l}0.003^{* * *} \\
(0.00)\end{array}$ & $\begin{array}{l}0.003^{* * *} \\
(0.00)\end{array}$ & $\begin{array}{l}0.001^{* *} \\
(0.00)\end{array}$ & $\begin{array}{l}0.001^{* * *} \\
(0.00)\end{array}$ \\
\hline Female (dummy) & $\begin{array}{r}-0.021 \\
(0.06)\end{array}$ & $\begin{array}{l}-0.032 \\
(0.06)\end{array}$ & $\begin{array}{l}-0.004 \\
(0.03)\end{array}$ & $\begin{array}{l}-0.025 \\
(0.03)\end{array}$ \\
\hline $\begin{array}{l}\text { Household expenditure (1000 Ksh } \\
\text { per AE and month) }\end{array}$ & $\begin{array}{l}-0.007 \\
(0.01)\end{array}$ & $\begin{array}{l}-0.005 \\
(0.01)\end{array}$ & $0.003(0.00)$ & $0.004(0.00)$ \\
\hline $\begin{array}{l}\text { Education of person responsible for } \\
\text { food (years) }\end{array}$ & $\begin{array}{l}-0.006 \\
(0.01)\end{array}$ & $\begin{array}{l}-0.004 \\
(0.01)\end{array}$ & $\begin{array}{c}-0.012^{* * *} \\
(0.00)\end{array}$ & $\begin{array}{r}-0.012^{*} \\
(0.01)\end{array}$ \\
\hline Married household head (dummy) & $\begin{array}{l}-0.087 \\
(0.07)\end{array}$ & $\begin{array}{l}-0.099 \\
(0.07)\end{array}$ & $\begin{array}{l}-0.033 \\
(0.03)\end{array}$ & $\begin{array}{c}-0.063^{*} \\
(0.03)\end{array}$ \\
\hline $\begin{array}{l}\text { Malaria or respiratory infection } \\
\text { (dummy) }\end{array}$ & $0.097(0.10)$ & $0.095(0.10)$ & $\begin{array}{l}0.177^{* * * *} \\
(0.04)\end{array}$ & $\begin{array}{l}0.185^{* * *} \\
(0.05)\end{array}$ \\
\hline Height of female adult (cm) & $\begin{array}{c}-0.019^{* * *} \\
(0.00)\end{array}$ & $\begin{array}{c}-0.019^{* * *} \\
(0.00)\end{array}$ & $\begin{array}{l}-0.005 \\
(0.00)\end{array}$ & $\begin{array}{l}-0.005 \\
(0.00)\end{array}$ \\
\hline $\begin{array}{l}\text { Age of female when the child was } \\
\text { born (years) }\end{array}$ & $\begin{array}{c}-0.010^{* * * *} \\
(0.00)\end{array}$ & $\begin{array}{l}-0.010^{* * * *} \\
(0.00)\end{array}$ & $\begin{array}{l}-0.003^{*} \\
(0.00)\end{array}$ & $\begin{array}{l}-0.003^{*} \\
(0.00)\end{array}$ \\
\hline Household treats drinking water & $\begin{array}{r}-0.105^{*} \\
(0.06)\end{array}$ & $\begin{array}{r}-0.096^{*} \\
(0.06)\end{array}$ & $\begin{array}{l}-0.017 \\
(0.04)\end{array}$ & $\begin{array}{l}-0.009 \\
(0.03)\end{array}$ \\
\hline $\begin{array}{l}\text { Distance to nearest health care } \\
\text { center (log of } \mathrm{km})\end{array}$ & $\begin{array}{r}-0.052^{*} \\
(0.03)\end{array}$ & $\begin{array}{l}-0.065^{* *} \\
(0.03)\end{array}$ & $\begin{array}{l}0.048^{* *} \\
(0.02)\end{array}$ & $\begin{array}{l}0.037^{*} \\
(0.02)\end{array}$ \\
\hline Number of observations & 216 & 216 & 216 & 216 \\
\hline
\end{tabular}


Table A3.6. Causal chain model to explain the impact of supermarket purchase on adult BMI

\begin{tabular}{|c|c|c|c|c|}
\hline Explanatory variables & $\mathrm{BMI}\left(\mathrm{Kg} / \mathrm{m}^{2}\right)$ & $\begin{array}{c}\text { Calorie } \\
\text { consumption } \\
\text { per day } \\
\text { (kcal) }\end{array}$ & $\begin{array}{c}\text { Share of } \\
\text { calories from } \\
\text { processed } \\
\text { foods }(\%)\end{array}$ & $\begin{array}{c}\text { Supermarket } \\
\text { purchase } \\
\text { share }(\%)\end{array}$ \\
\hline Calorie consumption per day (kcal) & $\begin{array}{l}0.002^{* * * *} \\
(0.00)\end{array}$ & -- & -- & -- \\
\hline $\begin{array}{l}\text { Share of calories from processed foods } \\
(\%)\end{array}$ & $\begin{array}{c}0.118^{* * * *} \\
(0.04)\end{array}$ & -- & -- & -- \\
\hline Age (years) & $\begin{array}{c}0.112^{* * * *} \\
(0.02)\end{array}$ & -- & -- & -- \\
\hline Female (dummy) & $1.344(1.23)$ & -- & -- & -- \\
\hline Female-age interaction & $0.040(0.03)$ & -- & -- & -- \\
\hline Heavy work (dummy) & $\begin{array}{c}-0.672^{*} \\
(0.37)\end{array}$ & -- & -- & -- \\
\hline $\begin{array}{l}\text { Leisure-time physical activity (hours } \\
\text { per week) }\end{array}$ & $\begin{array}{c}-0.041^{*} \\
(0.02)\end{array}$ & -- & ${ }^{--}$ & -- \\
\hline Supermarket purchase share (\%) & -- & $\begin{array}{c}15.443^{*} \\
(8.53)\end{array}$ & $\begin{array}{c}0.330^{* * *} \\
(0.11)\end{array}$ & -- \\
\hline $\begin{array}{l}\text { Household expenditure (1000 Ksh per } \\
\text { AE and month) }\end{array}$ & -- & $\begin{array}{l}39.060^{* * *} \\
(5.78)\end{array}$ & $\begin{array}{c}-0.241^{* * *} \\
(0.07)\end{array}$ & $\begin{array}{c}0.144^{* * *} \\
(0.04)\end{array}$ \\
\hline $\begin{array}{l}\text { Education of person responsible for } \\
\text { food (years) }\end{array}$ & -- & $\begin{array}{r}-12.780 \\
(15.06)\end{array}$ & $\begin{array}{l}0.755^{* * *} \\
(0.19)\end{array}$ & $\begin{array}{c}0.448^{* * * *} \\
(0.11)\end{array}$ \\
\hline Household size (AE) & -- & $\begin{array}{r}-30.612 \\
(41.79)\end{array}$ & $\begin{array}{c}-0.990^{*} \\
(0.52)\end{array}$ & -- \\
\hline Household does farming (dummy) & -- & $\begin{array}{l}179.862^{*} \\
(108.04)\end{array}$ & $\begin{array}{c}-4.230^{* * * *} \\
(1.37)\end{array}$ & $\begin{array}{c}-2.522^{* * *} \\
(0.79)\end{array}$ \\
\hline Household owns television (dummy) & -- & -- & $\begin{array}{l}3.075^{* *} \\
(1.29)\end{array}$ & $\begin{array}{c}2.274^{* * *} \\
(0.80)\end{array}$ \\
\hline $\begin{array}{l}\text { Distance to nearest supermarket (log } \\
\text { of } \mathrm{km} \text { ) }\end{array}$ & -- & -- & -- & $\begin{array}{l}-2.564^{* * *} \\
(0.18)\end{array}$ \\
\hline Constant & $\begin{array}{l}6.996^{* *} \\
(2.88)\end{array}$ & $\begin{array}{c}2820.068^{* * *} \\
(199.77)\end{array}$ & $\begin{array}{l}44.416^{* * *} \\
(2.48)\end{array}$ & $\begin{array}{l}6.420^{* * *} \\
(1.22)\end{array}$ \\
\hline $\begin{array}{l}\text { Number of observations } \\
\text { Chi-squared }\end{array}$ & \multicolumn{4}{|c|}{$\begin{array}{c}615 \\
130.044^{* * *}\end{array}$} \\
\hline
\end{tabular}

$*, * *, * * *$, statistically significant at the $10 \%, 5 \%$, and $1 \%$, level respectively. Coefficient estimates are shown with standard errors in parentheses. The system of simultaneous equations was estimated with three-stage least squares. BMI, body mass index; Ksh, Kenyan shillings; AE, adult equivalent. 
Table A3.7. Causal chain model to explain the impact of supermarket purchase on child/adolescent HAZ

\begin{tabular}{|c|c|c|c|c|}
\hline Explanatory variables & HAZ & $\begin{array}{c}\text { Calorie } \\
\text { consumptio } \\
\text { n per day } \\
(\mathrm{kcal})\end{array}$ & $\begin{array}{l}\text { Share of } \\
\text { calories } \\
\text { from } \\
\text { processed } \\
\text { foods }(\%)\end{array}$ & $\begin{array}{c}\text { Supermarke } \\
\text { t purchase } \\
\text { share }(\%)\end{array}$ \\
\hline Calorie consumption per day (kcal) & $\begin{array}{l}0.001^{*} \\
(0.00)\end{array}$ & -- & -- & -- \\
\hline $\begin{array}{l}\text { Share of calories from processed foods } \\
(\%)\end{array}$ & $\begin{array}{l}0.025^{*} \\
(0.01)\end{array}$ & -- & -- & -- \\
\hline Age (months) & $\begin{array}{c}-0.009^{* * *} \\
(0.00)\end{array}$ & -- & -- & -- \\
\hline Female (dummy) & $0.105(0.15)$ & -- & -- & -- \\
\hline Malaria or respiratory infection (dummy) & $\begin{array}{c}-0.436^{*} \\
(0.26)\end{array}$ & -- & -- & -- \\
\hline Height of female adult $(\mathrm{cm})$ & $\begin{array}{l}0.059^{* * * *} \\
(0.01)\end{array}$ & -- & -- & -- \\
\hline $\begin{array}{l}\text { Age of female adult when the child was } \\
\text { born (years) }\end{array}$ & $\begin{array}{l}0.019^{*} \\
(0.01)\end{array}$ & -- & -- & -- \\
\hline $\begin{array}{l}\text { Household treats drinking water } \\
\text { (dummy) }\end{array}$ & $\begin{array}{l}0.364^{* *} \\
(0.16)\end{array}$ & -- & -- & -- \\
\hline Supermarket purchase share (\%) & -- & $\begin{array}{l}17.240 \\
(13.25)\end{array}$ & $\begin{array}{l}0.447^{* *} \\
(0.18)\end{array}$ & -- \\
\hline $\begin{array}{l}\text { Household expenditure (1000 Ksh per } \\
\mathrm{AE} \text { and month) }\end{array}$ & -- & $\begin{array}{l}49.278^{* * *} \\
(16.12)\end{array}$ & $\begin{array}{r}-0.358 \\
(0.23)\end{array}$ & $\begin{array}{l}0.331^{* * *} \\
(0.11)\end{array}$ \\
\hline $\begin{array}{l}\text { Education of person responsible for food } \\
\text { (years) }\end{array}$ & -- & $\begin{array}{l}-23.578 \\
(30.37)\end{array}$ & $\begin{array}{l}-2.356^{* *} \\
(0.96)\end{array}$ & $0.201(0.18)$ \\
\hline Household size (AE) & -- & $\begin{array}{r}-41.883 \\
(69.42)\end{array}$ & $\begin{array}{l}0.876^{* * * *} \\
(0.33)\end{array}$ & -- \\
\hline Household does farming (dummy) & -- & $\begin{array}{l}-41.328 \\
(174.76)\end{array}$ & $\begin{array}{l}-6.007^{* *} \\
(2.42)\end{array}$ & $\begin{array}{r}-1.456 \\
(1.28)\end{array}$ \\
\hline Education of household head (years) & -- & $\begin{array}{r}-32.853 \\
(27.60)\end{array}$ & -- & -- \\
\hline Age of female adult (years) & -- & $3.467(7.89)$ & -- & -- \\
\hline Household owns television (dummy) & -- & -- & $1.918(2.17)$ & $0.566(1.28)$ \\
\hline $\begin{array}{l}\text { Distance to nearest supermarket (log of } \\
\mathrm{km})\end{array}$ & -- & -- & -- & $\begin{array}{c}-2.830^{* * *} \\
(0.30)\end{array}$ \\
\hline Constant & $\begin{array}{c}-12.428^{* * *} \\
(2.40)\end{array}$ & $\begin{array}{l}2383.898^{* * *} \\
(449.13)\end{array}$ & $\begin{array}{c}50.831^{* * *} \\
(4.52)\end{array}$ & $\begin{array}{c}7.586^{* * *} \\
(1.84)\end{array}$ \\
\hline $\begin{array}{l}\text { Number of observations } \\
\text { Chi-squared }\end{array}$ & \multicolumn{4}{|c|}{$\begin{array}{c}216 \\
65.561^{* * *}\end{array}$} \\
\hline
\end{tabular}

$*, * *, * * *$, statistically significant at the $10 \%, 5 \%$, and $1 \%$, level respectively. Coefficient estimates are shown with standard errors in parentheses. The system of simultaneous equations was estimated with three-stage least squares. HAZ, height-for-age Zscore; Ksh, Kenyan shillings; AE, adult equivalent. 
Figure A3.1. Most important reason for shopping in supermarket. Based on household survey responses. Only households that buy in a supermarket are included.

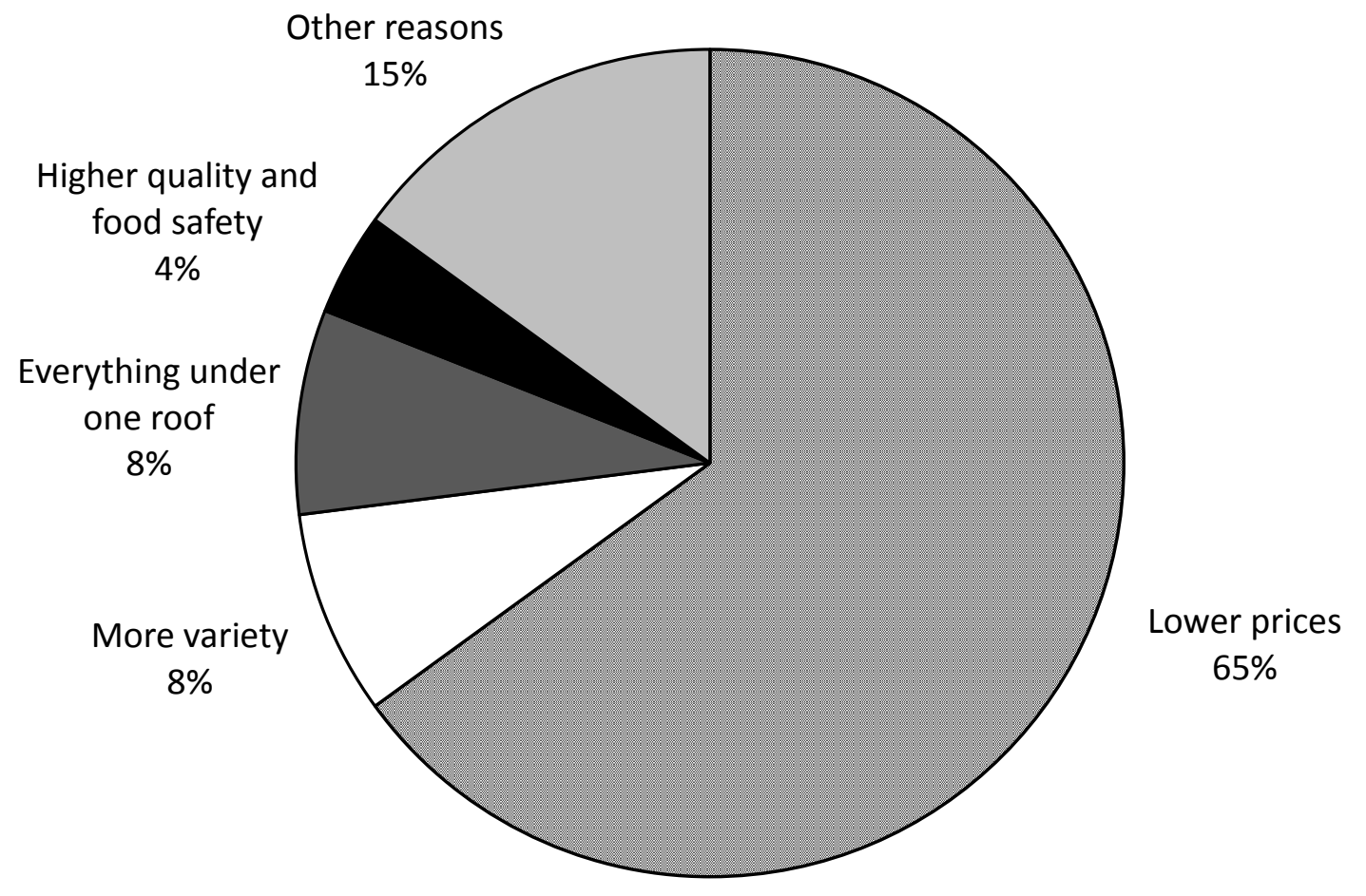




\title{
4 The Nutrition Transition and Indicators of Child Malnutrition ${ }^{3}$
}

\begin{abstract}
Many developing countries are undergoing a nutrition transition. At the same time, child overweight has been increasing, while child undernutrition rates have been falling. The observed reductions in underweight are higher than for stunting. This creates the notion that the reductions in underweight are due to the nutrition transition, which would primarily affect child weight but not growth. However, the relation between the nutrition transition and child malnutrition indicators has never been analyzed. We use a cross-country regression approach to estimate the effect of the nutrition transition on both child weight and growth indicators. Our results show that, indeed, the nutrition has effects on child weight. While the effects on child overweight are less clear, we get consistent results that the nutrition transition reduces underweight. In addition, we get clear and consistent results that the nutrition transition reduces stunting. A simple conclusion that the nutrition transition will only have undesirable effects in developing countries is therefore not justified.
\end{abstract}

\subsection{Introduction}

The nutrition transition, which consists of a rapid change in dietary habits towards more energydense, processed foods and more sedentary lifestyles, is being witnessed in many developing countries (Popkin \& Ng 2007). This nutrition transition is being driven by demand side-factors such as increasing incomes and urbanization (Pingali, 2007), as well as supply-side factors such as globalizing food systems (Hawkes et al., 2009). A result of the nutrition transition is increasing overweight and obesity rates (Popkin \& Ng, 2007; Popkin et al., 2012). In 2008, 34\% of all adults were overweight or obese (Finucane et al., 2011). Though the effects of the nutrition transition have primarily been observed in adults, the same is expected for children. Statistics show that an estimated $6.6 \%$ of children below five years were either overweight or obese in 2011, an increase from $4.5 \%$ in 1990 (UNICEF et al., 2012).

As the rates of child overweight increase, the prevalence of underweight for children below five years has reduced by an annual rate of $2.2 \%$ since 1990 , to an estimate of $16 \%$ in 2011 . With

\footnotetext{
${ }^{3}$ This chapter is co-authored by Matin Qaim. The following roles were performed by me: designing of the study, data analysis, and interpretation of the research results in cooperation with Matin Qaim; writing of the paper.
} 
this reduction, the world is almost on track to meet the MDG one target of halving underweight by 2015 (Haddad, 2013). Observed reductions in child underweight in many developing countries may be spurred by the nutrition transition and its related dietary changes (de Haen et al., 2011; de Onis et al., 2004; Haddad, 2013; Lutter et al., 2011; Misselhorn, 2010; UNICEF, 2013). In comparison, reduction in child stunting is lower: an estimated $26 \%$ of children below five years were stunted in 2011 (UNICEF et al., 2012). This has given rise to the notion that the nutrition transition may have primarily effects on child weight, but not on child growth (de Haen et al., 2011; de Onis et al., 2004; Haddad, 2013; Lutter et al., 2011; Misselhorn, 2010; UNICEF, 2013).

If this is the case, the nutrition transition would be an additional reason why using child underweight as a single indicator of child undernutrition, as done in the millennium development goal (MDG) nutrition target, is misleading. Previous arguments against the use of underweight stem from the observations that is just a summary indicator (Black et al., 2013), and that stunting, a suggested alternative tracking indicator, is a problem of higher magnitude with longterm consequences on child health (Black et al., 2013; Haddad, 2013; UNICEF, 1998). However, the notion that the nutrition transition would reduce child underweight but not stunting is not based on conclusive empirical evidence. In fact, the relation has never been analyzed. In this paper, we challenge this notion by using a cross-country regression approach to estimate the effect of the nutrition transition on both child weight and growth indicators. Pooling datasets from Demographic and Health Surveys, Planet Retail, FAOSTAT, and World Development Indicators, we estimate fixed and random effects regression models to analyze this relation.

\subsection{Dietary Trends and Child Nutrition: Expected Relationships}

In this section, we describe how the nutrition transition might influence child malnutrition based on past studies. According to the UNICEF conceptual model, inadequate dietary intake and disease are the immediate determinants of child undernutrition (UNICEF, 1990). Underweight and stunting are commonly used measures of child undernutrition. A modified version of this conceptual model focuses on optimal child growth, hence allowing the inclusion of overweight and obesity in children as a deviation from optimal child growth (Black et al., 2013). In this study, we use fat consumption, share of modern retail in grocery sales, and the prevalence of women overweight as indicators of the nutrition transition. These indicators would fall within 
underlying determinants in the UNICEF conceptual model. Based on the literature, we hypothesize that nutrition transition would mainly affect household dietary patterns, and to some extent, provision of care to children, which would in turn have an effect on dietary intake by children and disease likelihood, the immediate causes of childhood malnutrition.

Various past studies show that fat consumption can have an effect on childhood malnutrition. On the beneficial aspect, dietary fat provides a sufficiently energy-dense diet to meet energy needs, supplies essential fatty acids and allows absorption of fat-soluble vitamins (Biesalski, 1997; Brown et al., 1995; Prentice \& Pau, 2000). We would thus expect fat consumption to be beneficial to child health and hence reduce the prevalence of underweight and stunting. On the other hand, consumption of fats in excess of requirements, or increased consumption of saturated fats, is expected to have a positive effect on child overweight. A positive association of increased fat intake and the probability of overweight and obesity in children has been shown (Patterson et al., 2010). In recognition of this association, diet recommendations for children advocate for less saturated fats (Gidding et al., 2006; Patterson et al., 2010).

An expectation of a positive association between share of modern retail in grocery sales and child overweight and obesity seems straightforward based on literature. Emerging supermarkets have readily available stocks of highly processed foods and drinks (Hawkes, 2008; Pingali, 2007; Reardon et al., 2003). In addition to the types of products they offer, the retail format influences dietary choice through prices and marketing strategies, some of which are directly targeted at children (Bragg et al., 2012; Hawkes, 2008; Swinburn et al., 2011). There is evidence that supermarkets increase the consumption of processed foods for households in developing countries (Asfaw, 2008; Hawkes, 2008; Rischke et al., 2014). For adults, supermarkets significantly increase adult BMI and the probability of being overweight (Asfaw, 2008). We would expect the same effects on children, since growing up in obesogenic environments would come with increased risks for childhood overweight (Black et al., 2013). One can also hypothesize that increase in the share of modern retail in grocery sales would reduce child undernutrition. We do not find research evidence towards this direction. However, it is possible that a larger variety of processed foods would lead to a more diversified diet that is supplying more micronutrients, especially for children from poor settings. 
We also draw expectations of a positive association between prevalence of women overweight and child overweight based on past studies. A positive effect of consumption of processed foods and adult overweight indicators has been observed (Asfaw, 2011). Overweight and obese adults are also known to engage in less physical activity (Simon et al., 2014). We argue that children growing up in such environments, characterized by sedentary behavior and consumption of more calories and processed foods, have a higher risk for overweight and obesity. Such children are likely to learn and imitate such dietary behavior and sedentary lifestyles (Danesh et al., 2011; Grote et al., 2012; Savage et al., 2007). In addition, there is evidence that maternal overweight and obesity during pregnancy increase the risk of childhood obesity (McGuire et al., 2010). Within the intra-uterine environment, programming for such things as food preferences is already taking place and children born of obese mothers are likely to have more fat mass at birth (Catalano et al., 2009; Fall, 2011; Sewell et al., 2006). Overweight or obese mothers are also less likely to meet recommended breastfeeding requirements hence increasing the risk of overweight for their children (Baker et al., 2007). On the other side, children from overweight or obese mothers are more likely to enjoy better socioeconomic status, such as higher education and more household assets, which may come with better nutrition and care. Literature towards this direction is scarce, but an inverse relationship of maternal overweight and child undernutrition has been observed (Dieffenbach \& Stein, 2012). In South Africa, significantly higher mean Z-scores were observed for children of obese mothers as compared to those of mothers who were not obese (Steyn et al., 2011). That study showed a lower likelihood of underweight and stunting for children of obese mothers, and a bigger risk for children of underweight mothers, mainly because of difference in socioeconomic status. We would therefore expect the prevalence of women overweight to have a negative effect on child undernutrition.

\subsection{Materials and Methods}

\subsubsection{Estimation Strategy}

Given the longitudinal nature of our data, we estimate models of the following general form:

$$
C M_{i t}=\beta_{0}+\beta_{1} N T_{i t}+\beta_{2} \boldsymbol{X}_{i t}+\mathrm{c}_{i}+\mathrm{u}_{i t}, i=1 ; N ; t=1 ; T
$$


where $C M_{i t}$ is the child malnutrition indicator, $N T_{i t}$ is the nutrition transition indicator, $\boldsymbol{X}_{i t}$ is a vector of other explanatory variables, $i$ denotes countries, $t$ denotes time in years, $c_{i}$ denotes unobserved effects (unobserved heterogeneity), and $\mathrm{u}_{i t}$ are idiosyncratic errors.

Common methods for estimating this model are either fixed or random effects models. The choice between fixed or random effects estimation depends on how $c_{i}$ is interpreted. If the unobserved effects are treated as parameters to be estimated, this yields the fixed effects model. Treating $c_{i}$ as a fixed effect (hence time-invariant country specific effects) means that we are allowing $c_{i}$ to be correlated with the observed explanatory variables. The fixed-effects estimator removes the fixed-effects parameters from the estimator during estimation. If $c_{i}$ is treated as a random effect, we assume that the unobserved effects are not correlated with observed explanatory variables and therefore $c_{i}$ is treated as a random error, giving rise to a composite error $\left(c_{i}+u_{i t}\right)$. Whether $c_{i}$ is correlated with the observed explanatory variables is the criteria for choosing between a random effects and a fixed effects model. We use the Hausman test (Hausman, 1978) to decide which estimator is more efficient, and this is the result we report. This test compares the results of the fixed and random effects models. A significant Hausman test statistic implies that the unobserved heterogeneity cannot be considered as random and hence we use the fixed effects model. We show this test statistics in the results.

\subsubsection{Child Nutritional Indicators}

Undernutrition is mainly the outcome of insufficient food intake and repeated infectious diseases. Commonly used indicators for measuring undernutrition in children are stunting, wasting, underweight and micronutrient deficiency (Black et al., 2008). In this study, we analyze the effect of nutrition transition on both the underweight and stunting indicators. A stunted child has a low height for their age, reflecting chronic hunger, while a wasted child has a low weight for their height, reflecting acute weight loss (Black et al., 2008; UNICEF, 1998). Underweight, which refers to a low weight-for-age, is used as a summary indicator which can result due to a child being stunted or wasted. These indicators are usually determined with the help of Z-scores, depicting minus two standard deviations from the median of a reference population (WHO, 2006). Undernutrition in children increases the risk of mortality. In fact, each of these anthropometric indicators is responsible for at least $14.5 \%$ of deaths of children below five years 
globally (Black et al., 2008). In addition, undernutrition leads to the weakening of the immune system, lifetime disabilities and poor growth and cognition development (UNICEF, 1998), with negative consequences in life. Reducing children undernutrition comes with many desirable effects even beyond the individual or household level. For instance, there is evidence that improvements in early childhood nutrition have an effect on economic growth (Hoddinott et al., 2008).

In addition to undernutrition, overweight and obesity in children is the other aspect of child malnutrition (Black et al., 2013). A child is considered overweight if their weight for height is greater than two standard deviations of the median of the reference population based on WHO's new child growth standards (WHO, 2006). While rapid weight gain in the first 1000 days is considered beneficial to child health, there is evidence that weight-gained later on in children leads to a high adult fat mass (Black et al., 2013). This weight gain confers a greater risk for adult obesity and non-communicable diseases, especially for children who experienced undernutrition in early life (Victora et al., 2008).

Among the current global efforts to tackle child undernutrition is the Millennium Development Goals (MDG), with the first goal being "to halve, between 1990 and 2015, the proportion of people who suffer from hunger" (UN Millennium, 2005). For children, underweight is the official indicator for tracking progress under MDG1 (UNSCN, 2012). Current initiatives being formulated, such as World Health Assembly (WHO, 2012) and the Zero Hunger Challenge have targets to reduce childhood overweight and obesity, in addition to those directed at undernutrition.

\subsubsection{Indicators of the Nutrition Transition}

Nutrition transition is characterized by two components: a rapid change in dietary habits towards more energy-dense, processed foods, and a reduction in physical activity leading to more sedentary lifestyles (Popkin \& Ng 2007). If data were available on any of these two components, we could use it to measure nutrition transition. Such data is not available however. Instead, we could use data on consumption of certain foods or nutrients associated with the nutrition transition as a proxy for it. Fats, sugar or caloric sweeteners are an example of foods and nutrients associated with the nutrition transition. Though there has been the observation that diets have become more and more sweet (Popkin \& Ng, 2007), data on overall sugar consumption is 
not available. We argue that fat consumption would be suitable to proxy nutrition transition. This is because a common element of the dietary transformation in developing countries, be it towards increased consumption of animal source foods, or towards increased consumption of processed and convenience foods, is that it increases the supply of fats in diets (Pingali, 2007); (Popkin et $a l ., 2012)$. Research shows that consumers have been increasingly getting their energy from fats as the importance of carbohydrates as a source of energy falls (Popkin \& Ng, 2007). We argue therefore that fat consumption would be a good proxy of the nutrition transition. Fortunately, data on fat consumption is available for many countries. In this study, we use this data on fat consumption as one indicator of the nutrition transition.

In addition to fat consumption, we use two other indicators, whose data are available, to proxy nutrition transition. These are share of modern retail in grocery sales and prevalence of women overweight. The term supermarket as used in literature refers to several types of chain stores that include supermarkets, hypermarkets, and convenience and neighborhood stores (Reardon \& Gulati, 2008), which is essentially modern retail. Hence the two terms may be taken to mean the same thing. Supermarkets have spread so rapidly in developing countries that the term "supermarket revolution" has been coined (Reardon et al., 2003). Several demand-side factors such as liberalization of foreign direct investment (FDI) rules, rapid urbanization, and a growing middle class attracted global supermarkets to locate in developing countries (Hawkes, 2008). In some of the developing countries where there are no global chains, there are domestic chains that have usually adopted the look and functioning like that of global chains (Popkin et al., 2012). How would spread of supermarkets fuel the nutrition transition and hence be a good proxy for it? Literature shows that highly processed foods and drinks are not only readily available in emerging supermarkets (Pingali, 2007), but they also occupy large shelf-spaces and are targets of various promoting strategies (Hawkes, 2008). Some of these strategies are directed specifically at children (Bragg et al., 2012). These strategies have largely been effective, and supermarkets are hypothesized to be major driving forces of shifts in food expenditure and consumption behavior (Hawkes et al., 2009; Popkin, 2006; Popkin et al., 2012). Empirical evidence shows that buying in supermarkets increases the consumption of processed foods (Asfaw, 2008; Rischke et al., 2014). We therefore argue that the size of the modern retail sector in a country can be taken as a reflection of the level of the nutrition transition. Hence we use the share of modern retail in grocery sales as the second proxy of the nutrition transition. 
Finally, we capture nutrition transition with one of its outcomes: prevalence of women overweight. Dietary change that is associated with the nutrition transition is one hypothesized cause of adult overweight and obesity in developing countries (Hawkes et al., 2009). Rigorous empirical research on this topic is rare, but there is limited evidence that consumption of processed foods, a characteristic of the nutrition transition, has a causal effect on overweight/obesity in adults in developing countries (Asfaw, 2008). Low physical activity and increased sedentary behavior, the other component of the nutrition transition, have been found to have a positive effect on body mass index (BMI) of adults and their probability of being overweight (Prentice \& Pau, 2000; Roemling \& Qaim, 2012; Simon et al., 2014; Strong et al., 2005; WHO, 2004). Therefore, the two components of the nutrition transition are associated with increased probability of overweight for adults. We therefore argue that prevalence of adult overweight in a country is a reflection of the nutrition transition and would be a good indicator of the nutrition transition. Most available data on overweight and obesity in developing countries is for women of child-bearing age, which we use as the last nutrition transition indicator.

\subsubsection{Control Variables}

We use two main control variables that have been found to have an influence on child malnutrition; economic growth and female education. Evidence on the influence of economic growth on child nutritional outcomes has been mixed, with some studies finding a significant negative relationship of economic growth and undernutrition (Heady, 2013; Smith \& Haddad, 2002) and others finding almost null associations (Vollmer et al., 2014). Most of the studies that found significant effects estimated cross-country regressions like we do in this study. While we expect a negative association between economic growth and undernutrition, a positive relation is the more likely outcome for economic growth and child overweight. We capture economic growth using GDP per capita.

Our other main control variable is maternal education. Maternal education affects child malnutrition by influencing how children are cared for. Several studies have shown that child undernutrition is affected negatively by formal maternal education (Aslam \& Kingdon, 2012; Desai \& Alva, 1998; Semba et al., 2008) as well as female literacy (Gokhale et al., 2004; Heaton \& Forste, 2003; Smith \& Haddad, 1999). We use female literacy to capture maternal education in this study. 
In addition to economic growth and maternal education, we control for other factors such as the prevalence of undernourishment and proportion with improved sanitation. One of the underlying determinants of child undernutrition is household food insecurity, and significant effects have been shown (Ali et al., 2013; Psaki et al., 2012). To capture food insecurity status, we use the undernourishment indicator, which refers to the proportion of those who are below minimum level of dietary energy requirement as measured by Food and Agriculture Organization (FAO). Though there is criticism on how this indicator is calculated (de Haen et al., 2011; Klasen, 2008), small effects on child undernutrition have been observed (Klasen, 2008). The other additional control, improved sanitation, has been found to have a positive effect on child undernutrition (Fink et al., 2011; Heaton \& Forste, 2003; Spears, 2013).

In the child overweight models, we additionally include urbanization as a control variable so as to capture rural-urban differences that may influence probability of overweight. Literature shows that there is more likelihood for overweight in urban areas due to consumption of more animal-source foods, more processed foods and engaging in less physical activity (Popkin \& Gordon-Larsen, 2004). This may not just be applicable to adults but also to children. In addition, there is evidence that urban mothers do less breastfeeding, resulting to more bottle feeding, with increased risks of overweight for children (Savage et al., 2007).

In the full-control models where we use share of modern retail in grocery sales as an indicator of the nutrition transition, we further control for country openness, measured as total of exports and imports as a proportion of GDP. This is a commonly used measure of country openness (Liargovas \& Skandalis, 2012). We would expect country openness to be strongly correlated with share of modern retail in grocery sales through its effects on inflows of FDI. In fact, it has been observed that liberalization of FDI is one aspect of globalization that is fueling the spread of supermarkets (Hawkes et al., 2009). Inflows of FDI may have effects on child malnutrition as well, such that not controlling for country openness would likely bias the results.

\subsubsection{Data Sources}

We are using three outcome variables: prevalence of child overweight, underweight and stunting for children below five years at country level. Prevalence of underweight and stunting are sourced from Demographic and Health Surveys (DHS) (ICF, 2012). Data on prevalence of child overweight is available in the World Development Indicators (WB, 2014). 
The treatment variable is nutrition transition, proxied in this case by three indicators: fat consumption, share of modern retail in grocery sales, and prevalence of women overweight. Data on fat consumption comes from food balance sheets available from FAO (FAO, 2014). In compiling the food balance sheets, production, trade, stock changes, non-food uses, and extrahousehold waste are put into consideration (de Haen et al., 2011). From all foods available for consumption in these balance sheets, we aggregate the total amount of fat which is in grams per capita per day. The data is available for many countries from as early as 1961 to 2009.

Data on share of modern retail in grocery sales comes from Planet Retail (PlanetRetail, 2013b). Planet Retail is a leading retail data services firm in the world, tracking leading retailers at a national level in more than 200 countries (Reardon et al., 2012). Though this list of leading retailers may not include several important local chains in a country for some cases, the data on market share growth can be taken to represent the general picture of the importance of modern retail in these countries (Reardon et al., 2012). In the Planet Retail dataset, the share of modern retail in grocery sales refers to the total grocery sales by modern retail as a percentage of total market spending by consumers on grocery for a certain country and year (PlanetRetail, 2013b). Planet Retail defines modern grocery retailers as largely multiple and chain stores such as hypermarkets and supermarkets, but it also includes other smaller formats such as neighborhood stores, discount stores and cash \& carries/warehouse clubs. In this dataset, total grocery comprises food, drinks, tobacco, household \& pet care, and health \& beauty products. This data is available for several countries from as early as 1994 to present.

Data on prevalence of women overweight is from DHS (ICF, 2012). Prevalence of women overweight refers to the proportion of women who are either overweight or obese. An adult is classified as either overweight or obese if their BMI, defined as weight in kilograms divided by squared height in meters, is equal to or greater than $25 \mathrm{~kg} / \mathrm{m}^{2}$ (WHO, 2000). In DHS, the target is usually women of child bearing age (between 15 to 49 years) though in a few of these surveys, the age range deviated from the typical (Vollmer et al., 2014). DHS data is representative at the country level and it follows a multiple-stage cluster design.

We are using two main control variables. We capture economic growth using GDP per capita expressed in 2005 dollars and adjusted for purchasing power parity exchange rates, which is available from World Development Indicators (WDI) (WB, 2014). Data on female literacy, which we use to capture maternal education, is available in DHS, and it reflects the proportion of 
females, mainly between 15-49 years, who can read part of a sentence (ICF, 2012). Missing data on female literacy is filled mainly from WDI. In WDI, female literacy refers to the proportion of women 15 years and above who can read and write a short, simple statement with understanding (WB, 2014).

Other control variables we use are proportion undernourished, improved sanitation, country openness, and urbanization. Data on proportion undernourished is available in the WDI (WB, 2014). Data on improved sanitation comes also from WDI, and it refers to the percentage of the population with adequate access to excreta disposal facilities such as protected pit latrines and flush toilets (WB, 2014). Data on country openness as well as the rate of urbanization come from WDI. In this case, urbanization refers to "the percentage of a country's population living in metropolitan areas that in 2000 had a population of more than one million people" (WB, 2014).

\subsubsection{Sample Size and Handling of Missing Data}

We merge country level data from DHS, WDI, FAOSTAT and Planet Retail for this analysis. The sample size is driven mainly by the undernutrition indicators that are sourced from DHS. Though DHS has collected this data for more than 82 countries (Vollmer et al., 2014), the prevalence rates are not available for download from the DHS STATcompiler for all countries. We drop all countries for which we have one data point (one DHS survey year) since our aim is to use panel econometric estimations. For years that we have data for most other key variables and not undernutrition indicators, we result to WDI to fill such gaps; WDI has data on child underweight and stunting. We fill these gaps with WDI for similar years, or when such is not available, with adjacent two years on both sides but not beyond. For instance, if we are missing stunting rate for a certain country for the year 2000, we take the stunting figure for the same year from WDI, and if this is not available, we check for the years 1998, 1999, 2001 or 2002, and we take the closest available figure. In total, we have a sample of 109 observations in 41 countries, for the years 1996 to 2012 .

We also fill missing years for other key variables as well. For prevalence of women overweight, we fill missing years with data from WDI, mostly for the same years, or the closest years from the adjacent two years on both sides. For the prevalence of child overweight, which comes from WDI, we fill missing years with near ones from the same dataset, but also ensuring that we are not going beyond two adjacent years on both sides. Female literacy data comes from 
DHS, but we also had missing years. We fill mainly from WDI using as close years as possible. We also get a few data years from DHS comparative or country reports (ICF, 2014), and in very few cases country statistics from index mundi (Index Mundi, 2014) which are based on data from United Nations Educational Scientific and Cultural Organization (UNESCO).

In addition to the above cases, data for some variables are missing some figures for recent years for which we have data on child undernourishment indicators. For instance, fat consumption data is not available for years beyond 2009. To fill for the consecutive three years (2010-2012), we predict using the average annual increment rate based on the last 10 years (2000 to 2009). Undernourishment and improved sanitation variables are missing data for the year 2012, and we use the 2011 figures. We still have missing years for some of the variables in particular countries. Since missing data on any variable means we cannot use that country year in the estimation, most of our model results are based on samples sizes below 109.

\subsection{Results}

Descriptive results show that stunting is a problem of higher magnitude as opposed to underweight, which is in agreement with literature. The overall mean for stunting is $34 \%$, as compared to $16.1 \%$ for underweight. Trends for these two indicators show that child undernutrition has decreased with time (Figures A4.1and A4.2 in appendix A4). The overall mean for child overweight is $6.6 \%$. Unlike the undernutrition indicators, child overweight is increasing with time (Figure A4.3 in appendix A4).

In challenging the notion that the nutrition transition would affect child weight and not growth, we present the results of our estimation in two subsections. First, we show the effect of the nutrition transition on child weight, that is, child overweight and underweight. Though this effect has not been analyzed before, it is largely expected considering the large body of hypothesis and few empirical evidence on the effect of the nutrition transition on adult weight. In the second subsection, we show the effect of the nutrition transition on stunting, a relation that is not even been mentioned in literature.

\subsubsection{Effect of the Nutrition Transition on Child Weight}

We start by examining the association between the nutrition transition and child weight without controlling for other factors. We therefore regress both child overweight and underweight on the 
nutrition transition indicators, estimating either a fixed or random effects regression, whichever is suggested by the Hausman test. We find a mainly positive association between the nutrition transition indicators and child overweight (Table 4.1). Two of the nutrition transition indicators, fat consumption and women overweight, are associated positively and significantly with child overweight.

Table 4.1. Association between the nutrition transition, child overweight and underweight

\begin{tabular}{|c|c|c|c|c|c|c|}
\hline Explanatory variables & \multicolumn{3}{|c|}{ Child overweight \% } & \multicolumn{3}{|c|}{ Underweight \% } \\
\hline Model specification & $\mathrm{RE}$ & $\mathrm{RE}$ & $\mathrm{RE}$ & $\mathrm{RE}$ & RE & $\mathrm{RE}$ \\
\hline Fat consumption & $0.093^{* * *}$ & & & $-0.324^{* * *}$ & & \\
\hline & $(0.03)$ & & & $(0.05)$ & & \\
\hline Share of modern & & -0.238 & & & $-1.816^{* * *}$ & \\
\hline & & $(0.24)$ & & & $(0.24)$ & \\
\hline Women overweight & & & $0.102^{* * *}$ & & & $-0.477^{* * *}$ \\
\hline & & & $(0.02)$ & & & $(0.05)$ \\
\hline Constant & 1.805 & $7.351^{* * *}$ & $3.241^{* * * *}$ & $33.608^{* * *}$ & $14.011^{* * *}$ & $30.637^{* * * *}$ \\
\hline & $(1.69)$ & $(0.93)$ & $(0.78)$ & $(3.13)$ & $(1.48)$ & $(1.72)$ \\
\hline Observations & 101 & 69 & 82 & 109 & 76 & 88 \\
\hline Chi-squared & $9.794^{* * *}$ & 1.018 & $17.810^{* * *}$ & $37.284^{* * *}$ & $56.965^{* * *}$ & $88.000^{* * *}$ \\
\hline Hausman test statistic & 0.01 & 0.08 & 0.37 & 0.31 & 0.03 & 0.00 \\
\hline
\end{tabular}

However, the share of grocery market by modern retail has a negative, but insignificant association. For underweight, we find that, irrespective of the nutrition indicator used, nutrition transition has is negatively associated with the prevalence of underweight significantly.

To examine causal effects, we estimate equation (4.1) while controlling for confounding factors, both for child overweight and underweight. We first control for GDP per capita and female literacy only, in a shorter model, before including other controls in a longer model. In both cases, we test whether the results are robust to controlling for period effects by adding 16 year dummies to the regressions. The results we report are for models without year dummies, but we indicate whether the coefficient for the particular nutrition transition indicator is significant with a "Yes" or a "No", in a similar model with year dummies included. We also add trade as a 
percentage of GDP in the models with share of modern retail in grocery sales as discussed earlier.

Table 4.2 shows the results for child overweight. The results are not consistent. When we control for only GDP per capita and female literacy, we only find one indicator of the nutrition transition, women overweight, having the expected significant and positive effect on child overweight. This effect is robust to controlling for period effects and adding more controls, in this case the prevalence of undernourishment and urbanization. The coefficient for fat consumption is positive but insignificant when we include only our main controls. With more controls in the model, this coefficient turns negative though it is still insignificant. On the other hand, the share modern retail in grocery sales has a significant negative effect on child overweight when controlling for GDP per capita and female literacy. This result remains even when we control for period effects. With more controls, the coefficient for share of modern retail in grocery sales remains negative but it is no longer significant. GDP per capita has a positive effect on child overweight in some of the models, but other controls remain insignificant. 
Table 4.2. Effect of the nutrition transition on child overweight

\begin{tabular}{|c|c|c|c|c|c|c|}
\hline Explanatory variables & & & Child & erweight $\%$ & & \\
\hline Model Specification & $\mathrm{RE}$ & $\mathrm{RE}$ & $\mathrm{RE}$ & $\mathrm{RE}$ & $\mathrm{RE}$ & RE \\
\hline Fat consumption & 0.028 & -0.023 & & & & \\
\hline & $(0.04)$ & $(0.04)$ & & & & \\
\hline Share of modern & & & $-0.613^{* *}$ & -0.150 & & \\
\hline & & & $(0.25)$ & $(0.28)$ & & \\
\hline Women overweight & & & & & $0.132^{* * *}$ & $0.142^{* * * *}$ \\
\hline & & & & & $(0.04)$ & $(0.04)$ \\
\hline GDP per capita, PPP & 1.560 & $4.302^{* * * *}$ & $3.375^{* * *}$ & $4.981^{* * *}$ & -0.817 & 1.183 \\
\hline & $(1.18)$ & $(1.41)$ & $(1.21)$ & $(1.58)$ & $(0.91)$ & $(1.63)$ \\
\hline Female literacy $\%$ & 0.012 & -0.047 & 0.027 & -0.051 & -0.004 & -0.025 \\
\hline & $(0.03)$ & $(0.03)$ & $(0.05)$ & $(0.05)$ & $(0.02)$ & $(0.03)$ \\
\hline Undernourished \% & & 0.024 & & 0.015 & & 0.037 \\
\hline & & $(0.05)$ & & $(0.07)$ & & $(0.05)$ \\
\hline Urbanization $\%$ & & -0.070 & & -0.156 & & -0.142 \\
\hline & & $(0.09)$ & & $(0.11)$ & & $(0.09)$ \\
\hline Trade ( $\%$ of GDP) & & & & $\begin{array}{l}-0.011 \\
(0.02)\end{array}$ & & \\
\hline Constant & $\begin{array}{l}-7.842 \\
(6.79)\end{array}$ & $\begin{array}{c}-22.307^{* * *} \\
(9.03)\end{array}$ & $\begin{array}{c}-21.277^{* *} \\
(8.39)\end{array}$ & $\begin{array}{c}-26.008^{* * *} \\
(11.65)\end{array}$ & $\begin{array}{l}8.909 \\
(5.78)\end{array}$ & $\begin{array}{l}-4.006 \\
(10.80)\end{array}$ \\
\hline $\begin{array}{l}\text { Significant effect } \\
\text { with year dummies }\end{array}$ & No & No & Yes & No & Yes & Yes \\
\hline Observations & 95 & 77 & 69 & 60 & 78 & 64 \\
\hline Chi-squared & $9.813^{* * *}$ & $15.337^{* * *}$ & $13.584^{* * *}$ & $13.599^{* *}$ & $18.347^{* * *}$ & $19.985^{* * *}$ \\
\hline Hausman test statistic & 1.05 & 6.21 & 6.05 & 8.94 & 3.49 & 3.54 \\
\hline
\end{tabular}

Results for child underweight are much more consistent (Table 4.3). Two indicators of the nutrition transition, fat consumption and share of modern retail in grocery sales, have a negative and significant effect on underweight. 
Table 4.3. Effect of the nutrition transition on underweight

\begin{tabular}{|c|c|c|c|c|c|c|}
\hline Explanatory variables & & & Under & ight $\%$ & & \\
\hline Model Specification & $\mathrm{RE}$ & $\mathrm{RE}$ & $\mathrm{RE}$ & $\mathrm{RE}$ & FE & FE \\
\hline Fat consumption & $-0.168^{* * *}$ & $-0.156^{* *}$ & & & & \\
\hline & $(0.06)$ & $(0.07)$ & & & & \\
\hline Share of modern retail & & & $-1.396^{* * * *}$ & $-1.380^{* * *}$ & & \\
\hline & & & $(0.25)$ & $(0.26)$ & & \\
\hline Women overweight $\%$ & & & & & $\begin{array}{l}-0.139 \\
(0.13)\end{array}$ & $\begin{array}{l}-0.128 \\
(0.13)\end{array}$ \\
\hline GDP per capita, PPP & $-4.219^{* * *}$ & $-4.032^{*}$ & $-4.469^{* * * *}$ & -3.457 & $-6.551^{* *}$ & $-6.071^{*}$ \\
\hline & $(1.74)$ & $(2.22)$ & $(1.52)$ & (2.13) & $(2.73)$ & $(3.40)$ \\
\hline Female literacy $\%$ & $-0.186^{* * * *}$ & $-0.165^{* * *}$ & -0.043 & -0.035 & $-0.257^{* * * *}$ & $-0.253^{* * *}$ \\
\hline & $(0.05)$ & $(0.06)$ & $(0.07)$ & $(0.07)$ & $(0.08)$ & $(0.11)$ \\
\hline Undernourished \% & & -0.002 & & -0.032 & & 0.108 \\
\hline & & $(0.09)$ & & $(0.09)$ & & $(0.12)$ \\
\hline Improved sanitation & & -0.038 & & -0.069 & & 0.054 \\
\hline & & $(0.07)$ & & $(0.07)$ & & $(0.20)$ \\
\hline Trade (\% of GDP) & & & & $\begin{array}{l}-0.000 \\
(0.02)\end{array}$ & & \\
\hline Constant & $\begin{array}{c}71.078^{* * *} \\
(10.28)\end{array}$ & $\begin{array}{c}69.448^{* * * *} \\
(14.70)\end{array}$ & $\begin{array}{c}52.634^{* * *} \\
(10.55)\end{array}$ & $\begin{array}{c}48.506^{* * *} \\
(14.79)\end{array}$ & $\begin{array}{c}88.246^{* * *} \\
(16.79)\end{array}$ & $\begin{array}{c}79.155^{* * *} \\
(22.52)\end{array}$ \\
\hline $\begin{array}{l}\text { Significant effect with } \\
\text { year dummies }\end{array}$ & Yes & No & Yes & Yes & Yes & Yes \\
\hline Observations & 103 & 101 & 76 & 76 & 84 & 82 \\
\hline F statistic & & & & & $22.099^{* * * *}$ & $12.434^{* * *}$ \\
\hline Chi-squared & $94.359^{* * * *}$ & $88.838^{* * *}$ & $79.190^{* * * *}$ & $77.757^{* * * *}$ & & \\
\hline Hausman test statistic & 5.32 & 7.25 & 0.31 & 2.21 & $19.36^{* * *}$ & $26.85^{* * * *}$ \\
\hline
\end{tabular}

This effect is mainly robust to controlling for year dummies. The results are also robust to including additional controls, namely undernourishment and improved sanitation. The coefficient for women overweight, though negative, is insignificant in both the short and the long models. However, when we control for period effects by adding year dummies, the coefficients turn significant with the sign remaining negative in both models. In most of the cases, the coefficients for GDP per capita and female literacy are negative and significant negative as expected. These results show that nutrition transition reduces child underweight. 


\subsubsection{Effect of the Nutrition Transition on Stunting}

So far, our results show that the nutrition transition has an effect on child weight. We do not do not find a consistent result on the effect of the nutrition transition on child overweight, but there is a robust negative effect on underweight. In this subsection, we examine whether the nutrition transition has any effect on stunting. Table 4.4 shows the results of associations between our indicators of the nutrition transition and stunting. We see significant negative associations with all cases, an indicator that the nutrition transition might be reducing stunting.

Table 4.4. Association between the nutrition transition and stunting

\begin{tabular}{|c|c|c|c|}
\hline Explanatory variables & & Stunting $(\%$ & \\
\hline Model specification & RE & $\mathrm{RE}$ & $\mathrm{FE}$ \\
\hline Fat consumption (g/capita/day) & $\begin{array}{c}-0.412^{* * *} \\
(0.06)\end{array}$ & & \\
\hline $\begin{array}{l}\text { Share of modern retail in grocery sales } \\
(\log )\end{array}$ & & $\begin{array}{c}-1.671^{* * *} \\
(0.43)\end{array}$ & \\
\hline Women overweight $\%$ & & & $\begin{array}{c}-0.876^{\text {**** }} \\
(0.12)\end{array}$ \\
\hline Constant & $\begin{array}{l}55.599^{* * *} \\
(3.31)\end{array}$ & $\begin{array}{l}32.299^{* * *} \\
(2.11)\end{array}$ & $\begin{array}{l}59.465^{* * *} \\
(3.40)\end{array}$ \\
\hline Observations & 109 & 76 & 88 \\
\hline F statistic & & & $51.700^{* * *}$ \\
\hline Chi-squared & $50.426^{* * *}$ & $14.761^{* * *}$ & \\
\hline Hausman test statistic & 0.86 & 0.00 & $8.80^{* * *}$ \\
\hline
\end{tabular}

To analyze the effect of the nutrition transition on stunting, we estimate equation (4.1) using the same controls like the ones we used in the underweight regressions (Table 4.3). Controlling for GDP per capita and female literacy only, we find that all indicators of the nutrition transition have a negative and significant effect on stunting (Table 4.5). In most cases, the result is robust to controlling for period effects. We find the same negative and significant effects when we add more controls in the model, which are also robust to including period effects in the estimation. This is a clear and consistent result that the nutrition transition reduces child stunting. 
Table 4.5. Effect of the nutrition transition on stunting

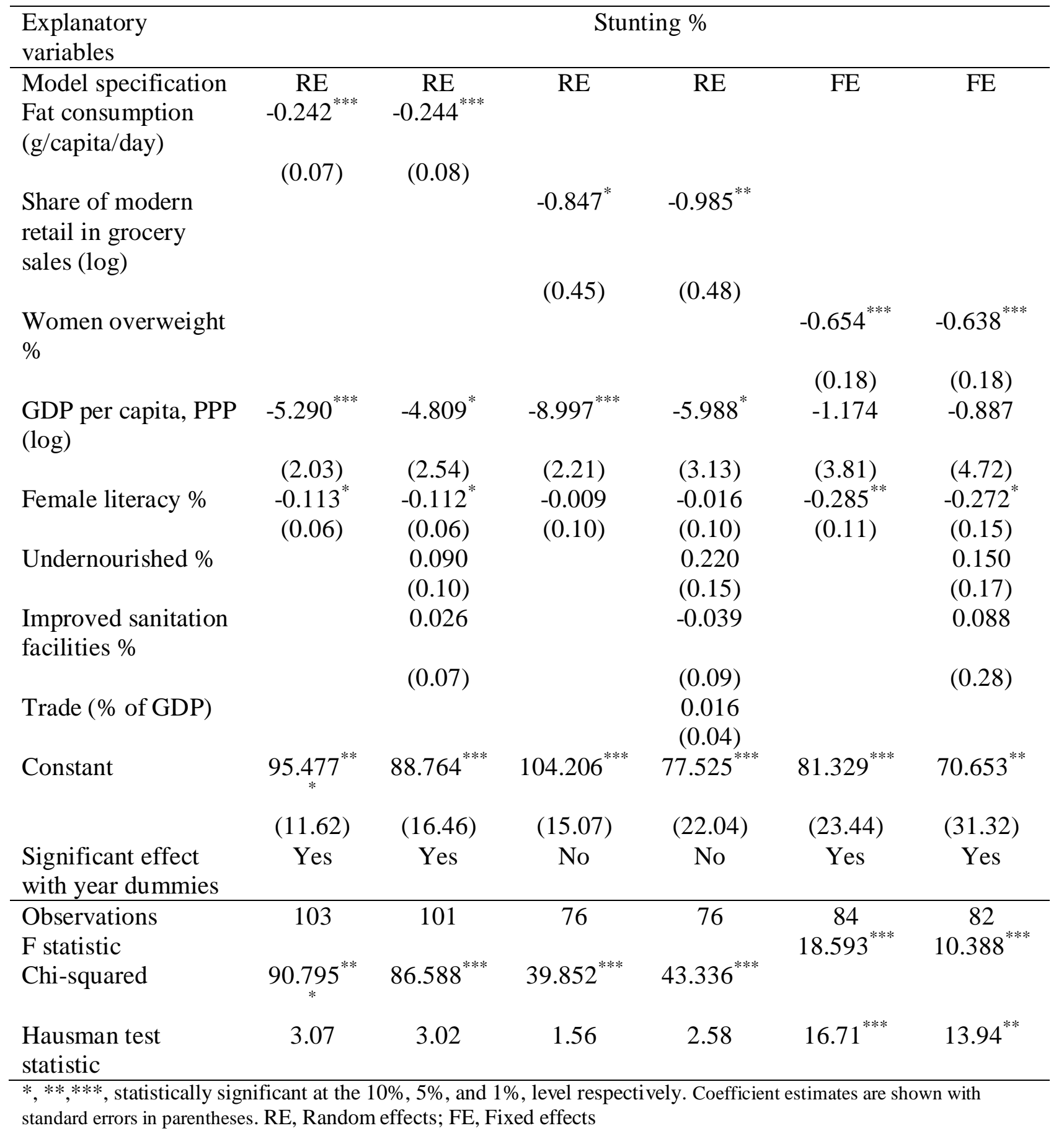

\subsection{Conclusion}

The results on the effect of the nutrition transition on child overweight are not clear and they depend on the indicator used. Fat consumption does not have a significant effect while share of modern retail in grocery sales has a negative and significant effect. On the other hand, 
prevalence of women overweight has a strong and robust positive effect on child overweight. Contrary to this, we get clear and consistent results showing that the nutrition transition reduces underweight. Two indicators of the nutrition transition, fat consumption and share of modern retail in grocery sales, have a negative and significant effect on underweight when we control for GDP per capita and female literacy. This result is in most cases robust to including period effects and adding more controls in the model. The other indicator, prevalence of women overweight, has a negative and significant effect when we control for year dummies. These results show that the nutrition transition has an effect on child weight. The results on the effect of the nutrition transition on stunting are clear and consistent. All our nutrition transition indicators have a significant negative effect on stunting, and this effect is robust to adding more controls in our models. In addition, the result is robust to inclusion of year dummies in most of the models. This is a clear result that the nutrition transition reduces stunting.

By reducing underweight, these results support the first part of the notion that the nutrition transition will have an effect on child weight. However, our results do not support the other part of this notion, that the nutrition transition does not have an effect on child growth. Contrary to this notion, the results are showing that nutrition transition has a desirable effect on child growth. We have discussed possible pathways on how the nutrition transition can affect child growth. To start with, fat is an essential nutrient for optimal child growth. In addition to supplying essential fatty acids, it is a source of energy and its consumption allows absorption of fat-soluble vitamins. For children from poor settings who may not yet be meeting their fat requirements, increased fat consumption would largely have such beneficial outcomes. It is also possible that increase in the share of modern retail in grocery sales, which comes with increased supply of consumption of processed foods, would come with beneficial effects on child growth. Such diets are likely to come with increased supply of micronutrients, which is more likely for children from poor back grounds with a low dietary diversity. Because of a positive association of women overweight and better socioeconomic status such as household assets, it is possible that children living in settings characterized by high women overweight receive better care and feeding practices.

Our indicators of the nutrition transition may be challenged, but we have argued why we think they are good proxies. Our sample sizes are also relatively small, largely due to unavailability of large datasets. But even with this limited data, we have done rigorous analysis to find results that partly support earlier views, and in addition challenge the view that the effects 
of the nutrition transition in developing countries will mainly be undesirable. We see desirable effects towards reduction of stunting. The nutrition transition is evolving, the rates of children undernutrition are falling, and the prevalence of child overweight increasing. In addition, more data will become available in future. More research will be needed to explore these relations further, especially with larger datasets and if possible with additional indicators of the nutrition transition.

\section{Appendix A4}

Figure A4.1. Prevalence of stunting overtime

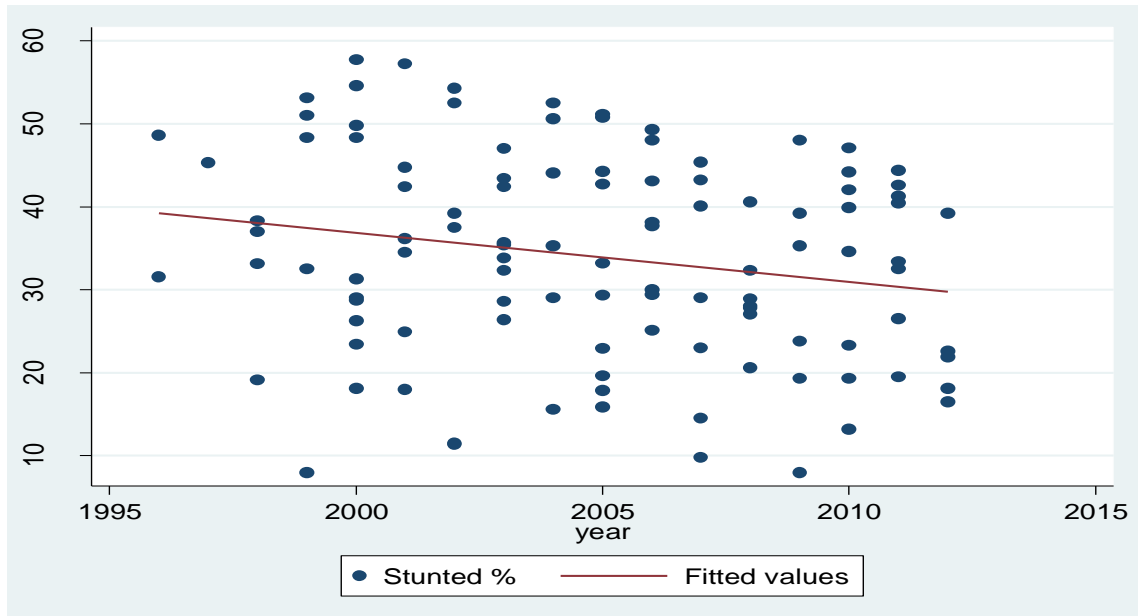

Figure A4.2. Prevalence of underweight over time

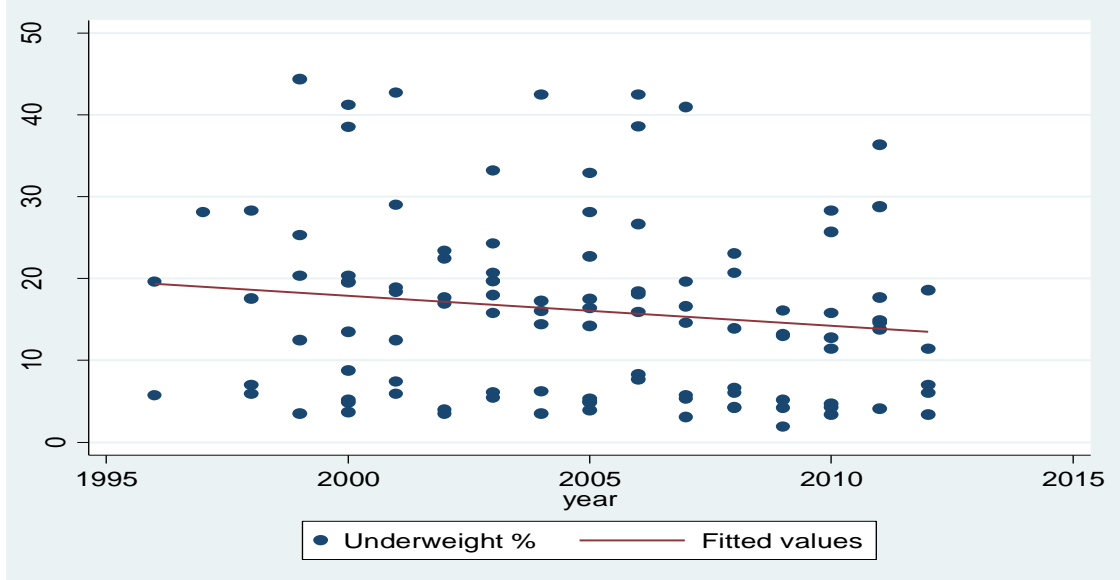


Figure A4.3. Prevalence of child overweight overtime

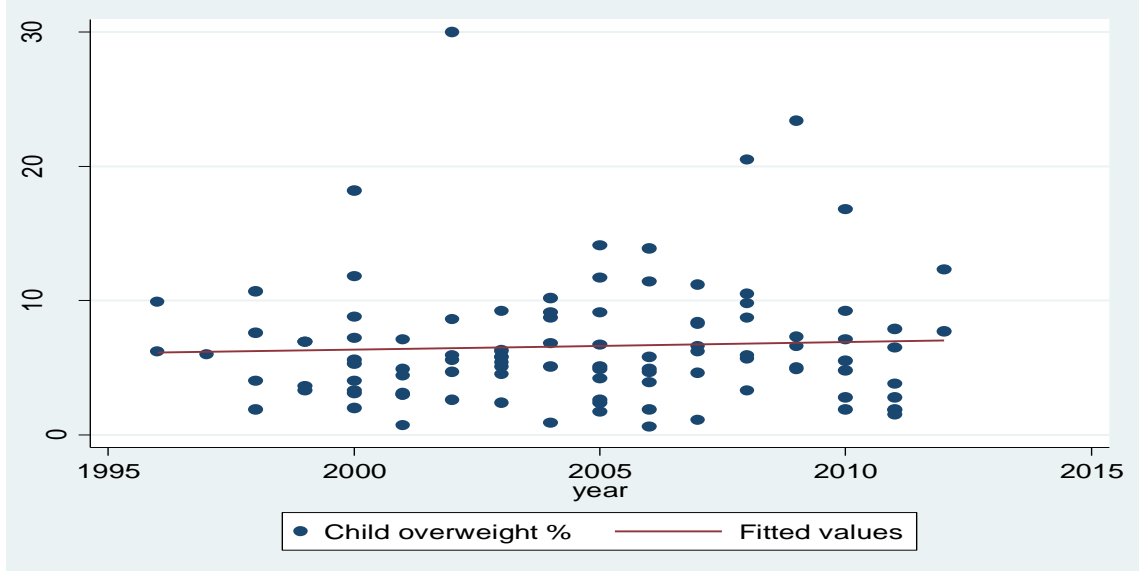




\section{General Conclusion}

\subsection{Main Findings}

Many developing countries are currently undergoing a rapid nutrition transition. This transition is characterized by changes in dietary habits towards more energy-dense, often processed foods with high fat and sugar contents, and more sedentary lifestyles. As a result, overweight and obesity rates have increased. In 2008, 34\% of all adults were overweight or obese. For children below five years of age, an estimated $6.6 \%$ were either overweight or obese in 2011. At the same time, undernutrition rates are still high. Globally, about $26 \%$ of all children under five were stunted, while $16 \%$ were underweight in 2011. One important driver of the nutrition transition is globalizing food systems. The food retail sector is becoming more and more modernized, and supermarkets are playing an increasing role. Some developing countries have witnessed a 'supermarket revolution', depicting a rapid spread of supermarkets within a short period of time. The retail format has an influence on the types of products offered, as well as on sales prices and shopping atmosphere, which may affect consumer food choices.

Despite many hypotheses, the impact of spreading supermarkets on dietary behavior in developing countries has only been analyzed in very few studies. Studies on the impact of spreading supermarkets on nutritional outcomes in developing countries are even rarer. In the first two essays (chapters 2 and 3), this dissertation sought to evaluate the impact of spreading supermarkets on dietary behavior and nutritional outcomes. This analysis relies on a crosssectional data collected in Kenya in 2012, a country that has witnessed a rapid spread of supermarkets recently and more than $25 \%$ of the women are overweight or obese. This study was specifically designed to answer these questions.

In a third essay (chapter 4), we turn the focus to the effect of the nutrition transition on child malnutrition. Due to many hypotheses and few empirical evidence showing that the nutrition transition has an effect on adult weight, it has been taken as a given conclusion that the nutrition transition will increase child weight but not growth, despite there being no empirical evidence on this. In the third essay, we evaluate the impact of the nutrition transition on child malnutrition indicators based on secondary panel data and using cross-country regressions.

Our results based on the primary survey in Kenya show that, first, supermarkets are drivers of the nutrition transition, causing dietary changes among consumers in developing 
countries. In Kenya, supermarkets are causing consumers not only to eat more calories, but also to get a bigger share of their calories from processed foods. An increase in the share of supermarket expenditure by one percentage point increases the share of expenditure on processed foods by 0.38 percentage points. However, our results do not support the expected outcome that supermarkets increase consumption of highly processed foods. In addition, we find that a one percentage point increase in the share of supermarket purchases increases calorie consumption by $0.85 \%$. This would translate to an additional daily consumption of 200 kilocalories for average consumers that currently do not purchase any food in supermarkets, if they were to switch to supermarkets, everything else held constant. This effect is partly driven by lower prices per calorie. Supermarket purchases also increase the dietary diversity of consumers. Second, we find that the direct impact of supermarket purchase on nutritional status depends on age cohorts and their initial nutritional status. Controlling for other factors, buying in a supermarket increases the BMI of adults by $1.7 \mathrm{~kg} / \mathrm{m}^{2}$ and raises the probability of adult overweight or obesity by 13 percentage points. For children and adolescents we do not find a significant impact on overweight. Instead, buying in a supermarket tends to decrease child undernutrition through an increase in HAZ and a reduction in severe stunting. Buying in a supermarket increases HAZ by 0.63 and it decreases the probability of severe stunting by 23 percentage points.

Results from the cross-country regressions show that the nutrition transition has an effect on child weight, as hypothesized. While the effects on child overweight are less clear, the nutrition transition significantly and consistently reduces underweight rates. In contrast to widely held views, we also find clear and consistent evidence that the nutrition transition reduces child stunting. This result is in agreement with the one based on our cross-section data from Kenya; that the nutrition transition has desirables effects in terms of reducing child stunting.

Taken together, these results support some previous hypotheses and notions while challenging others. The expectation in the literature is that the spread of supermarkets in developing countries would increase consumption of processed foods and total calories, and consequently overweight and obesity. Focusing on the first part of this expectation, we have found that indeed, supermarkets increase consumption of processed foods and total calories consumed. We do not find this effect with highly processed foods. Rather, we find that supermarkets increase dietary diversity. On the second part of the hypothesis, our results confirm 
expectations that supermarkets increase BMI and the probability of overweight for adults. This result is not observed for children. Instead, we find that supermarkets have a desirable effect on increasing HAZ and reducing severe stunting. This means that the effect on nutritional status varies by age cohort and initial nutritional status. From our sample in Kenya, we observed relatively high overweight rates among adults, while stunting was a more widespread problem among children and adolescents. Results in the third essay confirm that the nutrition transition indeed affects weight, but only by reducing underweight. The expected result that the nutrition transition would increase child overweight is not consistent.

A widely held view is that the nutrition transition, and the associated spread of supermarkets, would have undesirable effects in developing countries. Undesirable effects have been confirmed, in that supermarket purchase increases adult BMI and the probability of adult overweight. We however find desirable results as well: supermarkets increase dietary diversity (probably through supplying a large number of processed foods) and total calories consumed. For children and adolescents, this leads to a desirable effect, in that supermarkets increase HAZ and reduce stunting. Based on the available literature, this result was not expected. Therefore, simple statements or judgments on whether supermarkets are good or bad for nutrition and health are not justified. The results from the secondary data analyses show that the nutrition transition has positive effects in terms of reducing child stunting. These results challenge the general view that the nutrition transition will only have undesirable health effects in developing countries. Again, we conclude that simplistic statements or judgments about the nutrition transition in developing countries may not be justified.

Our analysis should not be seen as the final judgment about the nutrition transition and supermarkets in developing countries, but only as early evidence. The nutrition transition is evolving, and supermarkets may gradually offer a greater variety of products, including more fresh and healthy foods, or even a larger amount of highly processed foods. Rates of child undernutrition will decrease and childhood obesity may continue to increase, if current global trends are maintained. In addition, more data will become available in future. More research will be needed to confirm these results, especially with larger datasets and possibly in different contexts for comparisons. 


\subsection{Policy and Research Implications}

Our findings lead to several policy recommendations. First and foremost, policy making should be guided by rigorous research. The results in this dissertation are partly challenging widely held notions. Relying on such notions alone, without considering results of rigorous research, may lead to wrong policy decisions. This calls not only for policy makers to proactively work closely with scientists, but for scientists to seek mechanisms that allow their findings to reach policy makers.

The fact that our results show both desirable and undesirable effects of the nutrition transition makes it harder for policy making. Careful balancing would be needed so as to benefit from the desirable aspects of the nutrition transition, while putting mechanisms that mitigate the negative effects. The nutrition transition and the spread of supermarkets may come with other costs and benefits that are not analyzed here, but which may be of interest to policy makers. Such costs and benefits may include supermarket impacts on the rural economy, especially through household income distribution, and employment effects. Other research has shown that smallholder farmers and rural workers can improve their living standards through participating in supermarket supply chains. Despite such benefits, measures should be put in place to mitigate the negative health outcomes of the nutrition transition, especially in terms of rising overweight and obesity rates. These measures can either be directed at the consumer or the retail sector itself.

For consumers, one possible measure is the provision of broader nutrition education and awareness campaigns. Making consumers more nutritionally-aware so as to influence their preferences towards healthier foods is likely to have an effect on the behavior of the retail sector. This is because the retail sector usually does not just drive preferences, but also seeks to conform to existing and changing preferences, especially in the presence of competition. In such a case, a more nutritionally aware consumer base would affect what is stocked and promoted by retailers.

Beyond consumers, it is also possible that policy intervenes directly in the retail sector, for instance through specific regulations for supermarkets and other actors in the food industry. Such measures may include incentives or requirements to stock certain healthy products. As noted earlier, the supermarkets in our study sites did not stock fresh fruits and vegetables, which is unlike major supermarkets in bigger Kenyan cities. One direct policy intervention would be to give incentives to these smaller supermarkets to stock and promote healthier items such as unprocessed grains and fresh fruits and vegetables. Other possible direct interventions include 
stricter rules on labeling of products, or a restriction against stocking or promoting certain products or category of products.

Our results have shown that supermarkets have an influence, which can result in either desirable or undesirable effects on dietary behavior and nutritional outcomes. Results from other studies indicate that the spread of supermarkets in developing countries is continuing. It is therefore important that global, regional or national food and public health policies or programs consider retail sector or supermarkets. An important research question would be how the influence of the retail sector on consumers could be harnessed to bring about desirable changes in nutrition knowledge and dietary habits.

Important research questions still remain to be answered. First, this dissertation is not to be taken as the conclusive judgment on the effect of the nutrition transition or supermarkets but just as early evidence. More research needs to be done in different contexts and with larger datasets to confirm these results. Future research should also explore the exact mechanisms, in addition to price, through which supermarkets affect dietary behavior and nutritional outcomes. Also, there is need for research to determine what is causing childhood overweight in developing countries, as results from this dissertation show that the nutrition transition may not be the main driver. 


\section{Bibliography}

Ali, D., Saha, K.K., Nguyen, P.H., Diressie, M.T., Ruel, M.T., Menon, P., et al. (2013). Household food insecurity is associated with higher child undernutrition in Bangladesh, Ethiopia, and Vietnam, but the effect is not mediated by child dietary diversity. The Journal of Nutrition, 143, 2015-2021.

Asfaw, A. (2008). Does supermarket purchase affect the dietary practices of households? Some empirical evidence from Guatemala. Development Policy Review, 26 (2), 227-243.

Asfaw, A. (2011). Does consumption of processed foods explain disparities in the body weight of individuals? The case of Guatemala. Health Economics, 20, 184-195.

Aslam, M., and Kingdon, G. (2012). Parental education and child health - understanding the pathways of impact in Pakistan. World Development, 40, 2014-2032.

Baker, J.L. , Michaelsen, K.F., Sorensen, T.I. , and Rasmussen, K.M. (2007). High pre-pregnant body mass index is associated with early termination of full and any breastfeeding in Danish women. American Journal of Clinical Nutrition, 86, 404-411.

Biesalski, H.K. (1997). Bioavailability of vitamin A. European Journal of Clinical Nutrition, 51, S71-S75.

Black, R.E., Allen, L.H., Bhutta, Z.A., Caulfield, L.E., de Onis, M., Ezzati, M., et al. (2008). Maternal and child undernutrition: global and regional exposures and health consequences. Lancet, 371, 243-260.

Black, R.E., Victora, C.G., Walker, S.P., Bhutta, Z.A., Christian, P., de Onis, M., et al. (2013). Maternal and child undernutrition and overweight in low-income and middle-income countries. Lancet, 382, 427-451.

Bragg, M. A., Liu, P.J., Roberto, C.A., Sarda, V., Harris, J.L., and Brownell, K.D. (2012). The use of sports references in marketing of food and beverage products in supermarkets. Public Health Nutrition, 16, 738-742.

Brown, K.H., Sanchez-Grinan, M., Perez, F., Peerson, J., Ganoza, L., and Stern, J.S. (1995). Effects of dietary energy density and feeding frequency on total energy intakes of recovering malnourished children. American Journal of Clinical Nutrition, 62, 13-18.

Catalano, P.M., Presley, L., Minium, J., and Hauguel-de, M.S. (2009). Fetuses of obese mothers develop insulin resistance in utero. Diabetes Care, 32, 1076-1080. 
Chandon, P., and Wansink, B. (2012). Does food marketing need to make us fat? A review and solutions. Nutrition Reviews, 70 (10), 571-593.

Cummins, S., Petticrew, M., Higgins, C., Findlay, A., and Sparks, L. (2005). Large scale food retailing as an intervention for diet and health: quasi-experimental evaluation of a natural experiment. Journal of Epidemiology \& Community Health, 59, 1035-1040.

Danesh, N., Dehghan, M., Morrison, K.M., and Fonseka, S. (2011). Parents' perception and attitudes on childhood obesity: A Q-methodology study. Journal of the American Academy of Nurse Practioners, 23, 67-75.

de Haen, H., Klasen, S., and Qaim, M. (2011). What do we really know? Metrics for food insecurity and malnutrition. Food Policy, 36, 760-769.

de Onis, M., Blössner, M., Borghi, E., Morris, R., and Frongillo, E.A. (2004). Methodology for estimating regional and global trends of child malnutrition. International Journal of Epidemiology, 33, 1260-1270.

de Onis, M., Onyango, A.W., Borghi, E., Siyam, A., Nishida, C., and Siekmann, J. (2007). WHO growth reference for school-aged children and adolescents. Bulletin of the World Health Organization, 85, 660-667.

Desai, S., and Alva, S. (1998). Maternal education and child health: is there a strong causal relationship? Demography, 35, 71-81.

Dieffenbach, S., and Stein, A.D. (2012). Stunted child/overweight mother pairs represent a statistical artifact, not a distinct entity. Journal of Nutrition, 42, 771-773.

Doak, C.M., Adair, L.S., Bentley, M., Monteiro, C. , and Popkin, B.M. (2005). The dual burden household and the nutrition transition paradox. International Journal of Obesity, 29, 129136.

Drewnowski, A., Aggarwal, A., Hurvitz, P.M., Monsivais, P., and Moudon, A.V. (2012). Obesity and supermarket access: proximity or price? American Journal of Public Health, 102, e74-e80.

Dube, L., Pingali, P., and Webb, P. (2012). Paths of convergence for agriculture, health, and wealth. Proceedings of the National Academy of Sciences USA, 109, 12294-12301.

EuroFIR. (2008). Report on collection of rules on use of recipe calculation procedures including the use of yield and retention factors for imputing nutrient values for composite foods. Brussels: European Food Information Resource. 
Fall, C. (2011). Evidence for the intra-uterine programming of adiposity in later life. Annals of Humun Biology, 38, 410-428.

FAO. (2010). World Food Dietary Assessment System, Version 2.0. International Network of Food Data Systems of FAO. Rome: Food and Agricultural Organization.

FAO. (2012). West African Food Composition Table. Rome: FAO.

FAO. (2014). FAOSTAT. Rome: Food and Agriculture Organization. Available at < http://faostat3.fao.org/faostat-gateway/go/to/download/C/*/E $>$.

FAO, WHO, and UNU. (2004). Human energy requirements: report of a joint FAO/WHO/UNU Expert Consultation. Rome.

Fink, G., Günther, I., and Hill, K. (2011). The effect of water and sanitation on child health: evidence from the demographic and health surveys 1986-2007. International Journal of Epidemiology, 40, 1196-1204.

Finucane, M.M., Stevens, G.A., Cowan, M. J., Danaei, G., Lin, J.K., Paciorek, C.J., et al. (2011). National, regional, and global trends in body-mass index since 1980: systematic analysis of health examination surveys and epidemiological studies with 960 country-years and 9.1million participants. Lancet, 337, 557-567.

Gidding, S.S., Dennison, B.A., Birch, L.L., Daniels, S.R., Gilman, M.W., Lichtenstein, A.H., et al. (2006). Dietary recommendations for children and adolescents: a guide for practitioners. Pediatrics in Review, 117, 544-549.

Giskes, K., van Lenthe, M., Avendano-Pabon, M., and Brug, J. (2011). A systematic review of environmental factors and obesogenic dietary intakes among adults: are we getting closer to understanding obesogenic environments? Obesity Reviews, 12, e95-e106.

Gokhale, M.K. , Kanade, N., Rao, S. , Kelkar, R.S., Joshi, S.B., and Girigosavi, S.T. (2004). Female literacy: the multifactorial influence on child health in India. Ecology of Food and Nutrition, 43, 257-278.

Grote, V., Theurich, M., and Koletzko, B. (2012). Do complementary feeding practices predict the later risk of obesity? . Current Opinion in Clinical Nutrition and Metabolic Care, 15, 293-297.

Haddad, L. (2013). How should nutrition be positioned in the post-2015 agenda? Food Policy, 43, 341-352.

Hausman, J. A. (1978). Specification tests in econometrics. Econometrica, 46, 1251-1271. 
Hawkes, C. (2008). Dietary implications of supermarket development: a global perspective. Development Policy Review, 26 (6), 657-692.

Hawkes, C., Chopra, M., and Friel, S. (2009). Globalization, trade and the nutrition transition. In Globalization and health: pathways, evidence and policy, edited by R. Labonte, Schrecker, T., Packer, C. and Runnels, V. New York: Routledge.

Heady, D.D. (2013). Developmental drivers of nutritional change: a cross-country analysis. World Development, 42, 76-88.

Heaton, B., and Forste, R. (2003). Rural/urban differences in child growth and survival in Bolivia. Rural Sociology, 68, 410-433.

Hoddinott, J., Maluccio, J.A., Behrman, J.R., Flores, R., and Martorell, R. (2008). Effect of a nutrition intervention during early childhood on economic productivity in Guatemalan adults. Lancet, 371, 411-16.

ICF International. (2012). The DHS program STATcompiler - http://www.statcompiler.com. (accessed December 19 2013).

ICF International. (2014). DHS publications - https://dhsprogram.com/publications/index.cfm (accessed January 15 2014).

Index Mundi. (2014). Country facts - http://www.indexmundi.com/ (accessed January 25 2014).

Jones-Smith, J.C., Gordon-Larsen, P., Siddiqi, A. , and Popkin, B.M. (2012). Is the burden of overweight shifting to the poor across the globe? Time trends among women in 39 lowand middle-income countries (1991-2008). International Journal of Obesity, 36 (8), 1114-1120.

Kanter, R., and Caballero, B. (2012). Global gender disparities in obesity: a review. Advances in Nutrition, 3, 491-498.

Klasen, Stephan. (2008). Poverty, undernutrition, and child mortality: Some inter-regional puzzles and their implications for research and policy. Journal of Economic Inequality, 6, 89-115.

KNBS. (2010a). 2009 Kenya Population and Housing Census. Volume IA: Population Distribution by Administrative Units.: Kenya National Bureau of Statistics.

KNBS. (2010b). Kenya - 2009 Population Census Highlights.: Kenya National Bureau of Statistics. 
KNBS, and ICFMacro. (2010). Kenya demographic and health survey 2008-09. Calverton, Maryland: Kenya National Bureau of Statistics and ICF Macro.

Laraia, B., Siega-Riz, A., Kaufman, J., and Jones, S. (2004). Proximity of supermarkets is positively associated with diet quality index for pregnancy. Preventive Medicine, 39, 869875.

Lear, S.A., Gasevic, D., and Schuurman, N. (2013). Association of supermarket characteristics with the body mass index of their shoppers. Nutrition Journal, 12, 117.

Lee, J., Houser, R.F., and Must, A., Palma de Fulladolsa, P., Bermudez, O.I., . (2012). Socioeconomic disparities and the familial coexistence of child stunting and maternal overweight in Guatemala Economics \& Human Biology, 10, 232-241.

Liargovas, P.G., and Skandalis, K.S. (2012). Foreign Direct Investment and Trade Openness: The Case of Developing Economies. Social Indicators Research, 106, 323-331.

Lutter, C.K., Chaparro, C.M., and Muñoz, S. (2011). Progress towards Millennium Development Goal 1 in Latin America and the Caribbean: the importance of the choice of indicator for undernutrition. Bulletin of the World Health Organanization, 89, 22-30.

Martorell, R., Khan, L.K., and Schroeder, D.G. (1994). Reversibility of stunting: epidemiological findings in children from developing countries. European Journal of Clinical Nutrition, 48, S45-S57.

McGuire, W., Dyson, L., and Renfrew, M. (2010). Maternal obesity: consequences for children, challenges for clinicians and carers. Seminars in Fetal and Neonatal Medicine, 15, 108112.

Mergenthaler, M., Weinberger, K., and Qaim, M. ( 2009). The food system transformation in developing countries: a disaggregate demand analysis for fruits and vegetables in Vietnam. Food Policy, 34, 426-436.

Michimi, A., and Wimberly, M.C. (2010). Associations of supermarket accessibility with obesity and fruit and vegetable consumption in the conterminous United States International Journal of Health Geographics, 9, 49.

Misselhorn, M. (2010). Undernutrition and the Nutrition Transition. Courant Research Center Working Paper No. 35. University of Goettingen. 
Monteiro, C., Betrazzi Levy, R. , Moreira Claro, R., Rugani Ribeiro de Castro, I., and Cannon, G. (2010). Increasing consumption of ultra-processed foods and likely impact on human health: evidence from Brazil. Public Health Nutrition, 14 (1), 5-13.

Monteiro, C., Moura, E., Conde, W., and Popkin, B. (2004). Socieoeconomic status and obesity in adult populations of developing countries: a review. Bulletin of the World Health Organization, 82, 940-946.

Monteiro, C.A., Levy, R.B., Claro, R.M., Castro, I.R.R., and Cannon, G. (2011). Increasing consumption of ultra-processed foods and likely impact on human health: evidence from Brazil. Public Health Nutrition, 14, 5-13.

Moore, L., Diez Roux, A., Nettleton, J., and Jacobs, D. (2008a). Associations of the local food environment with diet quality - a comparison of assessments based on surveys and geographic information systems. American Journal of Epidemiology, 167, 917-924.

Morland, K., Diez, R.A.V., and Wing, S. (2006a). Supermarkets, other food stores, and obesity: the atherosclerosis risk in communities study American Journal of Preventive Medicine, 30, 333-339.

Neven, D., and Reardon, T. (2004). The rise of kenyan supermarkets and the evolution of their horticulture product procurement system. Development Policy Review, 22 (6), 669-699.

Neven, D., Reardon, T., Chege, J., and Wang, H. (2006). Supermarkets and consumers in Africa: the case of Nairobi, Kenya. International Food and Agribusiness Marketing, 18 $((1 / 2)), 103-123$.

Ng, S. W., and Popkin, B. M. (2012). Time use and physical activity: a shift away from movement across the globe. Obesity Reviews, 13, 659-680.

Patterson, E., Warnberg, J., Kearney, J., and Sjostrom, M. (2010). Sources of saturated fat and sucrose in the diets of Swedish children and adolescents in the European Youth Heart Study: strategies for improving intakes. Public Health Nutrition, 13, 1955-1964.

Pearce, J., Hiscock, R., Blakely, T., and Witten, K. (2008). The contextual effects of neighbourhood access to supermarkets and convenience stores on individual fruit and vegetable consumption. Journal of Epidemiology \& Community Health, 63, 198-201.

Pingali, P. (2007). Westernization of Asian diets and the transformation of food systems: implications for research and policy. Food Policy, 32, 281-298. 
PlanetRetail. (2013a). Country report: Kenya In http://www.planetretail.net/Markets/Country/91 (accessed 4 November 2031).

PlanetRetail. (2013b). Online retailer market share data. http://www.planetretail.net/DataAnalysis/Interactive (accessed December 18, 2013).

Popkin, B. (1997). The nutrition transition and its helath implications in lower-income countries. Public Health Nutrition, 1, 5-21.

Popkin, B. M. (2006). Global nutrition dynamics: the world is shifting rapidly toward a diet linked with noncommunicable diseases. American Journal of Clinical Nutrition, 84, 289298.

Popkin, B., and Ng, S. W. (2007). The nutrition transition in high- and low-income countries: what are the policy lessons? Agricultural Economics, 37, 199-211.

Popkin, B.M. (2004). The nutrition transition: An overview of world patterns of change. Nutrition Reviews, 62, S140-S143.

Popkin, B.M., Adair, L.S., and Ng, S.W. (2012). Global nutrition transition and the pandemic of obesity in developing countries. Nutrition Reviews, 70, 3-21.

Popkin, B.M., and Gordon-Larsen, P. (2004). The nutrition transition: worldwide obesity dynamics and their determinants. International Journal of Obesity, 28, S2-S9.

Powell, L., Auld, M., Chaloupka, F., O'Malley, P., and Johnsson, L. (2007). Associations between access to food stores and adolescent body mass index. American Journal of Preventive Medicine, 33 (4S), S301-S307.

Prentice, A.M., and Pau, A.A. (2000). Fat and energy needs of children in developing countries. American Journal of Clinical Nutrition, 72, 1253s-1265s.

Psaki, S., Bhutta, Z.A., Ahmed, T., Ahmed, S., Bessong, P., Islam, M., et al. (2012). Household food access and child malnutrition: results from the eight-country MAL-ED study. Population Health Metrics, 10, 24.

Rao, E.J.O., Brümmer, B., and Qaim, M. (2012). Farmer participation in supermarket channels, production technology, and efficiency: the case of vegetables in Kenya. American Journal of Agricultural Economics, 94, 891-912.

Rao, E.J.O., and Qaim, M. (2011). Supermarkets, farm household income, and poverty: insights from Kenya. World Development, 39, 784-796. 
Reardon, T. , and Gulati, A. (2008). The supermarket revolution in developing countries: policies for "competitiveness with inclusiveness". IFPRI Policy Brief 2. Available at http://www.ifpri.org/pubs/bp/bp002.asp

Reardon, T., and Timmer, C. P. (2007). Transformation of markets for agricultural output in developing countries since 1950: How has thinking changed? In Handbook of agricultural economics, 3: Agricultural development: Farmers, farm production and farm markets, edited by R. E. Evenson and Pingali, P. Amsterdam: : Elsevier Press.

Reardon, T., Timmer, C. P. , and Berdegué, J. (2004). The rapid rise of supermarkets in developing countries: induced organizational, institutional and technological change in agrifood systems. Electronic Journal of Agricultural and Development Economics, 1, 168 -183 .

Reardon, T., Timmer, C.P., Barrett, C.B. , and Berdegué, J. (2003). The rise of supermarkets in Africa, Asia, and Latin America. American Journal of Agricultural Economics, 85 (5), $1140-1146$.

Reardon, T., Timmer, C.P., and Minten, B. (2012). The supermarket revolution in Asia and emerging development strategies to include small farmers. Proceedings of the National Academy of Sciences USA, 109 (31), 12332-12337.

Rischke, R., Kimenju, S.C., Qaim, M., and Klasen, S. (2014). Supermarkets and the nutrition transition in Kenya. 2014. GlobalFood Discussion Papers No. 29. (http://www.unigoettingen.de/en/globalfood-discussion-paper-series/213486.html).

Roemling, C., and Qaim, M. (2012). Obesity trends and determinants in Indonesia. Appetite, 58, 1005-1013.

Roemling, C., and Qaim, M. (2013). Dual burden households and intra-household nutritional inequality in Indonesia. Economics and Human Biology, 11, 563-573.

Rosin, O. (2008). The economic causes of obesity: a survey. Journal of Economic Surveys, 22 (4), 617-647.

Ruel, M. (2002). Is dietary diversity an indicator of food security or dietary quality? A review of measurement issues and research needs. In FCDN Discussion Paper No. 140: IFPRI.

Savage, J.S., Fisher, J.O., and Birch, L.L. (2007). Parental influence on eating behavior: conception to adolescence. The Journal of Law, Medicine \& Ethics, 35, 22-34. 
Schipmann, C., and Qaim, M. (2011). Modern food retailers and traditional markets in developing countries: comparing quality, prices, and competition strategies in Thailand. Applied Economic Perspectives and Policy, 33, 345-362.

Sehmi, J.K. (1993). National food composition tables and the planning of satisfactory diets in Kenya. Nairobi: Ministry of Health, Government of Kenya, Pages.

Semba, R.D., de Pee, S., Sun, K., Sari, M., Akhter, N., and Bloem, M.W. (2008). Effect of parental formal education on risk of child stunting in Indonesia and Bangladesh: a crosssectional study. Lancet, 371, 322 - 328.

Sewell, M.F., Huston-Presley, L., Super, D.M., and Catalano, P. (2006). Increased neonatal fat mass, not lean body mass, is associated with maternal obesity. American Journal of Obstetrics and Gynecology, 195, 1100-1103.

Simon, C., Kellou, N., Dugas, J., Platat, C., Copin, N., Schweitzer, B., et al. (2014). A socioecological approach promoting physical activity and limiting sedentary behavior in adolescence showed weight benefits maintained 2.5 years after intervention cessation. International Journal of Obesity, e-pub ahead of print 10 February 2014. doi:10.1038/sj.bmt.1705565.

Smith, L.C., and Haddad, L. (1999). Explaining child malnutrition in developing countries: a cross-country analysis. Discussion Paper No. 60. Washington, DC: Food Consumption and Nutrition Division, International Food Policy Research Institute.

Smith, L.C., and Haddad, L. (2002). How potent is economic growth in reducing undernutrition? What are the pathways of impact? New cross-country evidence. Economic Development and Cultural Change, 51, 55-76

Spears, D. (2013). How much international variation in child height can sanitation explain? World Bank, Washington, DC. https://openknowledge.worldbank.org/handle/10986/13163

Steyn, N.P., Labadarios, D., Nel, J., Kruger, S., and Maunder, E.M.W. . (2011). What is the nutritional status of children of obese mothers in South Africa? Nutrition, 27, 904-911.

Stokke, H.E. (2009). Multinational supermarket chains in developing countries: does local agriculture benefit? Agricultural Economics, 40, 645-656. 
Strong, W.B., Malina, R.M., Blimkie, C.J., Daniels, S.R., Dishman, R.K., Gutin, B., et al. (2005). Evidence based physical activity for school-age youth. Journal of Pediatrics, $146,732-737$.

Sturm, R. (2002). The effects of obesity, smoking, and drinking on medical problems and costs. Health Affairs, 21, 245-253.

Swinburn, B.A., Sacks, G., Hall, K.D., McPherson, K., Finegood, D., Moodie, M.L., et al. (2011). The global obesity pandemic: global drivers and local environments. Lancet, 378, 804-814.

Tessier, S., Traissac, P., Maire, B., Bricas, N., Eymard-Duvernay, S., El Ati, J., et al. (2008). Regular users of supermarkets in greater Tunis have a slightly improved diet quality. The Journal of Nutrition, 138 (8), 768-774.

Timmer, C.P. (2009). Do supermarkets change the food policy agenda? World Development, 37 , 1812-19.

Timmer, P. (2008). The Impact of supermarkets on farmers, consumers and food security in developing countries. In Nutrition and Health Series: Nutrition and Health in Developing Countries, edited by E. R. Semba and Bloem, M. New York: Human Press.

UN Millennium, Project. (2005). Halving hunger: it can be done. Task Force on Hunger, 2005. London and Sterling, VA.

UNICEF. (1990). Strategy for improved nutrition of children and women in developing countries. In UNICEF Policy Review Paper. New York: UNICEF.

UNICEF. (1998). The state of world's children: focus on nutrition. New York: Oxford University Press.

UNICEF. (2013). Improving child nutrition: the achievable imperative for global progress. United Nation Children Fund. New York, USA.

UNICEF, WHO, and WB. (2012). UNICEF-WHO-World Bank joint child malnutrition estimates: United Nations Children's Fund, New York; World Health Organization, Geneva; The World Bank, Washington, DC.

UNSCN. (2012). Sixth world nutrition situation report: progress in nutrition. United Nations System Standing Committee on Nutrition. 
Victora, C.G., Adair, L., Fall, C., Hallal, P.C., Martorell, R., Richter, L., et al. (2008). Maternal and child undernutrition: consequences for adult health and human capital. Lancet, 371, $340-357$.

Vollmer, S., Harttgen, K., Subramanyam, M.A., Finlay, J., Klasen, S., and Subramanian, S. V. (2014). Association between economic growth and early childhood undernutrition: evidence from 121 demographic and health surveys from 36 low-income and middleincome countries. Lancet Global Health 2014, 2, e225-234.

Wang, Y.C., McPherson, K., Marsh, T., Gortmaker, S.L. , and Brown, M. (2011). Health and economic burden of the projected obesity trends in the USA and UK. Lancet, 377, 815825.

WB. (2014). World development indicators online. Washington, DC: The World Bank. Available at < http://data.worldbank.org/data-catalog/world-development-.

WHO. (2000). Obesity: preventing and managing the global epidemic. In WHO Technical Report No. 894. Geneva: World Health Organization.

WHO. (2004). Global strategy on diet, physical activity, and health. Geneva: World Health Organization.

WHO. (2006). WHO child growth standards: Length/height-for-age, weight-for-age, weight-forlength, weight-for-height and body mass index-for-age: methods and development. Geneva: World Health Organization.

WHO. (2009). Global health risks: mortality and burden of disease attributable to selected major risks. Geneva: World Health Organization.

WHO. (2011). Global status report on noncommunicable diseases 2010. Geneva: World Health Organization.

WHO. (2012). Proposed global targets for maternal, infant and young child nutrition. WHO Discussion Paper (6 February 2012).

Withrow, D., and Alter, D.A. (2011). The economic burden of obesity worldwide: a systematic review of the direct costs of obesity. Obesity Reviews, 12, 131-141.

Wrigley, N., Warm, D., and Margetts, B. (2003). Deprivation, diet, and food-retail access: findings from the Leeds 'food deserts' study. Environment and Planning A, 35, 151-188. 


\section{General Appendix}

\section{Household Questionnaire (Kenya)}




\section{KENYA HOUSEHOLD CONSUMPTION SURVEY 2012}

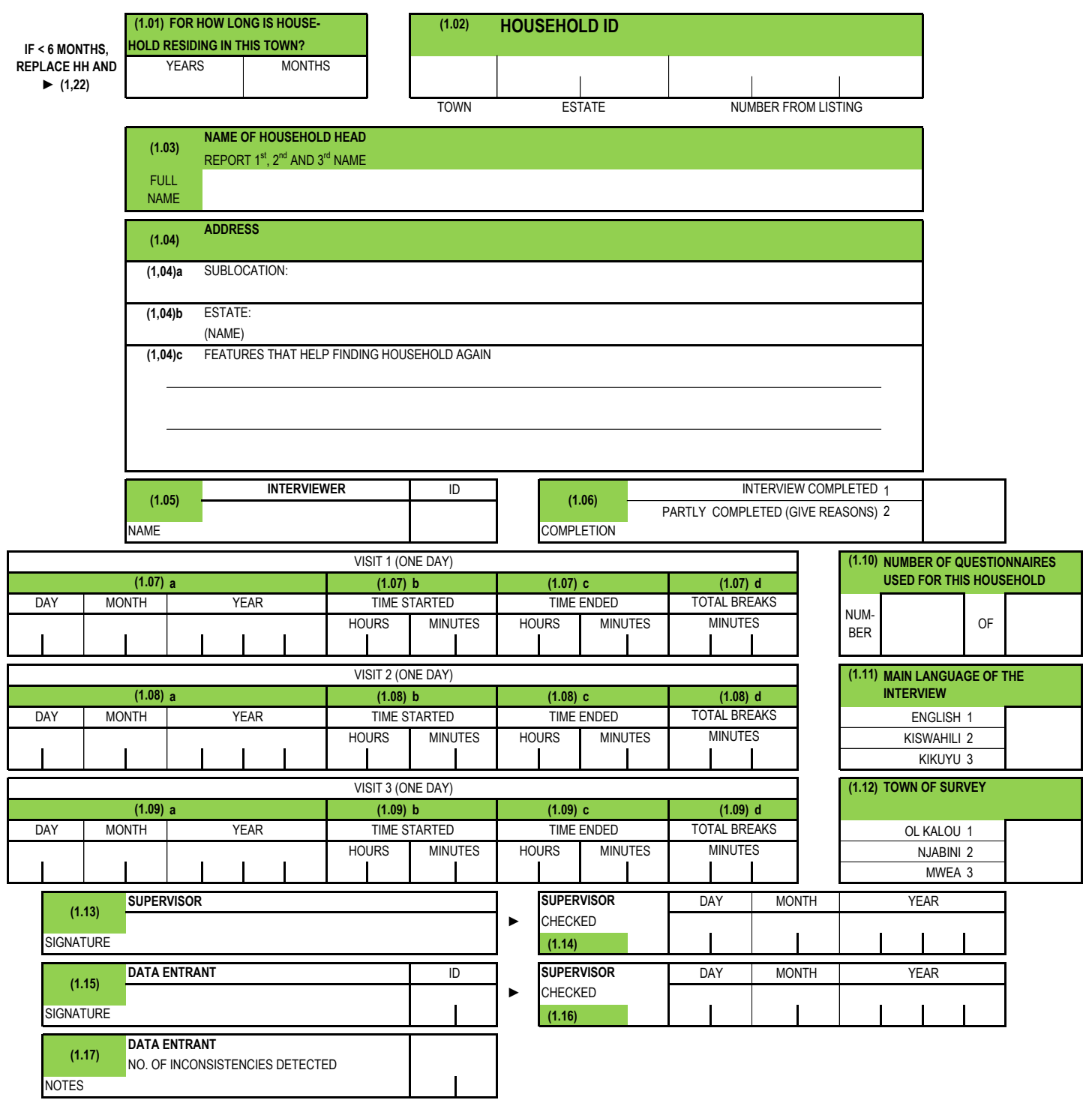

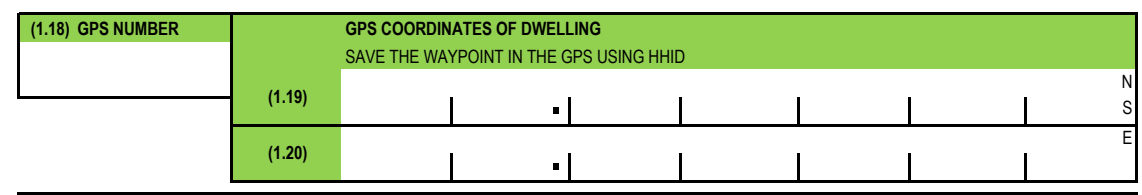

\begin{tabular}{|c|c|}
\hline \multirow[t]{2}{*}{ (1.21) } & $\begin{array}{l}\text { CENSUS ID FROM HOUSEWALL } \\
\text { IF NO CENSUS ID, CROSS OUT }\end{array}$ \\
\hline & $\perp$ \\
\hline (1.22) & IS THIS HOUSEHOLD A REPLACEMENT? \\
\hline YES 1 & $\begin{array}{l}\text { FLLL IN HOUSEHOLD ID OF HOUSEHOLD } \\
\text { REPLACED IN }(1,24)\end{array}$ \\
\hline NO 2 & $\boldsymbol{\nabla}(1,25)$ \\
\hline
\end{tabular}

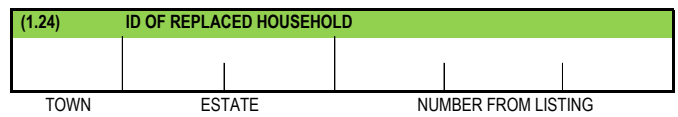

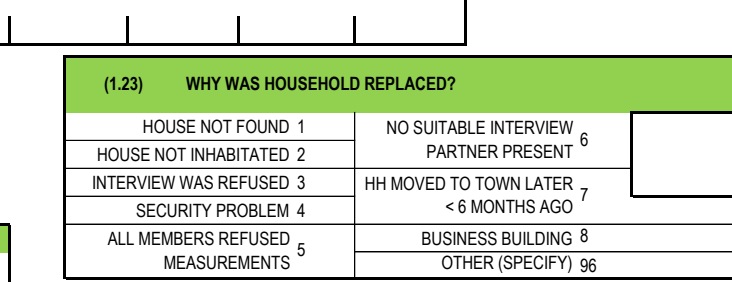



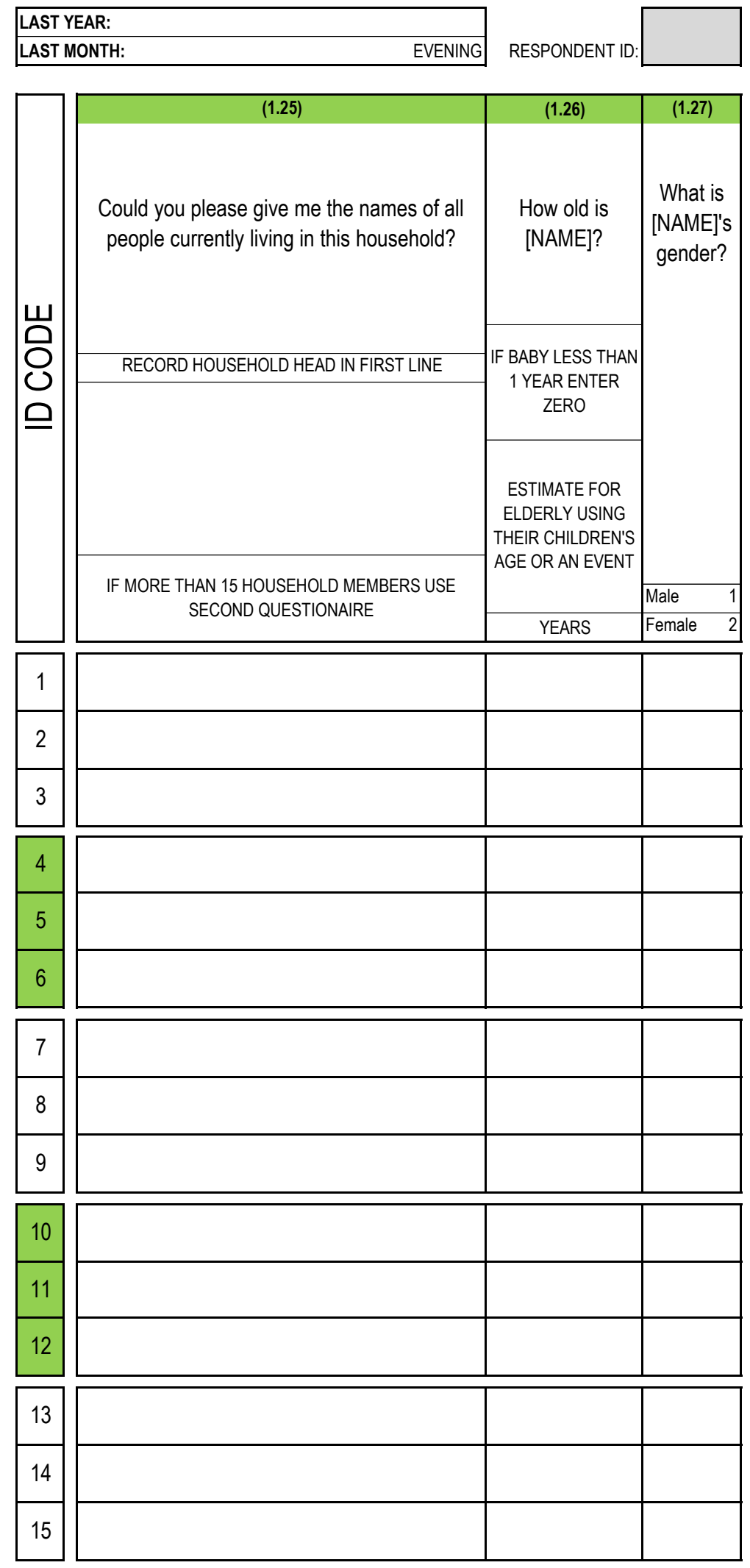
SECTION 1: Household Composition

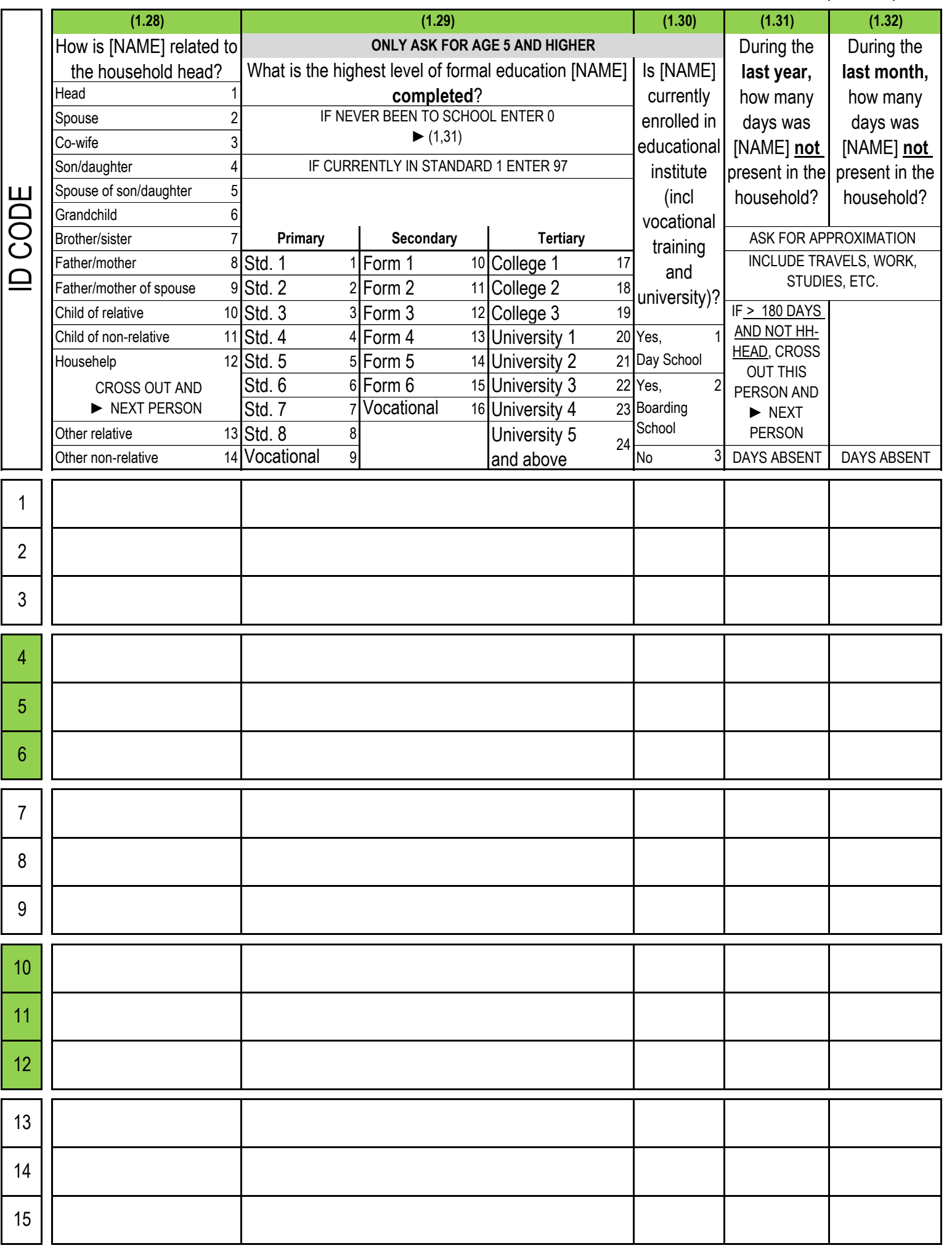

HHID: 
Household Composition

\begin{tabular}{|c|c|c|c|c|}
\hline & (1.33) & (1.34) & $(1.35)$ & $(1.36)$ \\
\hline & & ONLY ASK FOR & R AGE 10 AND OLD & \\
\hline & What is & During last & What was the & ONLY ASK IF \\
\hline & [NAME]'s & 6 months, & main job & $\begin{array}{l}\text { MAIN JOB IS } \\
\text { NOT A }\end{array}$ \\
\hline & main & did [NAME] & [NAME] & STUDENT OR \\
\hline & profession & mainly work & worked in & HOUSEWIFE \\
\hline & $?$ & $\begin{array}{c}\text { in [MAIN } \\
\text { PROFESSION] }\end{array}$ & $\begin{array}{c}\text { during last } 6 \\
\text { months? }\end{array}$ & Did [NAME] \\
\hline$\overline{0}$ & USE & & & contribute to \\
\hline 0 & OCCUPATIO & & $\begin{array}{l}\text { USE } \\
\text { UCCUPATION }\end{array}$ & covering \\
\hline$\supseteq$ & $\begin{array}{l}\text { N CODES ON } \\
\text { THF RIGHT }\end{array}$ & & CODES ON THE & expenses \\
\hline & & & RIGHT & any time \\
\hline & $\begin{array}{l}\text { IF NO PROFE } \\
\text { SSION CODE }\end{array}$ & & IF NOT WORKING & $\begin{array}{l}\text { during the } \\
\text { last } 6\end{array}$ \\
\hline & 97 & Yes & DURING LAST SIX & months? \\
\hline & $>(1,35)$ & $>(1,36)$ & 97 AND $(1,37)$ & Yes \\
\hline & CODE & No & CODE & No \\
\hline
\end{tabular}

\begin{tabular}{|c|l|l|l|l|}
\hline 1 \\
\cline { 2 - 5 } \\
\cline { 2 - 4 } \\
\hline 3
\end{tabular}

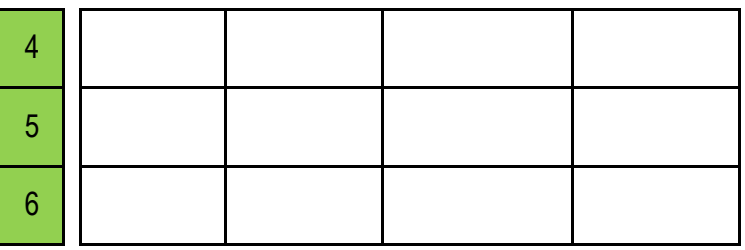

\begin{tabular}{|l|l|l|l|l|}
\hline 7 \\
\hline 8
\end{tabular}

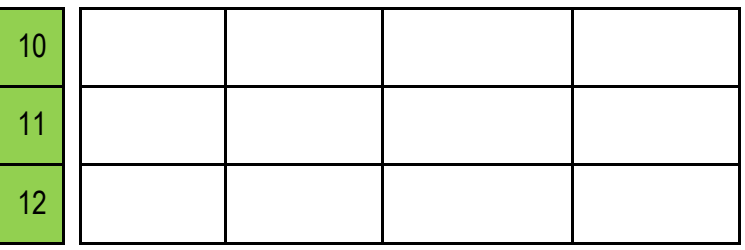

\begin{tabular}{|l|l|l|l|}
\hline 13 \\
\hline 14 \\
\hline 15
\end{tabular}

\section{OCCUPATION CODES}

96 Other(specify)

1 Accountant

2 Agricultural trading (incl timber)

3 Banker

4 Bicycle repair

5 Blacksmith

6 Boda boda operator (bicycle)

7 Boda boda operator (motor)

8 Butcher

9 Carpentry

10 Casual worker-farm

11 Casual worker-non-farm

12 Cleaning Personnel

13 Clerical/secretarial

14 Clothes/shoes business (trading)

15 Cobbler

16 Cook

17 Doctor

18 Door-to-door salesman (eg insurances)

19 Driver

20 Electrician

21 Farmer (working on own farm)

22 Hair dresser / barber

23 Handicraft trader

24 Hawker (incl street and office)

25 Househelp

26 Housewife

27 Livestock trader

28 Making handicraft

29 Manegerial/higher office

30 Masonry

31 Midwife

32 Nurse

33 Painter

34 Photographer/video maker

35 Plumber

36 Posho miller operator

37 Retail shop/kiosk/shopkeeping

38 Student

39 Surveyor

40 Tailor

41 Teacher

42 Tour guide

43 Turn boy/Tout

44 Vehicle mechanic

45 Veterinary doctor

46 Waiter/ bartender

47 Watchman/security

48 Welder 


\section{SECTION 1: Household Composition}

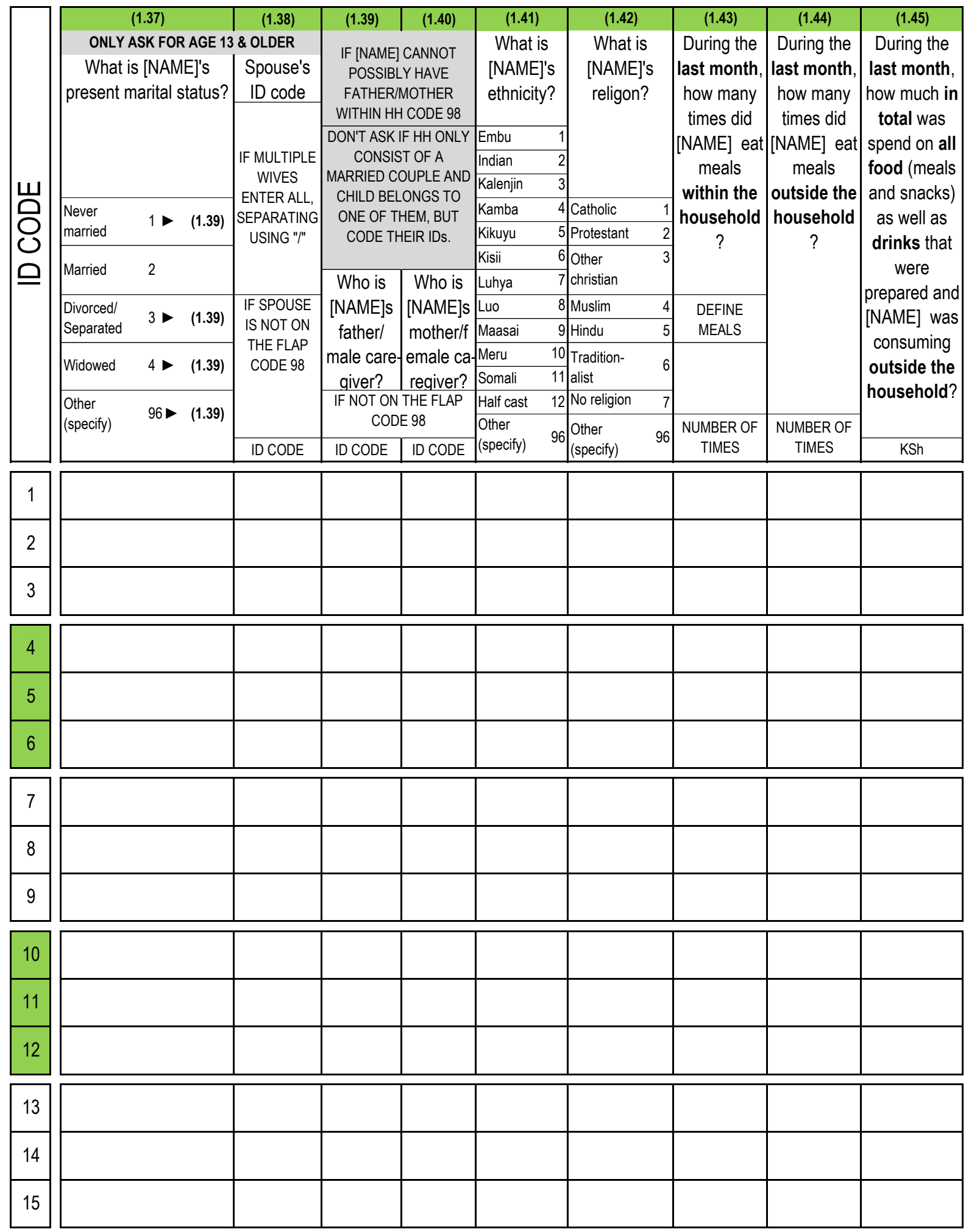




\section{Respondent Selection}

\begin{tabular}{|c|c|c|}
\hline \multirow{2}{*}{ (1.46) } & \multirow{2}{*}{$\begin{array}{l}\text { Who is mostly preparing food consumed in this } \\
\text { household? }\end{array}$} & IF NOT ON FLAP CODE 98 \\
\hline & & प MEMBER ID CODE \\
\hline \multirow[b]{2}{*}{$(1.47)$} & \multirow{2}{*}{$\begin{array}{l}\text { Who is mostly buying food items that are } \\
\text { consumed in this household? }\end{array}$} & IF NOT ON FLAP CODE 98 \\
\hline & & \begin{tabular}{l|l} 
& MEMBER ID CODE
\end{tabular} \\
\hline (1.48) & $\begin{array}{l}\text { Who is mostly deciding what food items are } \\
\text { bought for consumption in this household? }\end{array}$ & JMEMBER ID CODE \\
\hline (1.49) & $\begin{array}{l}\text { Who is mostly deciding how food items are } \\
\text { prepared for consumption in this household? }\end{array}$ & MEMBER ID CODE \\
\hline
\end{tabular}

\section{SELECTION OF HOUSEHOLD MEMBERS FOR WEIGHT MEASUREMENT}

1. PLEASE LIST ALL HOUSEHOLD MEMBERS BY THEIR MEMBER ID ACCORDING TO THEIR SEX AND AGE IN $(1,5)-(1,520)$.

2. FOR EACH CASE (MALE ADULT, FEMALE ADULT, CHILD/ADOLESCENT):

- CROSS OUT THE ONES THAT WERE CROSSED OUT IN $(1,28)$, OR IN $(1,31)$ CODE 97 AS REASON.

- COUNT OUT TO RANDOM NUMBER GOING THROUGH THE REMAINING LIST OF HOUSEHOLD MEMBERS AND ENCIRCLE THE PERSON YOU ARRIVE AT.

- PROBE FOR CONSENT TO INTERVIEW AND TO TAKE THE MEASUREMENTS OF THIS HOUSEHOLD MEMBER LATER. IN THE CASE OF CHILD/ ADOLESCENT, YOU NEED TO ASK CAREGIVER FOR CONSENT. IF CONSENT IS GIVEN, PROCEED.

IF INTERVIEWING THIS HOUSEHOLD MEMBER IS NOT POSSIBLE, CROSS HIM/HER OUT, REPORT THE REASON AND REPEAT THE COUNTING EXERCISE AMONG THE REMAINING LIST OF HOUSEHOLD MEMBERS TO FIND A REPLACEMENT

- IF THE CASE MAY BE, REPEAT THE LAST STEP UNTIL YOU FIND A HOUSEHOLD MEMBER THAT YOU WILL BE ABLE TO INTERVIEW/ TAKE MEASUREMENTS FROM.

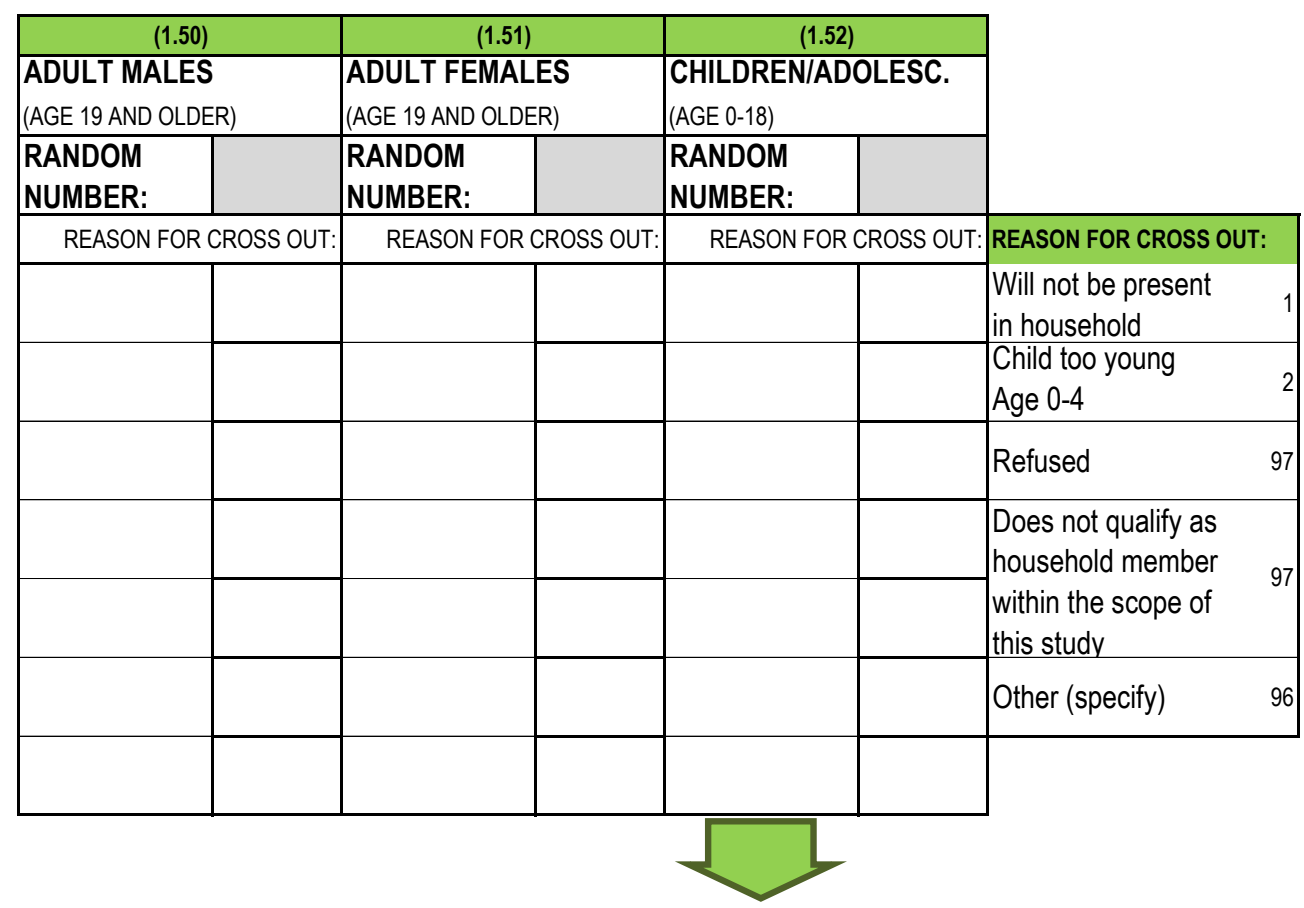

IF CHILD BELOW AGE OF 13, INTERVIEW CAREGIVER FOR SECTIONS 13-17 ON BEHALF OF CHILD/ ADOLESCENT SP

BEFORE YOU PROCEED WITH THE INTERVIEW, MAKE SURE TO SCHEDULE APPOINTMENTS FOR INTERVIEWING THE RESPONDENTS SELECTED FOR WEIGHT MEASUREMENT IF NECESSARY

HHID: 


\section{SECTION 2: Food Consumption Within Household}

READ OUT: IF YOU HOSTED A BIG FUNCTION DURING THE LAST MONTH (EG WEDDING, GRADUATION) PLEASE DO NOT INCLUDE THE ADDITIONAL FOOD

Y THAT EVENT. I WILL ALSO ASK YOU FOR THE VALUE OF FOOD YOU CONSUMED FROM PURCHASES DURIT

PURCHASES WAS WORTH

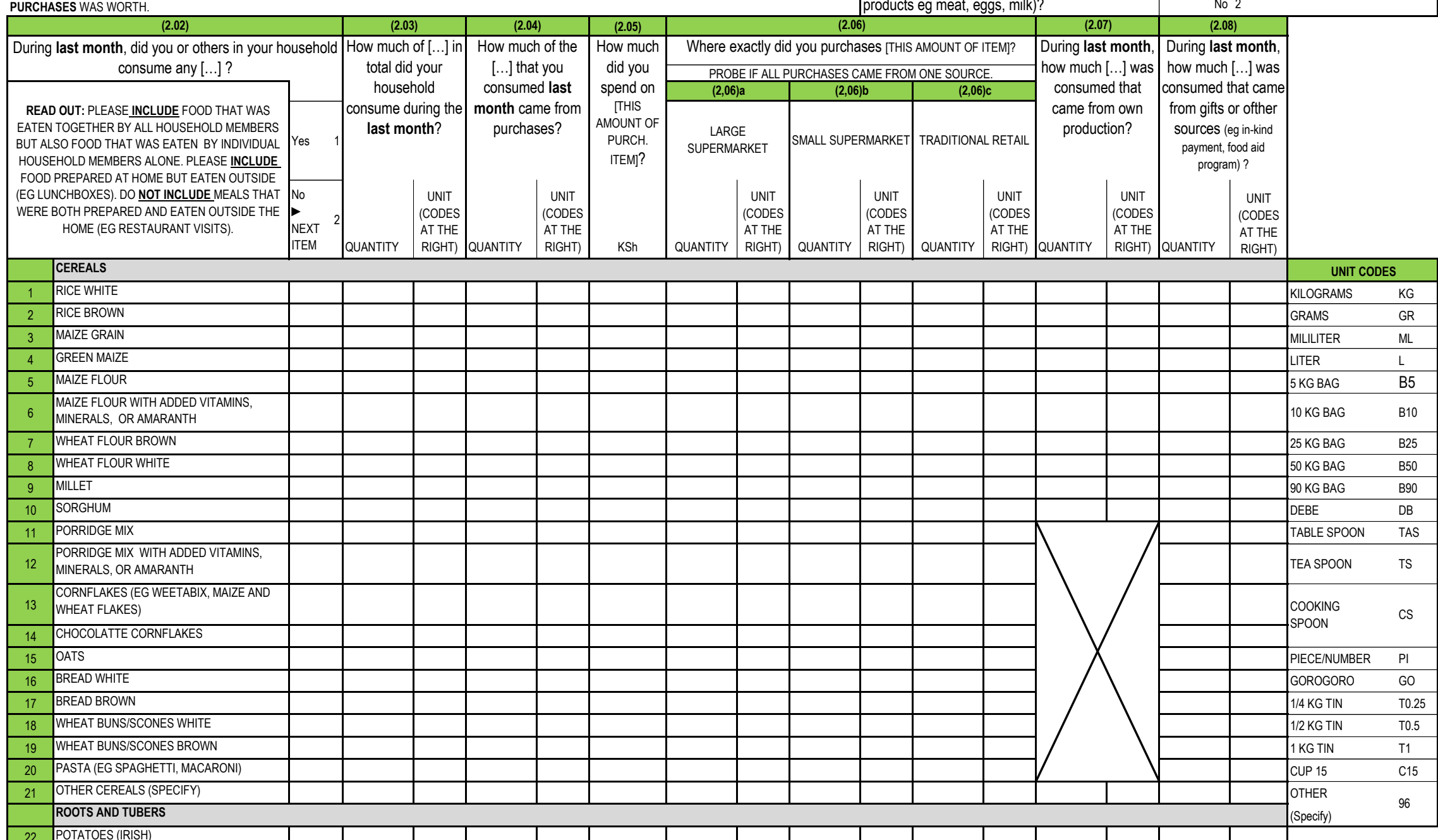

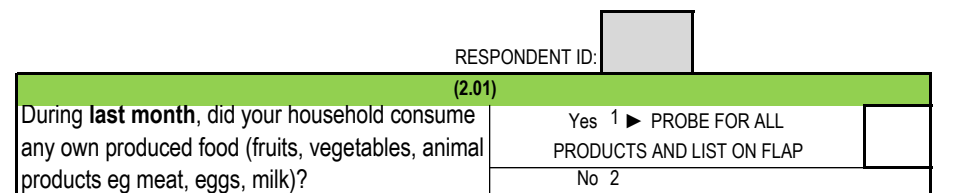

. 


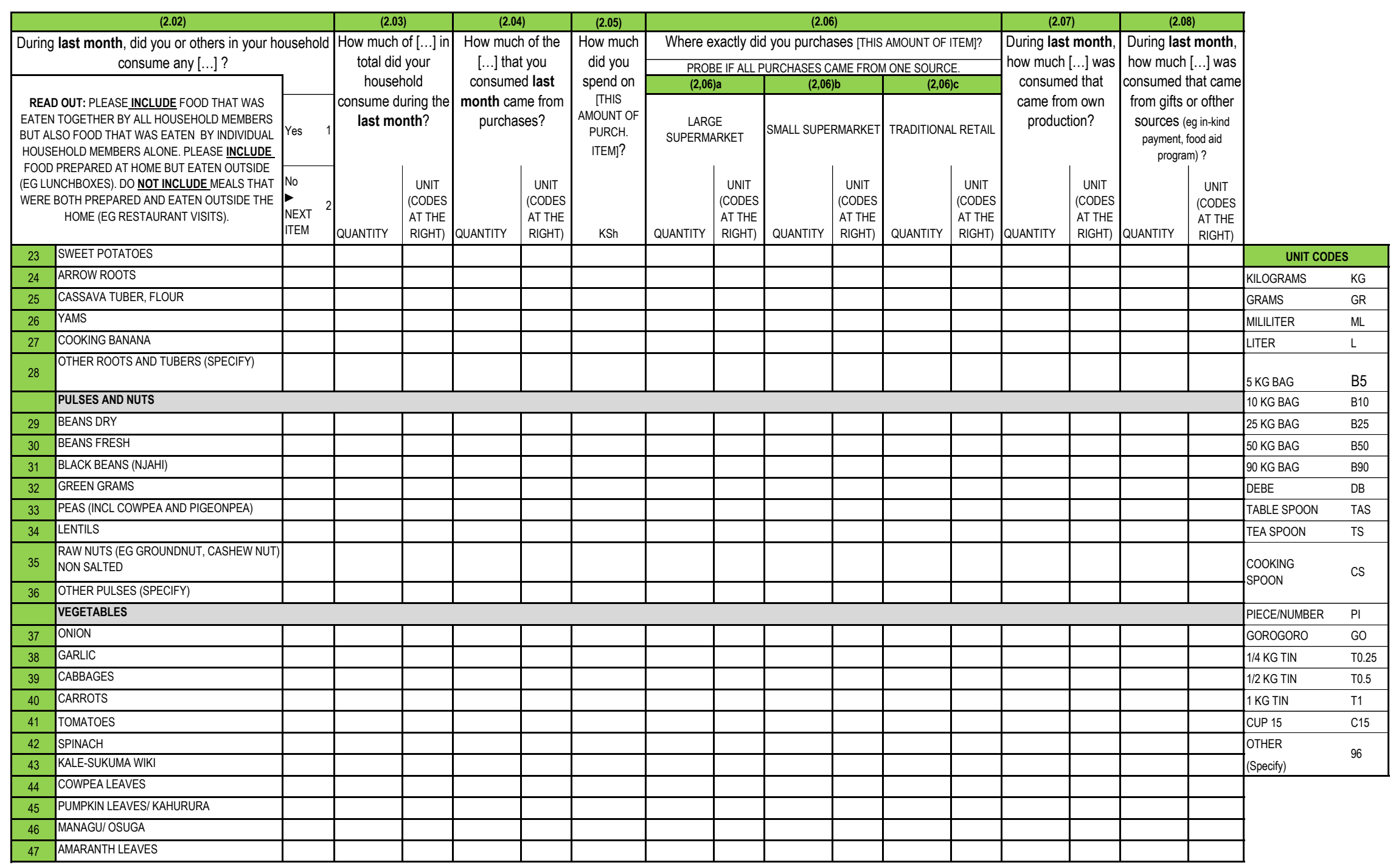




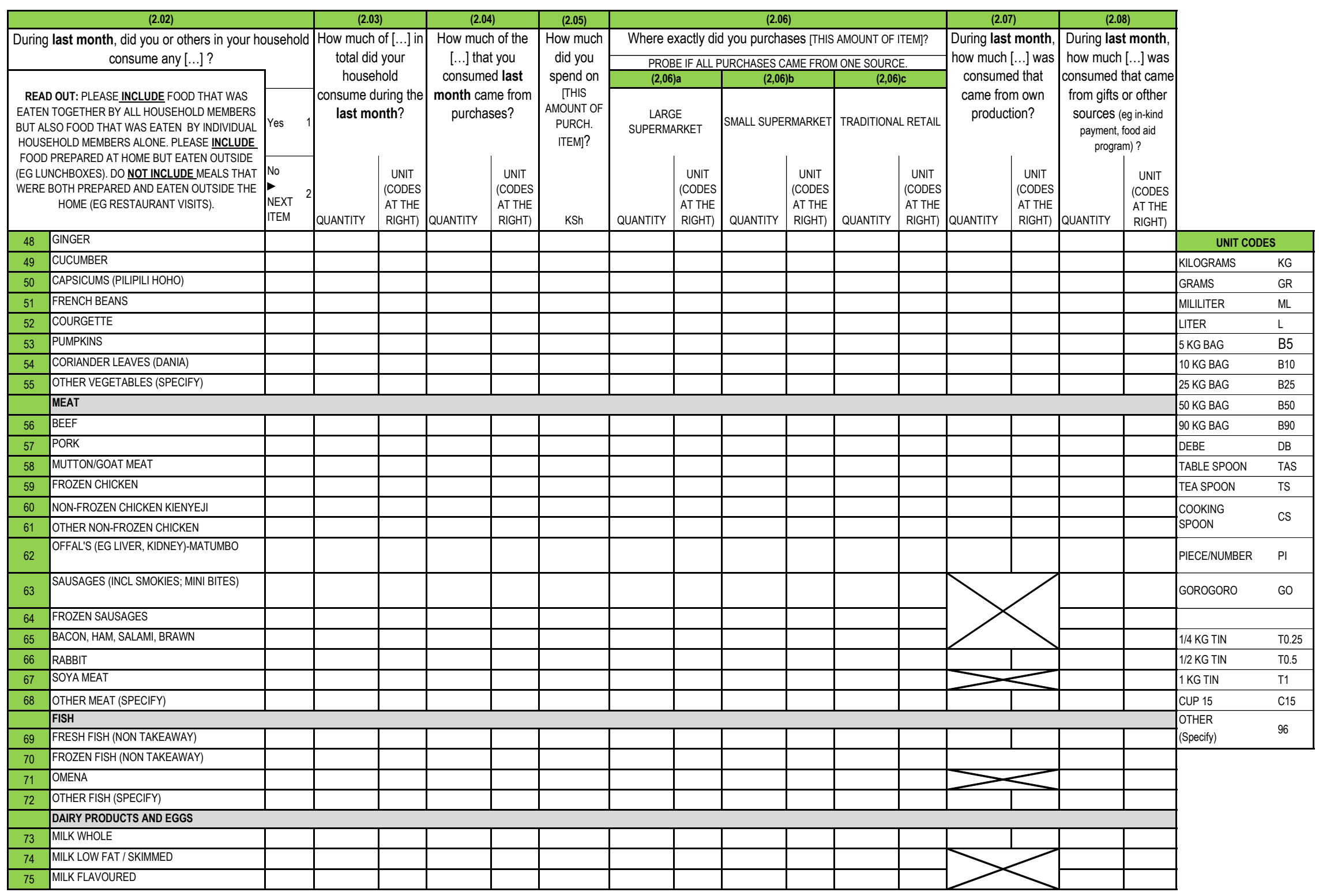




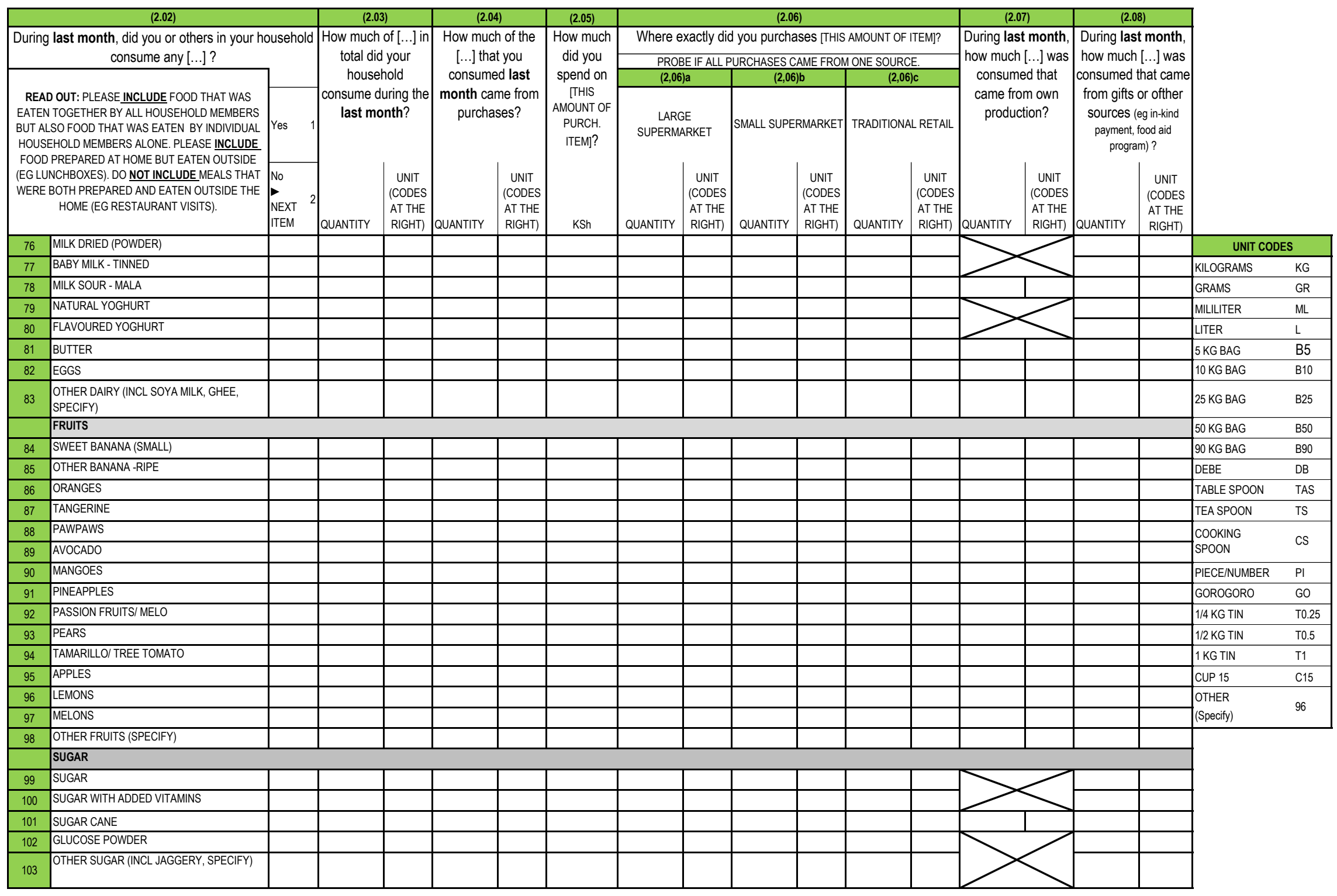




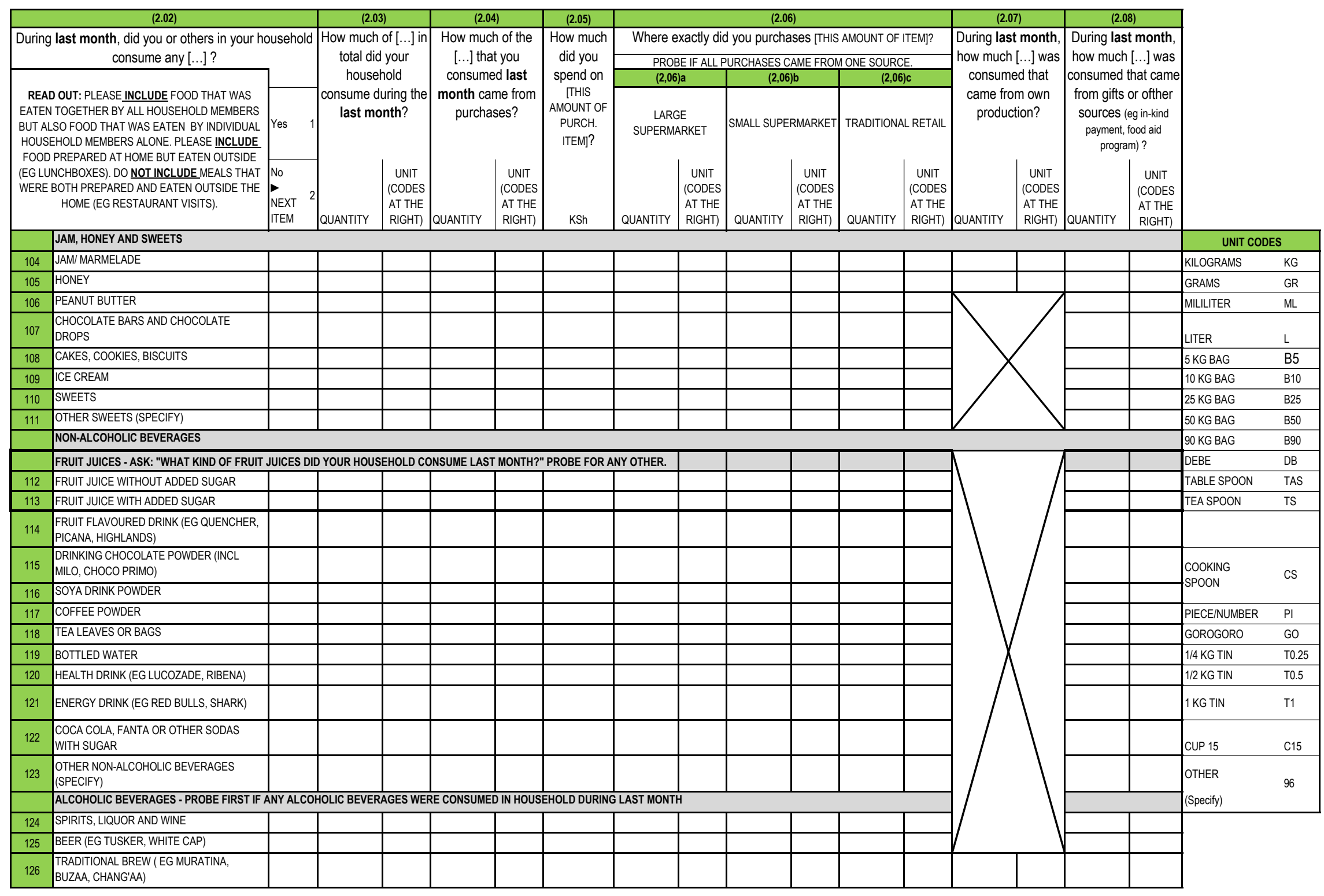




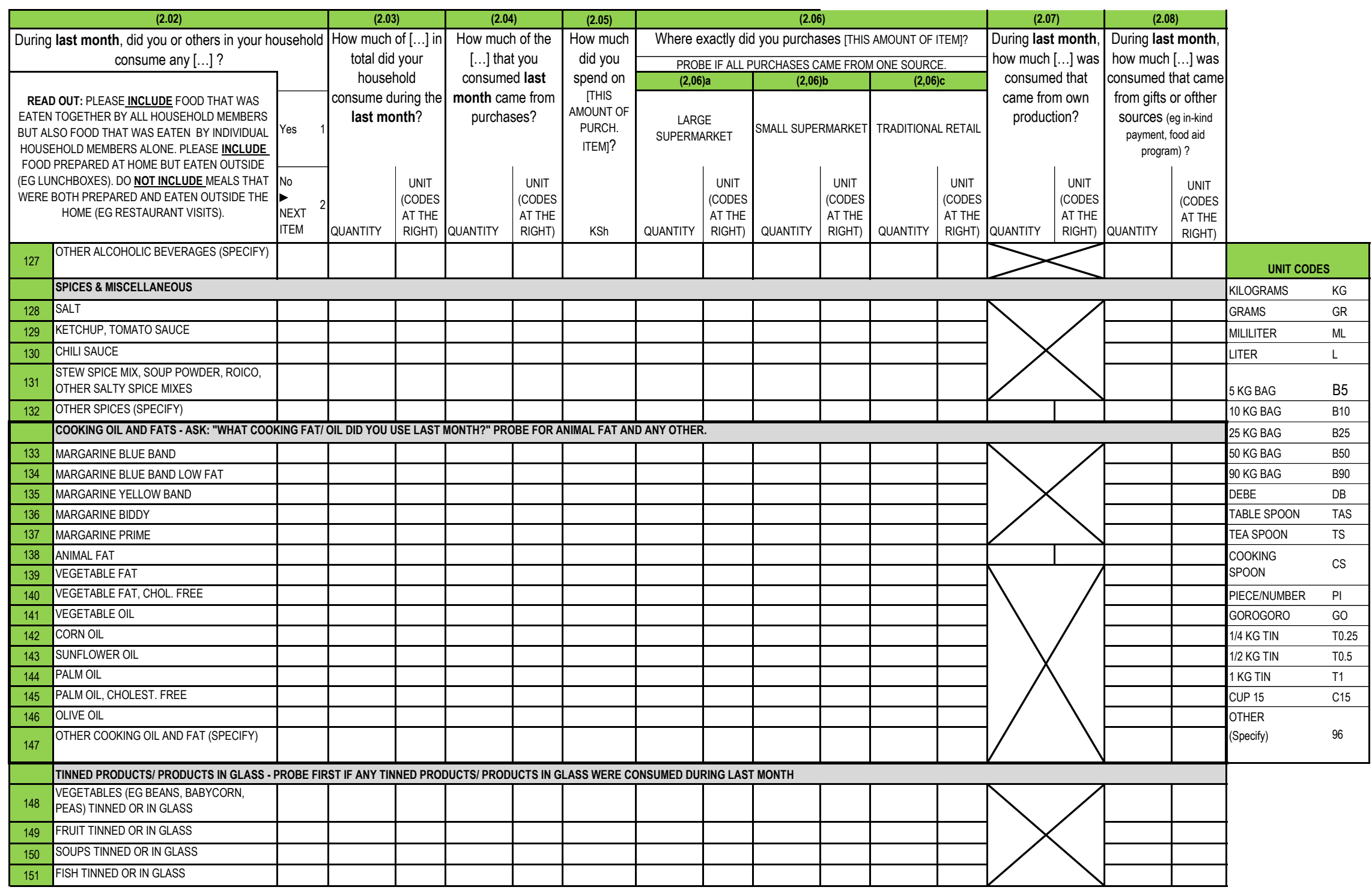




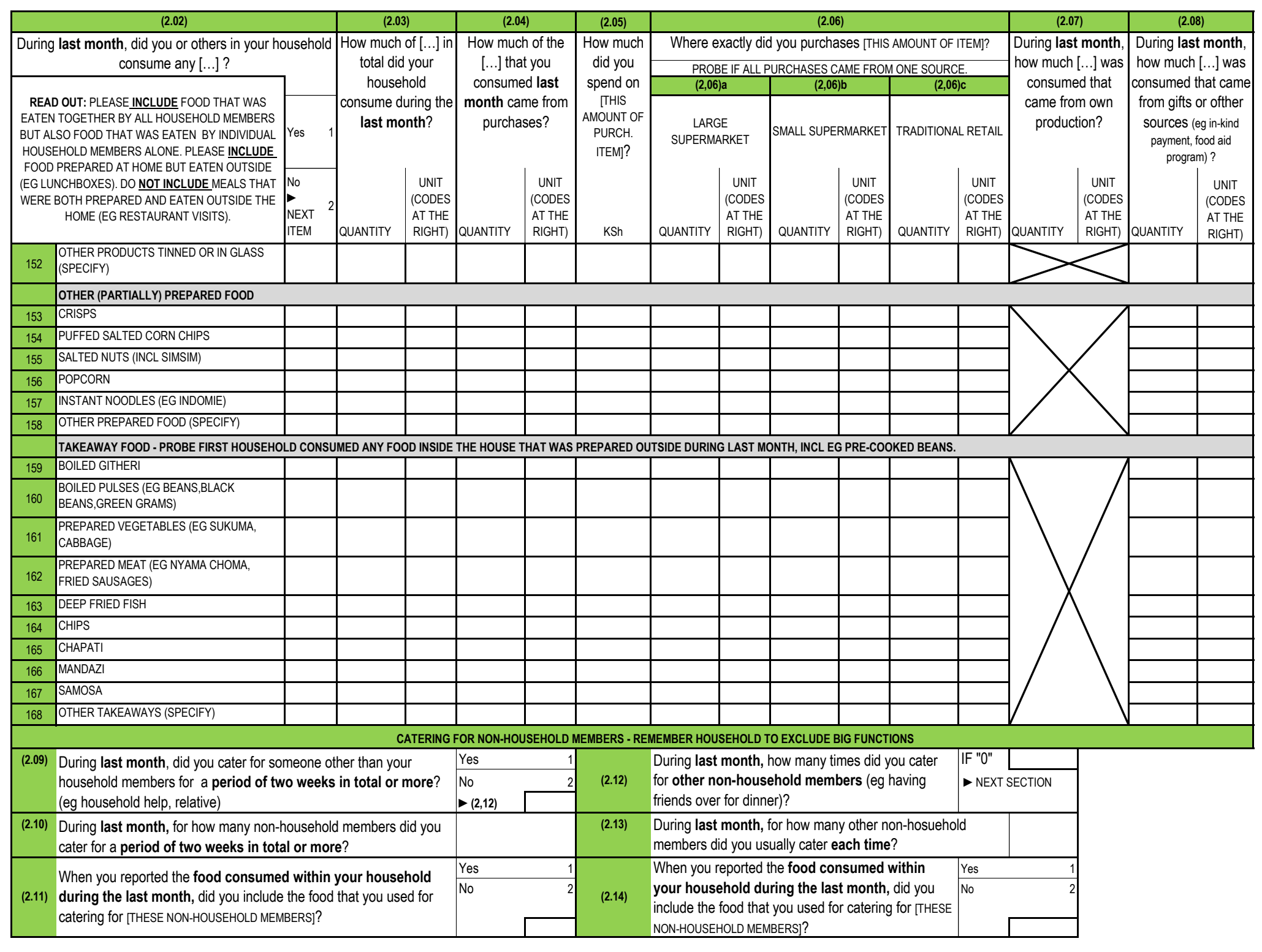


SECTION 3: Shopping Behaviour and Attitudes

RESPONDENT ID:

INTRODUCTION: DEFINE RETAIL OUTLETS

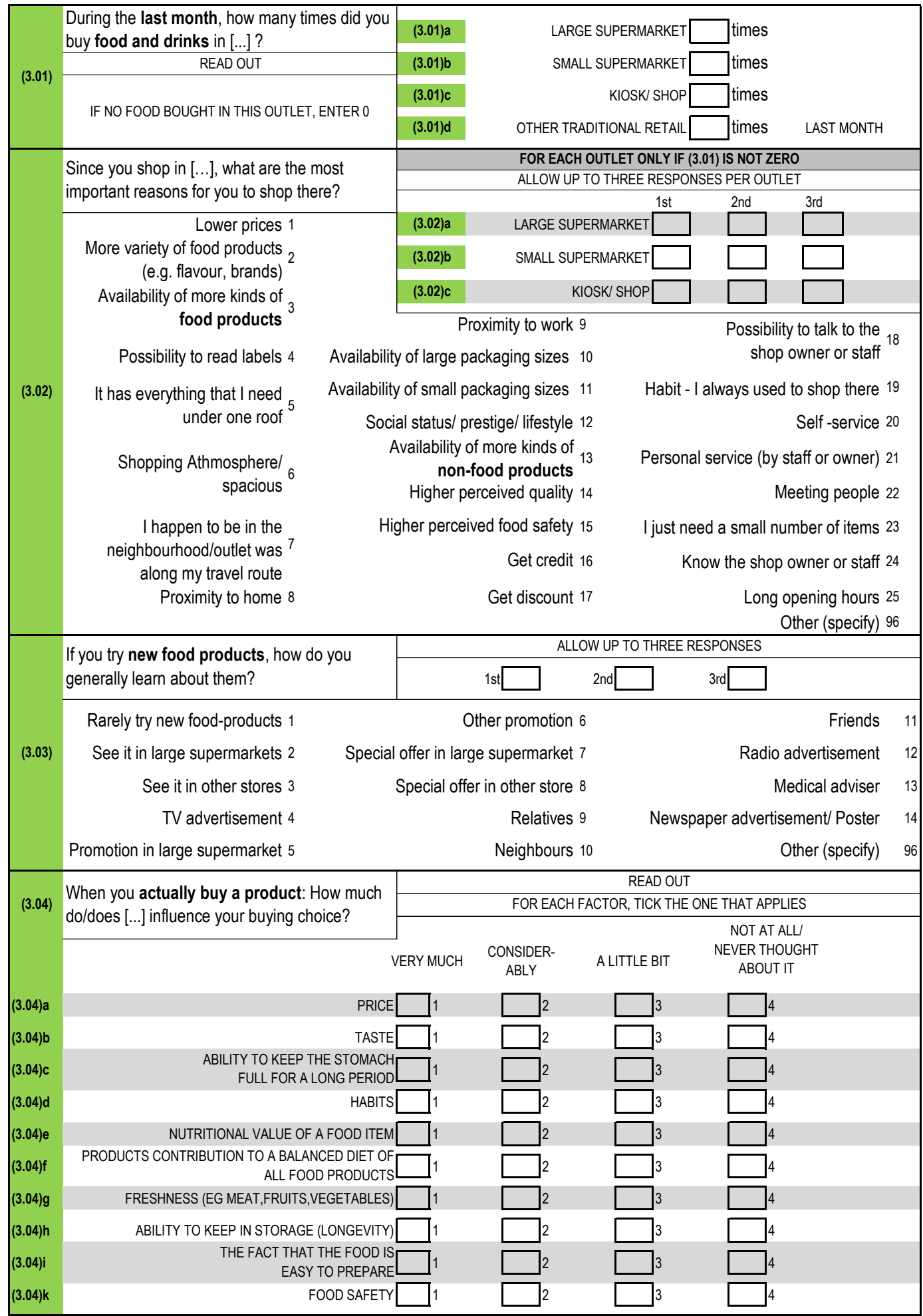




\section{SECTION 3: Shopping Behaviour and Attitudes}

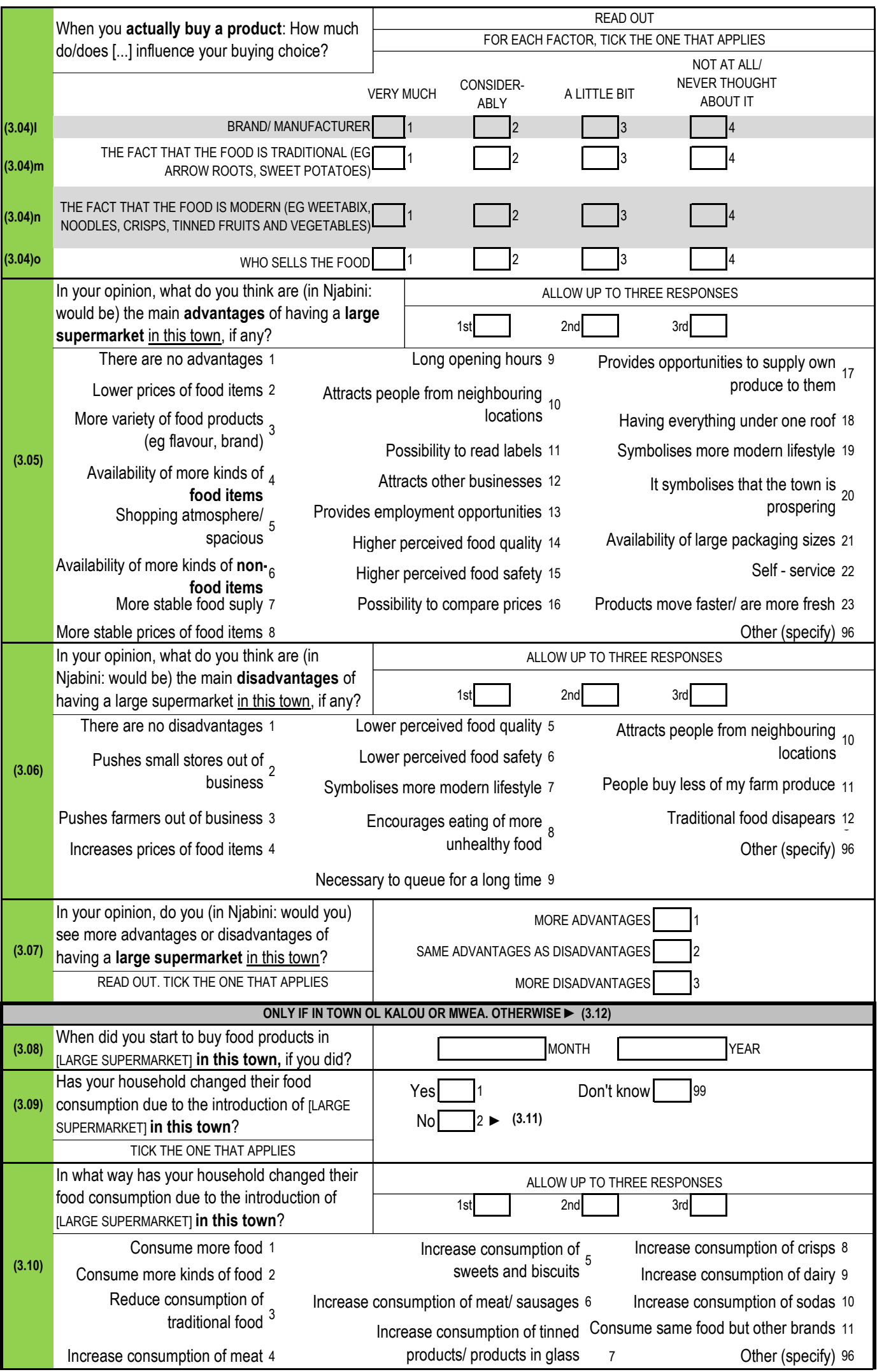


SECTION 3: SHOPPING BEHAVIOUR AND ATTITUDES

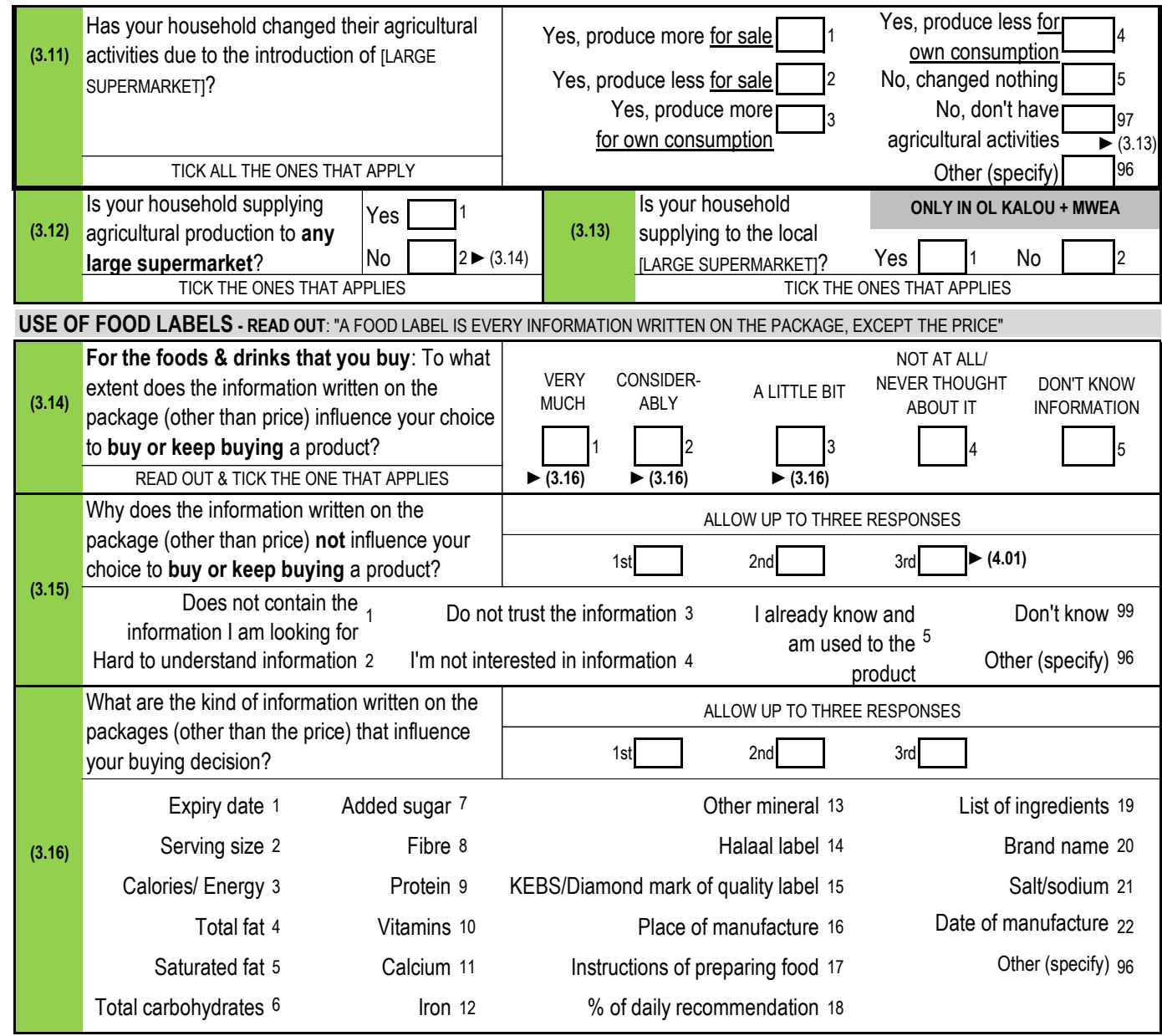

\section{SECTION 4: Food Preparation}

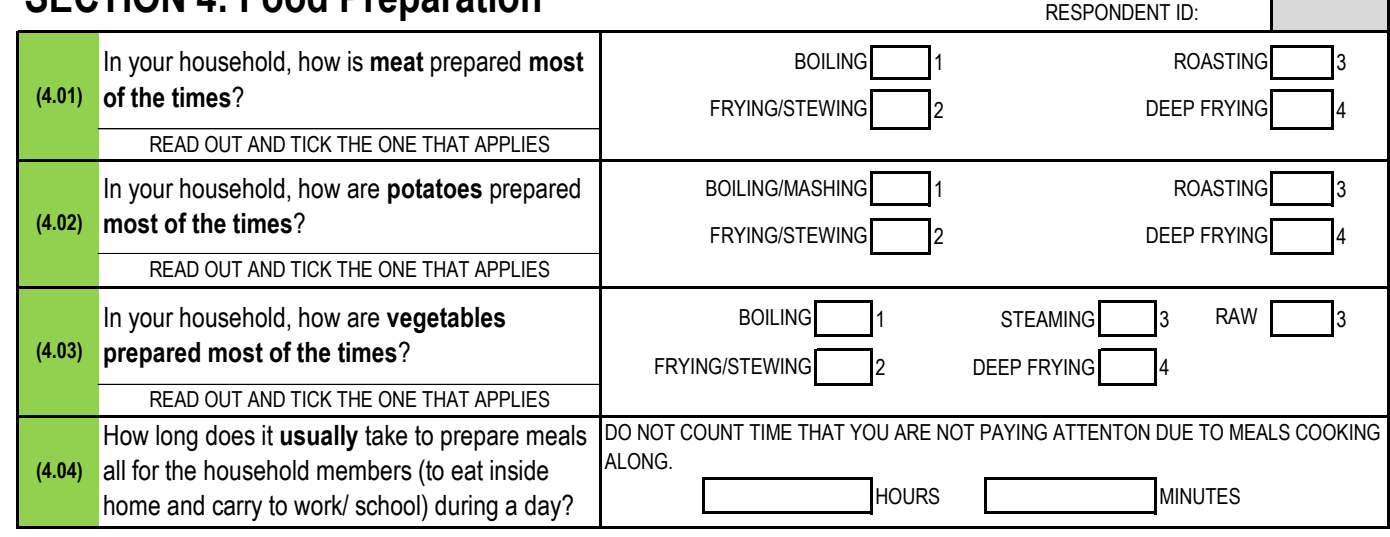




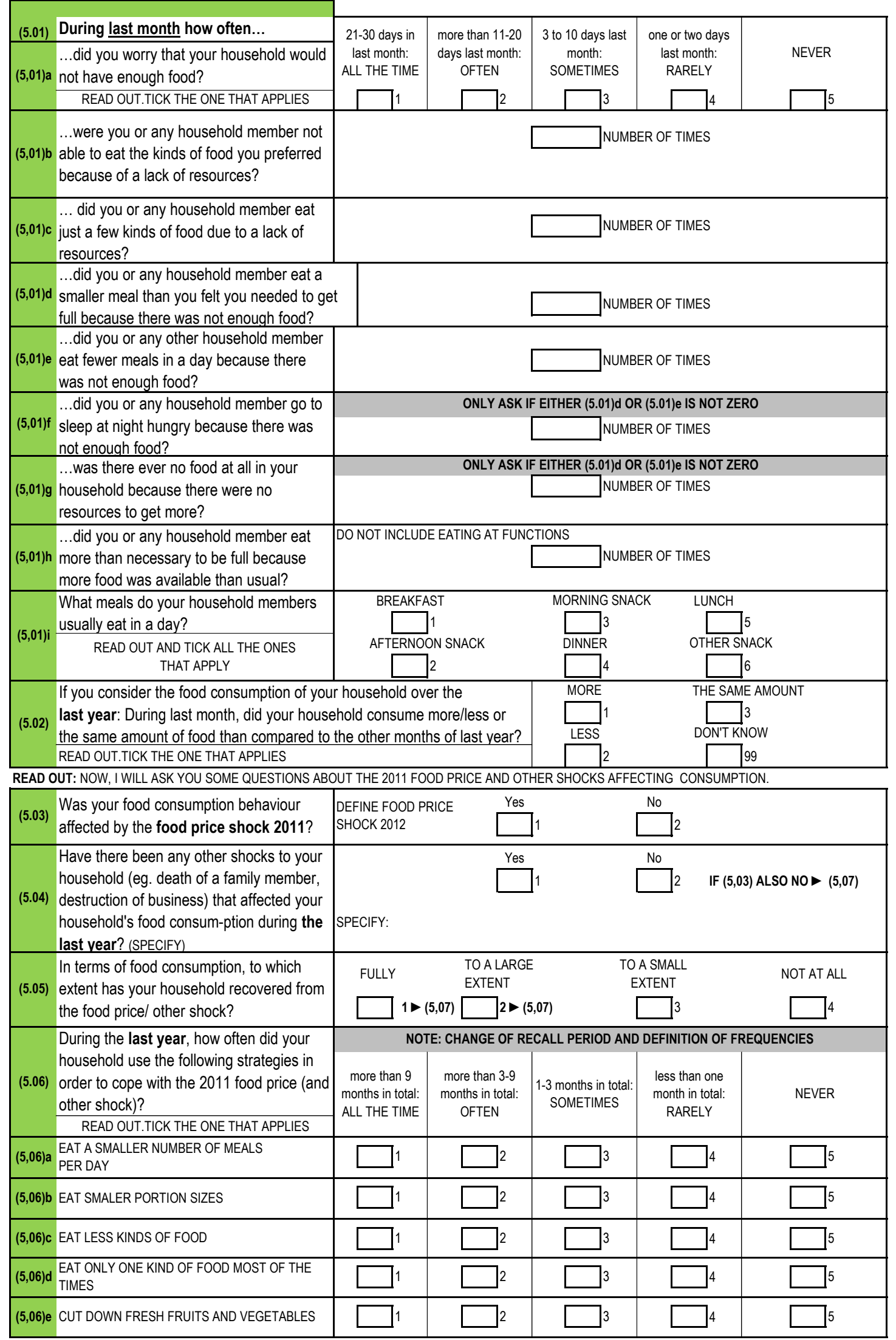


SECTION 5: Food Security and Accessibility

\begin{tabular}{|c|c|c|c|c|c|c|}
\hline & $\begin{array}{l}\text { During the last year, how often did your } \\
\text { household use the following strategies in } \\
\text { order to cope with the } 2011 \text { food price (and } \\
\text { other shock)? }\end{array}$ & $\begin{array}{l}\text { more than } 9 \\
\text { months in total: } \\
\text { ALL THE TIME }\end{array}$ & $\begin{array}{l}\text { more than 3-9 } \\
\text { months in total: } \\
\text { OFTEN }\end{array}$ & $\begin{array}{l}\text { 1-3 months in total: } \\
\text { SOMETIMES }\end{array}$ & $\begin{array}{l}\text { less than one } \\
\text { month in total: } \\
\text { RARELY }\end{array}$ & NEVER \\
\hline$(5,06) f$ & SUBSTITUTE MAIZE WITH OTHER CEREALS & 1 & $\sqrt{2}$ & ] 3 & $\sqrt{4}$ & ] 5 \\
\hline$(5,06) \mathrm{g}$ & CUT DOWN MEAT & 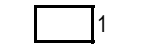 & ]$^{2}$ & ]$^{3}$ & ]4 & ]$_{5}$ \\
\hline$(5,06) \mathrm{h}$ & CUT DOWN DAIRY PRODUCTS & 1 & 2 & ] & ] 4 & ] 5 \\
\hline$(5,06) \mathrm{i}$ & $\begin{array}{l}\text { USE LESS COOKING OIL/FAT WHEN PREPARING } \\
\text { MEALS }\end{array}$ & \rceil 1 & ]$^{2}$ & ]$^{3}$ & ] 4 & \rfloor 5 \\
\hline$(5,06) \mathrm{j}$ & CUT DOWN SUGAR & 1 & 2 & ] 3 & ] 4 & ] 5 \\
\hline (5.07) & $\begin{array}{l}\text { Was your non-food expenditure affected by } \\
\text { the } 2011 \text { food price (and other) shock } \\
\text { during the last year? }\end{array}$ & & Yes & 1 & No & \\
\hline
\end{tabular}

READ OUT: NOW, I AM GOING TO ASK YOU A FEW QUESTIONS ABOUT FOOD ACCESSIBILITY

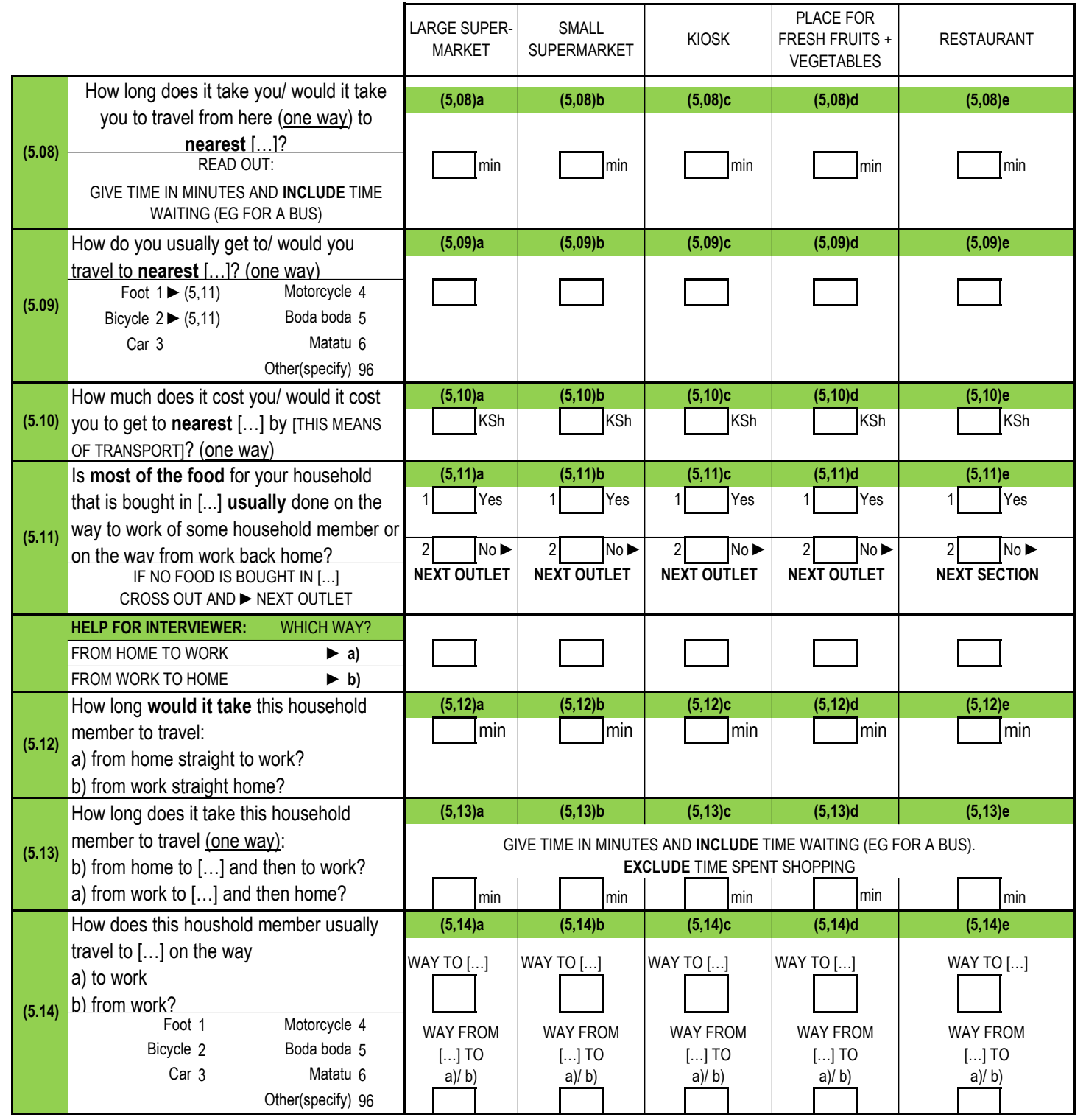


SECTION 6: Non-Food Expenditure

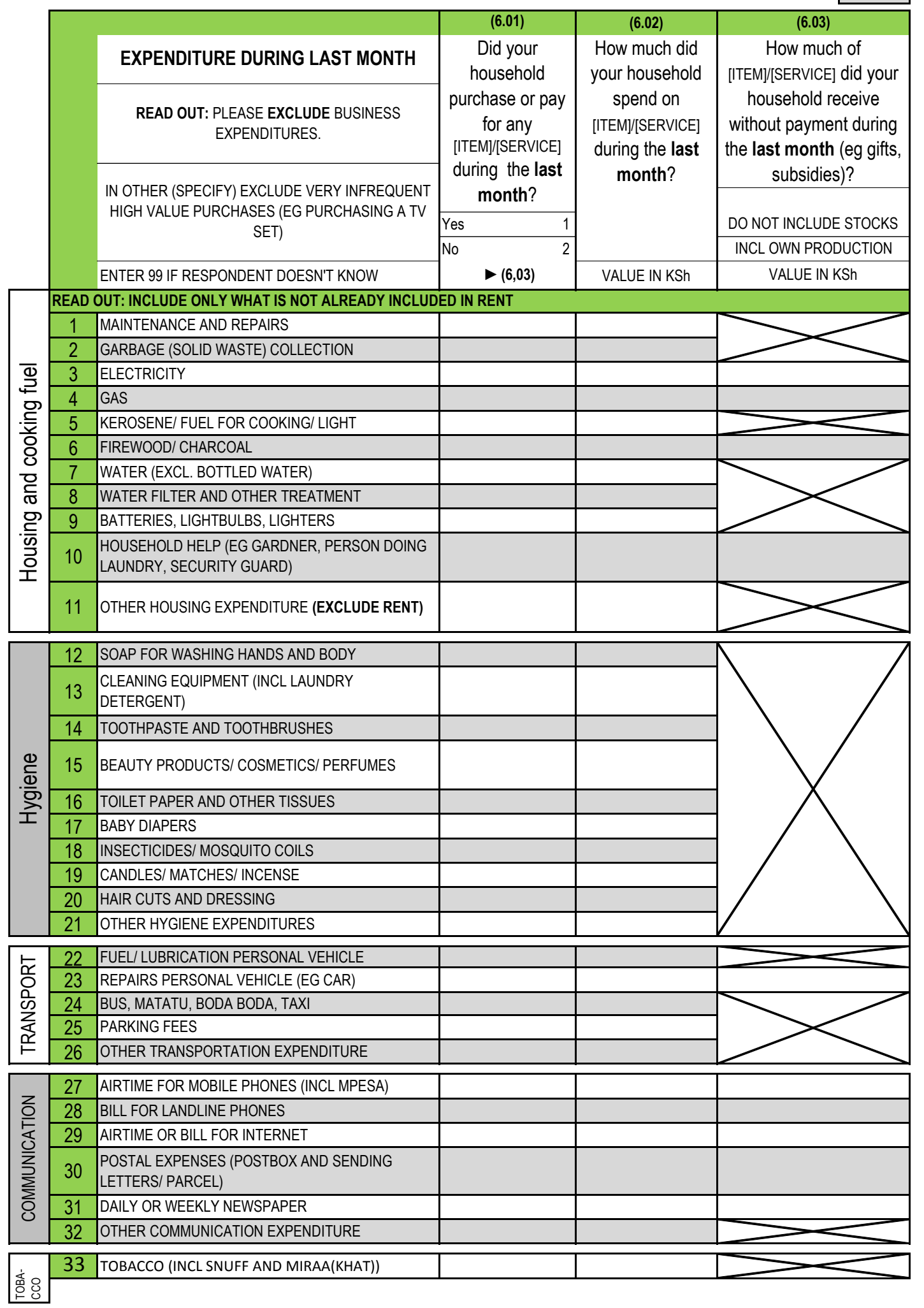


SECTION 6: Non-Food Expenditure

\begin{tabular}{|c|c|c|c|c|c|}
\hline & & & $(6.01)$ & $(6.02)$ & $(6.03)$ \\
\hline & & LAST YEAR & \multirow{3}{*}{$\begin{array}{c}\text { Did your } \\
\text { household } \\
\text { purchase or pay } \\
\text { for any } \\
\text { [ITEM]/[SERVICE] } \\
\text { during the last } \\
\text { year? }\end{array}$} & \multirow{4}{*}{$\begin{array}{l}\text { How much did } \\
\text { your household } \\
\text { spend on } \\
\text { [ITEM]/[SERVICE] } \\
\text { during the last } \\
\text { year? }\end{array}$} & $\begin{array}{c}\text { How much of } \\
\text { [ITEM]/[SERVICE] did }\end{array}$ \\
\hline & & $\begin{array}{c}\text { READ OUT: PLEASE EXCLUDE BUSINESS } \\
\text { EXPENDITURES. }\end{array}$ & & & $\begin{array}{l}\text { the last year (eg gifts, } \\
\text { subsidies)? }\end{array}$ \\
\hline & & & & & DO NOT INCLUDE STOCKS \\
\hline & & \multirow{2}{*}{ ENTER 99 IF RESPONDENT DOESN'T KNOW } & & & INCL OWN PRODUCTION \\
\hline & & & No & VALUE IN KSh & VALUE IN KSh \\
\hline \multirow{5}{*}{$\begin{array}{l}\text { 음 } \\
\text { 융 } \\
\text { 믐 }\end{array}$} & 34 & SCHOOL FEES & & & \\
\hline & 35 & SCHOOL TEXTBOOKS & & & \\
\hline & 36 & STATIONARY (EG PENCILS, NOTEBOOKS) & & & \\
\hline & 37 & SCHOOL UNIFORMS & & & \\
\hline & 38 & OTHER EDUCATION EXPENSES & & & \\
\hline \multirow{8}{*}{ 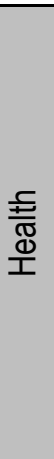 } & 39 & MEDICATION (PURCHASED PRIVATELY) & & & \\
\hline & 40 & $\begin{array}{l}\text { NUTRIENT SUPPLEMENTS (EG IRON, VITAMIN A } \\
\text { PILLS, NUTRITIOUS STONES) }\end{array}$ & & & \\
\hline & 41 & $\begin{array}{l}\text { FEES FOR DOCTORS/ CLINICAL OFFICER (INCL } \\
\text { REGISTRATION FEES) }\end{array}$ & & & \\
\hline & 42 & FEES FOR MIDWIVES/ DELIVERY & & & \\
\hline & 43 & FEES FOR HOSPITAL STAYS (EXCL DELIVERIES) & & & \\
\hline & 44 & FEES FOR TRADITIONAL HEALERS & & & \\
\hline & 45 & $\begin{array}{l}\text { THERAPEUTIC APPLIANCES (EG GLASSES, } \\
\text { CRUTCHES) }\end{array}$ & & & \\
\hline & 46 & OTHER HEALTH EXPENSES & & & \\
\hline
\end{tabular}

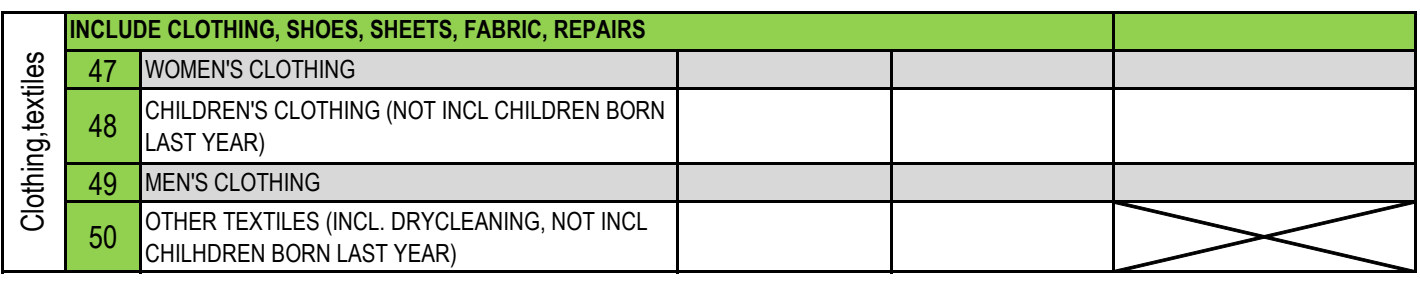

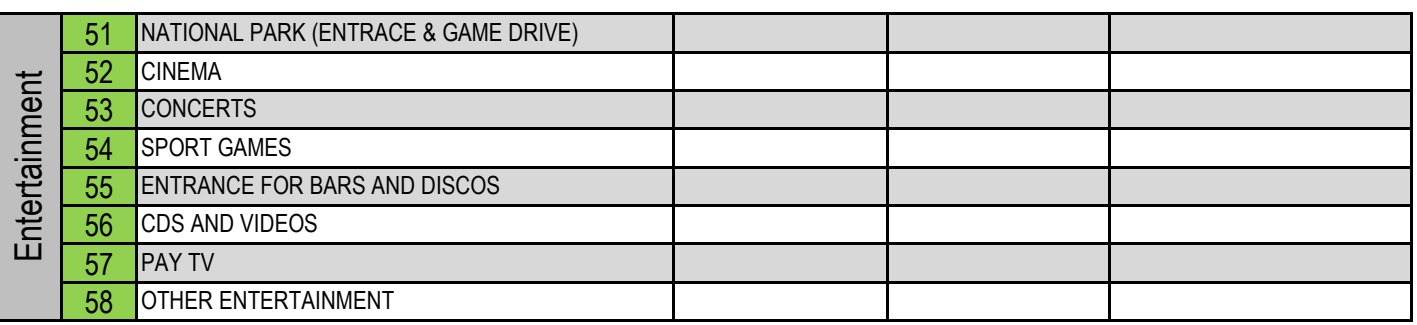

\begin{tabular}{|c|c|l|l|l|l|}
\hline 59 & MAGAZINES AND BOOKS (NO SCHOOLBOOKS) & & & \\
\cline { 2 - 5 } & 60 & $\begin{array}{l}\text { EXPENSES ON CHILDREN BORN LAST YEAR (FIRST } \\
\text { SUPPLY, EG TEXTILES, CRIB) }\end{array}$ & & & \\
\cline { 2 - 6 } & 61 & KITCHEN UTENSILS & & & \\
\cline { 2 - 6 } & 62 & LOAN REPAYMENTS & & & \\
\cline { 2 - 6 } & 63 & CONTRIBUTIONS (EG CHURCH, GROUPS) & & & \\
\hline 64 & INSURANCE (EG CAR, LIFE, HEALTH) & & & \\
\hline 65 & $\begin{array}{l}\text { REMITTANCES TRANSFERED TO OTHER } \\
\text { HOUSEHOLDS }\end{array}$ & & & \\
\hline 6 & $\begin{array}{l}\text { ATTENDING OR HOSTING SPECIAL OCCASIONS (EG } \\
\text { WEDDING, GRADUATION) }\end{array}$ & & & \\
\hline
\end{tabular}

(6.04) Taken together, how much did your household approximately spend on last months food consumption and non-food expenditure? 


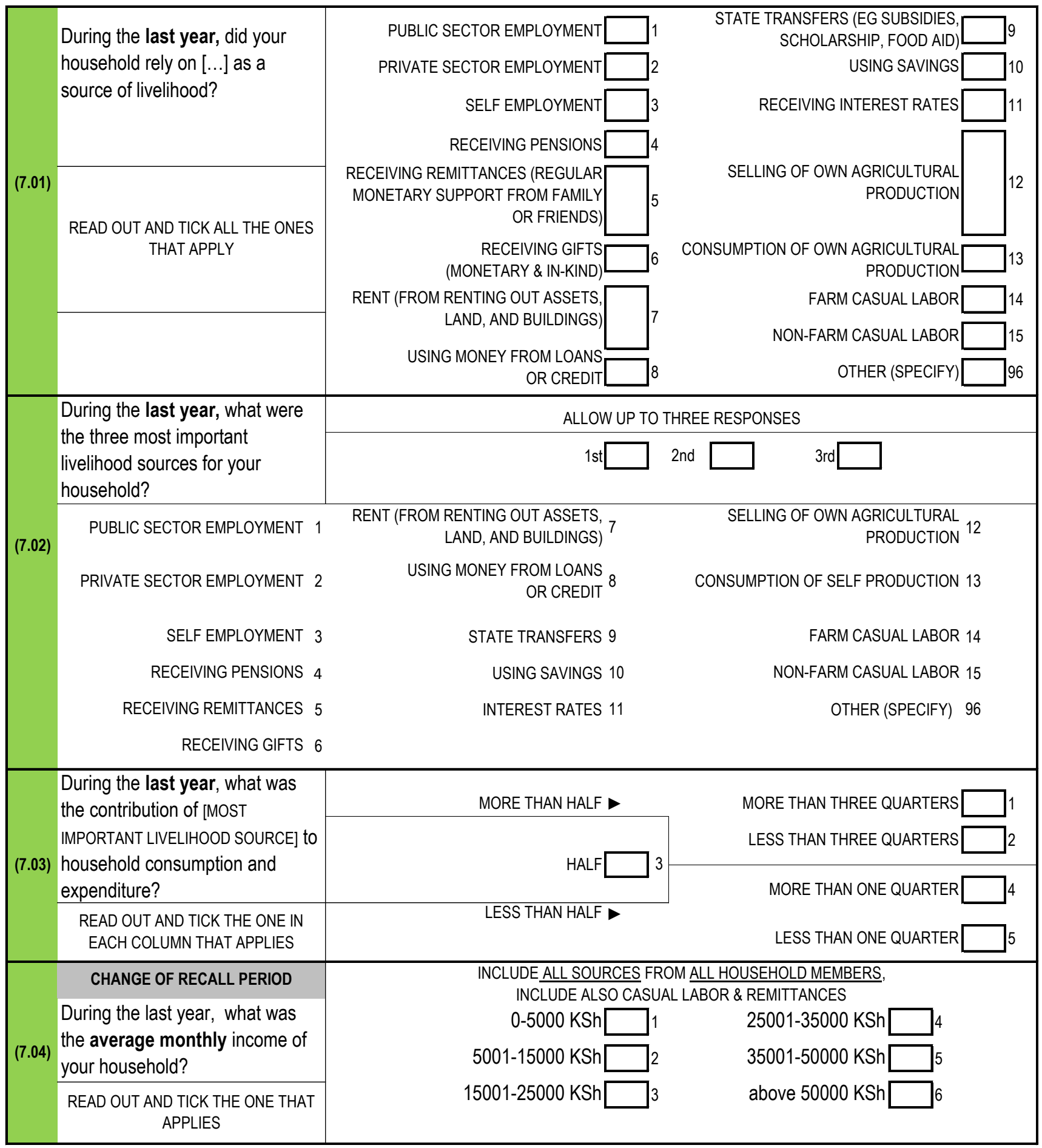

HHID: 
SECTION 8: Health

\begin{tabular}{|c|c|c|c|c|c|c|c|}
\hline \multirow{21}{*}{\begin{tabular}{|l} 
\\
\\
\\
$\Psi$ \\
0 \\
0 \\
$\varrho$ \\
$己$
\end{tabular}} & \multirow{9}{*}{$\begin{array}{c}\text { (8.01) } \\
\text { What chronic } \\
\text { illnesses/ } \\
\text { conditions has } \\
\text { [NAME] been } \\
\text { diagnosed } \\
\text { with and is still } \\
\text { suffering from, } \\
\text { if any? }\end{array}$} & \multirow{9}{*}{$\begin{array}{c}\text { (8.02) } \\
\text { For how } \\
\text { long has } \\
\text { [NAME] } \\
\text { been } \\
\text { diagnosed } \\
\text { with this } \\
\text { [CHRONIC } \\
\text { ILLNESS/CO } \\
\text { NDITION]? }\end{array}$} & \multirow{4}{*}{$\begin{array}{c}\text { (8.03) } \\
\text { Who told [NAME] that } \\
\text { he/she was suffering } \\
\text { from this [CHRONIC } \\
\text { ILLNESS/CONDITION]? }\end{array}$} & \multirow{10}{*}{\begin{tabular}{|c|} 
(8.04) \\
Since the \\
diagnosis of this \\
[CHRONIC \\
ILLNESS/CONDITI \\
ON], what have \\
been the total \\
direct costs \\
associated with \\
diagnosis and \\
treatment?
\end{tabular}} & \multirow{10}{*}{$\begin{array}{c}\text { (8.06) } \\
\text { During the } \\
\text { last } \\
\text { month, has } \\
\text { [NAME] } \\
\text { suffered } \\
\text { from any } \\
\text { other } \\
\text { illnesses/ } \\
\text { conditions } \\
?\end{array}$} & \multirow{4}{*}{$\begin{array}{l}\text { (8.07) } \\
\text { From whom did [NAME] } \\
\text { seek medical advice for } \\
\text { this [ILLNESS/ CONDITION], } \\
\text { if any? }\end{array}$} & \multirow{2}{*}{\begin{tabular}{|c} 
IF MORE THAN TWO ILLNESSES \\
RECORD THE TWO MOST \\
SEVERE \\
\end{tabular}} \\
\hline & & & & & & & \\
\hline & & & & & & & CHRONIC ILLNESSES \\
\hline & & & & & & & DIABETES 1 \\
\hline & & & & & & \multirow{2}{*}{$\begin{array}{l}\text { Medical Doctor/ } \\
\text { Clinical Officer }\end{array}$} & HYPERTENSION \\
\hline & & & Medical Doctor/ & & & & CARDIOVASCULAR/ HEART \\
\hline & & & Clinical Officer & & & \multirow{2}{*}{$\begin{array}{l}\text { Medical worker in } \\
\text { hospital }\end{array}$} & DISEASE \\
\hline & & & Medical worker in & & & & KWASHIAKOR \\
\hline & & & hospital & & & \multirow{2}{*}{$\begin{array}{l}\text { Medical worker at } \\
\text { dispensary }\end{array}$} & CANCER (Specify) \\
\hline & \multirow{5}{*}{$\begin{array}{l}\text { READ OUT } \\
\text { CHRONIC } \\
\text { DISEASES ON } \\
\text { THE RIGHT }\end{array}$} & & Medical worker at & & & & HIGH CHOLESTEROL \\
\hline & & & dispensary & \multirow{10}{*}{$\begin{array}{c}\text { READ OUT: } \\
\text { INCLUDE } \\
\text { TRANSPORTATION } \\
\text {, DIAGNOSIS, } \\
\text { MEDICATION, } \\
\text { MEDICAL CARE. } \\
\text { DO NOT INCLUDE } \\
\text { INCOME LOSS } \\
\text { AND OTHER } \\
\text { OPPORTUNITY } \\
\text { COSTS }\end{array}$} & & \multirow{2}{*}{$\begin{array}{l}\text { Medical worker at } \\
\text { non-health facility }\end{array}$} & ANAEMIA \\
\hline & & & Medical worker at & & & & RICKETTS \\
\hline & & & non-health facility & & & Pharmacist & \multirow{2}{*}{$\begin{array}{l}\text { IF NOT BY BIRTH: } \\
\text { BLINDNESS/ LOSS OF } \\
\text { (NIGHT)VISION }\end{array}$} \\
\hline & & & \begin{tabular}{|l} 
Pharmacist \\
Traditional healer
\end{tabular} & & & \begin{tabular}{|l} 
Traditional healer \\
Community Health
\end{tabular} & \\
\hline & \multirow{6}{*}{$\begin{array}{l}\text { IF NO ILLNESS } \\
\text { FILL IN 97, IF } \\
\text { DON'T KNOW, } \\
\text { FILL IN } 99 \text { AND } \\
\text { NEXT PERSON }\end{array}$} & & Community Health & & $\begin{array}{c}\text { IF NO } \\
\text { ILLNESS FILL }\end{array}$ & $\begin{array}{l}\text { Community Health } \\
\text { Worker }\end{array}$ & GOITER \\
\hline & & & Worker & & IN 97, IF & Advice from non- & GOUT \\
\hline & & & Self diagnosis/ & & DON'T KNOW, & medical persons (eg & BAD TEETH \\
\hline & & & other household & & $\begin{array}{c}\text { FILL IN } 99 \\
\text { AND } \triangleright \text { NEXT }\end{array}$ & friend, neighbour) & \\
\hline & & & Other (Specify) & & PERSON & Other (Specify) & \\
\hline & & & Don't know & & & Don't know & \\
\hline & CODE & MONTHS & CODE & KSh & CODE & CODE & NON-CHRONIC ILLNESSES \\
\hline 1 & 1 st & 1 st & 1 st & 1 st & 1 st & 1 st & FEVER, MALARIA \\
\hline 1 & 2nd & 2nd & 2nd & 2nd & 2nd & 2nd & DIARRHOEA \\
\hline 2 & 1 st & 1 st & 1 st & 1 st & 1 st & 1 st & STOMACH ACHE \\
\hline 2 & 2nd & 2nd & 2nd & 2nd & 2nd & 2nd & VOMITING \\
\hline 3 & 1 st & 1 st & 1 st & 1 st & 1 st & 1 st & FLU/ COLD \\
\hline 3 & 2nd & 2nd & 2nd & 2nd & 2nd & 2nd & HEADACHE \\
\hline 4 & 1 st & 1 st & 1 st & $1 s t$ & 1 st & 1 st & SKIN PROBLEM \\
\hline 4 & 2nd & 2nd & 2nd & 2nd & 2nd & 2nd & BAD TEETH (ACHE) \\
\hline 5 & 1 st & 1 st & 1 st & 1 st & 1 st & 1 st & EYE PROBLEM \\
\hline 0 & 2nd & 2nd & 2nd & 2nd & 2nd & 2nd & EAR/NOSE/THROAT \\
\hline 6 & 1 st & 1 st & 1 st & 1 st & 1 st & 1 st & PAIN WHEN PASSING URIN \\
\hline 0 & 2nd & 2nd & 2nd & 2nd & 2nd & 2nd & TAIN VUTEIV FAOSING URIIN \\
\hline 7 & 1 st & $1 s t$ & 1 st & $1 \mathrm{st}$ & 1 st & 1 st & TUBERCULOSIS \\
\hline$T$ & 2nd & 2nd & 2nd & 2nd & 2nd & 2nd & KWASHIAKOR \\
\hline 8 & 1 st & 1 st & 1 st & 1 st & 1 st & $1 s t$ & TYPHOID \\
\hline 8 & 2nd & 2nd & 2nd & 2nd & 2nd & 2nd & PNEUMONIA \\
\hline$a$ & 1 st & 1 st & 1 st & 1 st & 1 st & $1 s t$ & FAINTING \\
\hline$y$ & 2nd & 2nd & 2nd & 2nd & 2nd & 2nd & INTESTINAL WORMS \\
\hline 10 & 1 st & 1 st & 1 st & 1 st & 1 st & 1 st & OTHER (SPECIEY) \\
\hline 10 & 2nd & 2nd & 2nd & 2nd & 2nd & 2nd & OIHER (SPECIFY) \\
\hline 11 & 1st & 1 st & 1 st & $1 s t$ & 1 st & $1 s t$ & \\
\hline 11 & 2nd & 2nd & 2nd & 2nd & 2nd & 2nd & \\
\hline 12 & $1 s t$ & 1 st & 1st & $1 s t$ & 1st & 1st & \\
\hline & 2nd & 2nd & 2nd & 2nd & 2nd & 2nd & \\
\hline 12 & 1 st & 1st & 1st & 1st & 1st & 1st & \\
\hline 13 & 2nd & 2nd & 2nd & 2nd & 2nd & 2nd & \\
\hline 14 & $1 s t$ & 1 st & $1 s t$ & $1 s t$ & 1st & 1st & \\
\hline & 2nd & 2nd & 2nd & 2nd & 2nd & 2nd & \\
\hline 15 & $1 s t$ & 1 st & $1 \mathrm{st}$ & 1 st & 1 st & 1st & \\
\hline & 2nd & 2nd & 2nd & 2nd & 2nd & 2nd & \\
\hline
\end{tabular}

\begin{tabular}{|c|c|}
\hline $\begin{array}{c}\text { RECORD UP TO TWO ILLNESSES } \\
\text { PER MEMBER }\end{array}$ \\
\hline
\end{tabular}

\begin{tabular}{|c|c|}
\hline $\begin{array}{c}\text { RECORD UP TO TWO ILLNESSES } \\
\text { PER MEMBER }\end{array}$ \\
\hline
\end{tabular}

RESPONDENT ID:

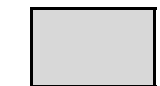

$(8.01)$

hat chronic

conditions has

diagnosed

with and is still

ring from

READ OUT

FILL IN 97, IF

DON'T KNOW,

FILL IN 99 AND

NEXT PERSON

CODE
Medicalv

dispensary

non-health facility

Pharmacist Community Health

Worker

Self diagnosis

members

Other (Specify) CODE

\section{(8.06)}

ring the

onth, has

any 
READ OUT: NOW I WOULD LIKE TO ASK YOU SOME QUESTIONS THAT WILL HELP US UNDERSTAND THE KNOWLEDGE ABOUT NUTRITION AND HEALTH OF THIS HOUSEHOLD. IF YOU ARE UNSURE ABOUT SOME QUESTIONS, PLEASE ALWAYS SAY SO AND DO NOT GUESS A RESPONSE.

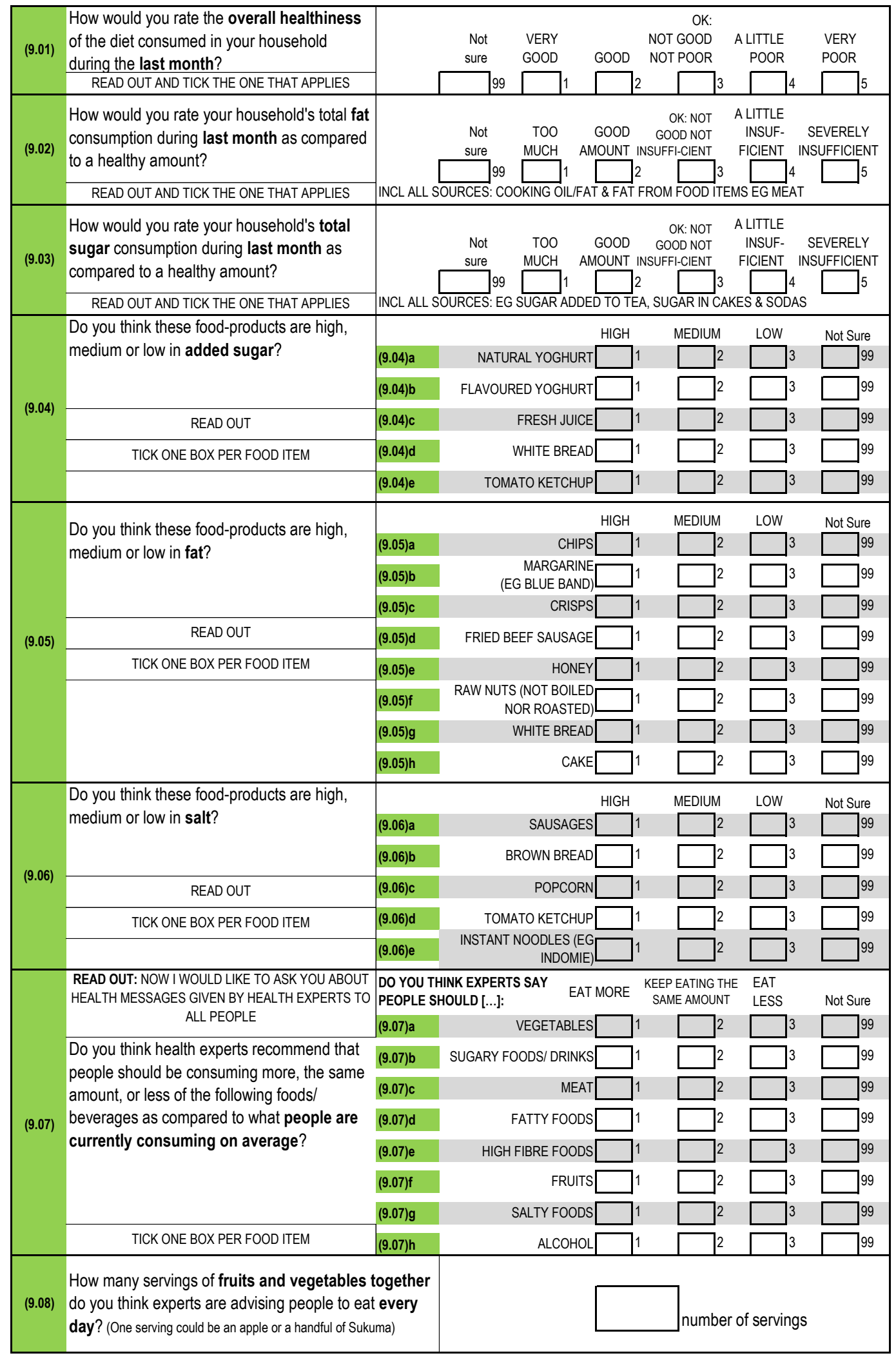


SECTION 9: Health Knowledge

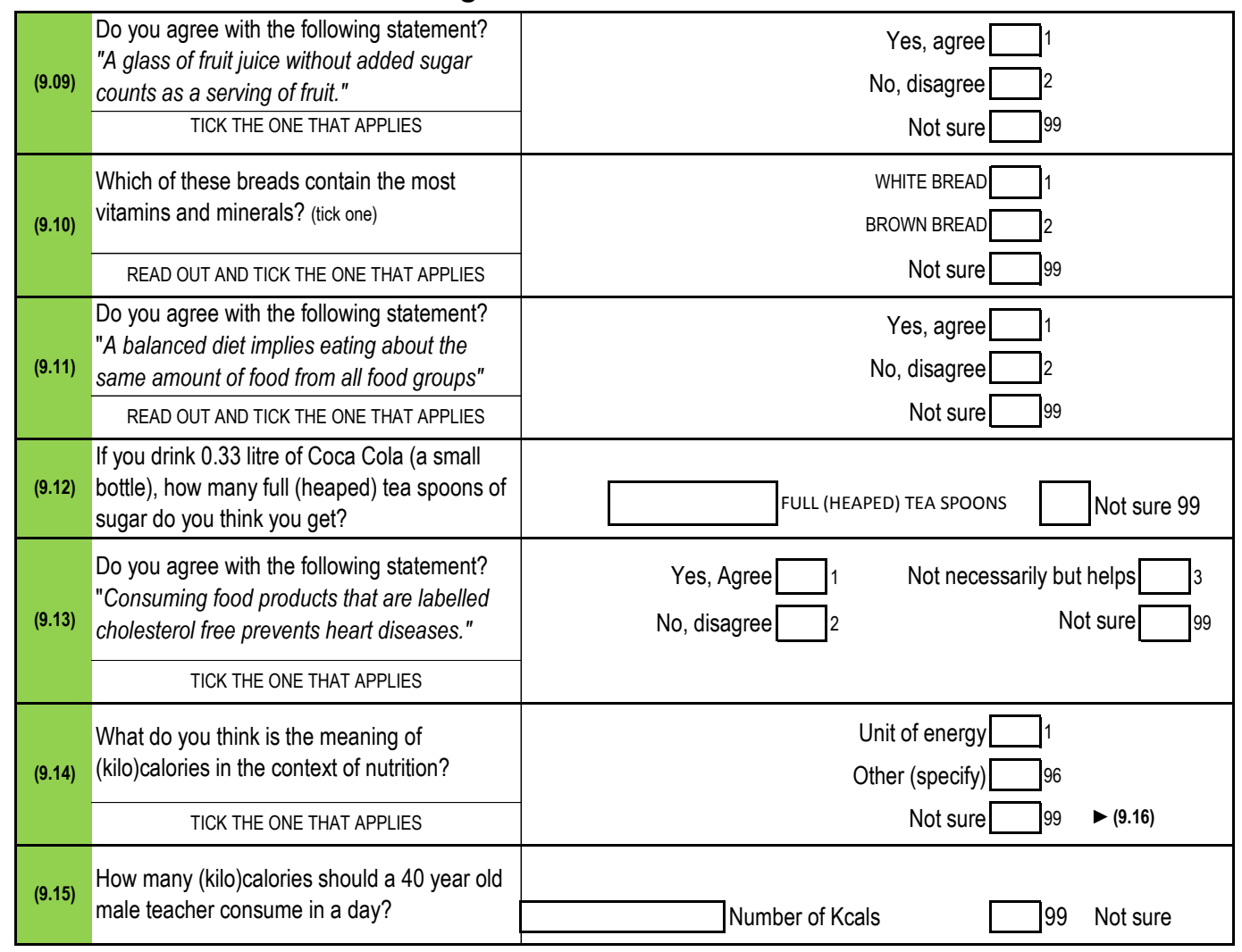

READ OUT: THE NEXT FEW QUESTIONS ARE ABOUT CHOOSING FOODS. PLEASE ANSWER WHAT IS BEING ASKED AND NOT WHETHER YOU LIKE OR DISLIKE THE FOOD!

\begin{tabular}{|c|c|c|c|}
\hline \multirow[t]{2}{*}{ (9.16) } & $\begin{array}{l}\text { If a person wanted to reduce the amount of fat } \\
\text { in their diet, which would be the best choice to } \\
\text { eat? }\end{array}$ & $\begin{array}{l}\text { STEWED KIENYEJI CHICKEN (1/4 KG) } \\
\text { ROASTED GOAT MEAT (1/4 KG) }\end{array}$ & ] 1 \\
\hline & READ OUT AND TICK THE ONE THAT APPLIES & DEEP FRIED TILAPIA FISH $(1 / 4 \mathrm{KG})$ & 3 \\
\hline \multirow[t]{2}{*}{ (9.17) } & $\begin{array}{l}\text { If a person felt like eating something sweet, } \\
\text { but was trying to cut down on sugar, which } \\
\text { would be the best choice? }\end{array}$ & $\begin{array}{l}2 \text { SLICES OF WHITE BREAD WITH FRUIT JAM } \\
\text { 1 SMALL BOTTLE OF COKE OR FANTA }\end{array}$ & 1 \\
\hline & READ OUT AND TICK THE ONE THAT APPLIES & 1 BANANA AND 500 ML PACK OF FLAVOURED YOGHURT & \\
\hline
\end{tabular}

READ OUT: THE NEXT QUESTIONS ARE ABOUT THE RELATIONSHIP BETWEEN NUTRITION AND HEALTH

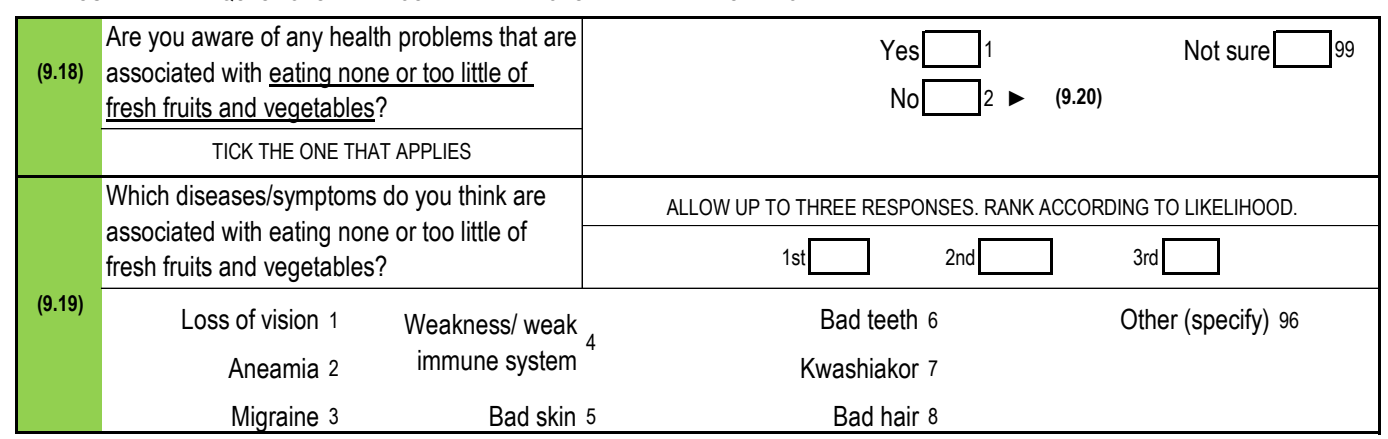


SECTION 9: Health Knowledge

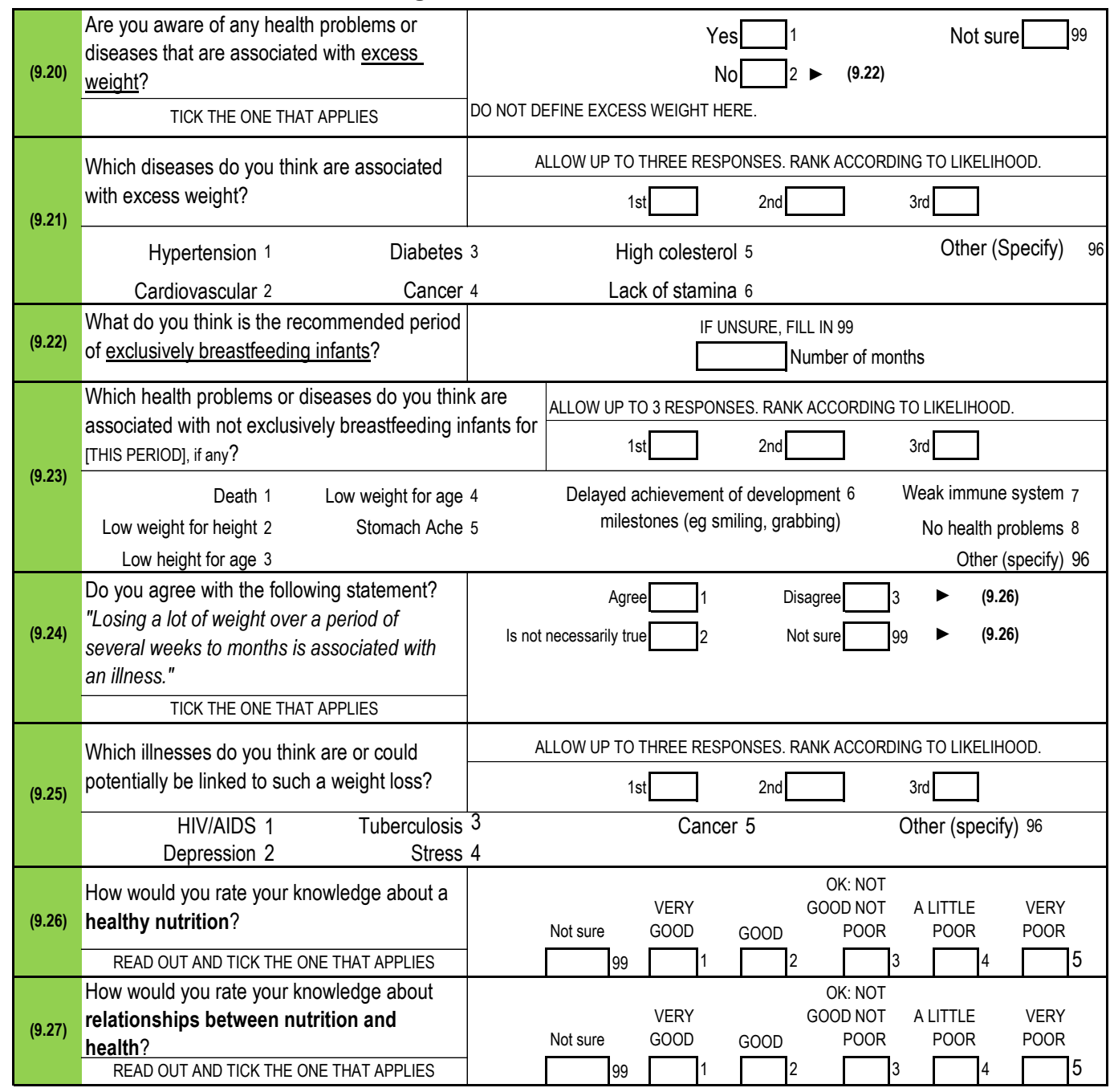

READ OUT: THE NEXT QUESTIONS ARE ABOUT SOURCES OF NUTRITION AND HEALTH INFORMATION

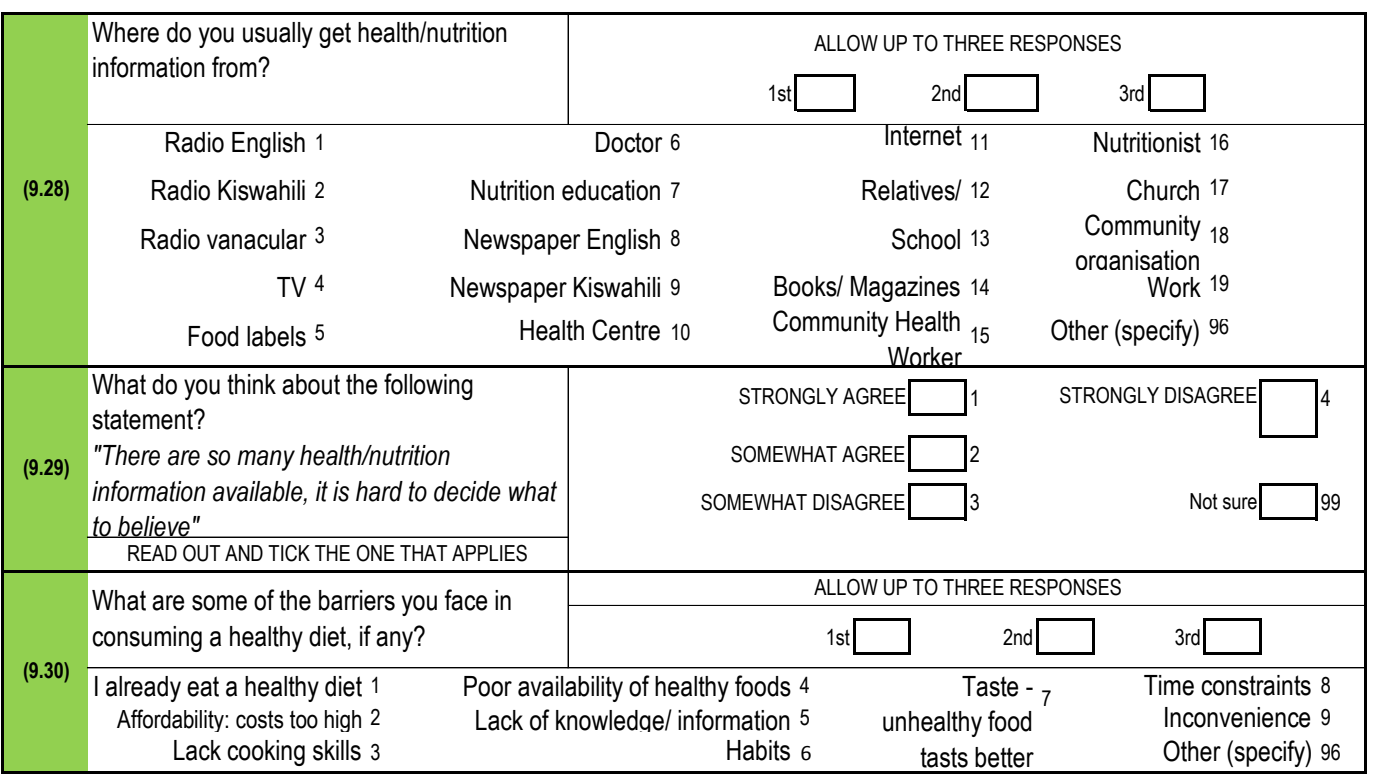


SECTION 10: Housing

RESPONDENT ID:

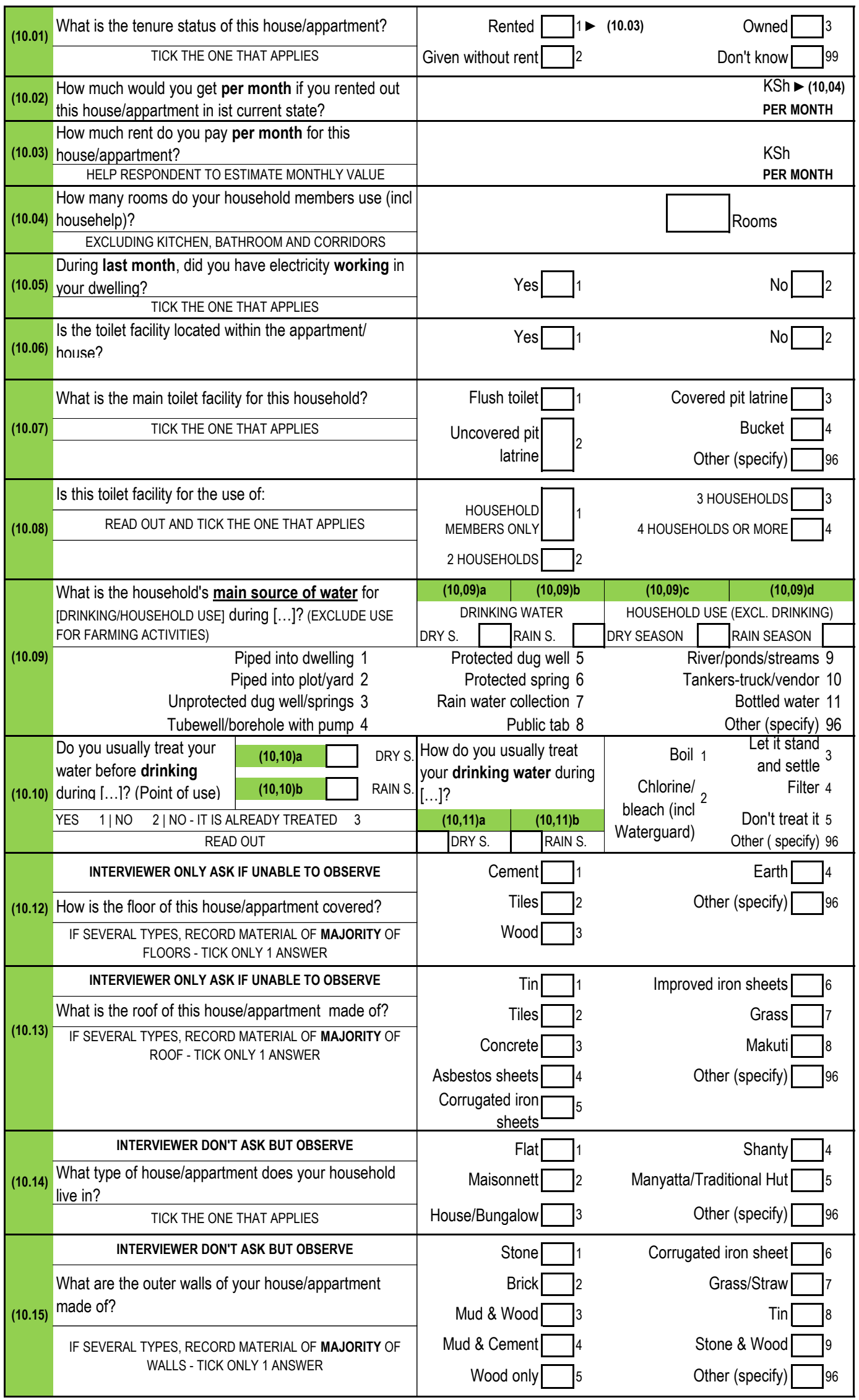

HHID: 
SECTION 11: Assets

RESPONDENT ID:

INTRODUCTION: DO NOT COUNT PERMANENTLY BROKEN ITEMS. COUNT ITEMS OF ALL HOUSEHOLD MEMBERS.



Does your household have any agricultural activities?

Is your household usually able to store food you produce to the extent and for the period that you wanted to?

Why is your household not able to store food to the extent and for the period that you wanted to?

(11.06) ALLOW UP TO THREE RESPONSES

\begin{tabular}{|l|}
\hline \\
\hline \\
\hline \\
\hline \\
\hline \\
\hline
\end{tabular}

\begin{tabular}{|lr|}
\hline Yes & 1 \\
\hline No & 2 \\
NEXT SECTION & \\
\hline YeS & 1 \\
\hline NEXT SECTION & \\
\hline
\end{tabular}

Not enough production 1

No appropriate storing facility 2

Sell right away in need for cash 3

Only produce perishable items 4

Sell after harvest because price is high 5

Don't want to incure costs for storage (eg chemicals, storage space in commercial storage) 6

Danger of theft 7

Other (specify) 96 
READ OUT: AS YOU KNOW; WE HAVE ASKED YOU QUESTIONS ABOUT HEALTH AND DISEASES IN THE PREVIOUS SECTIONS. WE ARE ALSO INTERESTED TO KNOW IF YOUR HOUSEHOLD HAS LOST MEMBERS THROUGH DEATH IN THE PAST FIVE YEARS DUE TO THE DISEASES WE PREVIOUSLY TALKED ABOUT. THIS IS WHY I WILL ASK YOU SOME QUESTIONS ABOUT DECEASED HOUSEHOLD MEMBERS AND CLOSE RELATIVES (PARENTS, GRANDPARENTS, CHILDREN AND SIBLINGS). PLEASE ANSWER AS ACCURATELY AS YOU CAN.

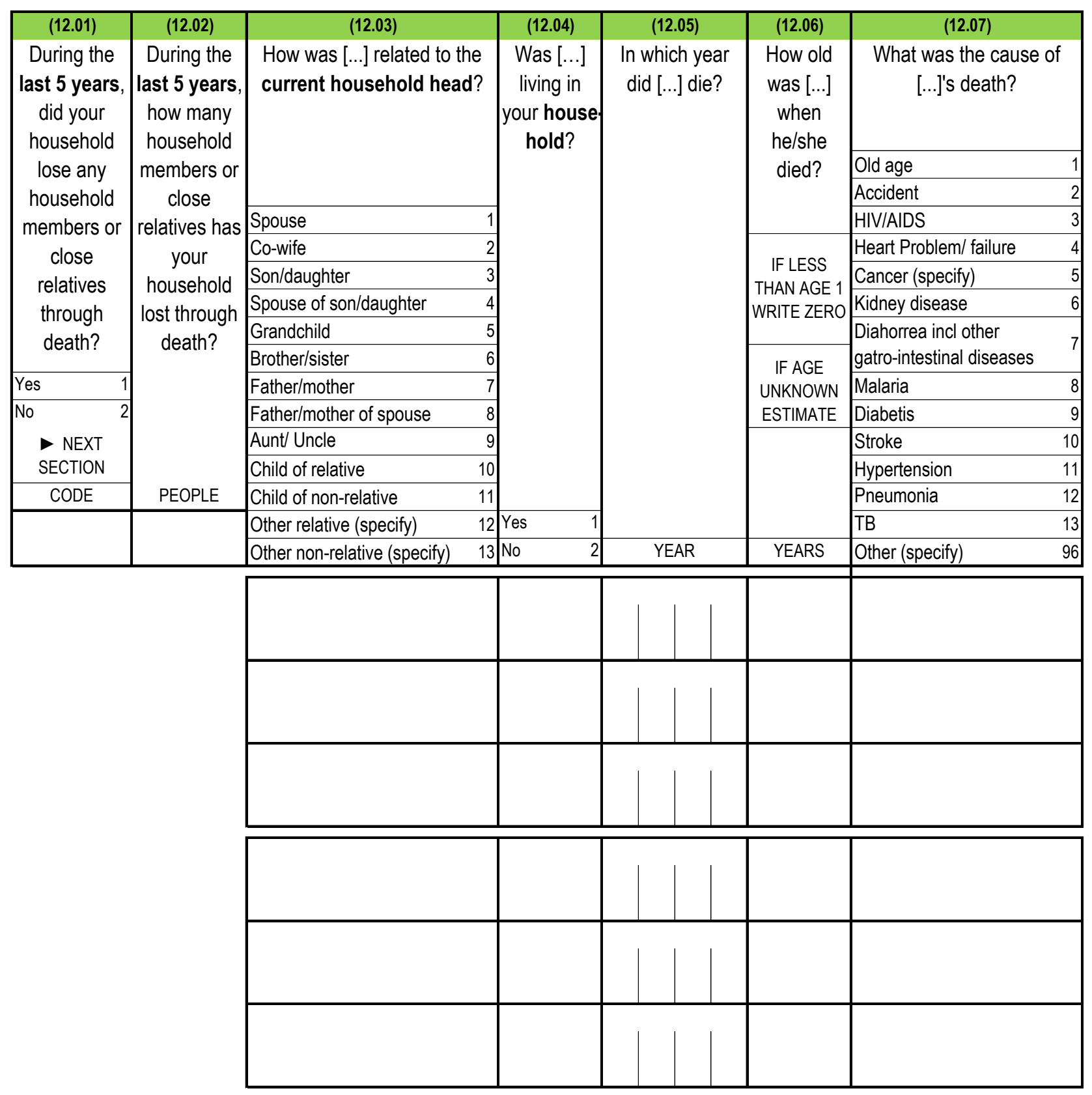

HHID: 


\section{SECTION 13: Weight and Health Related Behaviour and Food Eaten Away From Home}

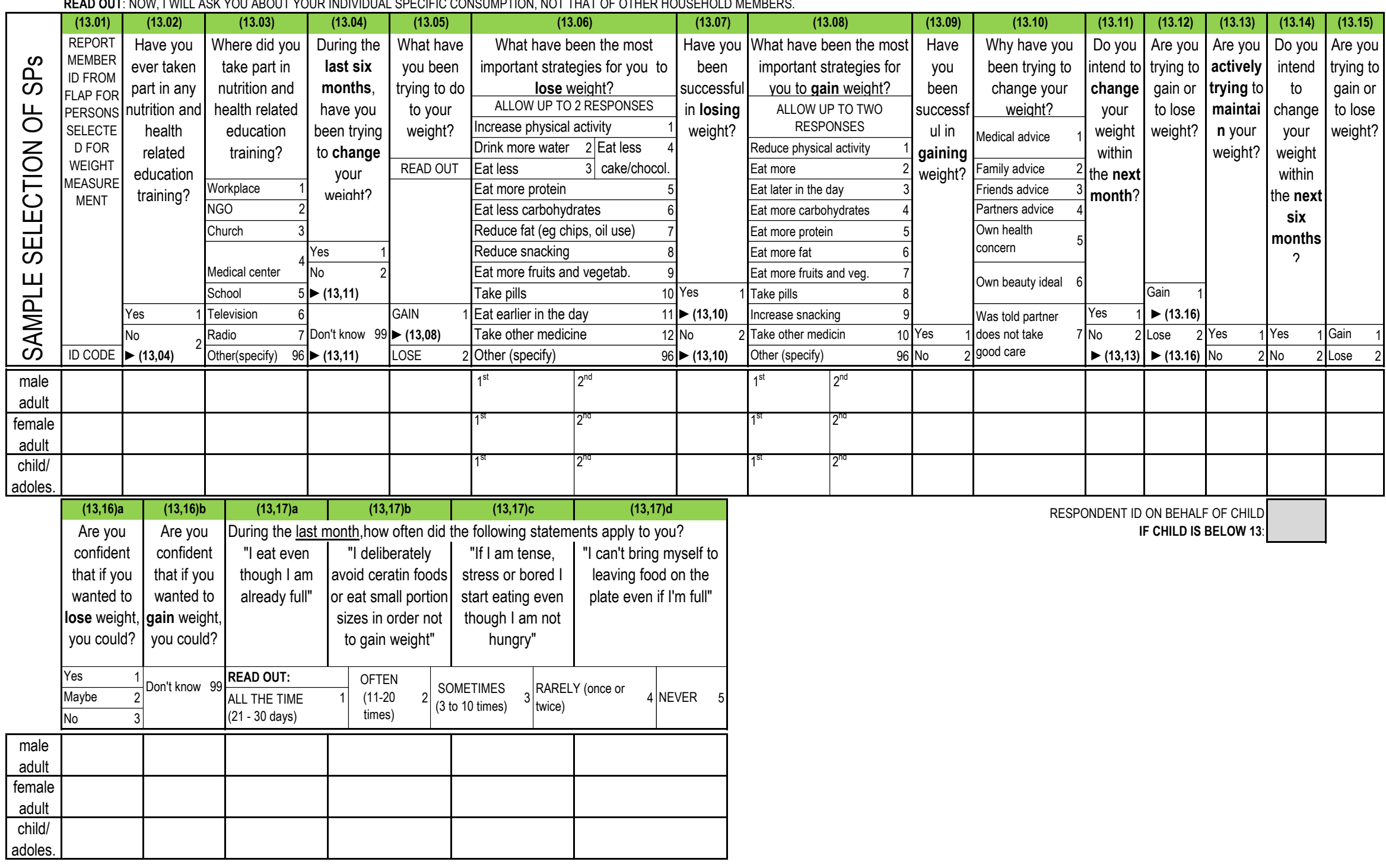


SECTION 13: Weight and Health Related Behaviour and Food Eaten Away From Home

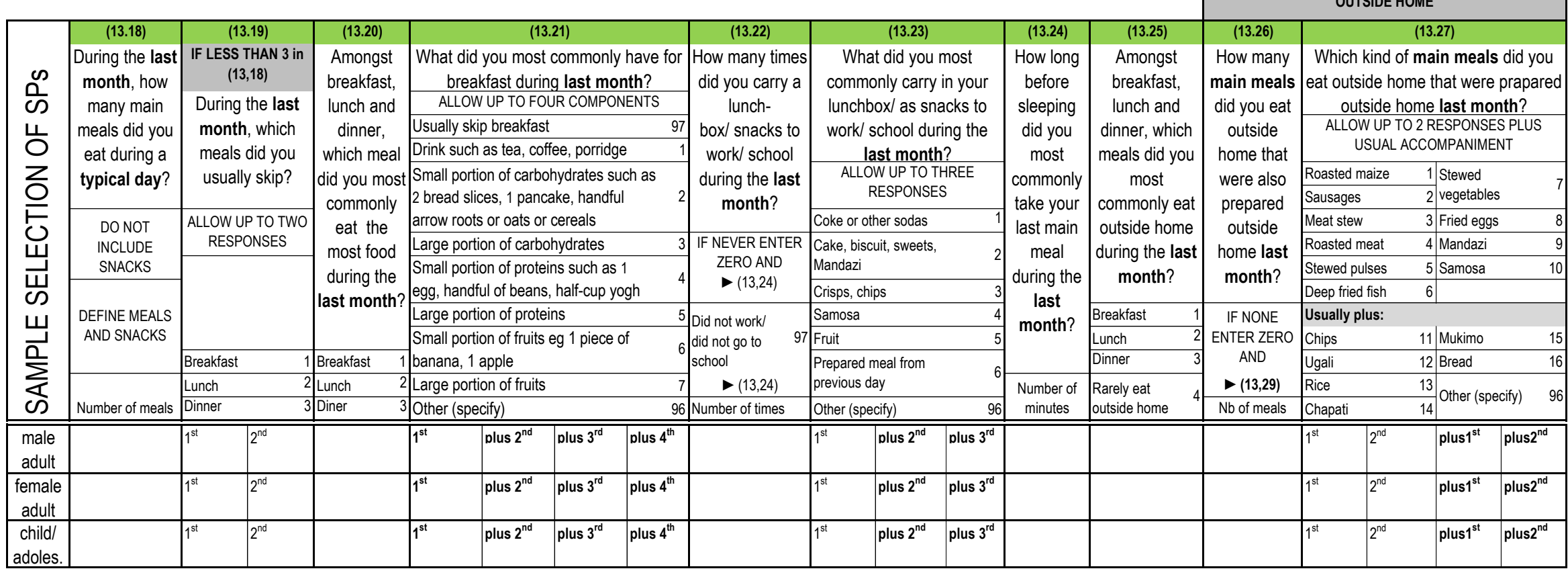


SECTION 13: Weight and Health Related Behaviour and Food Eaten Away From Home

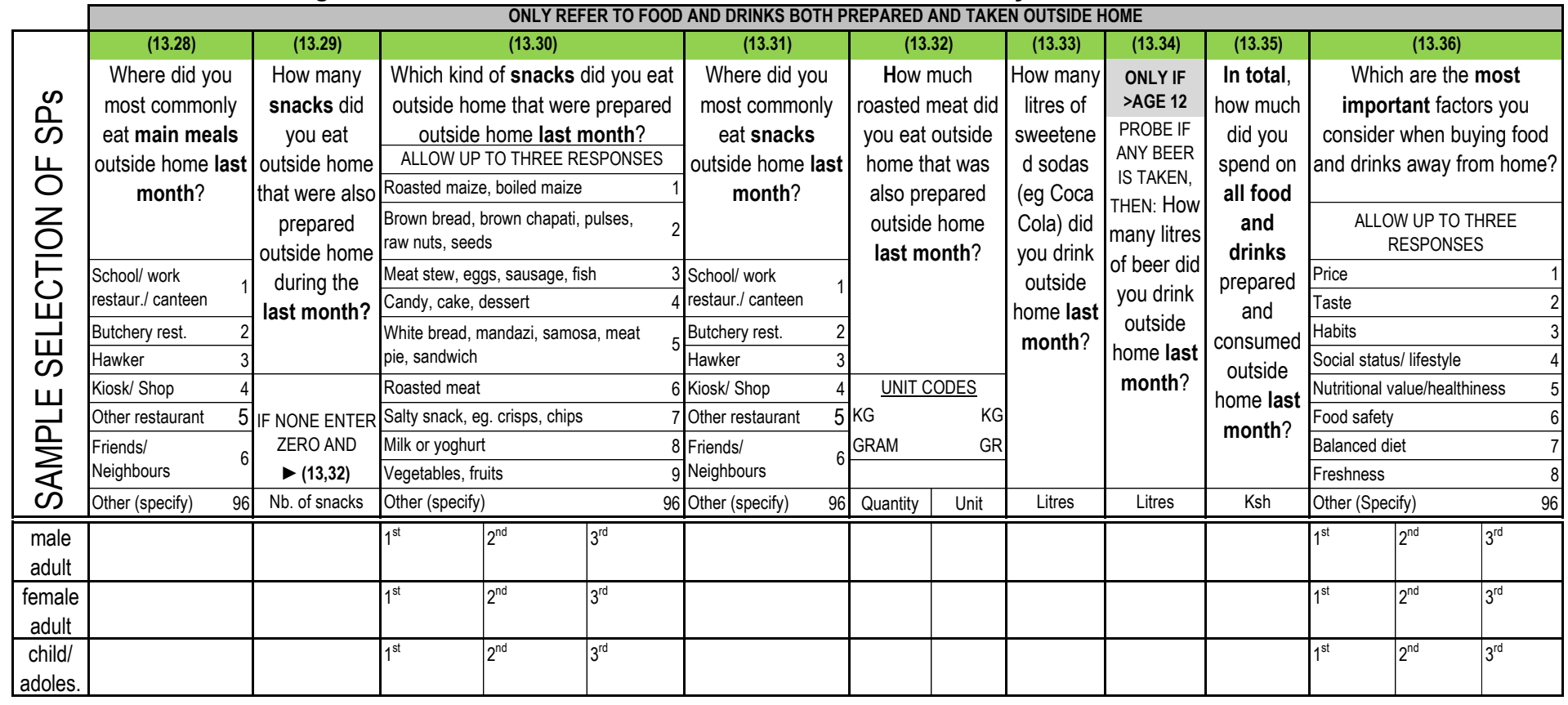


SECTION 14: Physical Activity at Work

READ OUT: NOW, I AM ASKING ABOUT WORK RELATED PHYSICAL ACTIVITY. FOR THE RESPONSES, PLEASE CONSIDER THE PERIOD OF THE LAST 6 MONTHS. PLEASE CONSIDER ALL OCCUPATIONAL ACTIVITIES.

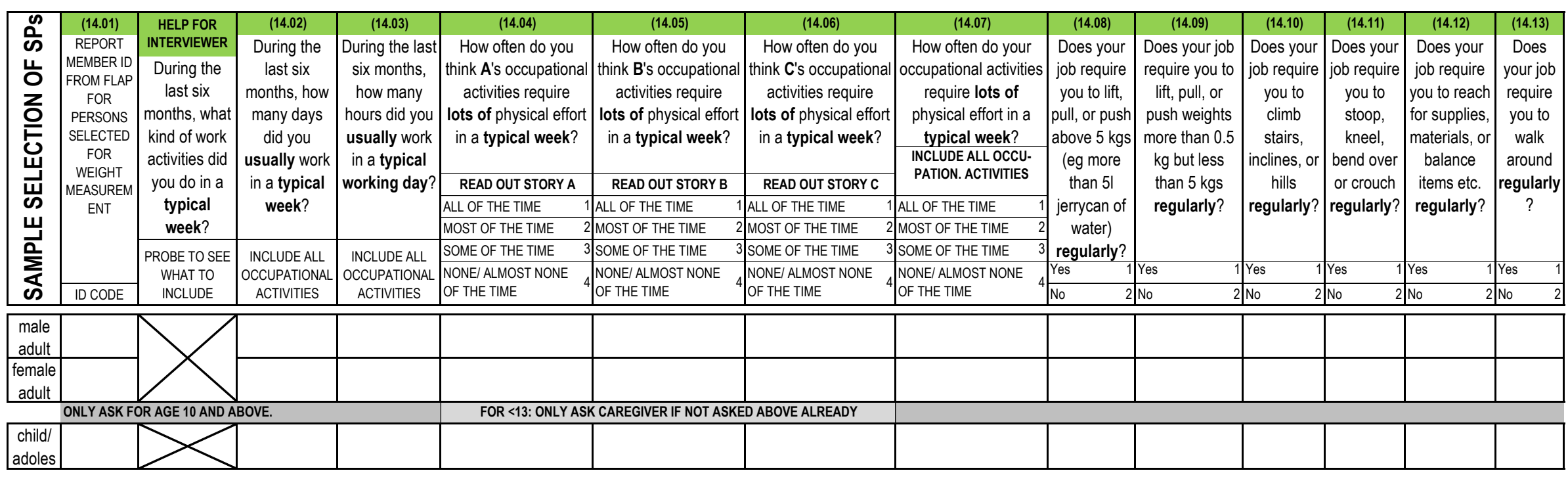

STORY A

Person A is a primary school teacher. Person A is teaching English and Math lessons.

A is usually teaching 7 hours a day, 5 days a week. Person A does teaching mainly standing but sometimes sitting down.

RESPONDENT ID ON BEHALF OF CHILD

1 day a week for 7 hours that day, Person $A$ is operating the kiosk of his/her spouse.

\section{STORY B}

Person $B$ is a casual construction worke

B usually works 7 hourhs a day, 6 days a week.

Most of the times, B is responsible for providing coworkers with a sand cement mix. This involves transporting the ingredients to the mixing point, manually mixing sand, cement and water

and transporting the mix to the coworkers with a wheelbarrow.

\section{STORY C}

Person $\mathrm{C}$ works in a butchery.

C usually works 7 hours a day, 6 days a week.

$C$ usually receives a full cow carcas three times a week that he has to cut into large pieces and hang. This takes him 30 minutes per cow.

When serving customers, $\mathrm{C}$ sometimes has to unhang the pieces. Most of the time $\mathrm{C}$ can cut the meat for the customers from the hanging pieces directly.

$\mathrm{C}$ also is responsible for weighing and wrapping the meat and cutting into small pieces if the customer wishes. 
SECTION 15: Physical and leisure related activity

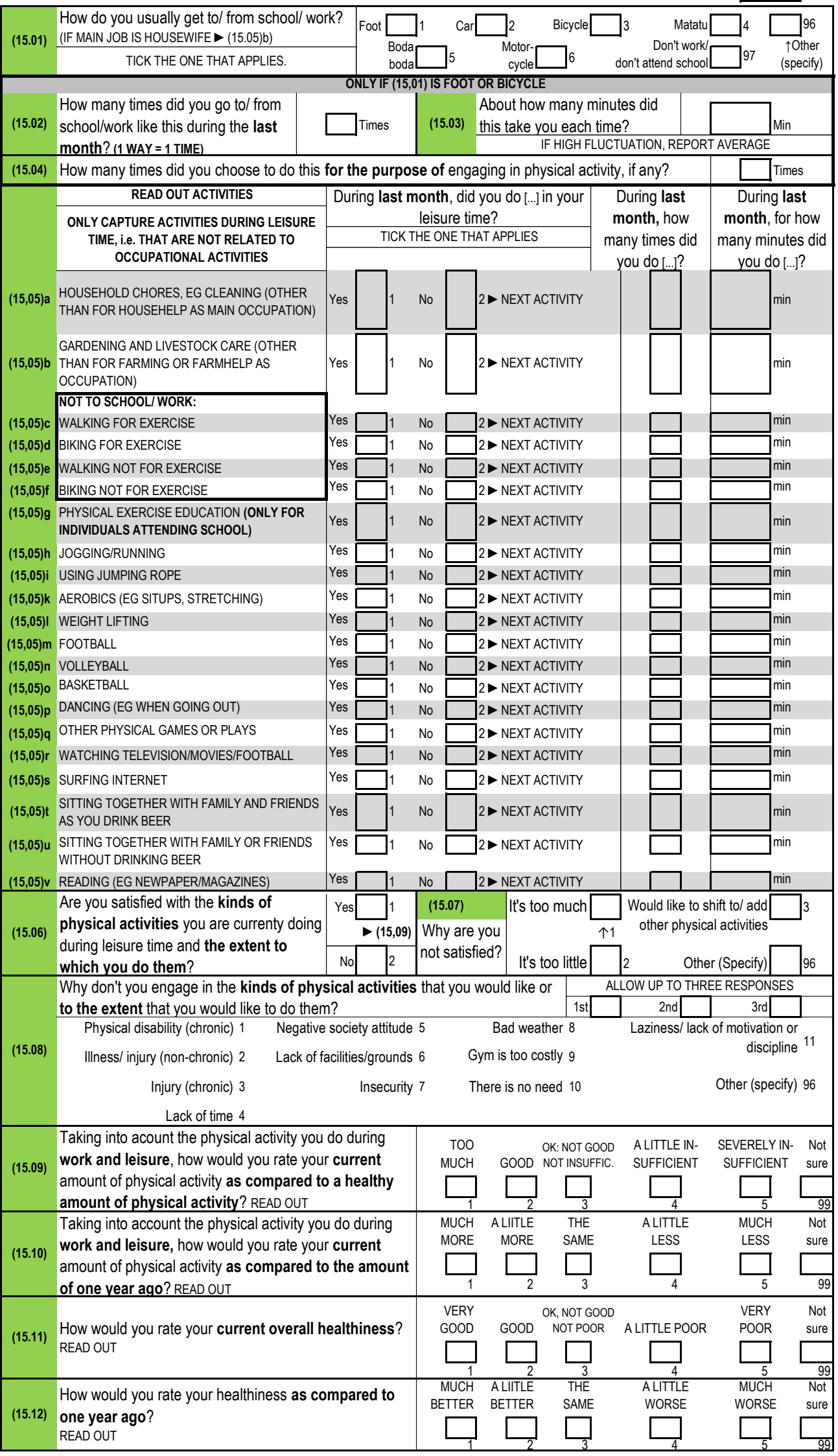


SECTION 15: Physical and leisure related activity

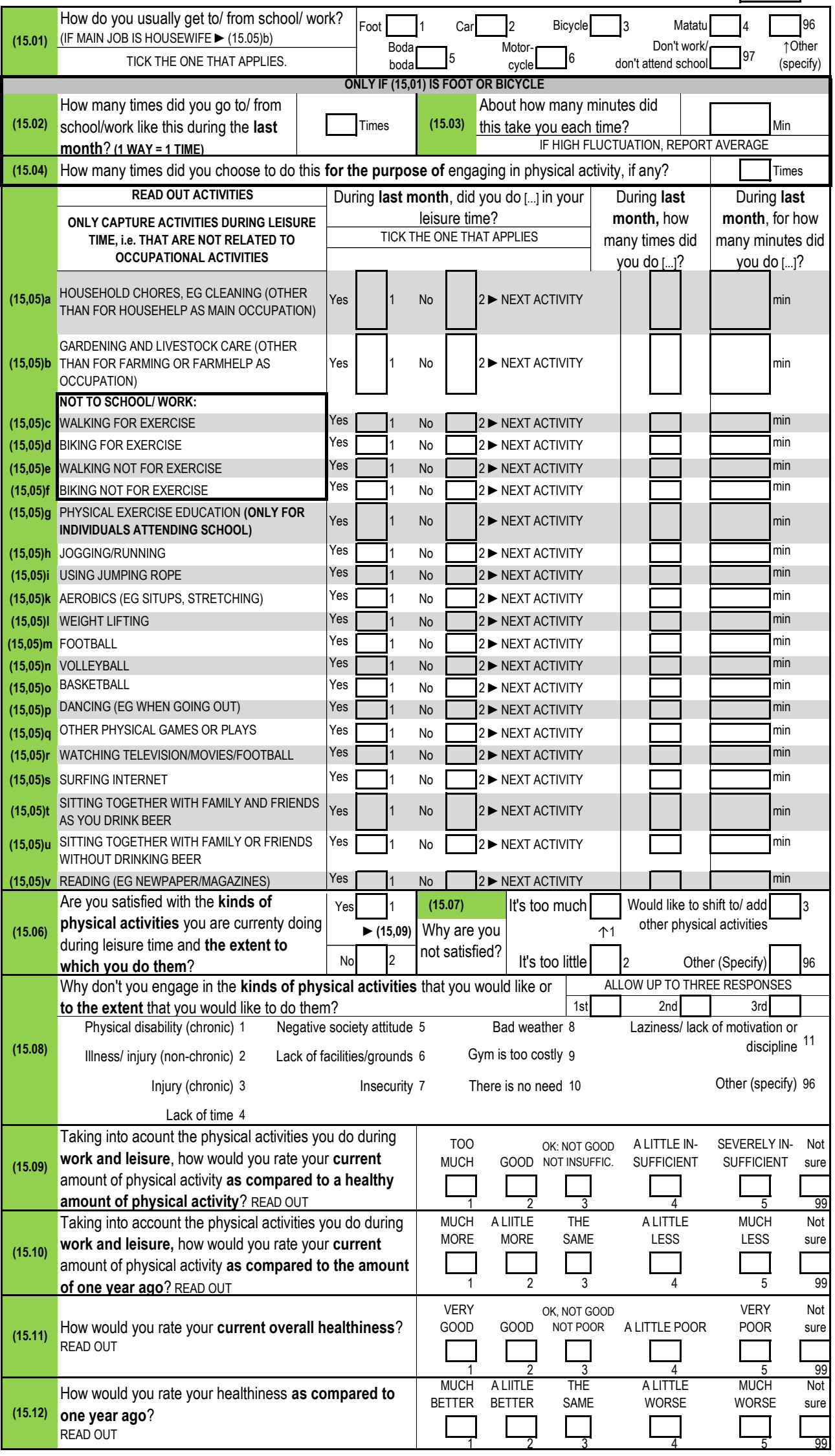




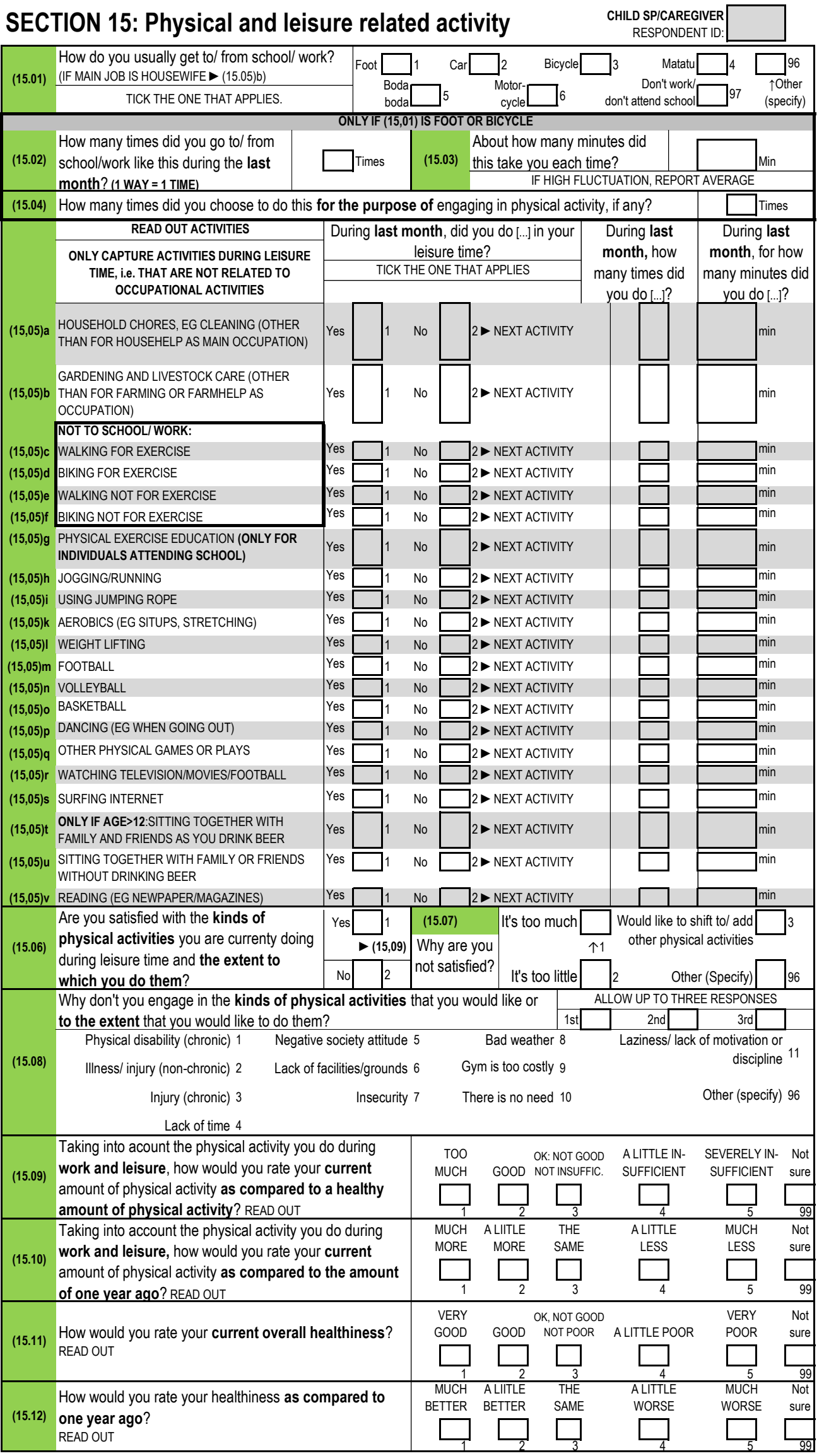


SECTION 16: Beauty Ideals

READ OUT: NOW, I WILL ASK QUESTIONS ABOUT YOUR PERCEPTION OF DIFFERENT BODY IMAGES. PLEASE CONSIDER THE PICTURES OF FEMALE AND MALE ADULTS.



\section{IF CHILD/ ADOLESESCENT SP AGE 5-12 ASK THE FOLLOWING QUESTIONS TO MOTHER OF THAT SP}

READ OUT: PLEASE CONSIDER THIS PICTURE OF CHILDREN.

DEFINE EXCESS/ STRONG EXCESS/ TOO LITTLE WEIGHT PRIOR TO CORRESPONDING QUESTIONS

\begin{tabular}{|c|c|c|}
\hline (16.23) $\begin{array}{l}\text { Which one of the bodies would you say resembles an ideal } \\
\text { body stature for boys? }\end{array}$ & \\
\hline (16.24) & $\begin{array}{l}\text { Which one of the bodies would you say resembles an ideal } \\
\text { body stature for girls? }\end{array}$ & \\
\hline \multicolumn{2}{|c|}{ FOR ALL FOLLOWING QUESTIONS: IF YES, PROBE "WHICH ONE". } \\
\hline (16.25) $\begin{array}{l}\text { Would classify any boy as having excess weight? PROBE } \\
\text { FOR FIRST ONE LOOKING FROM SKINNIEST TO BIGGEST. }\end{array}$ & \\
\hline (16.26) & $\begin{array}{l}\text { Would classify any girl as having excess weight? PROBE } \\
\text { FOR FIRST ONE LOOKING FROM SKINNIEST TO BIGGEST. }\end{array}$ & \\
\hline (16.27) & $\begin{array}{l}\text { Would classify any boy as having strong excess weight? } \\
\text { PROBE FOR FIRST ONE LOOKING FROM SKINNIEST TO BIGGEST. }\end{array}$ & \\
\hline & $\begin{array}{l}\text { Would classify any girl as having strong excess weight? } \\
\text { PROBE FOR FIRST ONE LOOKING FROM SKINNIEST TO BIGGEST. }\end{array}$ & \\
\hline
\end{tabular}

MOTHER OF CHILD RESPONDENT ID:
Would you classify any boy as weighing too little

(16.29) (low weight for height)? PROBE FOR FIRST ONE LOOKING FROM BIGGEST TO SKINNIEST.

Would you classify any girl as weighing too little

(16.30) (low weight for height)? PROBE FOR FIRST ONE LOOKING FROM BIGGEST TO SKINNIEST.

(16.31) Would you say that any boys is healthiest?

(16.32) Would you say that any girls is healthiest? 
SECTION 17: Anthropometry and Weight Related Risk Factors

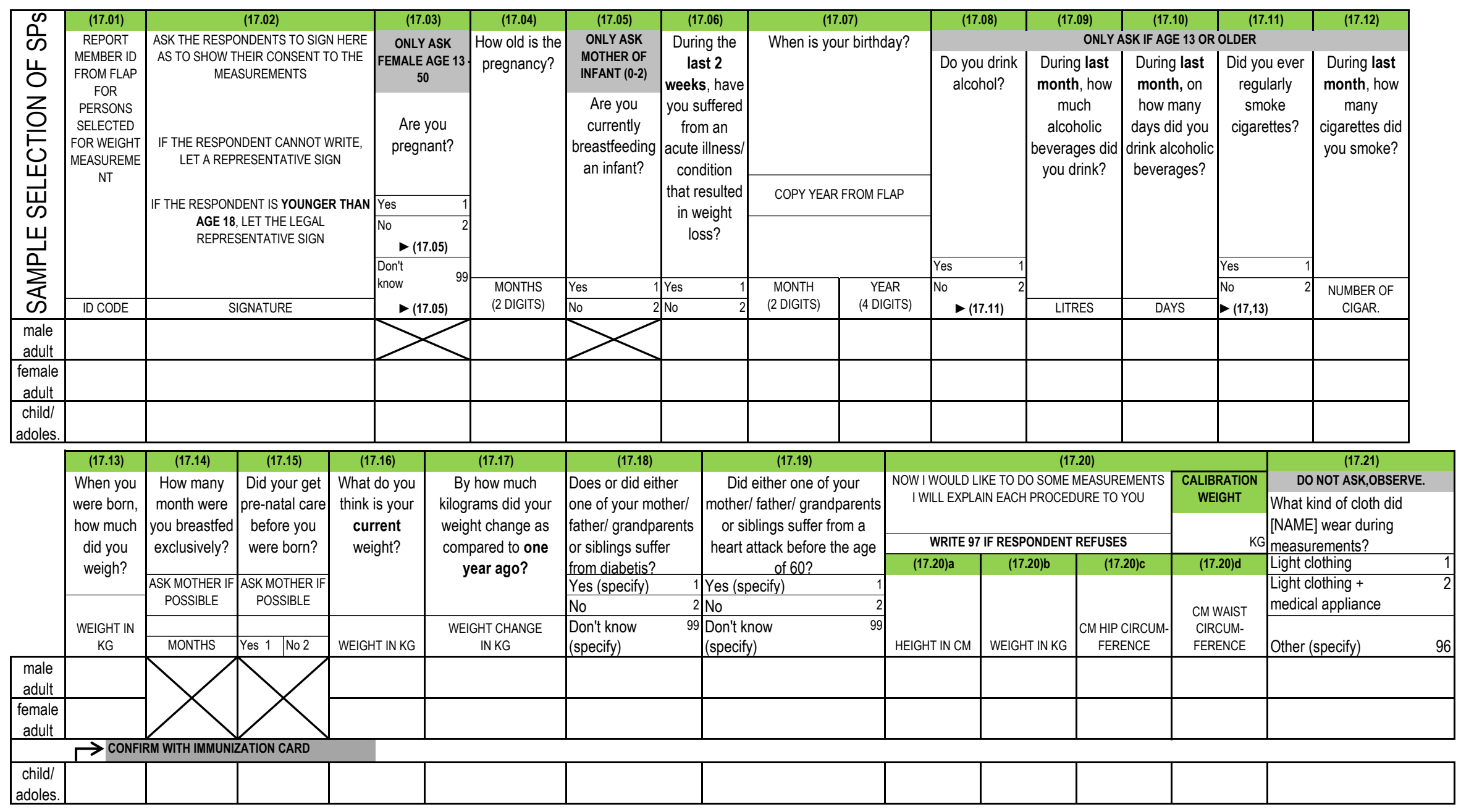




\section{Section 18: End of the Questionnaire}

Could you please give us your cellphone number?

\begin{tabular}{|c|c|}
\hline NAME & PHONE NUMBER \\
\hline & \\
\hline
\end{tabular}

Could you please give us also the cellphone numbers of at least two other family members/relatives/friends of your household such that we can contact you if we need more information?

\begin{tabular}{|c|c|}
\hline NAME & PHONE NUMBER \\
\hline & \\
\hline & \\
\hline & \\
\hline
\end{tabular}

For enumerator's comments/notes 